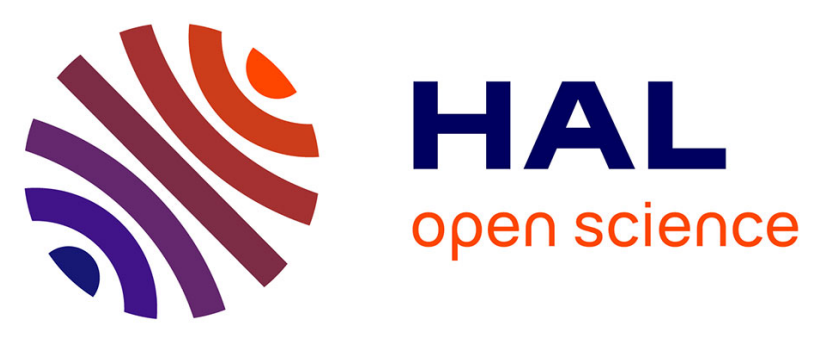

\title{
La France du Sud-Est (Languedoc-Roussillon, Midi-Pyrénées, Provence-Alpes-Côte d'Azur)
}

Patrice Arcelin, Philippe Gruat, Philippe Boissinot, Jean Chausserie-Laprée, Bernard Dedet, Philippe Ferrando, Georges Marchand, Guillaume Maza, Núria Nin, Jean-Louis Paillet, et al.

\section{To cite this version:}

Patrice Arcelin, Philippe Gruat, Philippe Boissinot, Jean Chausserie-Laprée, Bernard Dedet, et al.. La France du Sud-Est (Languedoc-Roussillon, Midi-Pyrénées, Provence-Alpes-Côte d'Azur). Gallia Archéologie de la France antique, 2003, Cultes et sanctuaires en France à l'âge du Fer, 60, pp.169-241. 10.3406/galia.2003.3147 . hal-01911759

\section{HAL Id: hal-01911759 \\ https://hal.science/hal-01911759}

Submitted on 6 Feb 2020

HAL is a multi-disciplinary open access archive for the deposit and dissemination of scientific research documents, whether they are published or not. The documents may come from teaching and research institutions in France or abroad, or from public or private research centers.
L'archive ouverte pluridisciplinaire HAL, est destinée au dépôt et à la diffusion de documents scientifiques de niveau recherche, publiés ou non, émanant des établissements d'enseignement et de recherche français ou étrangers, des laboratoires publics ou privés.

\section{(ㅇ)(1) $\$$}

Distributed under a Creative Commons Attribution - NonCommercial - NoDerivatives 44.0 


\title{
LA FRANCE DU SUd-EST
}

\section{(Languedoc-Roussillon, Midi-Pyrénées, Provence-Alpes-Côte d'Azur)}

\author{
Patrice Arcelin et Philippe Gruat \\ avec la participation de Philippe BoIsSinot, Jean Chausserie-LAPRÉE, \\ Bernard Dedet, Philippe FerRando, Éric GaIlledrat, Georges Marchand, \\ Guillaume MAZA, Núria Nin, Jean-Louis PaIllet, \\ Anne Roth Congès et Henri TRÉZINY
}

\begin{abstract}
Mots-clés. Âge du Fer, lieux de culte, pratiques cultuelles, dépôts, offrandes, culte des ancêtres, héroïsation, iconographie, mutations sociocultuelles.

Résumé. Ce bilan sur les deux décennies de recherches dans le Sud-Est de la France veut dépasser le cadre des inventaires préexistants. Il tente de reformuler les questions en suspens, de mettre également en perspective les acquis récents de la recherche dans le domaine des croyances et de leurs pratiques au sein d'une vision socioculturelle plus large. Un vaste tour d'horizon des différents lieux de culte est réalisé, qui met en valeur la part majeure des territoires et la lente émergence de celle des habitats groupés jusqu'aux premières mutations culturelles du IF s. avant J.-C. Au travers de l'affirmation des cultes rendus aux ancêtres et aux héros dès le début de l'âge du Fer, cette région de la Gaule révèle avec acuité le rôle dynamique d'une élite sociale, puis d'une aristocratie équestre à partir du III' s. avant J.-C. Dès lors, la piété populaire sera souvent absorbée par l'expression croissante de la valorisation sociale.
\end{abstract}

Key-words. Iron Age, cult places, cult practices, deposit, offerings, cult of ancestors, heroisation, iconography, socio-cultural mutation.

Abstract. This report of a two decades research in Sout-East France, intends to go beyond the pattern of the previous gazetteers. The purpose is a new definition of the outstanding questions altogether with putting in prospect new established facts in the field of beliefs and practices inside a broad socio-cultural sight. An extensive survey of the different cult sites is presented here and emphasizes the predominant participation of terrilories and the slow emergence of the part played by settlements until the first cultural mutations in the $2^{\text {nd }}$ century BC. From the assertion of cults to the ancestors and of heroic-cults as soon as the beginning of the Iron Age, this part of Gaul sharply shows the dynamic function of a social elite then of the warrior aristocracy since the $3^{\text {rd }}$ century $B C$. From then on, the popular devotions will often be absorbed by the growing manifestation of a social valorization.

Schlagwörter. Eisenzeit, Kultstätten, Religiöse Praktiken, Deponierungen, Weihegaben, Ahnenkult, Heroisierung, Ikonographie, Soziokultureller Wandel.

Zusammenfassung. Diese Bilanz von zwei Jahrzehnten Forschung in Südwestfrankreich soll über die vorhandenen Bestandsaufnahmen deutlich hinausgehen. Ungelöste Fragen sollen neu formuliert und dazu jüngste Erkenntnisse über religiöse Vorstellungen und Praktiken im Rahmen eines umfassenden soziokulturellen Ansatzes ins Blickfeld gerückt werden. Eine ausführliche tour d'horizon der unterschiedlichen Kultstätten läßt die entscheidende Rolle der Territorien erkennen und zeigt, wie die der Siedelgemeinschaften bis zu den ersten kulturellen Veränderungen des 2. Jahrh. $v$. Chr. allmählich an Bedeutung gewinnt. Im beharrlichen Festhalten an Ahnen- und Heroenverehrung erweist sich für diese Region Galliens vom Beginn der Eisenzeit an deutlich das machtvolle Wirken einer gesellschaftlichen Elite bzw. (ab dem 3. Jahrh. v. Chr.) einer Reiteraristokratie. Infolgedessen ist auch der Volksglaube häufig überformt von den religiösen Ausdrucksformen des Strebens nach Rang und Ansehen.

Übersetzt vom Stefan WIRTH 


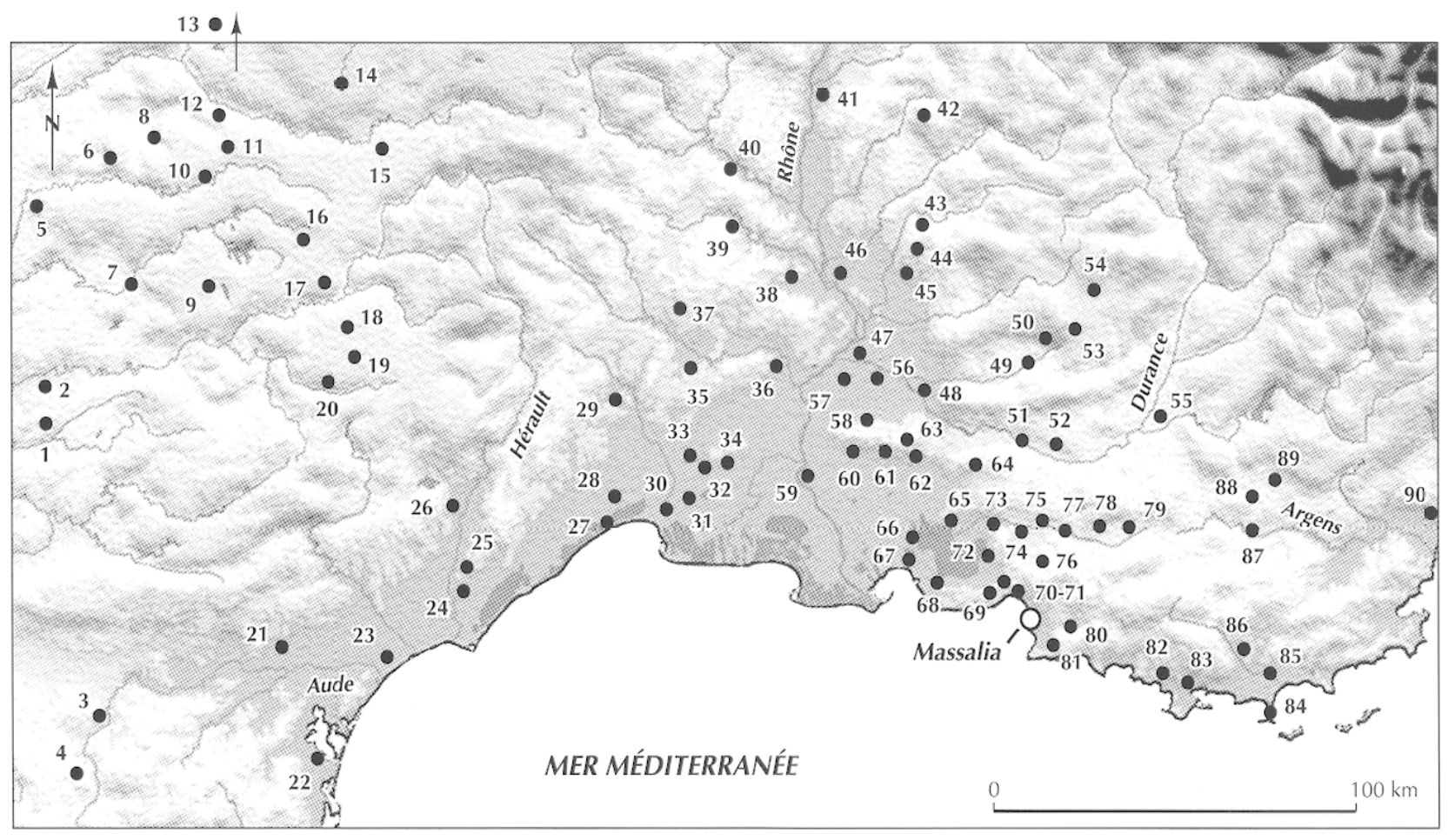

\begin{tabular}{|c|c|c|c|c|c|}
\hline $\mathrm{N}^{\circ}$ & Commune & Lieu-dit & Département & $\mathrm{N}^{\circ}$ notice & Pagination \\
\hline 1 & Poulan-Pouzols & Le Coutarel & Tarn & - & - \\
\hline 2 & Albi & & Tarn & - & - \\
\hline \multirow{2}{*}{3} & Pomas & La Lagaste & Aude & - & - \\
\hline & Rouffiac-d'Aude & La Lagaste & Aude & - & - \\
\hline 4 & Bouriège & Le Carla & Aude & - & - \\
\hline 5 & Villefranche-de-Rouergue & La Maladrerie & Aveyron & - & - \\
\hline 6 & Goutrens & La Sancy & Aveyron & - & - \\
\hline \multirow{2}{*}{7} & Centrès & Miramont-la-Calmésie & Aveyron & - & - \\
\hline & Saint-Just-sur-Viaur & Miramont-la-Calmésie & Aveyron & - & - \\
\hline 8 & Salles-la-Source & La Robertie & Aveyron & - & - \\
\hline 9 & Durenque & & Aveyron & - & - \\
\hline 10 & Rodez & caserne Rauch & Aveyron & - & - \\
\hline 11 & Bozouls & La Devèze d'Ayrebesque & Aveyron & - & - \\
\hline 12 & Rodelle & Sainte-Eulalie-du-Causse & Aveyron & - & - \\
\hline 13 & Taussac & Passevanneau & Aveyron & - & - \\
\hline 14 & Marchastel & lac de Saint-Andéol & Lozère & - & - \\
\hline 15 & Saint-Romc-dc-Dolan & aven de Baumas & Lozère & - & - \\
\hline 16 & Recoules-Prévinquières & Le Méjanel & Aveyron & - & - \\
\hline 17 & Viala-du-Tarn & Valencas & Aveyron & - & - \\
\hline 18 & Millau & Le Rajal del Gorp & Aveyron & - & - \\
\hline 19 & Sainte-Eulalie-de-Cernon & L'Ourtiguet et Le Puech de Mus & Aveyron & - & - \\
\hline 20 & Marnhagues-et-Latour & Le Plô de Maroui & Aveyron & - & - \\
\hline 21 & Mailhac & Le Cayla et Le Traversant & Aude & 1 & $217-220$ \\
\hline 22 & Sigean & Pech Maho & Aude & 6 & $234-238$ \\
\hline 23 & Nissan-lez-Ensérune & Ensérune & Hérault & - & - \\
\hline 24 & Aumes & & Hérault & - & - \\
\hline 25 & Montagnac & & Hérault & - & - \\
\hline 26 & Clermont-I'Hérault & La Ramasse & Hérault & - & - \\
\hline $27 \mid$ & Lattes & Saint-Sauveur & Hérault & - & - \\
\hline 28 & Castelnau-le-Lez & Sextantio & Hérault & - & - \\
\hline 29 & Corconne & Le Valat de Cremal & Gard & - & - \\
\hline 30 & Villetelle & Ambrussum & Hérault & - & - \\
\hline
\end{tabular}

Fig. 85 - Carte des principaux siles et découvertes à connotation cultuelle du Sud-Est gaulois, voir tabl. V. La numérotation est également celle des cartes 102, 110 et 119 (relevé P. Arcelin et P. Cruat). 


\begin{tabular}{|c|c|c|c|c|c|}
\hline $\mathrm{N}^{\circ}$ & Commune & Lieu-dit & Département & $\mathrm{N}^{0}$ notice & Pagination \\
\hline 31 & Veslric-el-Candiac & Cantière du Moulin & Gard & 1 & $217-220$ \\
\hline 32 & Nages-et-Solorgues & Les Castels & Gard & - & - \\
\hline 33 & Saint-Côme-et-Maruéjols & Mauressip & Gard & - & - \\
\hline 34 & Nîmes & agglomération, Grézan et région & Gard & - & - \\
\hline 35 & Sainte-Anastasie & Camp-Guiraud et Castelvielh & Gard & - & - \\
\hline 36 & Saint-Bonnet-du-Gard & Le Marduel & Gard & - & - \\
\hline \multirow{2}{*}{37} & Mons & Vié-Cioutat & Gard & - & - \\
\hline & Monteils & Vié-Cioutat & Gard & - & - \\
\hline 38 & Gaujac & Saint-Vincent & Gard & - & - \\
\hline 39 & Montclus & Le Travès & Gard & - & - \\
\hline 40 & Labastide-de-Virac & La Foussoubie & Ardèche & - & - \\
\hline 41 & Mondragon & & Vaucluse & - & - \\
\hline 42 & Le Pègue & Saint-Marcel & Drôme & - & - \\
\hline 43 & Vaison-la-Romaine & & Vaucluse & - & - \\
\hline 44 & Malaucène & Le Groseau & Vaucluse & - & - \\
\hline 45 & Beaumes-de-Venise & Durban & Vaucluse & - & - \\
\hline 46 & Orange & & Vaucluse & - & - \\
\hline 47 & Avignon & & Vaucluse & - & - \\
\hline 48 & Cavaillon & Saint-Jacques & Vaucluse & - & - \\
\hline 49 & Apt & quartier de La Doa & Vaucluse & - & - \\
\hline 50 & Rustrel & Le Pied de l'Aygues & Vaucluse & - & - \\
\hline 51 & Cadenet & Le Castellar & Vaucluse & - & - \\
\hline 52 & Villelaure & & Vaucluse & - & - \\
\hline 53 & Vachères & & Alpes-de-Haute-Provence & - & - \\
\hline 54 & Lardiers & Le Chastellard & Alpes-de-Haute-Provence & - & - \\
\hline 55 & Saint-Martin-de-Brômes & Buffe-Arnaud & Alpes-de-Haute-Provence & - & - \\
\hline 56 & Noves & nécropole du Puech & Bouches-du-Rhône & - & - \\
\hline 57 & Graveson & La Roque, Mourre Pela & Bouches-du-Rhône & 3 & $222-225$ \\
\hline 58 & Saint-Rémy-de-Provence & Glanon & Bouches-du-Rhône & 5 & $230-235$ \\
\hline 59 & Arles & & Bouches-du-Rhône & - & - \\
\hline 60 & Paradou & L'Arcoule & Bouches-du-Rhône & - & - \\
\hline 61 & Mouriès & Caisses et environs & Bouches-du-Rhône & - & - \\
\hline 62 & Eyguières & Saint-Pierre & Bouches-du-Rhône & - & - \\
\hline 63 & Eyguières & La Patouillarde & Bouches-du-Rhône & - & - \\
\hline 64 & Vernègues & Badasset & Bouches-du-Rhône & - & - \\
\hline 65 & Lançon-Provence & Constantine et Calissanne & Bouches-du-Rhône & - & - \\
\hline 66 & Istres & Le Castellan & Bouches-du-Rhône & - & - \\
\hline 67 & Saint-Mitre-les-Remparts & Saint-Blaise & Bouches-du-Rhône & - & - \\
\hline 68 & Martigues & L'île, Saint-Pierre et Tamaris & Bouches-du-Rhône & 4 & $225-230$ \\
\hline 69 & Les Pennes-Mirabeau & La Cloche & Bouches-du-Rhône & - & - \\
\hline 70 & Les Pennes-Mirabeau & Teste-Nègre & Bouches-du-Rhône & - & - \\
\hline 71 & Marseille & Verduron & Bouches-du-Rhône & - & - \\
\hline 72 & Rognac & Le Clapier et Le Castellas & Bouches-du-Rhône & - & - \\
\hline 73 & Velaux & Roquepertuse & Bouches-du-Rhône & 7 & $238-241$ \\
\hline 74 & Roquefavour & Le Castellas & Bouches-du-Rhône & - & - \\
\hline 75 & F́guilles & Pierredon & Bouches-du-Rhône & - & - \\
\hline 76 & Bouc-Bel-Air & Le Baou-Roux & Bouches-du-Rhône & - & - \\
\hline 77 & Aix-en-Provence & Entremont et Terrain Coq & Bouches-du-Rhône & 2 & $220-222$ \\
\hline 78 & Puyloubier & Bramefan & Bouches-du-Rhône & - & - \\
\hline 79 & Puyloubier & Mas du Jasmin & Bouches-du-Rhône & - & - \\
\hline 80 & Marseille & Les Baou de Saint-Marcel & Bouches-du-Rhône & - & - \\
\hline 81 & Marseille & grotte du Draïou & Bouches-du-Rhône & - & - \\
\hline 82 & Sanary-sur-Mer & Le Mont-Garou & Var & - & - \\
\hline 83 & Ollioules & La Courtine & Var & - & - \\
\hline 84 & Hyères & L'Acapte & Var & - & - \\
\hline 85 & Hyères & Saint-Michel-de-Valbonne & Var & - & - \\
\hline 86 & Cuers & La Peiro de l'Autar & Var & - & - \\
\hline 87 & Correns & Les Cannebières & Var & - & - \\
\hline 88 & Fox-Amphoux & La Bresque & Var & - & - \\
\hline 89 & Aups & Plérimond & Var & - & - \\
\hline 90 & Bagnols-en-Forêt & & Var & - & - \\
\hline
\end{tabular}

Tabl. V - Tableau des sites mentionnés sur la carte figure 85. 


\section{DYNAMIQUE SOCIALE ET EXPRESSIONS RELIGIEUSES}

L'âge du Fer de la façade méditerranéenne de la Gaule apparaît, au fil de la progression des recherches, comme un ensemble composite tant par la diversité des héritages de l'âge du Bronze que par leur devenir jusqu'à la romanisation effective de la seconde moitié du $\mathrm{I}^{\text {er }} \mathrm{s}$. avant J.-C. De ce fait, trois considérations guideront notre approche des lieux de culte et des pratiques religieuses dans ces régions méridionales.

Notre première démarche consiste à les percevoir en tant qu'expressions formelles des croyances, modelées dans leurs héritages culturels, mais soumises également aux attentes des sociétés en évolution. Nous touchons là aux limites de notre discipline en l'absence de témoignages antiques conséquents sur les caractères contraignants des dogmes eschatologiques et leurs probables répercussions dans le comportement religieux. L'on ne saurait pourtant douter que, dans le Midi comme ailleurs, le respect et la crainte des dieux se conjuguent aux traditions, plus floues mais aussi plus proches, de l'influence protectrice des illustres disparus aux péripéties louées par les bardes ou des pratiques divinatoires reliant le monde des vivants à celui des morts. La vie quotidienne d'alors côtoyait très certainement l'univers invisible des génies protecteurs et des démons redoutés, laissant le champ ouvert aux offrandes propitiatoires (Duval, 1993, p. 87-88), comme aux pratiques extrêmes de la magie (Lambert, 1994 ; Guyonvarc'h, 1997). Humble et attentive dans l'approche des croyances des Celtes du Midi ", notre démarche se concentrera sur l'inventaire des vestiges matériels possibles laissés par leurs manifestations individuelles ou collectives, sur l'interprétation des espaces consacrés et de leurs offrandes.

Au-delà de la difficulté d'établir une grille de lecture efficiente pour la détermination de la nature possible et de la finalité probable des dépôts rencontrés, notre deuxième démarche dans la compréhension de l'information présumée cultuelle consiste à la replacer au plus près de la dynamique sociale de la région concernée. Si les systèmes

11. Le qualificatif de Celles pour les populations de la façade méditerranéenne de la Gaule, par-delà les fonds culturels ibères ou ligures, découle des apports septentrionaux intervenus dès le premier âge du Fer. Ultérieurement, ces liens sont perceptibles dans l'analyse des armes et bijoux de la nécropole d'Ensérune ou de la statuaire d'Entremont. Avec les liens de dépendance rapprochant l'aristocratie des Salyens de celle des Allobroges (Appien, Histoire romaine, IV, 12), on rappellera que Tite-Live fait dire aux populations du Languedoc occidental, lors du passage des armées d'Hannibal en - 218, leur parenté avec celle des Gaulois cisalpins (Histoire de Rome, XXI, 20). Les populations du sud-est de la Gaule sont d'ailleurs appelées keltoï par Strabon (Géographie, IV, 1, 14). religieux de l'âge du Fer peuvent globalement se percevoir dans un cadre de croyances naturalistes héritées de la Préhistoire finale (Lévêque, 1997 ; Vendryes, 1997, p. 45-55), la complexification des rapports sociaux perceptibles dès la fin du VI ${ }^{\mathrm{e}}$ s. dans le Midi (Py, 1993, p. 83-93) ne saurait être à terme sans implications formelles sur la pratique et le contenu des cultes traditionnels. Ainsi, la prégnance croissante de l'habitat groupé et fortifié sur les territoires va contribuer à l'extension des manifestations de la piété, des territoires d'exploitation vers l'agglomération, de l'habitation familiale à la protection communautaire, de l'acte individuel aux rituels collectifs par le biais de la valorisation des élites (Arcelin, Rapin, 2002). De même, la lente osmose culturelle opérée avec le monde méditerranéen va se traduire par des évolutions en ce domaine au sein des communautés indigènes du second âge du Fer, en particulier autour du Rhône après la fin du III $^{\mathrm{c}}$ s. avant J.-C. Les profondes mutations sociales, politiques et économiques, décelées dès - 175/- 150 dans plusieurs agglomérations de cette région, recouvrent également des bouleversements religieux de même ampleur illustrés par l'adoption du temple de type gréco-italique comme lieu cultuel, sans préjuger bien sûr de celle de l'ensemble des croyances y afférant.

Troisième contrainte de cette approche, celle des choix opérés dans l'information disponible. Nous optons, dans l'esprit de ce dossier, pour une présentation partielle et sélectionnée de l'information disponible, sans prétention à l'exhaustivité (fig. 85 et tabl. V). Le renvoi régulier à des bilans précédents ou aux publications des données factuelles nous en dispensera. Nous avons plutôt favorisé des exemples représentatifs ou discutés, porteurs d'une information fonctionnelle ou chronologique. Nous concentrerons l'éclairage sur les nouvelles acquisitions archéologiques comme sur les remises en cause de données ou de concepts plus anciens. Les apports archéologiques de ces dix dernières années, comme le réexamen d'une iconographie connue, déterminent aujourd'hui une perception renouvelée des caractères stylistiques méridionaux, de leurs significations probables et de leurs répartitions chronologiques dès le premier âge du Fer. Les cartes de distribution et leurs commentaires montrent, au-delà des traits communs, l'existence de sectorisations géographiques dans les pratiques, recouvrant des déterminismes environnementaux mais aussi très certainement de réelles fluctuations culturelles (ainsi chez les Rutènes, fig. 87) (Gruat, 1998, p. 103-110, fig. 6 ; Gruat, Izac-Imbert, 2002, p. 75, fig. 8). Dans l'ensemble, nous demeurons conscients que certaines répartitions spatiales ou silences archéologiques peuvent résulter pour l'essentiel de carences documentaires. Nous ne passerons pas non plus sous silence les importantes 
discordances chronologiques, plusieurs fois constatées, entre le moment de l'élaboration d'une œuvre à caractère cultuel et celui de la fin de son utilisation, avant sa destruction. Comme pour certains mobiliers céramiques et métalliques d'usage profane, la notion de concordance parfaite entre le temps de la fréquentation d'un lieu cultuel et le moment de la création des objets déposés doit pouvoir être mise en cause. Conservatisme cultuel et transmission patrimoniale d'objets à forte charge spirituelle, aussi à haute connotation sociale comme la statuaire, peuvent déterminer un décalage temporel majeur entre le moment de la création et l'acte de destruction finale. Pour l'espace gaulois ici considéré, nous sommes persuadés que cette apparente distorsion ne saurait se résoudre par le seul recours à l'hypothèse de la pérennité stylistique, en décalage avec le reste de l'Europe occidentale.

Écartant de cette approche les espaces collectifs bâtis sans fonction religieuse clairement établie (Arcelin, 1992a), ainsi que les manifestations des rites de victoire (Arcelin, à paraître c) et l'essentiel des pratiques de la vie domestique ou du rituel funéraire (Nin, 1999, p. 264-269 ; Dedet, 2000), notre propos sera scindé en deux volets. Il analysera d'abord les différents types de lieux de culte connus tant sur les territoires qu'en relation avec les habitats groupés, avant d'essayer de cerner leur caractérisation religieuse et culturelle au sein de l'évolution des sociétés méridionales, de la fin du VII ${ }^{\mathrm{e}}$ au milieu du $\mathrm{I}^{\mathrm{er}}$ s. avant J.-C. Si le milieu grec de Marseille et de ses colonies a fait par ailleurs l'objet de publications récentes en ce domaine et ne sera ici qu'indirectement abordé (Hermary, Tréziny dir., 2000 ; Gantès et al., 2001 , p. 205-207), en revanche nous ferons appel à des sources textuelles ou à l'épigraphie régionale.

Enfin, nous avons souhaité que ce tour d'horizon synthétique soit accompagné d'informations plus développées sur quelques opérations archéologiques récentes ou thématiques, seulement suggérées dans le cours du texte principal (voir infra notices 1 à 7, p. 217-241).

\section{LES LIEUX DE CULTE}

Pour les Celtes, comme pour leurs ancêtres, les dieux communiquent avec les hommes au travers de manifestations naturelles, singularités des paysages ou phénomènes troublants. Pline $(H . N$., XII, 2, 1) rapporte que chez les Anciens " les forêts furent les temples des divinités » et Lucain, dans le texte emphatique de la Pharsale (I, 453-454), insiste sur ces druides qui fréquentent [près de Marseille] de «profonds sanctuaires dans des bois reculés 》. Pomponius Mela (De Chrrngraphia, III, 2), qui souligne le rôle majeur des druides dans l'éducation de la jeunesse aristocratique, précise que leur enseignement, confidentiel, a lieu « soit dans une caverne, soit dans des bois reculés. " C'est dire que les croyances naturalistes constituent toujours à l'âge du Fer l'armature des manifestations de la piété populaire, dans le Midi comme ailleurs en Gaule. De ce fait, les aires cultuelles, familiales et modestes ou collectives et amples, trouvent place pour l'essentiel sur le territoire, en des lieux majeurs pour les hommes (limites de peuples, routes ou gué...) ou censément marqués par l'empreinte d'une divinité (jaillissement des eaux, impact de la foudre, curiosité géologique...). Les espaces entourant les agglomérations, et singulièrement dans la basse vallée du Rhône du fait d'une occupation parfois très concentrée à l'intérieur de l'enceinte (Py, 1990, p. 135-138; Arcelin, 2001 et à paraître a), sont, tant par tradition que par nécessité, primordiaux pour les Gaulois méridionaux, à n'en pas douter tout aussi « fortement concernés par les choses de la religion " que leurs parents ou alliés septentrionaux (César, $B$. G., VI, 16). Dans la majorité des agglomérations antérieures à la conquête, la modestie, voire l'absence de véritables aires ouvertes et de bâtiments collectifs ${ }^{12}$ trouvent leur justification dans la primauté persistante des espaces extérieurs pour la rencontre des populations, lors des fêtes et des foires de l'échange, comme pour l'expression dévotionnelle envers les divinités protectrices de leurs activités rurales. Nous savons désormais, et selon des modalités variables en fonction des caractères culturcls rćgionaux qui prévalent (Py, 1993, p. 240-241), que les élites de la fin du premier âge du Fer, et plus certainement l'aristocratie au cours du second, peuvent résider dans leurs domaines ruraux, hors des agglomérations où la part des agriculteurs et petits artisans demeure essentielle (Arcelin, 1999b). D'ailleurs, à notre connaissance, nulle part sur la façade méditerranéenne avant le courant du $\mathrm{II}^{\mathrm{e}}$ s., l'agglomération n'intègre un centre religieux, caractérisé comme tel par des aménagements spécifiques et quelque peu monumentalisés. Tout au mieux, de modestes espaces cultuels que l'on peut lire dans l'habitat dès la fin du $\mathrm{VI}^{\mathrm{e}} \mathrm{s}$. prendront-ils ultérieurement un peu plus d'importance en quelques lieux privilégiés et fortement hellénisés comme sur la côte du Languedoc occidental, à Pech Maho au cours du III ${ }^{\mathrm{c}} \mathrm{s}$. (voir infra notice 6 , p. 234-238). Les premières manifestations

12. Ce point de vue prévaut aujourd'hui dans le Midi méditerranéen pour les habitats à occupation fortement concentrée. Il en va ainsi pour les agglomérations d'Entremont, de Nages, ou de Lattes jusque vers la fin du III ${ }^{e}$ s. En Languedoc occidental et Roussillon, deux agglomérations de superficies et de chronologies bien différentes montrent l'intégration d'un modeste espace ouvert aménagé dans l'enceinte, l'un établi au $\mathrm{V}^{\mathrm{e}} \mathrm{s}$. avant $\mathrm{J}$.-C. en arrière de la porte d'accès (Le Port à Salses), l'autre au III ${ }^{e}$ s. à Pech Maho, également près de la porte, dégagement devant un lieu cultuel (voir infra notice 6, p. 234-238). 
décelables d'une intégration d'aires cultuelles spécifiques dans l'habitat groupé paraissent liées à la présence d'éléments méditerranéens, en rapport avec les implantations coloniales grecques de Marseille, et surtout au phénomène de "protoromanisation " précoce qui intervient près des côtes (peut-être à Lattes ?) et dans la basse vallée du Rhône dès la seconde guerre punique. Il en va ainsi à Glanon, dans les Alpilles, et peut-être en Avignon (Roth Congès, 1992a ; Carru, 2000), plus sûrement après la conquête militaire de la fin du siècle dans un plus grand nombre d'agglomérations alors en pleine mutation urbanistique et architecturale (Ensérune, Nîmes, Cavaillon, Orange... ; voir Garcia, 1992 ; Monteil, 1999, p. 321-340 ; Dufraigne, 2000 ; sur la question, voir Arcelin, à paraître b). La présence de résurgences pérennes dans l'enceinte (à Nîmes et à Glanon par exemple) ou à sa périphérie immédiate (ainsi à Graveson ou Nages) participe de la renommée des sites concernés par le biais du phénomène de sacralisation. À Glanon, la réalisation d'aménagements cultuels paraît initialement limitée à l'environnement des accès. Ainsi les nombreux vestiges retrouvés en remploi dans la porte du vallon de Notre-Dame de Laval ou à sa proximité (voir infra notice 5, p. 231-234) soulignent sans doute la renommée de la source bien avant le milieu du $\mathrm{II}^{\mathrm{e}} \mathrm{s}$. avant J.-C.

\section{SUR LES TERRITOIRES}

Le parcours des types de lieux cultuels repérés par l'archéologie ou par de rares informations épigraphiques ne recèle pas de hiérarchie, ni de dissociation radicale. Nous verrons pourtant que si la mixité des pratiques et des lieux est plusieurs fois constatée, de nettes préférences peuvent émerger en dehors des contraintes du milieu naturel. Au cours de l'âge du Fer, l'évolution des activités en rapport avec l'exploitation des territoires aura parfois des répercussions dans le choix des sites et les modes de l'expression de la piété. Mais au fond, l'essentiel des pratiques cultuelles sur les territoires demeure foncièrement traditionnelle durant toute la Protohistoire et, parfois même, jusqu'au début du haut Moyen Âge.

\section{COURS D'EAU, SOURCES ET RÉSURGENCES}

De fait, les cultes rendus aux divinités des sources et cours d'eau, de surface ou souterrains, tiennent une place considérable dans les régions karstiques du Midi où cet élément de vie indispensable aux activités de l'homme et à ses troupeaux se fait parfois rare en saison chaude. L'épigraphie gallo-grecque et latine a conservé les traces multiples de dieux indigènes associés à toutes les formes de la circulation de l'eau. On a depuis longtemps signalé que la moitié des noms régionaux de racines celtiques sont liés à cette manne liquide. On rappellera simplement, à titre d'exemples, les divinités liées aux rivières telles les Matres Ubelnae pour l'Huveaune près de Marseille, Umia pour l'Ourne (Gard) ou aux sources avec Graselos au Groseau près de Malaucène, encore Larraso pour la fontaine de Comigne à Moux, dans l'Aude. Certains de ces lieux auront une destinée majeure en relation avec le développement d'une vaste agglomération à la fin du second âge du Fer. C'est le cas de Nîmes où un culte à Namausos/Nemausus et aux Mères nîmoises s'est développé avec la création du sanctuaire de la Fontaine près d'une forte résurgence (Lejeune, 1985, p. 273-279; Monteil, 1999, p. 299-300) ou encore de Glanon, dans les Alpilles, avec les Matres Glanicae et Belenos (Provost et al., 1999, p. 297 et 324). La plupart pourtant sont demeurés bien plus modestes comme dans le cas de l'aménagement souterrain de la source de la combe d'Audoul, au nord de Nîmes, où ont été recueillis diverses offrandes ( $V^{\mathrm{e}} \mathrm{s}$. avant J.-C. ?) (Fiches, Veyrac dir., 1996, p. 478, n 592). Parfois, c'est la pérennité du nom d'une divinité à l'époque romaine qui permet d'inférer l'existence antérieure d'un lieu cultuel des eaux. Il en va ainsi à Graveson où la mutatio Bellinto de la Table de Peutinger perpétue le souvenir d'un culte à Belenos/Bellinto, certainement près des résurgences de La Roque (Arcelin, Ferrando, 2000 ; Jufer, Luginbühl, 2001, p. 28-29 et infra notice 3, p. 222-225).

En général, rivières, sources et résurgences sont les lieux d'une dévotion locale, souvent dans la durée, et ne comportent pas d'aménagement structuré pour les offrandes. Celles-ci sont soit immergées, soit déposées à même le sol si l'accès au cours d'eau se fait par une grotte ou une galerie souterraine.

Le lac de Saint-Andéol est un exemple particulièrement intéressant de lieu d'immersion lacustre où les pratiques dévotionnelles, relatées au $\mathrm{VI}^{\mathrm{e}} \mathrm{s}$. par Grégoire de Tours (De gloria beatorum confessorum, VII, 2), se seraient maintenues jusqu'au XIX ${ }^{e}$ s. Rècemment, deux vases non tournés (dont un miniature), appartenant à des séries connues dans les grottes à offrandes caussenardes, ont été remontés du fond du lac ${ }^{13}$. On remarquera la position particulière de cette étendue d'eau aux confins des départements actuels de la Lozère, de l'Aveyron et du Cantal, c'est-à-dire des populations Gabales, Rutènes et Arvernes.

L'évent de La Foussoubie à Labastide-de-Virac, sur la rive droite de l'Ardèche, est situé au fond d'une grotte où un

13. Découverte de juillet 1995, déposée au musée de Rouergue à Montrozier. Vases attribuables, par comparaison, aux $\mathrm{II}^{e}$ ou $\mathrm{I}^{\mathrm{er}} \mathrm{s}$. avant J.-C. (Gruat, Izac-Imbert, 2002, fig. 9). 


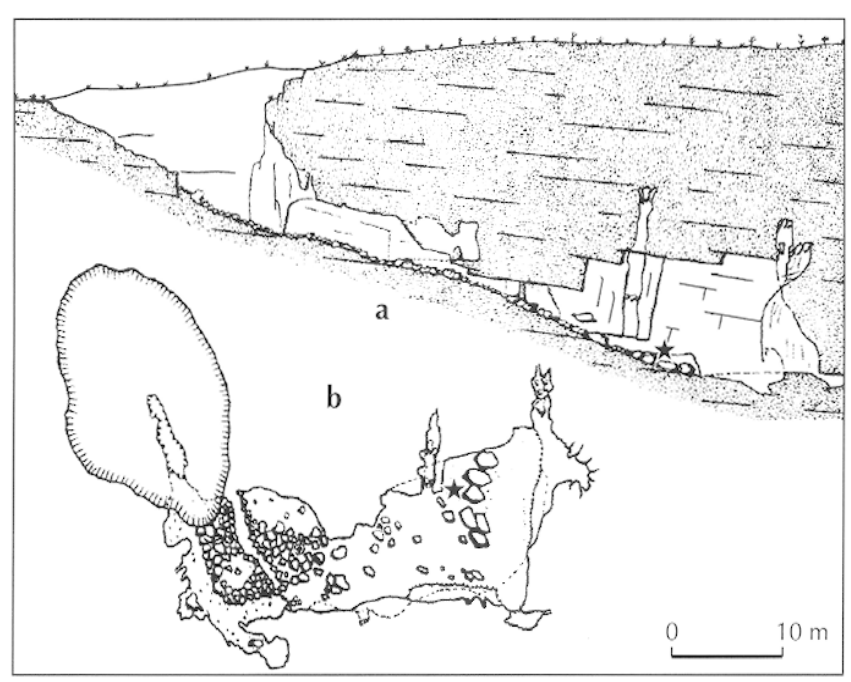

Fig. 86 - Millau (Aveyron). Coupe (a) et plan (b) de la grotte à offrandes du Rajal del Gorp fréquentée de la fin du IIP s. au milieu $d u I^{e r}$ s. av. J.-C., puis jusqu'au IV s. apr. J.-C. (étoile à l'emplacement des principaux dépôts) (d'après Vidal et al., 2000, fig. 2).

siphon permet d'accéder à la rivière souterraine. Un lot d'objets métalliques a été anciennement exhumé dans une galerie voisine, mais sans contexte clairement identifié. Les artefacts se divisent en deux lots : un du Bronze final, l'autre du premier âge du Fer (Tscherter, Roudil, 1996). Le cas de l'aven du Rajal del Gorp, près de Millau est bien plus intéressant car le site a été correctement fouillé (fig. 86). C'est à proximité de la rivière souterraine, à $-25 \mathrm{~m}$, que les offrandes étaient étalées : 430 fibules, 411 monnaies, une abondante vaisselle régionale ou importée, le tout réparti de la fin du $\mathrm{II}^{\mathrm{e}} \mathrm{s}$. avant J.-C. au $\mathrm{IV}^{\mathrm{e}} \mathrm{s}$. de notre ère (Vidal $e t$ al., 2000, p. 65-66).

Enfin, vers le milieu du VI' ${ }^{\mathrm{e}}$ s. avant J.-C., des offrandes de pièces d'armement et de bijouterie ont été enterrées au pied d'un rocher, à proximité de la résurgence de la Source du Noyer à Roquefort-les-Pins (Vindry, 1978, p. 28-29).

\section{Grottes ou AVENS}

Grottes et forêts apparaissent dans la littérature antique comme des lieux favorables à la méditation et à l'enseignement, les points de rencontre de l'homme avec le divin, par les forces telluriques et fécondes de la terre. Silence et pénombre sont autant propices aux fantasmagories qu'à l'isolement pour une écoute du monde et la transmission des connaissances druidiques. Pline, Pomponius Mela, Lucain (supra) ou encore Sénèque (Epist., IV, 12, 41, 3) font état dc cc bcsoin d'un rcpli « hors du monde " pour honorer les divinités, tenter de percevoir leurs signes ou méditer sur un enseignement théologique. La grotte est le lieu idéal pour une claustration, au cour même du domaine des puissances chthoniennes où règne l'essence de toute chose en Dis Pater. Cette religiosité qui plonge ses racines dans la Préhistoire se maintient au long de l'âge du Fer et au-delà. La récurrence des pictogrammes peints et gravés souligne la pérennité de l'usage des grottes et abris-sousroche dans l'ensemble du Midi, tant à des fins cultuelles que pratiques (Combier, 1972 ; Hameau, 1989).

L'inventaire des grottes à offrandes de la façade méditerranéenne, tant pour la Protohistoire (Arcelin el al., 1992, p. 185-187 ; Vidal et al., 2000) que pour leur continuité sous l'Empire (Barruol, 1994, p. 51-52), montre une répartition préférentielle dans les zones élevées du Languedoc occidental, davantage que dans les environnements similaires de la Provence ou de la vallée du Rhône. Une distribution plus affinée sur les Causses languedociens met en valeur un regroupement dans le quart sud-est du territoire des Rutènes: Causses noir, Méjean, Larzac et marges méridionales (fig. 87). À l'inverse, plus au nord, dans le Quercy, dans un contexte pourtant similaire, on note une absence totale de ce type de sanctuaire (Buchsenschutz, Izac, 2000, p. 109-110). Parmi les sept grottes recensées, toujours isolées, celle de L'Ourtiguet à Sainte-Eulalie-de-Cernon, au cœur du plateau du Larzac, est très représentative de ce type de lieu à offrandes (Pujol, 1996). Ce sont d'abord des fibules en bronze et en fer qui sont déposées dès la fin du $\mathrm{V}^{\mathrm{e}} \mathrm{s}$., mais surtout de la fin du $\mathrm{II}^{\mathrm{e}} \mathrm{s}$. à la première moitié du $\mathrm{I}^{\text {er }}$ s. avant J.-C. (560 ex. sur 600), relayées par les monnaies jusqu'au $\mathrm{V}^{c} \mathrm{~s}$. de notre ère. Céramiques régionales et importées montrent une fréquentation irrégulière, étalée jusqu'au VII s. Certaines fabrications non tournées miniatures sont très caractéristiques de ces dépôts aveyronnais des $\mathrm{II}^{\mathrm{e}}$ et $\mathrm{I}^{\mathrm{er}}$ s. avant $\mathrm{J}$.-C. Ces grottes-sanctuaires se distinguent par leurs offrandes près de points d'eau (gours) et/ou d'importantes concrétions, loin de la lumière du jour.

$\mathrm{Si}$ les accumulations importantes d'objets comme celles de L'Ourtiguet ne laissent guère de place au doute quant à la fonction des lieux, d'autres plus limitées ne permettent pas d'être toujours aussi affirmatif. Pourtant, même modestes, ces groupements peuvent être révélateurs de pratiques plus occasionnelles. Le cas se pose, par exemple, pour les quelques objets métalliques découverts dans la grotte du Travès à Montclus, des fibules, anneaux, bracelets, etc., déposés durant la seconde moitié du VIe $s$. avant J.-C. (Dedet, Roudil, 1983). Dans cette perspective, encore plus délicats d'interprétation seraient les deux bracelets en bronze intacts de même époque, retrouvés par des spéléologues dans l'anfractuosité d'une corniche, à $30 \mathrm{~m}$ de profondeur dans un puits d'accès à l'aven de Baumas, à Saint-Rome-de-Dolan (Brouillet, 1984). Comme 


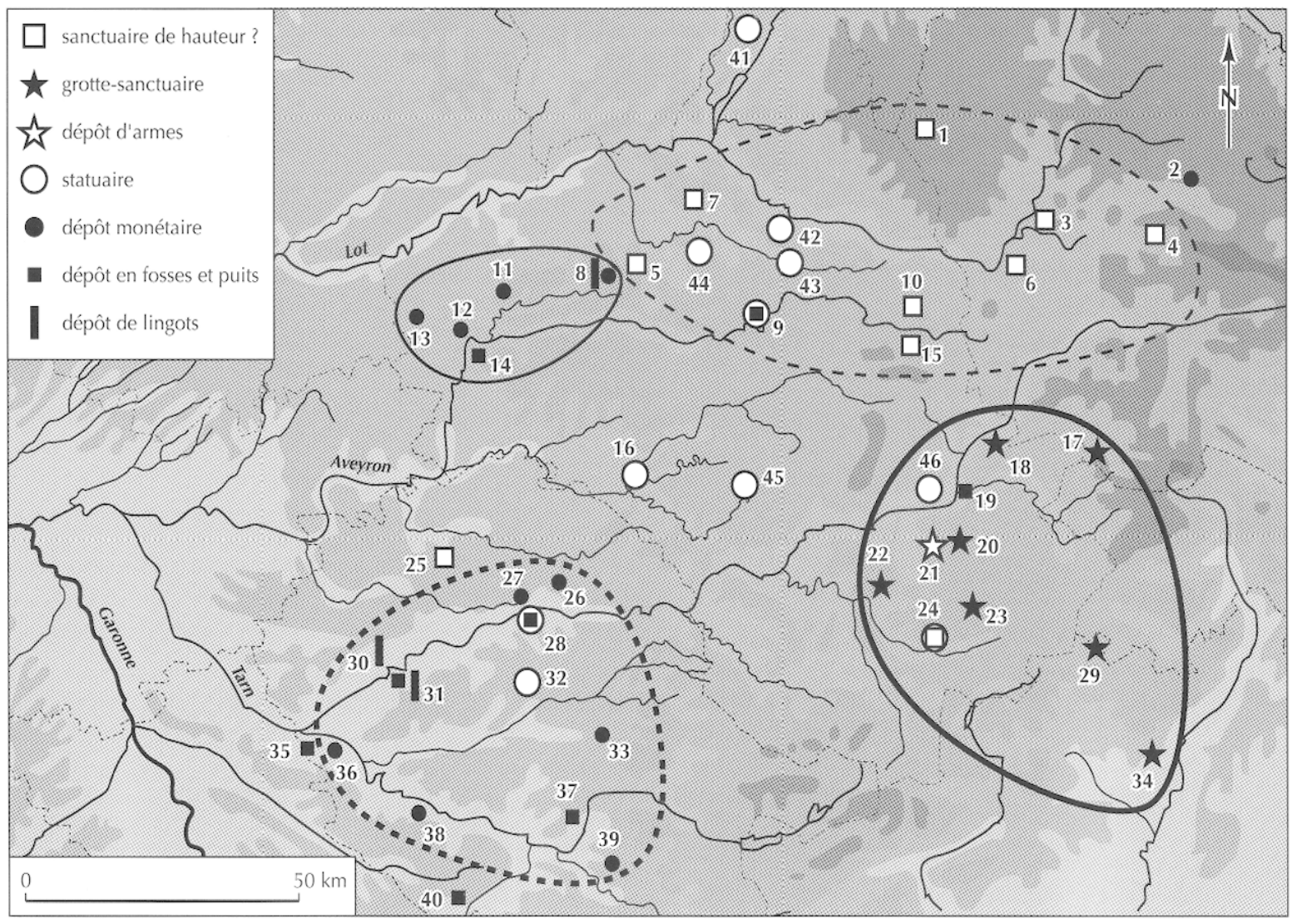

\begin{tabular}{|c|c|c|c|}
\hline $\mathrm{N}^{0}$ & Commune & Lieu-dit & Département \\
\hline 1 & Marchastel & lac de Saint-Andéol & Lozère \\
\hline 2 & Allenc & & Lozère \\
\hline 3 & Saint-Bonnet-de-Chirac & Le Truc & Lozère \\
\hline 4 & Brenoux & Langlade & Lozère \\
\hline 5 & Saint-Christophe-Vallon & Puech du Caylar & Aveyron \\
\hline 6 & La Canourgue & Ron de Gleizo à Cadoule & Lozère \\
\hline 7 & Pruines & Puech du Kaymar & Aveyron \\
\hline 8 & Goutrens & La Sancy & Aveyron \\
\hline 9 & Rodez & & Aveyron \\
\hline 10 & Buzeins & Le Puech & Aveyron \\
\hline 11 & Maleville & La Loubière & Aveyron \\
\hline 12 & Villefranche-de-Rouergue & La Gasse & Aveyron \\
\hline 13 & Martiel & & Aveyron \\
\hline 14 & Villefranche-de-Rouergue & La Maladrerie & Aveyron \\
\hline 15 & Recoules-Prévinquières & Le Méjanel & Aveyron \\
\hline \multirow{2}{*}{16} & Centrès & Miramont-la-Calmésie & Aveyron \\
\hline & Saint-Just-sur-Viaur & Miramont-la-Calmésie & Aveyron \\
\hline 17 & Meyrueis & Costeguizon ou Tres Berbous & Lozère \\
\hline 18 & La Cresse & Céliose & Aveyron \\
\hline 19 & Millau & La Graufesenque & Aveyron \\
\hline 20 & Millau & Le Rajal del Gorp & Aveyron \\
\hline 21 & Creissels & Bel-Air I & Aveyron \\
\hline 22 & Saint-Rome-de-Cernon & Sargel I & Aveyron \\
\hline 23 & Sainte-Eulalie-de-Cernon & L'Ourtiguet & Aveyron \\
\hline
\end{tabular}

\begin{tabular}{|l|l|l|l|}
\hline$N^{\circ}$ & \multicolumn{1}{|c|}{ Commune } & \multicolumn{1}{|c|}{ Lieu-dit } & Département \\
\hline 24 & Marnhagues-et-Latour & Le Plô de Maroui & Aveyron \\
\hline 25 & Loubers & Camp Ferrus & Tarn \\
\hline 26 & Le Garric & Le Trap & Tarn \\
\hline 27 & Castelnau-de-Lévis & Champ Robert & Tarn \\
\hline 28 & Albi & & Tarn \\
\hline 29 & Le Cros & Mouniès & Hérault \\
\hline 30 & Rabastens & La Montresse & Tarn \\
\hline 31 & Montans & & Tarn \\
\hline 32 & Poulan-Pouzols & Le Coutarel & Tarn \\
\hline 33 & Montredon-Labessonnié & Paulhe & Tarn \\
\hline 34 & Montpeyroux & Grotte-des-Fées & Hérault \\
\hline 35 & Saint-Sulpice & La Pointe & Tarn \\
\hline 36 & Lugan & Pédelort & Tarn \\
\hline 37 & Castres & & Tarn \\
\hline 38 & Viterbe & & Tarn \\
\hline 39 & Valdurenque & & Tarn \\
\hline 40 & Palleville & Solomiac & Tarn \\
\hline 41 & Taussac & Passevanneau & Aveyron \\
\hline 42 & Rodelle & Sainte-Eulalie-du-Causse & Aveyron \\
\hline 43 & Bozouls & La Devèze d'Ayrebesque & Aveyron \\
\hline 44 & Salles-la-Source & La Robertie & Aveyron \\
\hline 45 & Durenque & & Aveyron \\
\hline 46 & Viala-du-Tarn & Valencas & Aveyron \\
\hline
\end{tabular}

Fig. 87 - Un récent inventaire régional en Aveyron, Tarn et marges, sur le territoire des Rutènes, montre la diversité des lieux et des modes de l'expression cultuelle. Quatre secteurs présentent de nettes dominantes (d'après Gruat, Izac-Imbert, 2002, fig. 8 complétée). 
pour certaines résurgences incorporées dès la fin du premier âge du Fer dans l'enccinte d'une agglomération (Nîmes, Glanon) ou à proximité immédiate d'un accès principal (tel à Graveson), des grottes et avens peuvent être inclus dans l'enceinte d'un habitat en développement et devenir des instruments de sa valorisation comme de sa protection. À Glanon, une petite grotte est située en face de la source du vallon (secteur XXXVI, fig. 136 ; Rolland, 1962, fig. 2 et 3 ). Une utilisation similaire se présente sur le vaste oppidum de Constantine à Lançon-Provence où les orifices d'un aven s'ouvrent à même le plateau. Les cavités des deux sites précédents, fréquentés dès la Préhistoire récente, seront incorporées, à la fin du premier âge du Fer (pour Glanon) ou au II's. avant J.-C. (pour l'autre), dans l'enceinte de vastes habitats groupés. Plus spécifiquement, ils sont les éléments à l'origine d'aménagements monumentaux érigés entre le milieu du II $^{e}$ s. (pour le premier) et le courant du $\mathrm{I}^{\text {er }}$ s. avant J.-C. (pour l'autre). Ainsi, autour de l'aven de Constantine, un mur à deux parements en grand appareil, de type tardo-hellénistique, délimite une aire ovale d'environ $240 \mathrm{~m}^{2}$, certainement pourvue d'une porte monumentale, en somme un espace sacré équivalent de ceux délimités en plaine par un fossé (voir infra). La part cultuelle de ce temenos est complétée de bâtiments voisins, dont une vaste salle d'environ $45 \mathrm{~m}^{2}$, au sol en opus signinum, auxquels pourrait se rattacher une partie des éléments architecturaux moulurés signalés de longue date sur le site $^{14}$ (Verdin, 1993, p. 142-144 et 1995, f. 225-243).

Autre cas, autre lieu, avec les grottes à offrandes proches de la ville grecque de Marseille et de sa chôra. La mieux connue est celle du Draïou, dans le massif de Marseilleveyre. Au début du siècle, elle a livré aux prospecteurs un lot important de céramiques tournées à pâte calcaire et de lampes, déposées de la seconde moitié du VI ${ }^{\mathrm{e}} \mathrm{s}$. jusque dans le courant du II $^{\mathrm{c}}$ s. avant J.-C. (Gantès, 1990). Les formes sont sélectionnées pour leur petite taille, et les lampes usagées révèlent qu'elles ont été en activité sans doute lors de leur consécration au sein de la caverne. L'absence de dédicaces votives, même pour la période tardive, inclinerait à considérer ces offrandes comme celles de groupes indigènes travaillant sur la chôra plutôt que de Grecs marseillais eux-mêmes.

\section{HaUteuRS ET SOMMETS}

Montagnes et massifs sont parcourus et exploités par les hommes de l'âge du Fer, comme ils l'étaient au cours des millénaires antérieurs. Milieux de solitude pour les bergers, trappeurs, bûcherons ou miniers, dominés parfois par de

14. Recherches actuellement en cours. hauts sommets, terrains souvent difficiles et hostiles, les lieux d'altitude sont également des zones de circulation et d'échanges. Les risques encourus deviennent autant de raisons pour les appels à la protection bienveillante des divinités, la perception de l'ampleur des lieux rapprochant l'homme du domaine des puissances ouraniennes. La richesse documentaire des gravures de montagne, symboliques ou figuratives, est la marque récurrente de ces transhumants et plus généralement de leurs dévotions aux puissances célestes (orages, foudres...). Les gravures des Alpes méridionales autour du mont Bego (Lumley, 1984 ; Lumley et al., 1992) ou celles des Pyrénées orientales (Campmajo, Untermann, 1986) sont autant de traces de ces pratiques propitiatoires.

C'est au travers de l'épigraphie gallo-romaine et de l'onomastique que nous sont parvenus quelques noms de divinités et avec eux la trace de manifestations cultuelles liées aux massifs montagneux (Arcelin et al., 1992, p. 187). Le plus répandu en Provence est celui de Vintur(os), attesté aux pieds du mont Ventoux, à Mirabel, et du Luberon, près d'Apt (CIL, XII, 1431 et 1104) ou dans la transposition christianisée du nom de la Sainte-Victoire, près d'Aix-enProvence.

Très souvent, c'est le repérage d'un sanctuaire galloromain qui permet d'inférer l'existence d'un lieu dévotionnel antérieur, seulement caractérisé par la présence de mobiliers des $\mathrm{II}^{\mathrm{c}}$ ou $\mathrm{I}^{\mathrm{cr}}$ s. avant J.-C. (Barruol, 1994). Outre l'exemple célèbre du Chastellard au Lardiers, dans les Alpes-de-Haute-Provence (Barruol, 1990), d'autres paraissent avoir existé à la fin de l'âge du Fer à l'emplacement ultérieur de plusieurs fana de l'Aveyron, comme au Méjanel, à Recoules-Prévinquières ou au Plô de Maroui à Marnhagues-et-Latour, avec une stèle anthropomorphe (Gruat, 1998, p. 108-109) (fig. 87). D'autres sont repérés en Lozère, à Langlade (Brenoux), au Truc (Saint-Bonnetde-Chirac), au Ron de Gleizo/Cadoule (La Canourgue) ou près du lac de Saint-Andéol (Marchastel). On citera également celui de Camp Ferrus à Loubers, dans le Tarn, où exceptionnellement un modeste aménagement de sol de la fin de l'âge du Fer a été relevé, certainement en relation avec des parois en matériaux périssables (Comité départemental d'archéologie du Tarn, 1995, p. 154-156). Il en va peut-être de même pour l'aménagement du Puech du Caylar à SaintChristophe-Vallon, dans l'Aveyron (Gruat, Marty, 1996, p. 128). Parmi cette concentration de sanctuaires de hauteur rutènes, plusieurs pourraient être fréquentés par des miniers dès la fin du second âge du Fer, si l'on en juge par le dépôt de blocs de minerais contenant de la galène impure, du cuivre ou de l'argent et de la barytine (à Camp Ferrus) ou encore du cuivre seul (au Méjanel, voir supra). La relation "sanctuaire-mine ", qui est évidente dans ces 


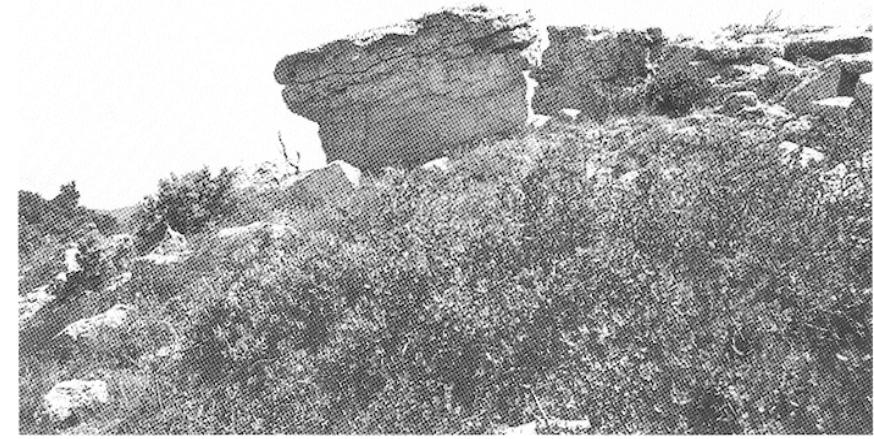

a

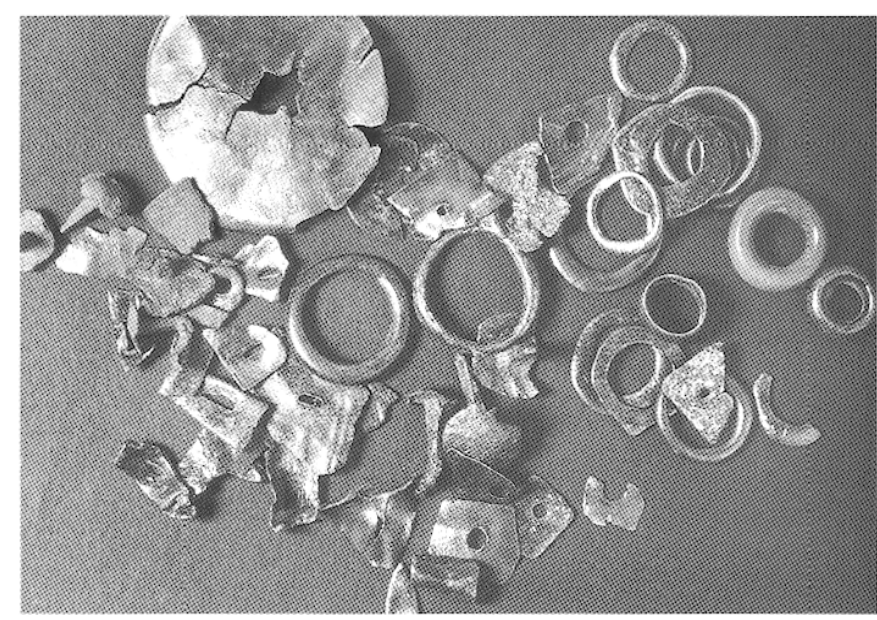

h

Fig. 88 - Cuers (Var), La Peiro de l'Autar. Un rocher de 1,30 m de hauteur (a) sur une légère éminence.

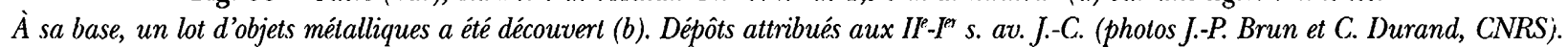

deux cas, pourrait être étendue aux lieux cultuels précédents du fait de la proximité de gisements miniers ou d'exploitations à ciel ouvert ${ }^{15}$.

Deux lieux votifs, établis sur des emplacements de hauteur, ont été fouillés ces dernières années dans le département du Var. Le premier, très modeste dans son étendue, utilise l'espace autour d'un gros bloc rocheux, en forme de table, au lieu-dit La Peiro de l'Mutar (Cucrs). La pctitc éminence d'installation est à faible distance d'un habitat fortifié qui paraît contemporain : $\mathrm{II}^{\mathrm{e}}$ ou I ${ }^{\mathrm{er}} \mathrm{s}$. avant J.-C. ${ }^{16}$ (fig. 88a). Bien que partiellement pillé, le site a laissé apparaître, à très faible profondeur, un lot de plusieurs dizaines de pièces métalliques, 14 anneaux, 18 plaquettes, 3 rondelles et des morceaux de tôle en bronze découpés. La plupart sont volontairement perforées (fig. 88b). Ces éléments de forme, comme le mode de percement, sont caractéristiques des dépôts de plusieurs lieux votifs de hauteur dans le Sud-Est gaulois, à l'époque augustéenne comme au Chastellard de Lardiers (Barruol, 1997, fig. 210-211) ou en relation avec des habitats groupés et perchés antérieurs, comme à Entremont et La Cloche (voir infra), Cavaillon (sur la colline Saint-Jacques) ou encore à Mauressip. On retrouvera également, plus loin, cette même pratique au sein de dépôts volontairement enfouis. Dans

15. Ainsi pour le Puech de Buzeins, près d'une exploitation d'antimoinc, où fut découvert sur les pentes un lingot de plomb; au Puech de la Table, dans lc district d'exploitation de fer du Kaimar; au Puech du Caylar, qui est entouré d'indices cuprifères (Gruat, Marty, 1996, p. 118); ou encore au Plô de Maroui.

16. Fourchette chronolngique proposée par rapprochement stylistique des mobiliers. tous les cas, le percement, mode de neutralisation de la pièce ou trace d'une ancienne fixation sur bois pour une exposition, devient une marque rituelle liée au geste de l'offrande d'objets métalliques ou de morceaux découpés et réutilisés. Ces modestes présents devaient être simplement étalés ou suspendus sur l'emplacement sacralisé, lieu reconnu de tous, éventuellement délimité avec un repérage symbolique, petits bétyles (comme autour de la stèlestatue de la Tour Magne à Nîmes, voir infra) ou potelets en bois, cordelettes, fils de laine... (Brun, Borréani dir., 1999, p. 369-370 ; Brun, Michel, 2000, p. 262-263).

Le second site cultuel varois est celui des Cannebières, sur la commune de Correns. La découverte se positionne sur un massif, isolé par des vallons encaissés des hauteurs proches où plusieurs habitats de l'âge du Fer sont inventoriés (Brun, Michel, 2000, fig. 1). Le mobilier était répandu sur $170 \mathrm{~m}^{2}$, à la surface d'une avancée du plateau dans sa partie sommitale. L'élévation a pu constituer une ancienne limite de peuples, si l'on reprend celles des diocèses de la fin du Moyen Âge. Les objets recueillis étaient dispersés à faible profondeur. Ils se composent de 58 monnaies, 72 jetons en plomb, ornés de croix ou d'étoile (fig. 89), 2 en argent, 78 clous en fer, 1 pointe de flèche en bronze et 140 récipients céramiques de dimensions réduites (essentiellement d'époque romaine). Aucune trace d'aménagement de surface n'a pu être observée à la fouille, les objets reposant à même le substrat dans une fine couche de terre « charbonneuse " (Brun, Borréani dir., 1999, p. 348349). Les monnaies montrent une répartition chronologique $d u V^{e}$ s. avant J.-C. au IV ${ }^{e} s$. de notre ère. Les quelques pièces plus anciennes (pointe de flèche du Bronze final, par exemple) soulignent peut-être seulement le choix 


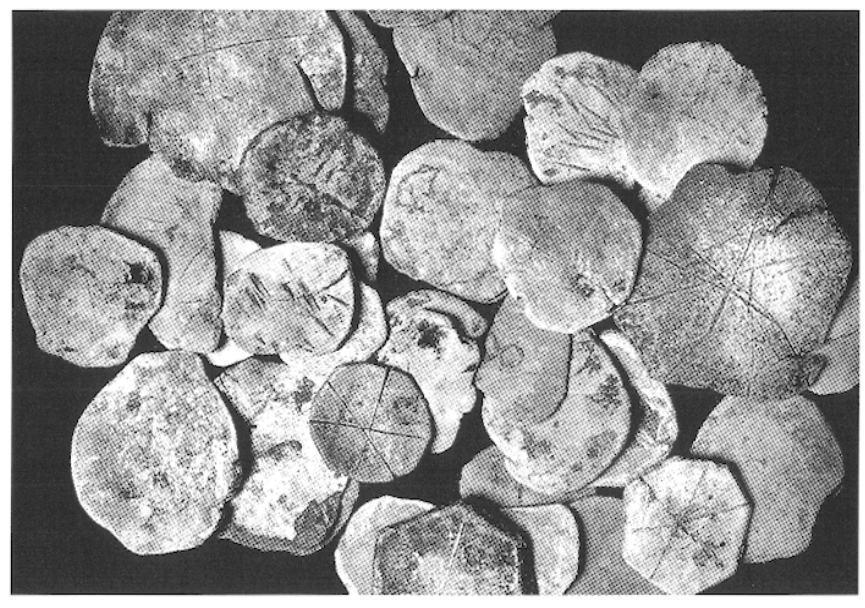

Fig. 89 - Correns (Var), Les Cannebières. Jetons votifs en plomb d'un dépôt de plein air. Les indications monétaires montrent une fréquentation du $V^{*}$ s. av. J.-C. au IV s. de notre ère (photo C. Durand, CNRS).

délibéré d'une offrande de vieux objets. Le symbole récurrent gravé sur les jetons, l'étoile ou les rayons de la roue du " char solaire ", suggère une aire de dépôts consacrée à Taranis/Jupiter, divinité des éléments déchaînés et du tonnerre, gardien des frontières, dont le nom apparaît en Provence au ${ }^{\text {er }}$ s. avant J.-C. (Lejeune, 1985, p. 52-56 ; Duval, 1993, p. 29 ; Vendryes, 1997, p. 32).

Ces lieux de culte érigés sur des éminences semblent nombreux, répondant en cela à un besoin "d'élévation » vers les divinités ouraniennes. Le phénomène est récurrent également dans les zones plus basses des secteurs côtiers ou deltaïques, où de modestes hauteurs, collines, écailles rocheuses ou rebords de plateaux, peuvent être utilisées pour l'implantation de lieux cultuels, modestes ou plus structurés. Les édifications pérennes ne constituent pas la norme dans le processus de gestion des lieux de culte celtiques et des offrandes offertes aux dieux. C'est l'environnement contextuel qui compose le réceptacle fondamental des dépôts, sans besoin de protection particulière. Le meilleur garant de leur permanence en regard de la cupidité des hommes est la sacralisation du lieu sur le territoire par la divinité elle-même. Tout manquement, stipule César (B. G., VI, 17), est " puni d'une mort terrible dans les tourments ». C'est dire que la notion de «temple », en tant qu'espace construit et fermé, ne trouve pas place dans la conception religieuse traditionnelle des Celtes. Ainsi le fanum est une évolution tardive de l'enclos délimité et de son autel (en creux); il n'apparaîtra d'ailleurs dans l'ensemble du Midi, comme dans le reste de la Gaule, qu'au $\mathrm{I}^{\text {er }}$ s. avant J.-C., avec une multiplication à la période augustéenne (Fauduet, 1993, p. 118-120).

\section{ENCLOS, FOSSÉS ET PUITS}

Parmi les modes d'aménagement des pratiques socioreligieuses, l'acte de délimitation d'une aire consacrée à la divinité est fondamental. Le fait de circonscrire un espace cultuel participe de sa sacralisation et lui confère une valeur d'inviolabilité. Les hommes ne peuvent y pénétrer que dans le respect d'un rituel établi. En Gaule plus septentrionale, la notion d'enclos fossoyé recouvre des usages et des fonctions variés, tant profanes que cultuels. De fait, dans un système de construction où le bois et la terre dominent, l'ensemble des structures rurales ou d'habitat (limites de parcelles ou de chemins, délimitations des cours de ferme, intégration aux systèmes défensifs d'une aedificia privata ou d'un oppidum...) fait appel à ce mode de délimitation, de protection mais également de drainage fonctionnel (Marion, Blancquaert dir., 2000). Le même principe de la limitation fossoyée peut participer aux tracés d'espaces circulaires ou quadrangulaires autour d'une ou de plusieurs sépultures, mais aussi d'aires connexes, apparemment vides, perçues comme cultuelles et cérémonielles (Pautreau, 1992, p. 298-299; Chaume et al., 1995). Poseidonios fait le récit d'un banquet de Luern, qui se déroule plusieurs jours durant au sein d'une aire de douze stades carrés (plus de six cents mètres de côté !), avec moult boissons et victuailles (apud Athénée, IV, 152, e-f). Il témoigne de la création de vastcs cnclos quadrangulaires pour le déroulement de manifestations collectives ${ }^{17}$. Dans la Gaule celtique, de tels espaces à délimitation fossoyée, désignés sous le nom allemand peu spécifique de Viereckschanzen, ont été reconnus par l'archéologie (Berger, 1963; Wieland et al., 1999) ; ils sont fréquemment dépourvus de vestiges internes interprétables (Buchsenschutz, 1989, 1991). Mais les fossés d'autres enclos peuvent être bien plus riches en vestiges. Leur analyse permet désormais de définir un groupe d'« enclos à banquets ", aires de grands festins cérémoniels où le don du " prince » rejoint les exigences du cultuel (voir en dernier lieu, Poux, 2000a ; Brunaux, 2000b).

17. Ce banquet est organisé par le père de Bituit(os) qui est lui-même vaincu par les troupes romaines en 121 avant J.-C. On peut donc placer le récit au début du troisième quart du $\mathrm{II}^{\mathrm{e}} \mathrm{s}$., bien que le texte de Poseidonios soit écrit vers 100 . Un passage de l'historien grec Phylarque, cité par Athénée (IV, 150, d-f), est par ailleurs rappelé par F. Perrin et J.-C. Decourt (2002, p. 373-374). L'histoire se passe à haute date, sans doute bien avant l'époque du narrateur, au IVe s. avant J.-C. au moins, et certainement en Gaule même puisqu'une partie des sources provient du récit du voyage de Pythéas (discussions contradictoires dans Brunaux, 2000b, p. 273-274; Poux, 2000a, p. 218). Elle décrit les largesses d'un riche celte Ariamnès qui, à la suite d'une promesse, offrit le boire et le manger à qui voulait, pendant une année complète! Pour ce faire, il fit établir de vastes enclos capables de recevoir plus de 400 personnes, entourés de palissades de roseaux et d'osier, le long des principales voies de circulation. 
En regard de ces évolutions conceptuelles de la Gallia comata, le Midi s'est maintenu en retrait dans l'interrogation des potentialités structurelles des territoires, et ce malgré la présence de vastes plaines sur son littoral et dans les vallées de ses principaux fleuves. L'essentiel de son attention est demeuré longtemps attaché aux habitats groupés et à leur architecture à murs porteurs, en pierres sèches. L'évolution de ces dernières années, initiée par l'archéologie préventive autour des impératifs des grands travaux, a fortement contribué au déblocage de cette situation, tant sur le plan archéologique que conceptuel. Des textes anciens laissaient pourtant entrevoir la réalité d'aires cultuelles aménagées sur les territoires ouverts, telles les allusions du poème emphatique de Lucain sur le bois sacré des Ligures, près de Marseille. Le texte suggère également l'existence de simulacres en bois (plutôt ceux des ancêtres que des divinités) et de rites sanglants relevant du sacrifice humain à l'image de ceux des sanctuaires du Belgium (Pharsale, III, 399-452). Une dédicace rédigée en gallo-grec et provenant de Vaisonla-Romaine, révèle la réalité près de l'agglomération d'un de ces espaces sacrés. Il s'agit d'un nemeton à la divinité Belisama, une aire délimitée dans l'étymologie celtique, éventuellement entouré de bois. L'exécution est réalisée aux frais d'un certain Segomaros, magistrat de la ville de Nîmes au cours du $I^{\text {er }}$ s. avant J.-C. (Goudineau, 1991, p. 252-253, fig. 5). On retiendra du texte deux aspects : la consécration d'espaces collectifs et sacrés sur le territoire de proximité d'une agglomération alors en extension dans la plaine, la permanence des traditions celtiques au seuil de la prime romanisation (Goudineau, Kisch, 1991, p. 19-26). On comprend aisément que ces amples aménagements ne puissent trouver place dans la structuration de l'habitat concentré du second âge du Fer.

Si les zones forestières paraissent déjà limitées à l'âge du Fer, de par les effets cumulés d'une longue anthropisation, d'autres emplacements cultuels sont fréquentés. C'est par exemple celui implanté autour d'un rocher à L'Acapte, à quelques kilomètres de l'agglomération côtière d'Olbia à Hyères. Fidèles grecs pour l'essentiel, mais éyalement indigènes de la chôra, déposent ou brisent de la vaisselle céramique contre le bloc sacré, à partir de la fin du $\mathrm{II}^{\mathrm{e}} \mathbf{s}$. avant J.-C. Ces offrandes sont dédiées au dieu rural Aristée et portent inscrites, en grec, des formules de remerciement pour la demande exaucée (Giffault, Coupry, 1990).

Parmi les aires en plaine délimitées par un fossé, un premier ensemble relève de l'environnement cultuel du milieu funéraire. Ces dernières accompagnent l'inhumation ou l'incinération et les marques visibles sur les restes des disparus (Schwaller dir., 1994 et infra notice 1, p. 217-220). $\mathrm{Si}$ les traces d'offrandes sur le recouvrement de la sépulture sont attestées à plusieurs reprises, nous retiendrons deux aspects de probables espaces cultuels établis à proximité des nécropoles. Le plus ancien se place dans la continuité des enclos de la Préhistoire récente. Ces espaces circonscrits par un fossé sont généralement circulaires ou ovales, plus rarement quadrangulaires, et dispersés à proximité des nécropoles (Pautreau, 1992, p. 298-299 ; Lambot et al., 1994, p. 135-137). C'est à date récente que des fouilles préventives à Vestric-et-Candiac (Gard) ont permis de reconnaître plusieurs espaces sans fonction funéraire directe. Le site montre dans sa partie fouillée un fossé de forme ovale, discontinu, qui délimite un espace de $14,50 \mathrm{~m} \times 8,60 \mathrm{~m}$, orienté nord-sud (fig. 127). Le comblement du fossé est intervenu peu de temps après son creusement. Il ne contient que de rares objets dont un bracelet en fer, et deux urnes ont été déposées à sa superficie (points D1 et D2). À l'extérieur, vers le sud-est, un troisième récipient est écrasé sur le sol (point D3). Deux tombes à inhumation d'adultes, dont celle d'une femme, apparaissent à une dizaine de mètres dans la même direction (points $\mathrm{S} 1$ et $\mathrm{S} 2$ ). Les fouilles ont repéré, à une cinquantaine de mètres vers l'ouest, deux autres fossés circulaires concentriques (30 et $24 \mathrm{~m}$ de diamètre ; non figurés), mais ils n'ont pu être sondés (Dedet et al., 1997). L'enclos ovale de Vestric-et-Candiac parait bien lié à l'amorce d'une nécropole voisine. Mais on ignore totalement sa fonction en l'absence des sols intérieurs. L'hypothèse d'une aire (palissadée ?) à vocation cultuelle est une proposition temporaire qui résulte des rapprochements effectués avec les vestiges similaires d'autres régions gauloises, eux-mêmes souvent peu parlants (Buchsenschutz, 2000). La date proposée pour l'enclos est celle retenue pour les sépultures et les vases isolés, le début du premier âge du Fer (VIII'-VII s. avant J.-C.).

D'autres éléments de possibles aménagements à fonction votive, mais également à connotation socialement valorisante, apparaissent dès le premier âge du Fer en Languedoc occidental. La fouille du village de plaine du Traversant, au pied de l'oppidum du Cayla à Mailhac, a entraîné la découverte d'éléments sculptés en ronde bosse, d'autres peut-être en reliefs, le tout regroupé dans une fosse (Gailledrat, Bessac, 2000). Le bloc le plus net correspond à un élément du corps d'un lion accroupi, reprise locale de modèles du Sud de l'Espagne (Chapa Brunet, 1985 ; León, 1997). À défaut d'une datation clairement établie pour l'obturation de la fosse, la période du premier quart du $\mathrm{VI}^{\mathrm{e}} \mathrm{s}$. retenue pour cette sculpture reste sujette à caution et il n'est pas impossible que le creusement soit postérieur, dans le $V^{\mathrm{e}} \mathrm{s}$. avant J.-C. De toute manière, l'intérêt de cette ronde-bosse reste entier quelle que soit sa date exacte. L'animal illustre de façon concrète l'émergence de dispositifs cultuels sur les tombes ou à leur immédiate proximité, ailleurs difficile à reconnaître en l'absence de réalisations 


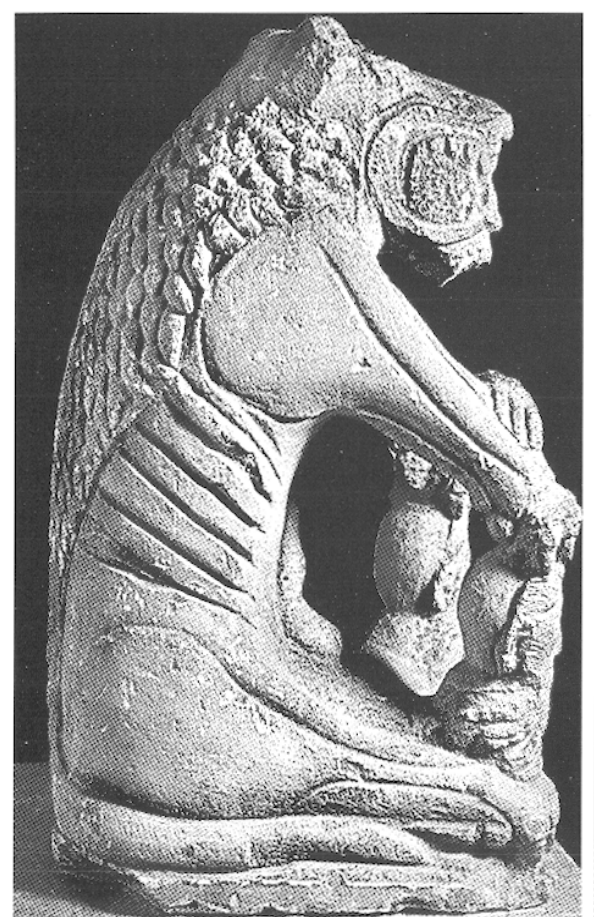

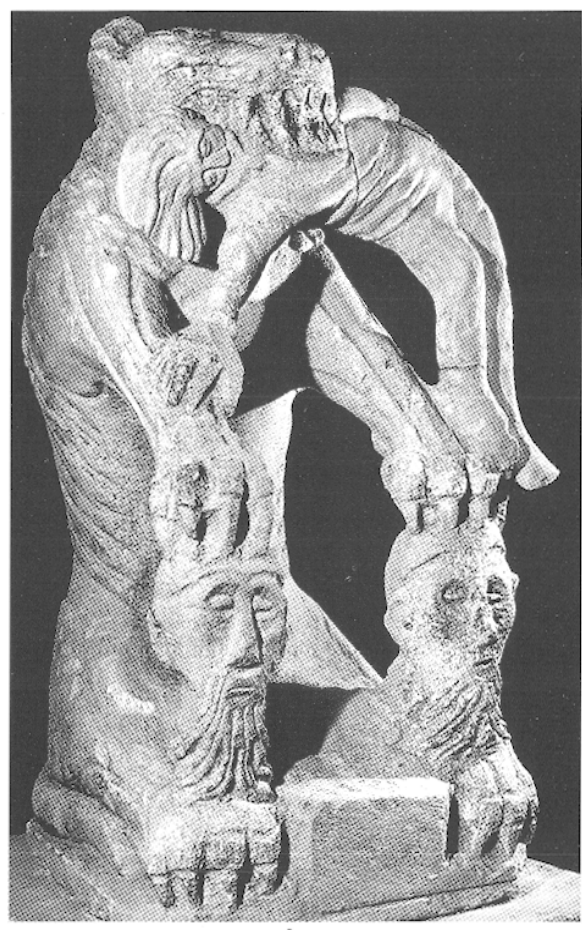

b

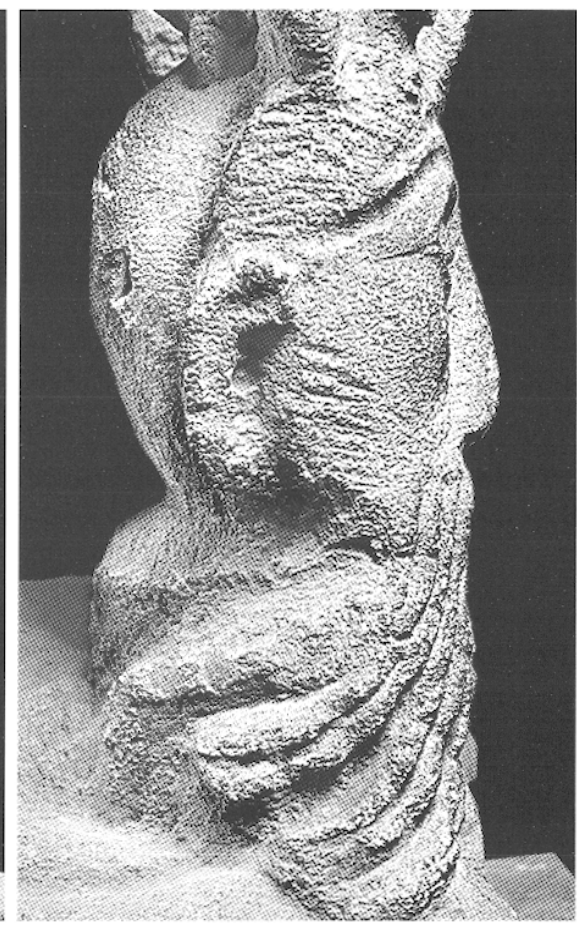

C

Fig. 90 - Noves (Bouches-du-Rhône), piémont du Puech. La sculplure dite la Tarasque (H. : 1,18 m) est une ouvre insolite, celle d'un animal fantastique porteur de messages symboliques forts dans une dialectique très celtisante. L'environnement de la découverte suggère une nécropole de la fin du II ${ }^{e}$ s. av. J.-C. au début de l'Empire : a, état après son nettoyage en 2001 ; b, proposition d'une restitution du personnage manquant; c, une des deux têtes qui montre le décroché $d u$ "masque " d'un visage barbu appliqué sur un "crâne lisse " (maquette el photos R. et $O$. Coignard).

aussi pérennes. Par delà la concrétisation des relations culturelles sud-nord, l'œuvre rend compte du souci croissant des populations de la fin du premier âge du Fer de répondre de façon plus pérenne aux besoins de valorisation des familles dominantes (Janin, 2000, p. 128).

À ce jour, le cas de Mailhac reste isolé dans le Midi jusqu'à la fin du second âge du Fer. Ce n'est qu'après la conquête romaine du Midi que cette expression sociocultuelle trouve ses modalités et son champ d'application. Les vestiges du mausolée romain d'Argenton au Fugeret, dans les Alpes-deHaute-Provence, sont de ce point de vue représentatifs des courants italianisants d'alors (Bérard, Roth Congès, 1997), au même titre que le trophée de Pompée à Panissars, au Perthus dans les Pyrénées (Castellvi et al., 1995). Ainsi, en Provence occidentale, autour des Alpilles dans les Bouchesdu-Rhône, émerge au I ${ }^{\text {cr }}$ s. avant J.-C. un nouveau courant d'expression sociocultuelle autour des nécropoles. Il se manifeste par l'édification de mausolées de type grécoitalique, mais également de possibles chapelles et autels votifs (Roth Congès, 1993 ; Arcelin, 1999a, p. 75 et fig. 13). Ces constructions, qui relèvent de concepts méditerranéens, sont ici réintégrées dans l'expression religieuse et sociale des classes dirigeantes indigènes. On observe dans plusieurs cas des symboles animaliers forts en relation avec ces constructions, comme celui du lion, au naturalisme très grécoitalique. Outre des reprises régionales de qualité moindre de ces animaux assis ou prêts à bondir, menaçants et rugissants comme dans la basse vallée de l'Hérault, à Aumes (Garcia, 1993, p. 310-311), nous nous arrêterons avec intérêt sur le cas singulier de l'œuvre de Noves, près des Alpilles (fig. 90) (Varagnac, Fabre, 1956, p. 81 et 95, pl. 24, 25, 29 ; Benoit, 1969a, p. 49-50). Cette « Tarasque », demeurée ces dernières années en retrait du discours iconographique de la Protohistoire récente faute de parallèles régionaux, vient d'être nettoyée et reconsidérée dans le cadre d'une récente table ronde ${ }^{18}$. L'image que nous retenons est celle d'une

18. L'analyse récente du contexte archéologique de la découverte, peu avant 1849 , suggère un milieu funérairc étalé entre la fin du II" $s$. avant $\mathrm{J}$.-C. et le début du I ${ }^{\mathrm{er}} \mathrm{s}$. de notre ère au plus tard (couvercle en plomb). Les actes de cette table ronde de décembre 2001 sont actuellement édités par $\mathrm{M}^{\mathrm{me}} \mathrm{O}$. Cavalier, conservateur au musée Calvet d'Avignon. On rappellera la publication récente d'une autre ocuvre aux caractères morphologiques proches et censément découverte dans le « Midi de la France» (Langloys, 1999, p. 294-297). 


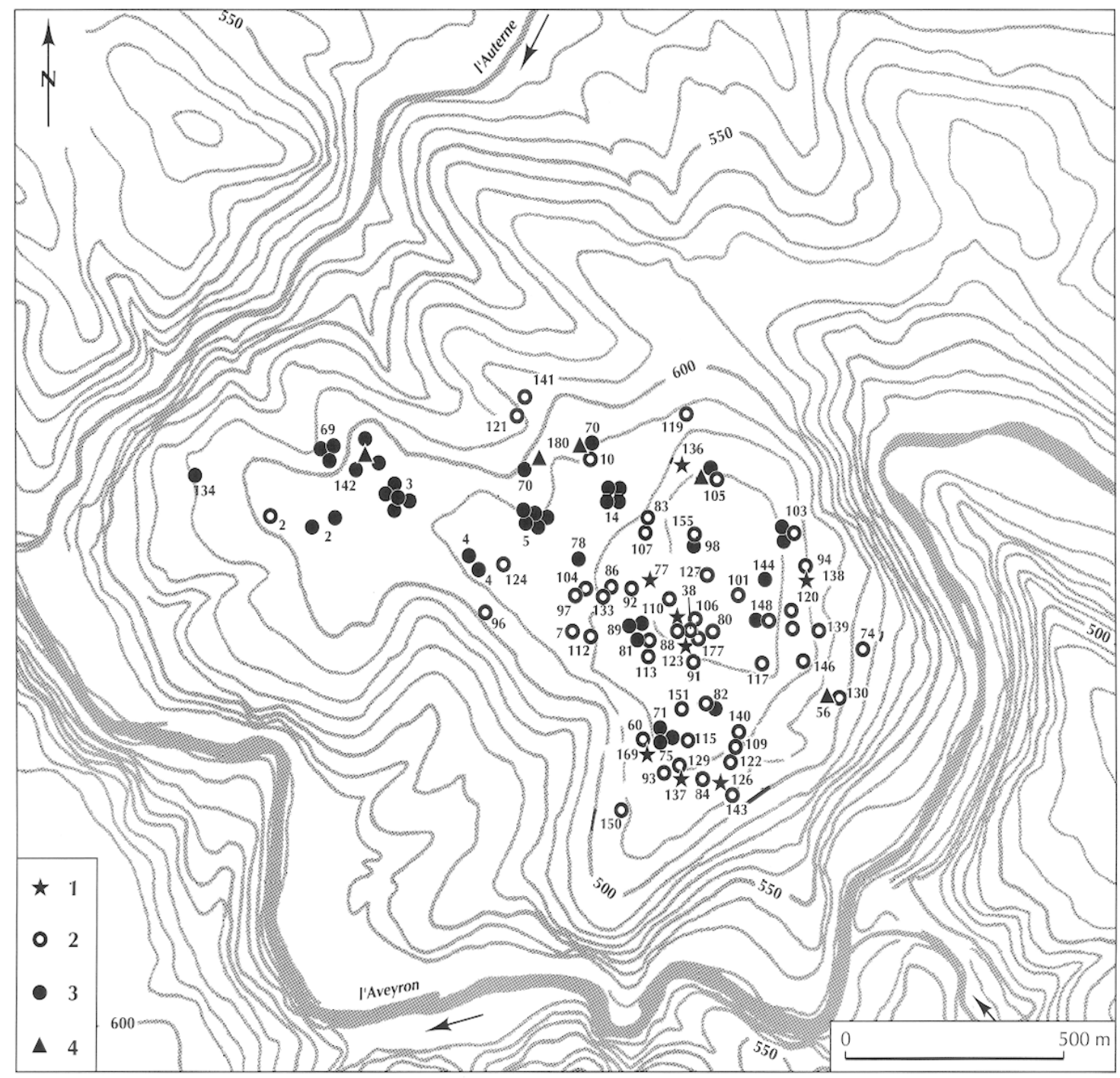

Fig. 91 - Rodez/Segodunum (Aveyron), à la fin de l'âge du Fer. Répartition de quatre types de vestiges archéologiques découverts depuis le XIX ${ }^{e}$ s. : 1, structure d'habitat ; 2, niveau d'occupation ou mobilier isolé; 3, puits à offrandes; 4, fosse ou fossé à offrandes (relevé P. Gruat).

libre adaptation du thème au lion gréco-romain alors en vogue, mais conçue dans un tout autre esprit. L'animal n'a plus rien de naturaliste, il n'est que le support pour la concrétisation d'un monstre fantastique porteur de caractères exacerbés qui expriment un concept majeur du monde celtique, celui du cycle de la vie (Arcelin, 2002). Dans cette relecture indigène, l'animal devient l'incarnation de l'idée d'un Dis Pater chthonien, à la fois destructeur (la gueule, les griffes) et source de vie, de l'éternel recommencement (le sexe en érection). Fort intéressantes sont les deux têtes maintenues en position de dépendance sous les pattes de l'animal. Comme cela a été analysé lors de la table ronde, il ne saurait s'agir de " têtes coupées " (des trophées guerriers), mais de « masques" dont le sculpteur a volontai- rement souligné la proéminence de la reconstitution faciale modelée sur le retrait de l'os du crâne, préalablement décharné et nettoyé (fig. 90c). Nous avons très certainement ici la représentation tridimensionnelle sur pierre des masques naturalistes en argile peinte, reconstitués sur la partie faciale de crânes humains. Il s'agit alors de « masquesreliquaires ", identiques à ceux destinés à l'exposition sur les piliers ou linteaux de portiques cultuels. Nous y reviendrons.

Nous possédons peu d'informations sur la présence d'enclos à proximité des nécropoles du second âge du Fer. Le seul cas de fossé repéré près d'une nécropole à Eyguières n'a été que très partiellement fouillé. La composition du mobilier céramique et les premières données ostéologiques suggèrent au fouilleur une sélection des dépôts, dans 
la première moitié du $\mathrm{I}^{\mathrm{er}} \mathrm{s}$. avant J.-C. (Verdin, 2000, p. 184-190). En dehors de cet exemple, trop incomplet pour être décisif, d'autres découvertes montrent désormais la réalité si ce n'est d'enclos quadrangulaires reconnus en tant que tels du moins de fossés et de puits à offrandes au second âge du Fer.

Les structures observées sont à proximité des agglomérations ou à leur contact direct, mais également, selon la nature de l'habitat, intercalées entre les secteurs bâtis. Quelques rappels de cas permettront de mieux expliciter le propos. L'exemple le mieux connu est celui de l'agglomération de Rodez, antique Segodunum (fig. 91) (Gruat et al., 1991). Une quarantaine de puits et fosses à offrandes ont été mis au jour sous l'agglomération gallo-romaine depuis le XIX ${ }^{\mathrm{e}}$ s. Longtemps considérées comme des sépultures, ces excavations sont perçues aujourd'hui dans leur diversité d'usage primaire, parfois de réutilisation. Parmi les fonctions probables figurent celles de pratiques cultuelles magnifiquement illustrées par les découvertes du toulousain et de l'oppidum de L'Ermitage à Agen (Boudet, 1996, p. 118). Â Rodez, les fouilles de 1989 à l'emplacement de la caserne Rauch, située à l'extérieur de l'agglomération antique (fig. 91 , point $\mathrm{n}^{\circ} 142$ ), ont pour la première fois autorisé une exploration extensive du terrain. Plusieurs types de structures excavées dans le substrat rocheux ont été relevés (fig. 92). Il s'agit d'abord de puits circulaires (fig. 93a) ou quadrangulaires (fig. 93b), de 1,50 à $3 \mathrm{~m}$ de profondeur, mais également d'un fossé, de 0,90 à $2 \mathrm{~m}$ de largeur pour 0,25 à $0,60 \mathrm{~m}$ de profondeur, creusé sur une longueur totale de $72 \mathrm{~m}$, en exploitant un pendage naturel menant à un puits disposé à son extrémité septentrionale (fig. 94a). Enfin des fosses, d'environ $1 \mathrm{~m}$ de diamètre pour $0,50 \mathrm{~m}$ de profondeur, ont été aménagées à proximité, dans la terre de surface. Toutes ces excavations sont au moins partiellement comblées par des dépôts d'objets, dont on a pu noter l'organisation. Ainsi les parties inférieures des puits et du fossé comportent de la vaisselle régionale ou importée, avec des meules et quelques objets métalliques, parfois disposés dans une cuvette (fig. 93b). Les parties supérieures sont composées d'une accumulation d'amphores vinaires, essentiellement italiques, avec des cols parfois disposés en position verticale, voire avec des bouchons de liège encore en place (fig. 94c). Ces apports sont ensuite scellés par une chape de blocs volontairement disposés. Les dépôts de ces puits, comme ceux du fossé, contiennent également des ossements d'animaux, le plus souvent incinérés. Aux rares végétaux de culture, s'ajoutent des plants sauvages qui ont probablement fait l'objet de collecte en raison de la nature comestible de leurs fruits. Datant pour l'essentiel de la fin du $\mathrm{II}^{\mathrm{e}}$ s. et de la première moitié du I ${ }^{\text {er }} \mathbf{s}$. avant J.-C., ces puits de Rodez ne

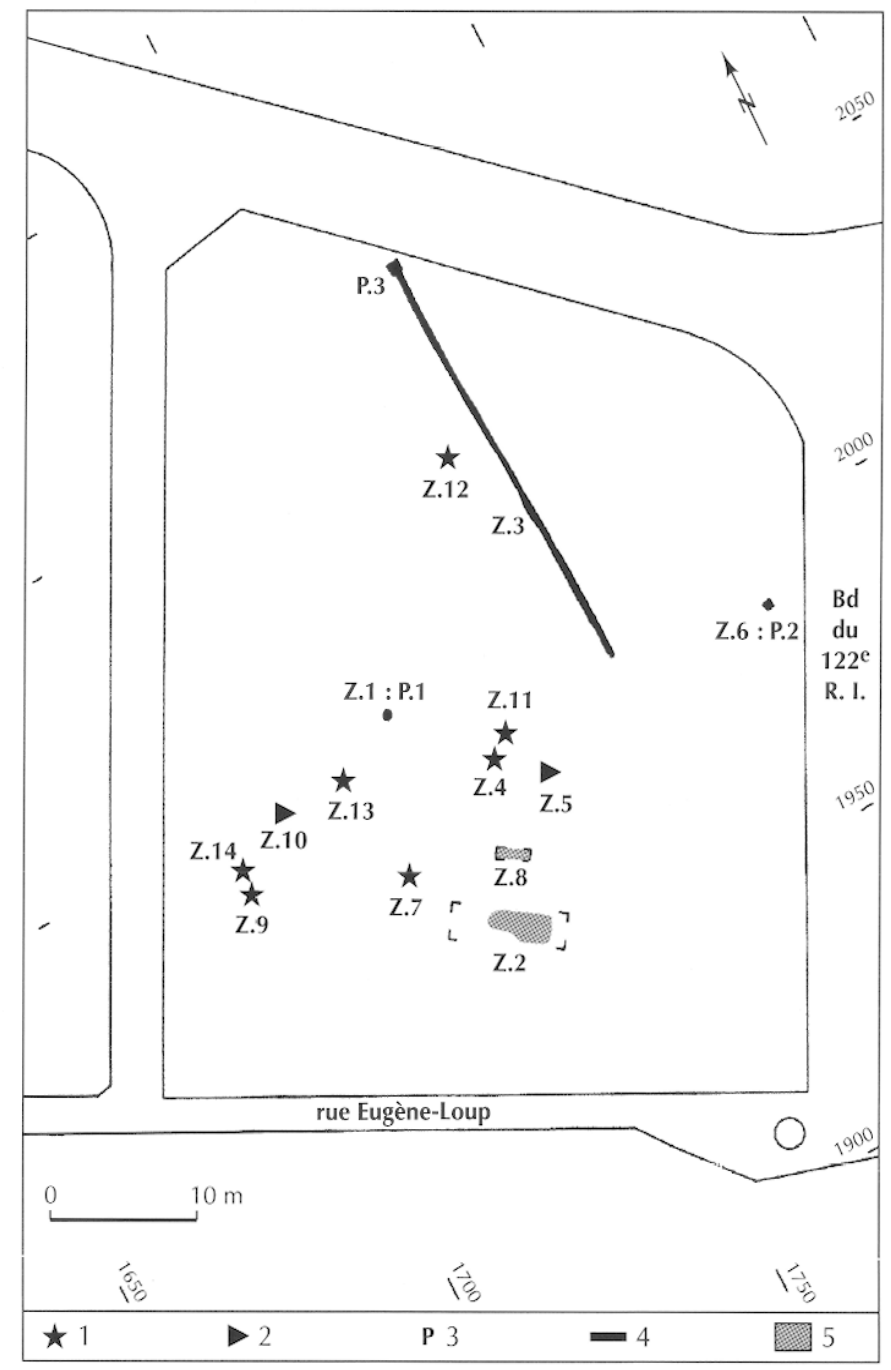

Fig. 92 - Rodez/Segodunum (Aveyron), Caserne Rauch. Répartition des aménagements à caractère cultuel découverts à proximité du fossé à offrandes (Z. 3): 1 , concentration d'amphores; 2 , fosse à offrandes ; 3, puits ; 4, fossé ; 5, zone d'occupation (d'après Gruat et al., 1991, fig. 2).

présentent pas la variété ni la richesse de leurs équivalents dans la vallée de la Garonne, bien que l'un d'entre eux ait donné un simulacrum en bois, une silhouette humaine taillée dans une branche ou un fût de chêne (fig. 95) (Gruat, 1998, p. 126).

D'autres puits et fosses sont connus en pays rutène, à La Graufesenque (Millau), Albi, Castres, La Pointe à SaintSulpice et Solomiac à Palleville, tous dans le Tarn (fig. 87), mais d'autres aussi plus au sud comme à La Lagaste, Rouffiac-d'Aude (Rancoule, 1980, p. 111-113). On remarque que ces dépôts, en excavations scellées ou en fossés rapidement comblés, ne sont pour l'instant repérés dans la partie occidentale de l'aire méditerranéenne qu'à 


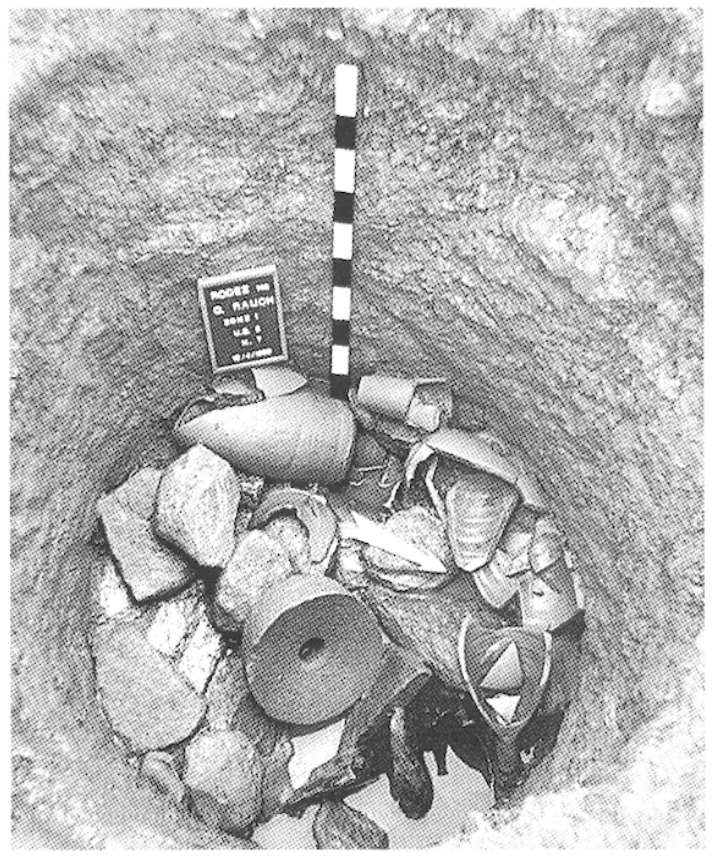

a

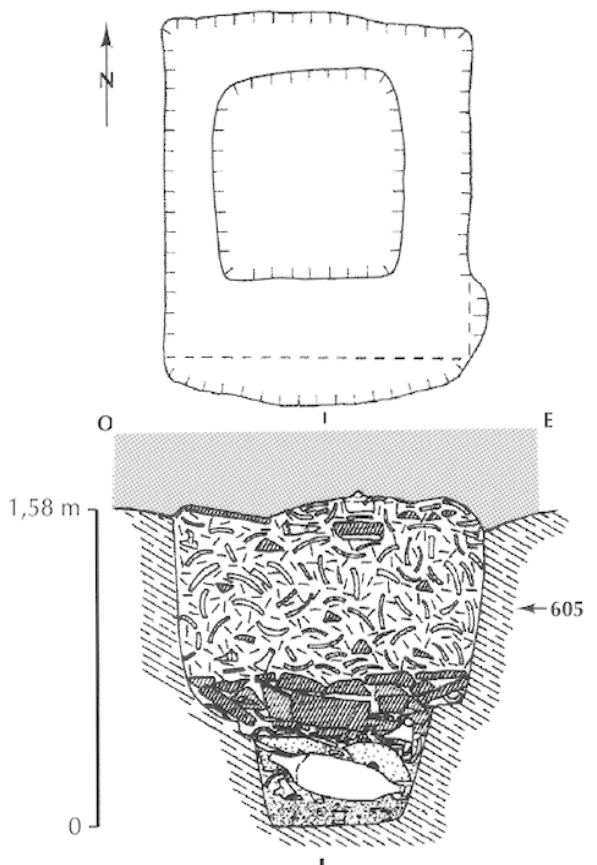

b

Fig. 93 - Rodez/Segodunum (Aveyron), Caserne Rauch :

a, puits à offrandes $n^{\circ} 1$ et son remplissage en cours de fouille;

b, plan et coupe du puits $n^{\circ} 2$ (d'après Grual et al., 1991, fig. 7; photo P. (rruat).

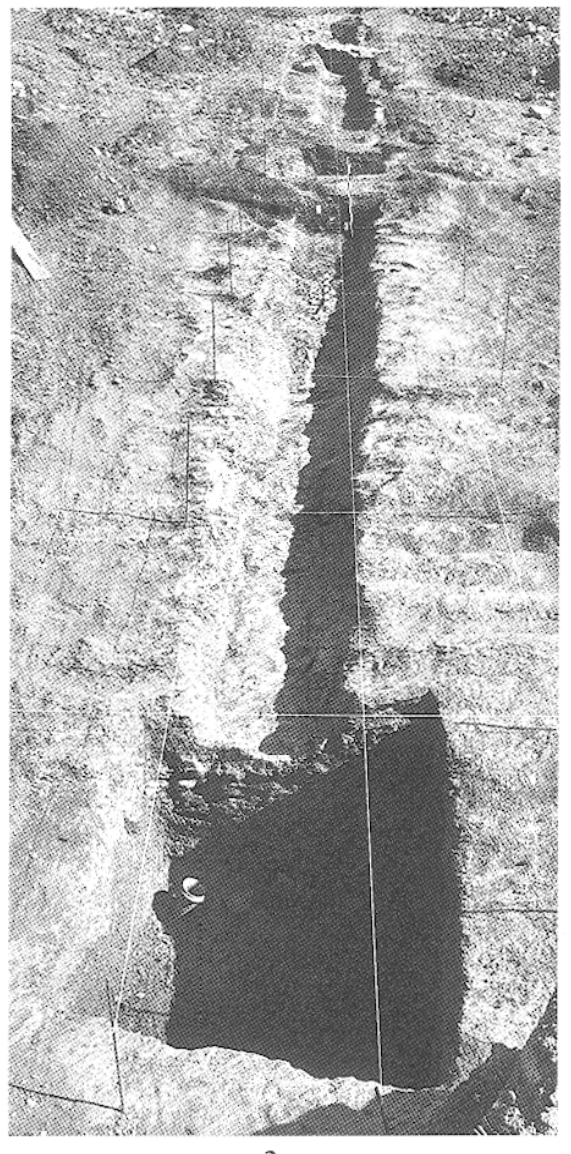

a

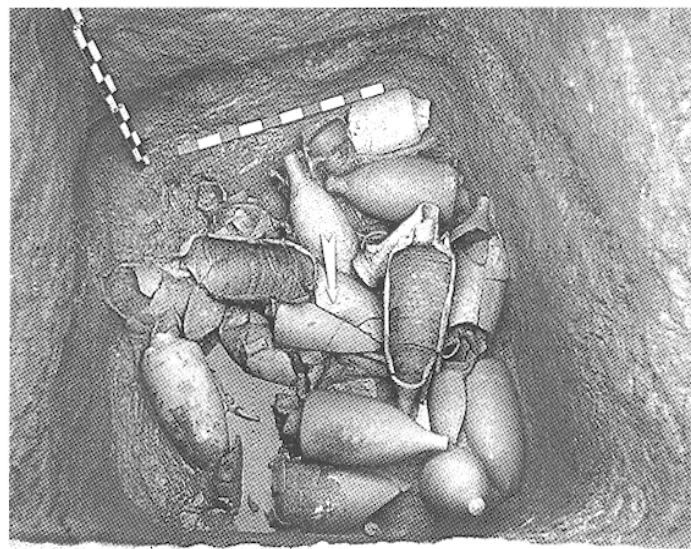

b

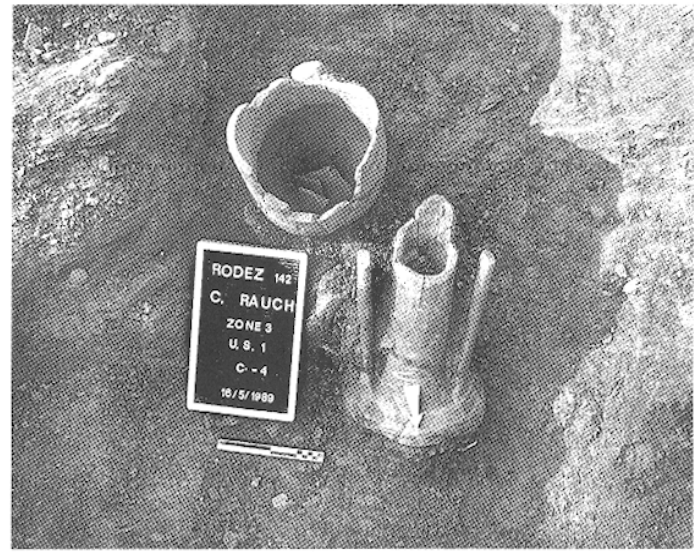

Fig. 94 - Rodez/Segodunum (Aveyron), Caserne Rauch : a, extrémité septentrionale du fossé de la zone 3 (voir fig. 92) et son contact avec le puits $n^{\circ} 3 ; b$, niveau. d'amphores souvent décolletées dans la partie inférieure du puits $n^{\circ} 3 ; c$, éléments d'amphores disposées en position verticale dans le haut du comblement du puits $n^{\circ} 3$, à son intersection avec le fossé qui s'y déverse (photos $P$. Gruat). 


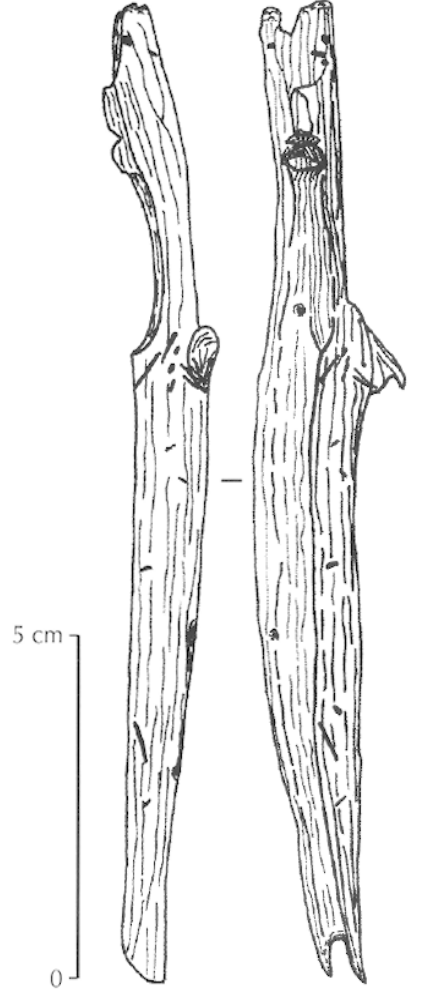

a

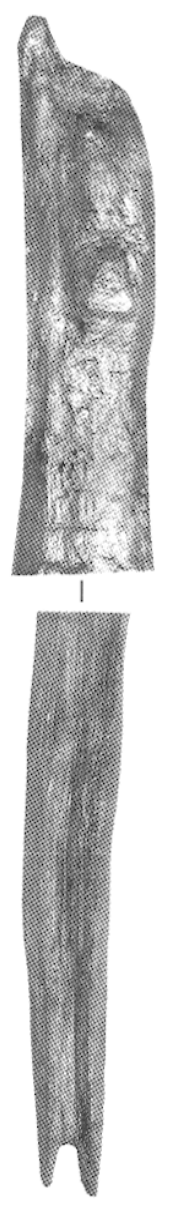

b
Fig. 95 - Rodez/Segodunum (Aveyron). Piquet anthropomorphe en chêne (L. actuelle: $1,40 \mathrm{~m}$ ) découvert dans la partie inférieure d'un puits, présumé à offrandes, boulevard François-Fabié, sile 137 (voir fig. 91): a, dessin de face et profil du piquet; $b$, détail des parties supérieures el inférieures (dessins et photos $P$. Cruat).

proximité immédiate des grandes agglomérations, qu'elles soient de hauteur ou en sites ouverts. Ailleurs, ce n'est qu'à une date récente que l'on s'est interrogé sur l'étendue possible des pratiques du "type toulousain ». Laissant de côté les puits et les fosses comblés des pentes de la colline Saint-Jacques à Cavaillon, qui paraissent de nature bien différente (Dumoulin, 1965), on rappellera le puits quadrangulaire soigneusement creusé dans le substrat rocheux au sommet de l'oppidum de Saint-Blaise à SaintMitre-les-Remparts. Anciennement fouillé par H. Rolland (1956, p. 39-41), seuls les éléments monumentaux de son comblement final ont été publiés, en relation avec la destruction d'un temple (proche ?) de type gréco-italique (tambours de colonne, autel mouluré). L'excavation, de 1,60 m par 1,30 m de côté et de $25 \mathrm{~m}$ de profondeur, est complétée au fond par un petit « puisard ». Des encoches, creusées dans les parois, ont contribué à la circulation verticale. Cette cavité quadrangulaire a été interprétée comme une citerne ou comme une tentative de captation de source (Bouloumié, 1984, p. 55). Faute d'une attention particulière à la composition du comblement inférieur, on s'interrogera aujourd'hui sur la fonction exacte de cet aménagement régularisé, l'usage cultuel ne devant pas être a priori écarté comme l'avait déjà envisagé le découvreur.

La perception archéologique de fossés à offrandes est désormais plus tangible dans la basse vallée du Rhône. Dans la même fourchette chronologique que Rodez (vers 120-80 avant J.-C.), un fossé de $120 \mathrm{~m}$ de long a été découvert à faible distance de l'oppidum d'Entremont, qui vivait alors ses dernières années d'occupation, et par ailleurs en périphérie de la jeune colonie latine d'Aquae Sexiae (fondée vers - 120 , selon les sources historiques). Au profil en V, de 1,50 m de largeur pour 1,20 $\mathrm{m}$ de profondeur, il ne donne pas d'indice sur l'éventuel changement de direction qui pourrait dénoter la délimitation d'une aire quadrangulaire. Aucun puits ou fosse n'a été observé alentour (voir infra notice 2, p. 220-222). L'importance des dépôts de petites céramiques et de meules, mais surtout d'amphores jetées ou déversées par charrettes dans le fossé durant un laps de temps très réduit avant le comblement général, rapproche fortement les pratiques de ce site de celles analysées à Rodez, à Lyon (au Verbe-Incarné) (Mandy et al., 1989) ou récemment en Auvergne (Poux, 2002), à la même époque ou peu après. Dans tous les cas, nous sommes en présence d'une masse considérable d'amphores dont l'état laisse fortement présager d'un usage de leur contenu vinaire en un laps de temps très bref. Autant de signes qui paraissent recouvrir des pratiques collectives du banquet et des libations accompagnées d'actions dévotionnelles (Poux, 1999b, 2000b, 2002). Le rapprochement avec l'attitude des personnages de la plaque gravée de Cavaillon prend ici tout son sens (voir infra).

Du site de Rodez provient la sculpture en ronde-bosse d'un personnage au torque (fig. 96a) mais qui paraît pouvoir se rattacher au début de l'Empire (Gruat, 1998, p. 125). Une autre a été découverte près du fanum du Plô de Maroui à Marnhagues-et-Latour (fig. 96b). Autour de ces premières figurations anthropomorphes gallo-romaines de divinités celtiques, comme pour les personnages héroïsés des siècles antérieurs, se trouve posée dans le Midi, comme ailleurs en Gaule, la question du rapport de ces représentations à l'existence d'aires consacrées qui pourraient leur être dédiées. La découverte de l'enclos des Herbues à Vix, avec les deux statues d'un couple honoré au tout début du $\mathrm{V}^{\mathrm{e}}$ s. avant J.-C. (Chaume et al., 2000a) ou encore celle très fruste d'un enclos de La Croix-Verte à Antran, dans la Vienne, au début de l'âge du Fer (Pautreau, 1985, p. 14), 


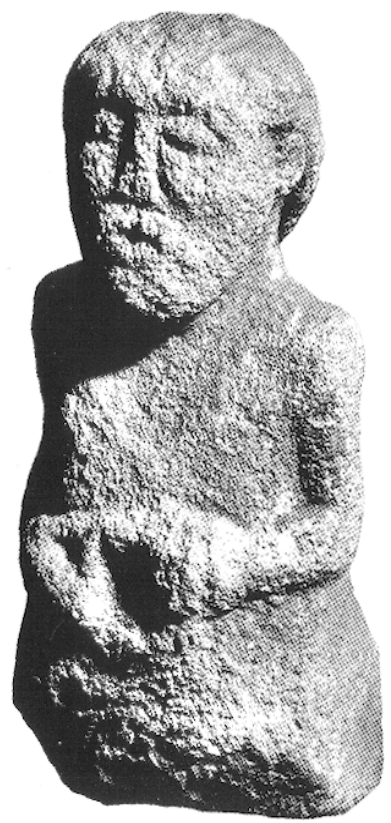

a

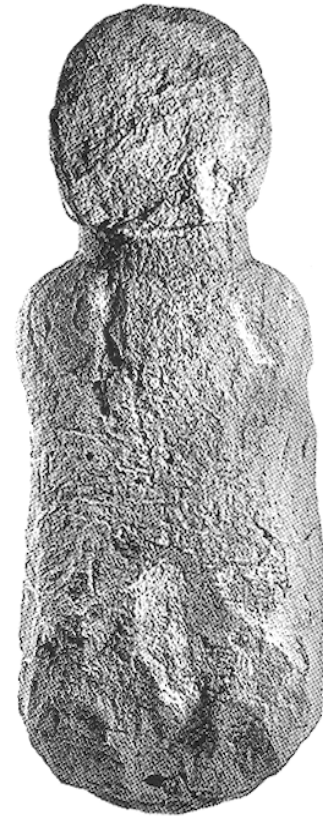

b
Fig. 96 - Deux slèles anthropomorphes de l'Aveyron, de l'extrême fin de l'âge du Fer, voire un peu plus récentes : a, personnage portant barbe et moustache, tenant un torque à la main (hôpital de Rodez; H. : 0,56 m) (photo C. Bousquet, musée Fenaille de Rodez); $b$, figuration compacte où seule la tête se dégage (visage détruit), découverte près d'un sanctuaire de hauteur du type fanum, au Plô de Maroui (Marnhagues-et-Latour; H. : 0,57 m) (photo P. Gruat).

suggèrent des environnements de même nature pour plusieurs des autres statues méridionales découvertes isolées hors d'une agglomération. Il en va ainsi pour l'essentiel de la statuaire connue dans le Gard, comme les deux bustes de Sainte-Anastasie (fig. 97), ou ceux de Grézan, de Castelnaule-Lez ou de Corconne, tous désormais datés des débuts du premier âge du Fer. Nous verrons plus loin qu'aucune des figurations humaines méridionales n'offre la certitude de pouvoir être mise en relation, dès leur état initial, avec un sanctuaire de vaste agglomération. Les exemples de Glanon ou d'Entremont, sites de référence jusqu'alors, sont désormais discutés dans leur homogénéité chronostylistique. Nous y reviendrons. Dans cette perspective, on peut aisément envisager que l'essentiel de l'expression iconographique méridionale, de la transition avec l'âge du Bronze à celle de la ronde-bosse datée du second âge du Fer (fig. 98), voire du début de l'Empire (comme à FoxAmphoux, Mondragon ou Vachères, voir fig. 119), soit intimement lié à deux types d'espaces religieux : les enclos ou aires cultuelles sur les territoires (points stratégiques, à proximité de voies très fréquentées ou d'une nécropole) ; les sanctuaires domaniaux, dépendant de grandes familles

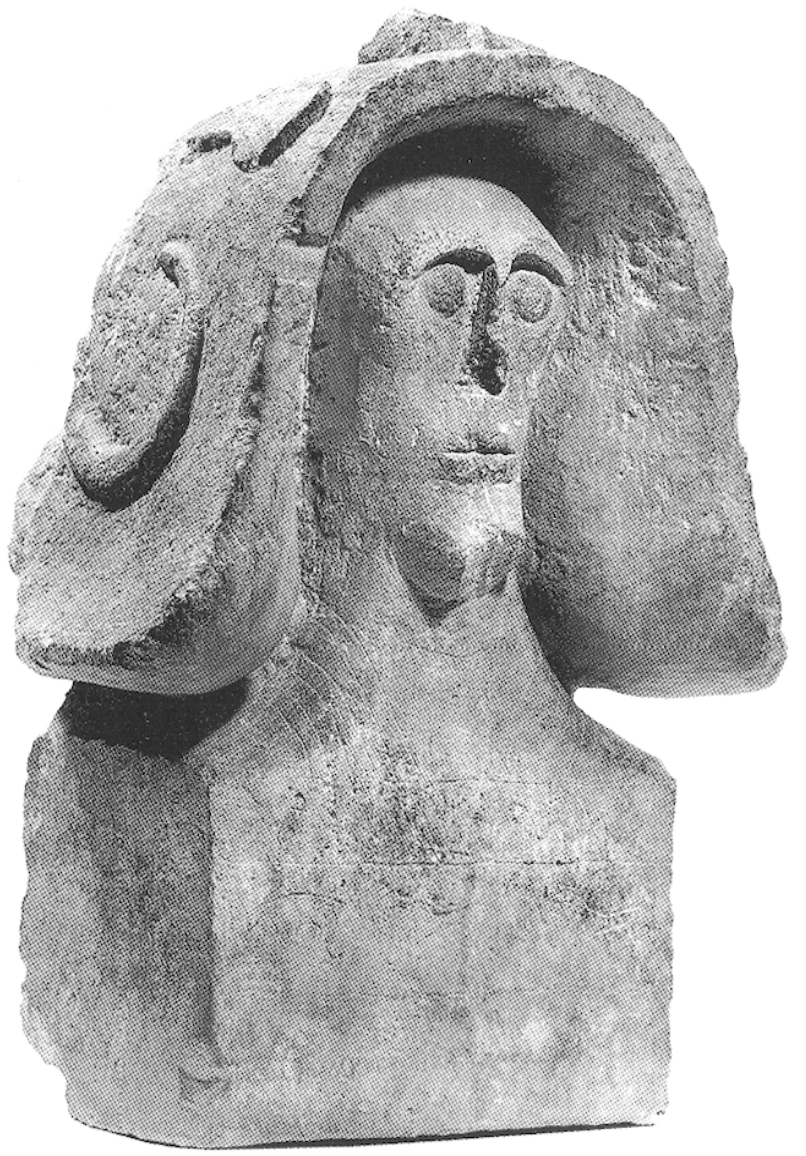

Fig. 97 - Sainte-Anastasie (Gard), Camp-Guiraud. Un des deux bustes similaires $(H .: 0,53 \mathrm{~m})$. Guerrier symbolisé par un large casque souple à ample crinière sommitale, retombant dans le dos. Autour du cou est incisé un collier à pendeloques ou la limite d'un vêtement, sur les épaules les rabats ou les éléments constitutifs d'une cuirasse. Sur les côtés des coiffes, figurations de trompes musicales terminées en pavillon, souvenir de fastes bruyants. Fin du VIII ou VII s. av. J.-C. (photo G. Foliot, CNRS).

(dès la fin du premier âge du Fer, en relation avec une vaste ferme isolée et/ou un hameau complémentaire et/ou leur nécropole). Nous verrons que leur présence en milieu d'habitat groupé, ou à leur immédiate périphérie, découle très certainement d'une réutilisation tardive à la fin du second âge du Fer. Le phénomène sera similaire pour les stèles, pour une part au moins reliées à l'expression iconographique précédente.

Divers points des territoires vont accueillir des dépôts enfouis, offrandes à l'image du groupement d'objets métalliques du VI ${ }^{e}$ s. avant J.-C. découvert à La Patouillarde, dans les Alpilles à Eyguières (fig. 99). Une spécificité des Rutènes concerne les dépôts monétaires et de lingots (Gruat, IzacImbert, 2002, p. 77). Ces concentrations métalliques ont une répartition essentiellement tarnaise (six cas sur dix), 


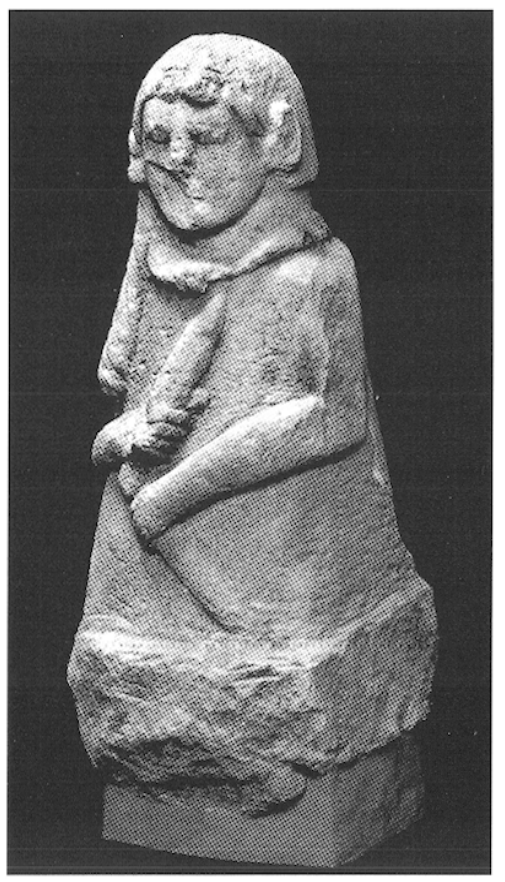

Fig. 98 - Bozouls (Aveyron), La Devèze d'Ayrebesque. La stèle souligne le caractère "guerrier" du personnage qui porte un torque à tampons. Coiffure ondulée et longue tresse latérale insistent sur l'esthétique "gauloise" du sujet. CEurre sans doute du second âge du Fer (H. : 0,95 m) (photo A. Méravilles, musée Fenaille de Rodez).

comprise grosso modo entre les vallées du Tarn, du Thoré et les massifs montagneux de la partie orientale et méridionale du département en question. D'une manière générale, les dépôts tarnais concernent un faible volume de monnaies (800 au plus à Valdurenque, voir fig. 87) et d'origines variées, vraisemblablement en raison de la proximité de l'axe Aude-Garonne. Malgré les abondantes ressources minières du secteur (Comité départemental d'archéologie du Tam, 1995, p. 46), seul le "trésor » de Paulhe (à MontredonLabessonnié, Tarn) peut éventuellement être mis en relation directe avec le district minier antique tout proche de la presqu'île d'Ambialet et du Prunié (Le Fraysse, Tarn), lié à l'extraction de fer. Quatre autres dépôts monétaires sont situés dans la partie occidentale du Rouergue, sur la rive droite de l'Aveyron, dans une zone d'exploitation de plomb argentifère, effective dès la fin de l'âge du Fer (Morasz, 1984). La relation mines/dépôts monétaires paraît d'autant plus évidente ici que le «trésor » de Goutrens (La Sancy, Aveyron) a livré notamment $4 \mathrm{~kg}$ de lingots d'argent (Gruat, 1998, p. 107-108 et 2001, p. 221). Ces derniers pécules mettent en jeu un nombre considérable de monnaies en argent $(20000$ à 25000 à Coutrens, 6000 à Martiel, etc.), toujours de types à la croix et parfois fleurs de coin.

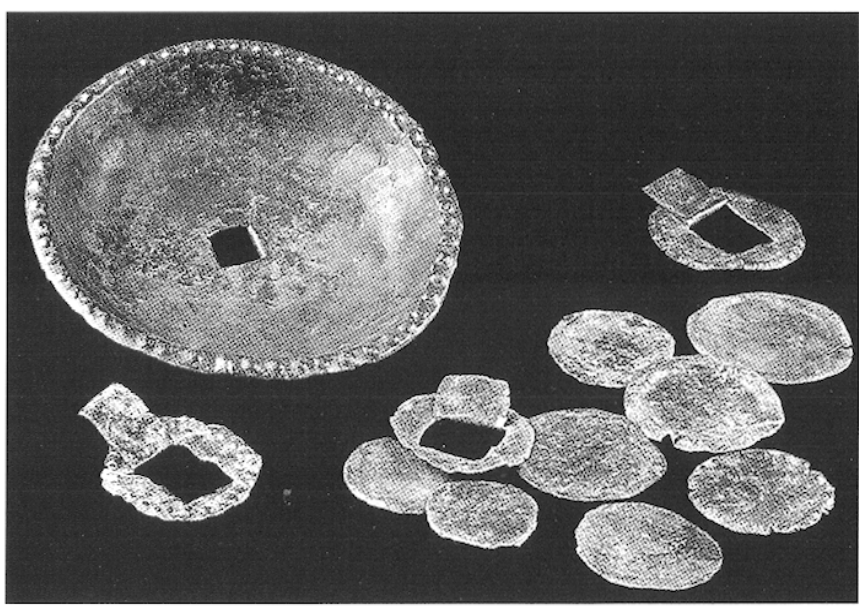

Fig. 99 - Eyguières (Bouches-du-Rhône), La Patouillarde 2. Lot de pièces en tôle de bronze composé d'un petit bassin à rebord perlé (diam. : $0,158 \mathrm{~m}$ ) et de onze disques dont trois à bordure également perlée. Ces derniers sont plusieurs fois associés dans le Midi à des dépôts votifs, parfois funéraires. Percements et découpages volontaires privilégient ici l'hypothèse votive. Courant du VIe s. ou début du Ve s. av. J.-C. (photo C. Durand, CNRS).

Tous ces " trésors ", déposés en pleine terre, plus rarement dans une céramique (comme à Paulhe, La Loubière et La Gasse), sont donc constitués d'objets précieux, bien connus en contextes cultuels à travers l'Europe (Brunaux, $2000 a$, p. 122-128). La présence d'un probable torque tubulaire en or dans le dépôt de La Loubière renforcerait le caractère strictement religieux de tels enfouissements (Bénévent, Boudet, 1990, p. 42-43).

En marge de ces ensembles monétaires, on doit signaler deux autres dépôts ayant à nouveau un rapport implicite avec les ressources minières et/ou la métallurgie. Il s'agit des lingots de fer découverts à La Montresse (Rabastens) et à Montans, dans le Tarn. Si le contexte du premier est mal documenté, celui du second est plus précis. Il contenait huit lingots à douille et bout arrondi, plus rarement en biseau, de 70,50 à $85 \mathrm{~cm}$ de long pour un poids de 1,165 à 2,145 kg (Martin, Ruffat, 1998). L'ensemble était enfoui dans une fosse, à proximité de deux dépôts de vases disposés dans des demi-dolia.

En effet, une autre singularité des pratiques cultuelles des Rutènes est illustrée par des dépôts de vases complets (de 3 à 33 exemplaires), de fabrication régionale, plus rarement d'importation méditerranéenne. Ils peuvent être associés à des ossements d'animaux, dans des demi-dolia disposés à plat (Gruat, Izac-Imbert, 2002, p. 77). Deux de ces récipients, d'environ $0,80 \mathrm{~m}$ de haut, ont été mis au jour à Labouygue, Montans, Tarn (fig. 100a) (Comité départemental d'archéologie du Tarm, 1995, p. 172 et 181). L'un se signale 

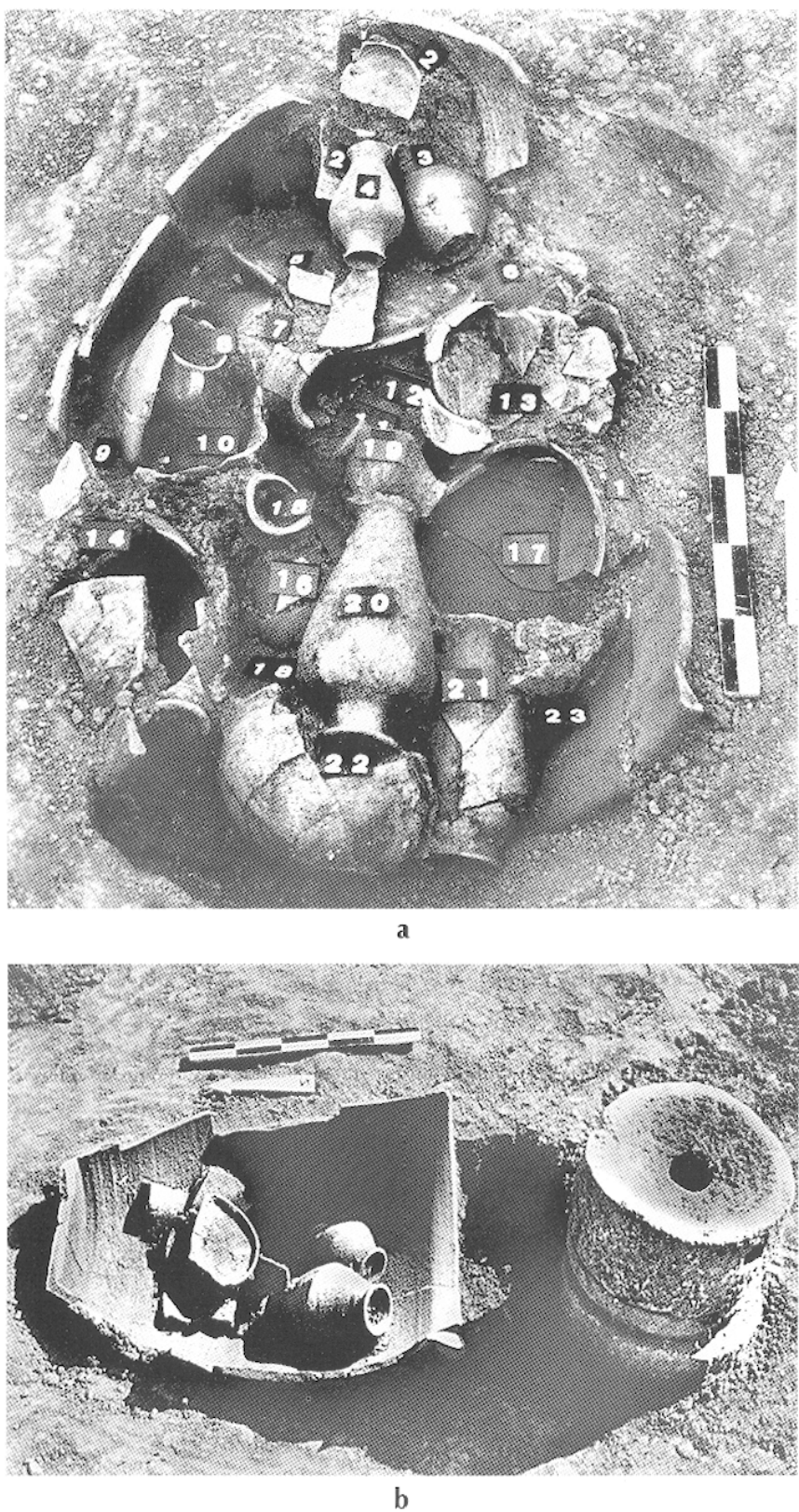

Fig. 100 - Montans (Tarn), Labouygue. Deux exemples d'offrandes de petiles céramiques disposées dans des dolia. L'un est accompagné de meules rotatives empilées (b). De la fin du II au milieu

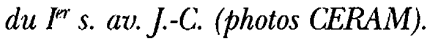

par des éléments de meules rotatives empilés (fig. 100b). Une telle disposition, ainsi que la prédominance de vases de forme fermée se rapprochent beaucoup des observations faites dans les puits et fosses à offrandes du Toulousain (Vidal, 1986). Un autre dépôt (inédit), dans un demidolium, fut également mis au jour à l'intérieur de la galerie de mine de plomb argentifère de La Maladrerie à Villefranche-de-Rouergue (Gruat, 1998, p. 108). Dans ce cas précis, outre l'aspect à nouveau souterrain du dépôt, on ne peut que souligner la relation évidente avec l'activité minière comme cela a été fait pour de probables sanctuaires de hauteur (voir supra). Tous ces ensembles votifs, qui restent à publier précisément, sont compris entre le milieu du II $^{\mathrm{e}}$ et le milieu du $\mathrm{I}^{\mathrm{er}}$ s. avant J.-C.

Au travers des dépôts précédents, nous avons entrevu la réalité des offrandes carnées ou végétales. Reste pour le Midi un sujet longtemps occulté et qui nous conduira à nouveau des territoires à la proximité des agglomérations, celui des sacrifices humains ou, du moins, de la manipulation de leurs restes.

Un premier ensemble de données vient d'être récemment publié sur les anciennes découvertes d'un aven du haut Var, celui de Plérimond, à Aups (Brun, Michel, 1999 ; Boyer, 2000). L'aven s'ouvre près du sommet d'une colline basse. L'accès, mal aisé, se fait par deux étroites galeries en plafond. D'après les plans et coupes dressés par le spéléoclub du var, des squelettes bouleversés ont été découverts dans une vaste salle souterraine, haute de 12 à $24 \mathrm{~m}$, pour $15 \mathrm{~m}$ x $27 \mathrm{~m}$ en plan (fig. 101a). Les restes humains étaient en partie dispersés sur le cône situé à l'aplomb de l'ouverture (A) et dans un diverticule voisin (C). Aucune connexion anatomique ni aucun regroupement intentionnel d'ossements n'ont été alors observés. Le réduit contenait encore 15 crânes et 56 mandibules intactes ou fragmentaires. Un mobilier, essentiellement métallique et majoritairement militaire, mais contenant également des pièces de vaisselle et de parure en bronze, était réparti sur le cône. Il n'est pas encore publié en détail mais paraît se répartir sur l'ensemble du premier âge du Fer, de la transition avec l'âge du Bronze (élément de cuirasse) apparemment jusqu'au Ve $\mathrm{V}$. avant J.-C. Il est intéressant de noter une fréquentation des lieux plus tardive, avec le dépôt en pot de cinq pic̀ces de monnaies datées de 312-313 de notre ère. L'analyse des vestiges osseux dénombre au moins une quarantaine d'individus. Les mensurations sur les 15 crânes laissent présager la présence de 7 hommes et 5 femmes, avec une majorité de sujets jeunes ou très jeunes des deux sexes (10 cas). Malgré le prélèvement des os et de nombreux objets sur le site (pillé par la suite), l'absence d'une approche taphonomique complète des lieux et d'une étude plus affinée de la répartition des vestiges, comme la recherche l'exigerait aujourd'hui, ne nous permet pas de suivre sans réserve la proposition avancée d'un lieu où auraient été jetés les corps de personnes, plutôt jeunes, des deux sexes, avec un accompagnement d'offrandes. Seul le petit vase contenant des pièces résulte sans ambiguïté d'un dépôt votif, mais il est tardif, peut-être éventuellement dissocié de la destination initiale de la cavité. Deux autres avens régionaux ont aussi fourni des objets métalliques de 

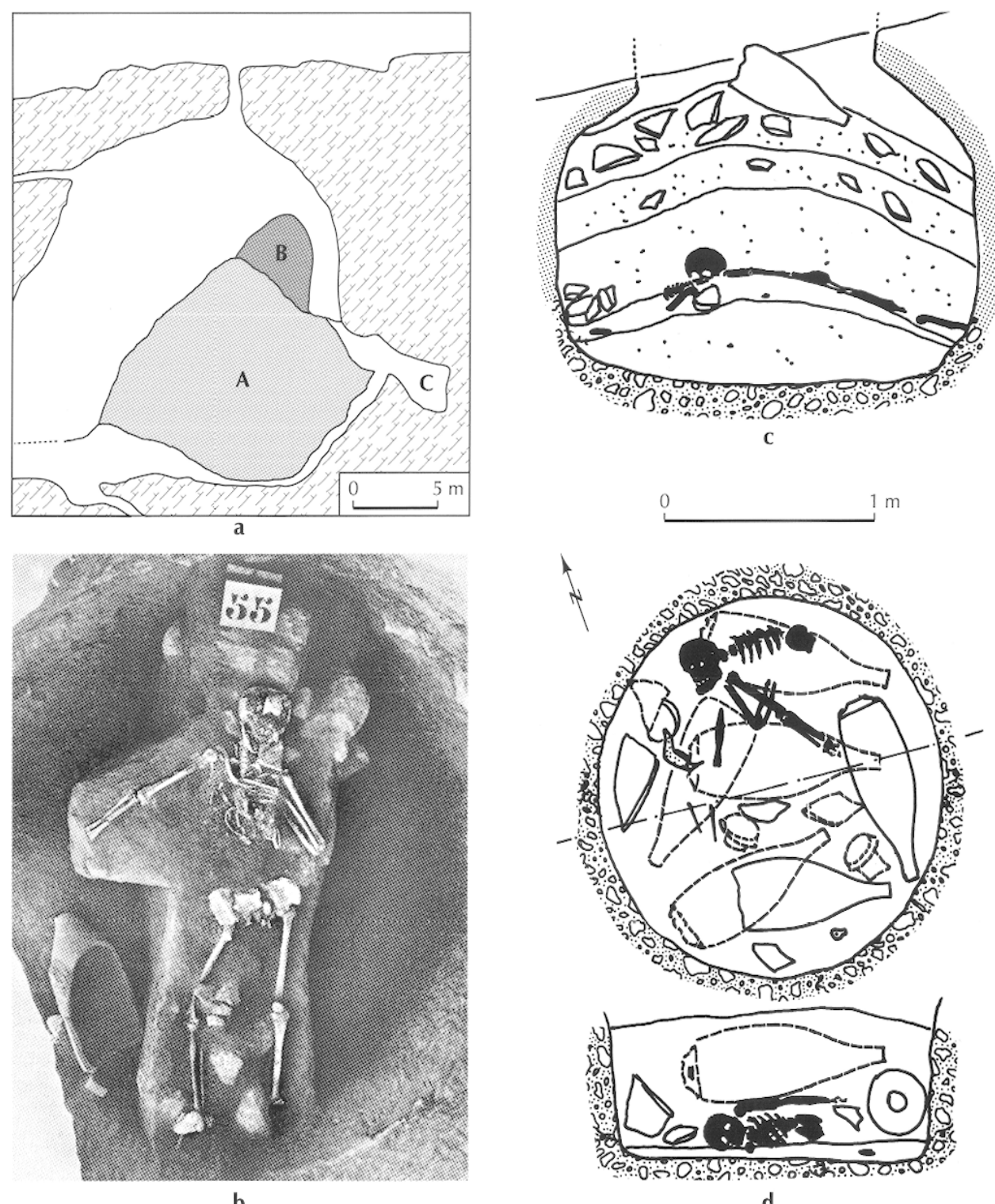

d

Fig. 101 - Sacrifices ou manipulations des restes humains, autant de questions posées autour des inhumations en aven ou des corps découverts dans des silos remblayés : a, coupe schématique est-ouest de l'aven Plérimond à Aups (Var); A, dépôts accumulés depuis le puits d'accès, avec mobiliers du premier âge du Fer; $B$, formation stalagmitique; $C$, diverticule constituant l'ossuaire très bouleversé de 45 à 50 individus (dessin M. Rétif d'après relevé spéléo-club du Var); b, squelette découvert en connexion dans le comblement du silo 55 d'Ensérune (Hérault), à la fin du second âge du Fer (d'après Gallet de Santerre, 1980, fig. VI, 2); c, d, deux types de dépôts en silos abandonnés de La Lagaste (Aude) (d'après Rancoule, 1980, fig. 54).

l'âge du Fer, comme celui de Taurenne, signalé non loin de Plérimond, avec des restes humains (Boyer, 2000, p. 259) ou Bernard à Vallauris (Alpes-Maritimes), avec seulement des pièces d'armement du second âge du Fer et quelques bijoux (Vindry, 1978, p. 35-37, fig. 36 et 37).

Un deuxième ensemble d'informations a composé depuis de nombreuses années une catégorie de lieux sépulcraux singuliers. La découverte des squelettes, en connexion ou bouleversés, de corps jetés dans des silos abandonnés, sans soins particuliers ni rituel perceptible, a été interprétée comme le reliquat d'inhumations cachées (Dedet, Schwaller, 1990, p. 156). Pour les trois exemples ici recensés vers la fin du second âge du Fer, la réalité d'une pratique funéraire serait d'autant plus troublante que le rite omniprésent dans le Midi est celui de l'incinération. Mais l'idée de l'homicide et de sa dissimulation pourrait être 
avancée si les corps étaient toujours complets. De plus, les découvertes similaires dans d'autres régions gauloises sont trop fréquentes, même en regard du nombre de silos reconnus, pour se contenter d'un seul type d'explication.

Le premier lot se situe en limite occidentale de la région concernée par cette étude, sur le plateau de La Lagaste, à proximité des habitats de la fin du $\mathrm{II}^{\mathrm{c}}$ et du I ${ }^{\mathrm{er}}$ s. avant J.-C. (Rancoule, 1980, p. 113-117 ; 1996, p. 56, fig. 3 et p. 67). Trois fosses à vestiges humains présentent deux types de dépôts : le rejet d'un corps ou de certains de ses éléments entre les couches successives de remblaiement d'un ancien silo (fig. 101c) ; le recouvrement du corps par du mobilier amphorique, presque complet ou fragmentaire (fig. 101d). D'autres fosses du même site, comblées d'amphores italiques, présentent des apports cendreux complémentaires mais sans vestiges humains incinérés. Ensérune est un autre site où plusieurs corps ont été signalés dans une dizaine de silos ou d'anciennes citernes abandonnées. L'essentiel des comblements semble devoir se placer entre le III ${ }^{\mathrm{e}}$ et le I ${ }^{\text {er }}$ s. avant J.-C. (Jannoray, 1955, p. 92, n. 2 ; Gallet de Santerre, 1980, p. 155-158). Si certains des corps ont été remaniés, d'autres sont demeurés en connexion (fig. 101b). Comme à La Lagaste, la disposition des corps ne paraît pas accompagnée d'un rituel formel particulier. Dernier témoignage, celui de Cavaillon (Vaucluse), au bas des pentes de la colline Saint-Jacques (Dumoulin, 1965, p. 78-82). Les deux premières "fosses funéraires " dérouvertes en 1936 apparaissent peu probantes pour notre propos. En revanche, la troisième est intéressante. Découverte en 1954, elle est plus importante que les précédentes et contenait de larges parties d'un squelette, disposé dans un remblaiement du Ier s. avant J.-C.

$\mathrm{Au}$ total, la présence, dans des contextes proches de vastes agglomérations de la fin du second âge du Fer, de corps ou de certains de leurs éléments disposés au sein du remblaiement d'un silo abandonné, éventuellement accompagnés d'autres dépôts sélectionnés, suggère la probabilité si ce n'est de sacrifices humains sur place du moins de dépôts volontaires de restes récupérés sur des lieux sacrificiels ou des trophées et disposés comme des offrandes. Une enquête a été effectuée en Seine-et-Marne sur 28 fosses-silos qui ont livré 37 individus dont les deux tiers de femmes (Delattre et al., 2000). Certains corps avaient été décapités et d'autres avaient même pu commencer leur dessiccation ailleurs. Des observations similaires ont été récemment publiées en contexte de silos du second âge du Fer au Chemin de Gionne, à proximité de l'oppidum d'Avaricum des Bituriges (Bourges) (Delattre, 2001 ; Buchsenschutz, Ralston dir., 2001, p. 171-172). On remarque que les dépôts laténiens de cette nature ( $\mathrm{La}$ Tène ancienne et moyenne surtout, contrairement au Midi) sont tous connus en silos, dans ou à proximité d'habitats. L'hypothèse avancée est celle de "silos à offrandes", associant les restes d'humains à ceux d'un animal parfois, voire à du mobilier. La finalité de ces pratiques, qui nous échappent encore largement sur le plan de leurs rituels, pourrait être de nature propitiatoire pour la fertilité de la terre et l'abondance des récoltes à venir, en relation avec les réserves de proximité toujours en activité.

\section{DANS LES AGGLOMÉRATIONS}

Les habitats groupés commencent à se multiplier dans le Midi méditerranéen à partir de l'extrême fin de l'âge du Bronze pour acquérir progressivement un certain nombre de spécificités, de la frange côtière au VI ${ }^{e} s$. avant J.-C. vers l'arrière-pays jusqu'au IV ${ }^{\mathrm{e}} \mathrm{s}$. avant J.-C. Le phénomène de perchement et de fortification (fossé et/ou rempart) est une constante, par étapes et sans exclusivité. Dans la partie occidentale du Languedoc, les agglomérations du premier âge du Fer peuvent demeurer relativement aérées et pourvues de larges espaces ouverts entre les bâtiments, conservant de ce fait une part des traditions de l'habitat dispersé antérieur. L'exemple des quartiers méridionaux de Montlaurès à Narbonne au $\mathrm{V}^{\mathrm{c}} \mathrm{s}$. est très représentatif, l'intensification du bâti n'intervenant sur le site qu'au second âge du Fer (Chazelles, 1997). À la même époque, des réalisations plus proches du littoral montrent l'amorce d'une organisation des constructions à pièces multiples, selon un canevas bien plus concentré, amorce de véritables îlots séparés par de petites voies ou venelles de circulation. Les sites de Pech Maho à Sigean ${ }^{19}$ (Py, 1993, fig. 27) ou du Port à Salses-le-Château (Pyrénées-Orientales) (Ugolini et al., 2000) peuvent en rendre compte. Plus à l'est, en Languedoc oriental comme dans la bassc vallée du Rhône et ses marges, le phénomène de concentration des composantes de l'habitat deviendra récurrent jusqu'à la romanisation et persistera parfois dans les agglomérations secondaires sous l'Empire (Py, 1993, p. 204-207; Garcia, 1996 ; Arcelin, à paraître a). La Provence centrale et orientale (Brun, Borréani dir., 1999, p. 106-108 et 118-120) présente une assez grande variété de modalités structurelles dans l'organisation interne de l'aire fortifiée, généralement réduite (Bérato et al., 1995, p. 49-50). Mais les enceintes repérées et présumées de l'âge du Fer dans cette dernière région ne sont pas toutes densément occupées, et surtout de façon permanente (Congès dir., 1993). Un processus

19. Le site de Pech Maho est en cours de publication dans le cadre d'un programme collectif de recherche (dirigé par E. Gailledrat). I es données architecturales scront totalement récxaminées, par époques. 
semblable est perçu en arrière des secteurs de plaine du Languedoc, sur les Causses, au Puech de Mus à SainteEulalie-de-Cernon durant le Ve s. (Gruat, Marty, 2000).

Sans épiloguer sur les processus d'organisation et leurs variabilités d'amplitude, on peut dire qu'à de rares exceptions près les agglomérations permanentes du Midi côtier adoptent peu ou prou à l'aube du second âge du Fer une tendance à la concentration maximale des unités domestiques sur des superficies limitées. Ces constructions sont alors mitoyennes, accolées en îlots dont la morphologie s'efforce de répondre aux potentialités de la topographie du site, tout en intégrant d'étroits espaces intermédiaires de circulation. Lattes, en bordure de l'étang de Thau, aux IV et III $^{e}$ s. avant J.-C. (Py, 1999; Garcia, 1999), Nageset-Solorgues (Py, 1978, p. 145-179) et ceux plus réduits de L'Île ou de Saint-Pierre à Martigues (Chausserie-Laprée, Nin, 1987) illustrent cette volonté de rationalisation extrême de l'espace intérieur des villages, bourgades ou bourgs. Le plan de la première implantation sur le plateau d'Entremont montre une des formes de l'aboutissement de ce long processus, vers 175 avant J.-C. (Arcelin, 1992b, p. 327-328, fig. 8).

Dans la très grande majorité des habitats de la bordure méditerranéenne de la Gaule, antérieurs à la conquête romaine, aucune aire intérieure ne peut être véritablement perçue comme relevant d'une volonté de création d'un espacc à vocation collcctivc, publique dans son essence politique et/ou religieuse. Les raisons sont à rechercher dans l'organisation même de la société celtique, en l'occurrence ici dans un système social fortement dominé par une classe possédante, franchement commerçante sur les rivages du Languedoc central et occidental, à la vocation guerrière plus affirmée en Languedoc oriental et en Provence. L'empreinte des modalités de ce pouvoir transparaît dans la basse vallée du Rhône du moins, grâce à une riche iconographie et à quelques textes antiques qui en relatent toute la prégnance à la fin du second âge du Fer (Arcelin, Rapin, 2002, 2003 ; Arcelin, Chausserie-Laprée, à paraître). De l'analyse interne des agglomérations de cette dernière région, pour l'essentiel à vocation agricole et artisanale, il en résulte que leur fonction, pour importante qu'elle soit sur le plan de l'économie et de la gestion des territoires, paraît devoir être dissociée des centres réels du pouvoir politique. L'hypothèse a été émise que ces derniers sont à rechercher sur les territoires, au sein de la diversité des propriétés domaniales de l'aristocratie (Arcelin, 1999b et 2001, p. 148-151). Mais le phénomène est apparemment plus nuancé pour le Languedoc occidental côtier.

Ce n'est qu'après la seconde guerre punique et ses conséquences en Méditerranée que vont émerger les signes de profondes modifications dans les sociétés établies près des côtes et dans la basse vallée du Rhône. Ce sont les agglomérations déjà en cours d'évolution dans le Midi qui vont bénéficier et développer de nouveaux apports économiques et culturels. Elles deviendront, plus ou moins tôt dans le courant du II $^{\mathrm{e}}$ s., les embryons des premiers véritables centres proto-urbanisés. Ensérune, Lattes peut-être, surtout au cour de la basse vallée du Rhône, Nîmes, Avignon, Arles, Cavaillon, Glanon..., vont développer des réponses architecturales et urbanistiques aux propositions culturelles méditerranéennes véhiculées par la présence gréco-italique grandissante (Goudineau, 1976; Arcelin, à paraître b). Une des conséquences de l'émergence de ces foyers de mutation des communautés indigènes est l'appaition d'une fracture sociale régionale, que les textes antiques laissent percevoir de façon explicite au sein de la haute aristocratie. Le récit de la prise du dernier "bastion " des Salyens, près de Marseille, est on ne peut plus clair (Diodore, Bibliothèque historique, XXXIV, 23). La diversité et la complexité des courants culturels régionaux de cette époque auront d'inévitables conséquences sur les modalités des pratiques religieuses.

Les recherches sur les agglomérations ont permis d'observer les traces d'un certain nombre de rites et de pratiques de nature cultuelle qui leur soient liés. La plupart des observations, leur analyse factuelle ou leur répartition régionale, ont fait l'objet de bilans depuis une dizaine d'années (Arcelin et al., 1992 ; Gruat, 1998; Arcelin, 2000b). Nous préférons ici focaliser notre propos sur trois aspects spécifiques de l'information aujourd'hui disponible: les données nouvelles développées autour d'interrogations thématiques demeurées longtemps en suspens ; leur signification dans l'organisation sociale et celle des agglomérations ; enfin, la reconsidération des indices chronologiques à la lumière de ces nouveaux apports.

\section{LES STÈLES ET LEUR RAPPORT AUX HABITATS}

La fouille des habitats méridionaux a déterminé le recensement à ce jour de près de 500 stèles, des bétyles ou cippes assimilables à des pierres brutes à peine équarries (minoritaires), taillées sous la forme de piliers quadrangulaires ou de dalles (majoritaires), aux surfaces le plus souvent abrasées, au sommet aplati ou en arrondi surbaissé, et aux arêtes fréquemment chanfreinées, voire en feuillure (Arcelin et al., 1992, p. 188-195). Ces stèles ont été associées très tôt à l'existence même des agglomérations, car presque toutes ont été découvertes en remploi dans les fortifications ou à proximité, dans les parements comme dans les matériaux de comblement des murs (fig. 102 et 103). Les lots les plus importants proviennent de Saint-Blaise, de Mouriès et de Glanon dans les Bouches-du-Rhône, et de 


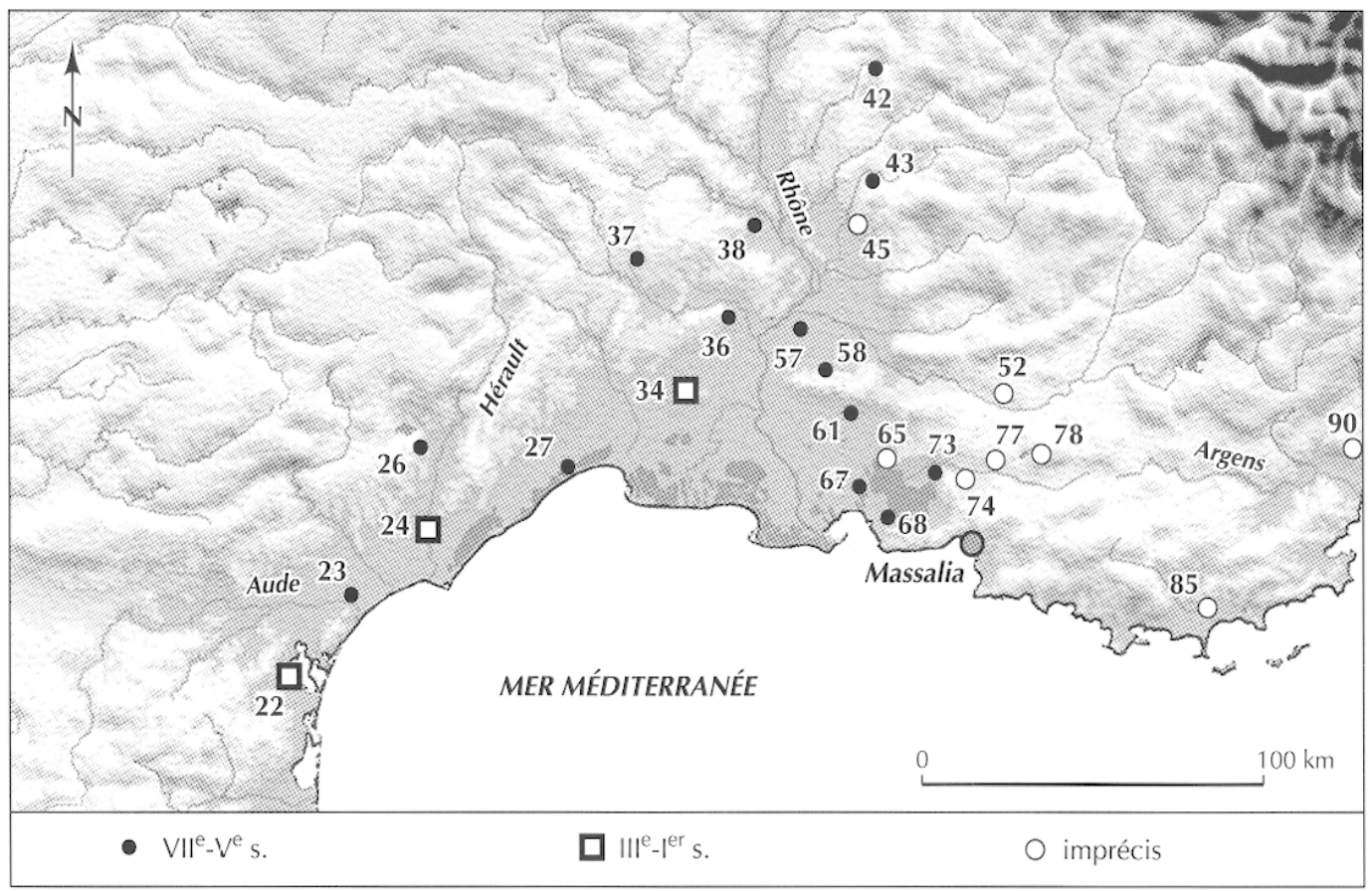

\begin{tabular}{|c|c|c|c|}
\hline$N^{0}$ & Commune & Lieu-dit & Département \\
\hline 22 & Sigean & Pech Maho & Aude \\
\hline 23 & Nissan-lez-Ensérune & Ensérune & Hérault \\
\hline 24 & Aumes & & Hérault \\
\hline 26 & Clermont-I'Hérault & La Ramasse & Hérault \\
\hline 27 & Lattes & Saint-Sauveur & Hérault \\
\hline 34 & Nîmes & agglomération, Grézan et région & Gard \\
\hline 36 & Saint-Bonnet-du-Gard & Le Marduel & Gard \\
\hline \multirow{2}{*}{37} & Mons & Vié-Cioutat & Gard \\
\hline & Monteils & Vié-Cioutat & Gard \\
\hline 38 & Gaujac & Saint-Vincent & Gard \\
\hline 42 & Le Pègue & Saint-Marcel & Drôme \\
\hline 43 & Vaison-la-Romaine & & Vaucluse \\
\hline 45 & Beaumes-de-Venise & Durban & Vaucluse \\
\hline 52 & Villelaure & & Vaucluse \\
\hline 57 & Graveson & Le Mourre Pela & Bouches-du-Rhône \\
\hline 58 & Saint-Rémy-de-Provence & Glanon & Bouches-du-Rhône \\
\hline 61 & Mouriès & Caisses et environs & Bouches-du-Rhône \\
\hline 65 & Lançon-Provence & Constantine et Calissanne & Bouches-du-Rhône \\
\hline 67 & Saint-Mitre-les-Remparts & Saint-Blaise & Bouches-du-Rhône \\
\hline 68 & Martigues & L'île, Saint-Pierre et Tamaris & Bouches-du-Rhône \\
\hline 73 & Velaux & Roquepertuse & Bouches-du-Rhône \\
\hline 74 & Roquefavour & Le Castellas & Bouches-du-Rhône \\
\hline 77 & Aix-en-Provence & Entremont et Terrain Coq & Bouches-du-Rhône \\
\hline 78 & Puyloubier & Bramefan & Bouches-du-Rhône \\
\hline 85 & Hyères & Saint-Michel-de-Valbonne & Var \\
\hline 90 & Bagnols-en-Forêt & & Var \\
\hline
\end{tabular}

Fig. 102 - Carte de répartition dans le Sud-Est gaulois des bétyles, cippes et piliers taillés à dévolution non funéraire (relevé $P$. Arcelin et $P$. Gruat).
La Ramasse dans l'Hérault (id., ibid., carte fig. 4). Une typologie est établie depuis une quinzaine d'années (Bessac, Bouloumié, 1985). Malgré les allusions de H. Rolland à des «stèles coniques » trouvées anciennement dans les premiers niveaux de Saint-Blaise (vers 600 avant J.-C. ?) (Bouloumié, 1992, p. 56-58), la recherche est longtemps demeurée dans l'expectative sur la destination réelle de ces cippes, leurs emplacements initiaux, leur disposition et la fourchette chronologique de leur durée d'utilisation (Py, 1993, p. 136-138). Bien sûr, la filiation a été faite d'emblée avec les vestiges similaires de la Préhistoire récente régionale, bétyles grossièrement équarris découverts sur le site de Roquepertuse (âge du Bronze ?) (Gérin-Ricard, 1927, p. 10-12 et pl. I), cippes soignés du dolmen du Bronze 

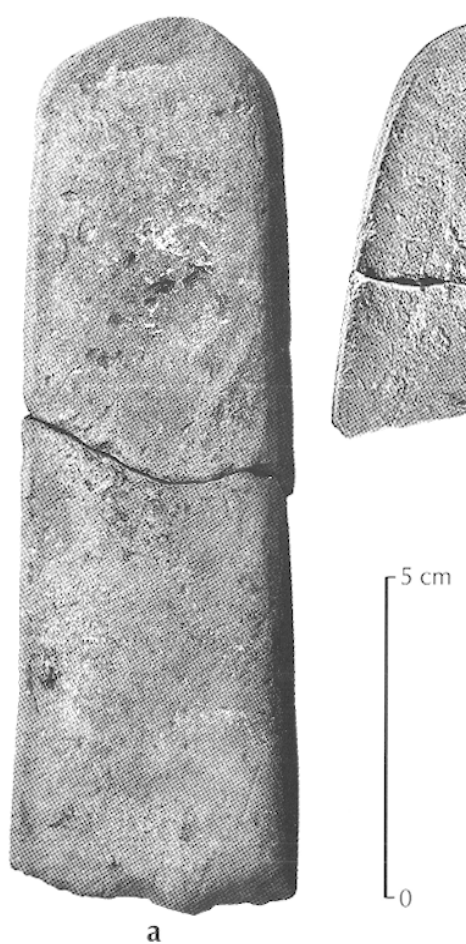

a

Fig. 103 - Vaison-la-Romaine (Vaucluse), quartier Saint-Laurent. Stèles remployées dans la fortification établie au pied de la colline du Château, au V s. av. J.-C. (photos J.-C. Meffre, INRAP).

ancien de l'Ubac à Goult, Vaucluse (Sauzade et al., 2001) ou décorés dans une ambiance ibérique en liaison, par exemple, avec une sépulture du Bronze final II à Buoux, également dans le Vaucluse (Müller et al., 1988). La plupart de ces cippes de pierre nous sont parvenus en remplois dans des constructions du $\mathrm{V}^{\mathrm{c}}$ s. ou du IV s. avant J.-C. Dans plusieurs sites qui ont fourni des stèles (Glanon, Saint-Blaise, Le Marduel, Cadenet, Roquepertuse, Entremont, Mouriès), ces dernières sont associées à des éléments monolithes appartenant à des portiques (piliers, linteaux). La découverte au Marduel de ces divers éléments en remploi dans un contexte du premier quart du Ve s. avant J.-C. a ôté les derniers doutes qui pouvaient subsister quant à l'ancienneté de ces créations, et autorisé à remonter leur utilisation antérieurement à 500 (Py et al., 1994, p. 251-262). D'autre part, le style décoratif zoomorphe et anthropomorphe répandu près des Alpilles, à Mouriès (fig. 104) (Coignard et al., 1998) comme à Glanon (voir infra notice 5, p. 230-235), relève sans grande ambiguïté d'une iconographie très archaïsante, dans la filiation des gravures du Néolithique à l'âge du Bronze de la vallée de Tende-Mont Bégo (Lumley et al., 1992, p. 38). La technique du piquetage à l'aide d'un instrument lithique qui préside à leur réalisation, encore récemment relevée à Glanon (fig. 104g et 142), est peu conciliable avec une date avancée dans l'âge du Fer, moment où les traces d'outils métalliques se multiplient : dès la fin du $\mathrm{VI}^{\mathrm{e}} \mathrm{s}$. (voir infra notice 5, p. 230-235). Contrairement aux hypothèses émises antérieurement (Arcelin et al., 1992, p. 192-193), nous serions désormais plus favorables à une chronologie haute, l'extrême fin de l'âge du Bronze et le début du Fer (milieu du IX ${ }^{\mathrm{e}}$-début du $\mathrm{VI}^{\mathrm{c}} \mathrm{s}$. avant J.-C.) paraissant constituer les termes d'une fourchette probable. Le style des motifs décoratifs de certains exemplaires de Saint-Pierre à Martigues iraient bien dans le même sens (voir infra notice 4, p. $225-230$ et fig. $135 \mathrm{c}$ et d) et ce, malgré l'existence d'un navire gravé sur un fragment isolé. L'abandon de l'usage des cippes de cette nature paraît se généraliser antérieurement à la fin $d u \mathrm{VI}^{\mathrm{e}} \mathrm{s}$., comme l'indiquent les remplois précédents du Marduel, auxquels on adjoindra désormais les récentes découvertes dans les fortifications de la fin $\mathrm{du} \mathrm{VI}^{\mathrm{c}}$ au $\mathrm{II}^{\mathrm{e}} \mathrm{s}$. sur les sites de Glanon (voir infra notice 5, p. 230-235), de La Roque à Graveson, entre 525 et 475 avant J.-C. (voir notice 3, p. 222-225) ou de Saint-Pierre à Martigues (voir notice 4, p. 225-230). Le gisement de Graveson montre une accumulation de fragments de stèles à fût abrasé avec chanfreins et base brute, en bordure d'une zone marécageuse, alimentée par des résurgences. Les éléments retrouvés ne sont plus en position initiale et ont déjà été partiellement retaillés ou découpés (traces d'outils métalliques). La constitution du lot semble immédiatement antérieure à l'édification d'un premier mur de défense dans lc dcrnicr quart du $\mathrm{VI}^{\mathrm{e}}$ s. avant J.-C., construction qui comporte déjà un fragment de petite stèle en remploi dans son parement extérieur. La seconde et plus importante ligne défensive, qui succédera au début du $\mathrm{V}^{\mathrm{e}} \mathrm{s}$., intègre dans un de ses bastions une quinzaine de fragments découverts dans les deux dernières assises conservées. Le peu de respect constaté dans le conditionnement de ces monolithes (brisés à la masse, retaillés, débités...) implique leur totale désacralisation, due certainement à leur ancienneté et à de probables modifications dans la composition des populations résidentes. Ici, comme à Saint-Blaise, Glanon ou Mouriès, les vestiges antérieurs au $\mathrm{VI}^{\mathrm{c}} \mathrm{s}$. sont à rechercher dans la présence de céramiques de la fin de l'âge du Bronze (récent à final) ou des premières années du Fer, en particulier à Glanon où ils sont très abondants.

On ignore tout du mode de regroupement et de l'organisation primitive de ces stèles. Leur découverte en contexte d'agglomération n'apparaît plus désormais comme le gage absolu d'une disposition sur l'élévation du site même. L'ampleur des regroupements comme leur réutilisation à valeur prophylactique dans les fortifications paraissent écarter l'hypothèse d'une destination funéraire dans la tradition de la fin de l'âge du Bronze. Leur vocation est certainement celle dévolue aux offrandes, un signe indivi- 


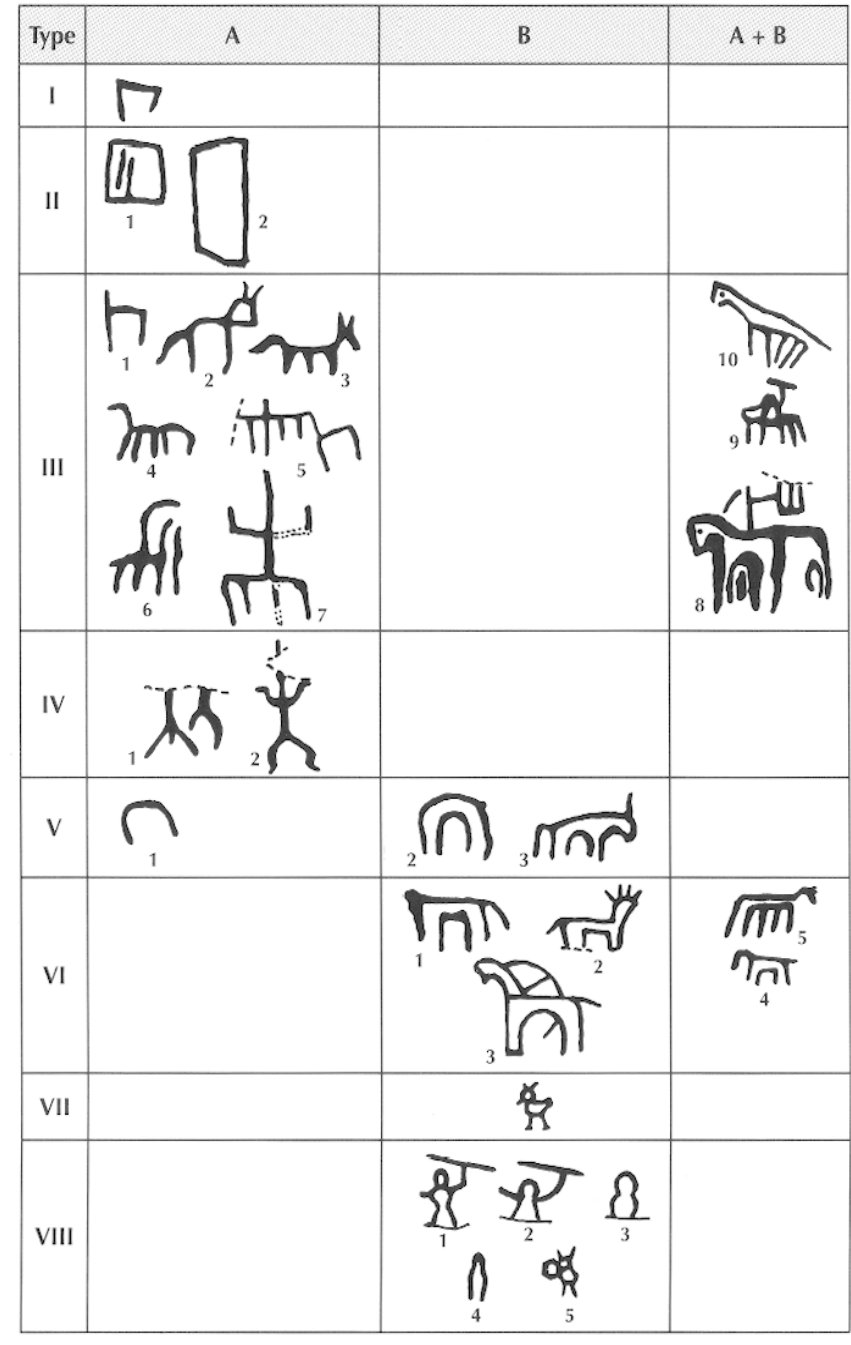

Fig. 104 - Mouriès (Bouches-du-Rhône), Les Caisses. Exemples d'éléments architecturaux et de stèles décorés de motifs anthropomorphes, zoomorphes $(a, b, c, d$ et $f)$ ou pectiformes (e). Le tableau résume la typologie morphologique de ces figurations (d'après Coignard et al., 1998 , fig. 5 à 9); g, détail de la technique de piquetage d'un motif sur une stèle de Glanon (photo C. Durand, CNRS). duel ou familial de remerciement comme le propose J.-C. Bessac (Bessac, Bouloumié, 1985, p. 174). Deux indices viendraient étayer cette proposition, l'un à Glanon oủ l'on constate une forte concentration de ces blocs remployés près de la porte XXXIII dans les remparts successifs et à faible distance d'une source (fig. 140), l'autre à Graveson, où la concentration de tous les fragments dans un seul et unique secteur de la fortification (fig. 129a: bastion 1, mur 026 et point S) est également positionnée en bordure d'une zone humide pérenne. Dans un cas, l'implantation est à envisager à proximité de l'accès et, dans l'autre, le nom de la proche agglomération d'époque romaine - la mutatio Bellinto - laisse entrevoir un lieu de culte protohistorique à Belenos-Bellinto, divinité des eaux qui pourrait être la destinataire de ces consécrations. En dépit des contextes de leur
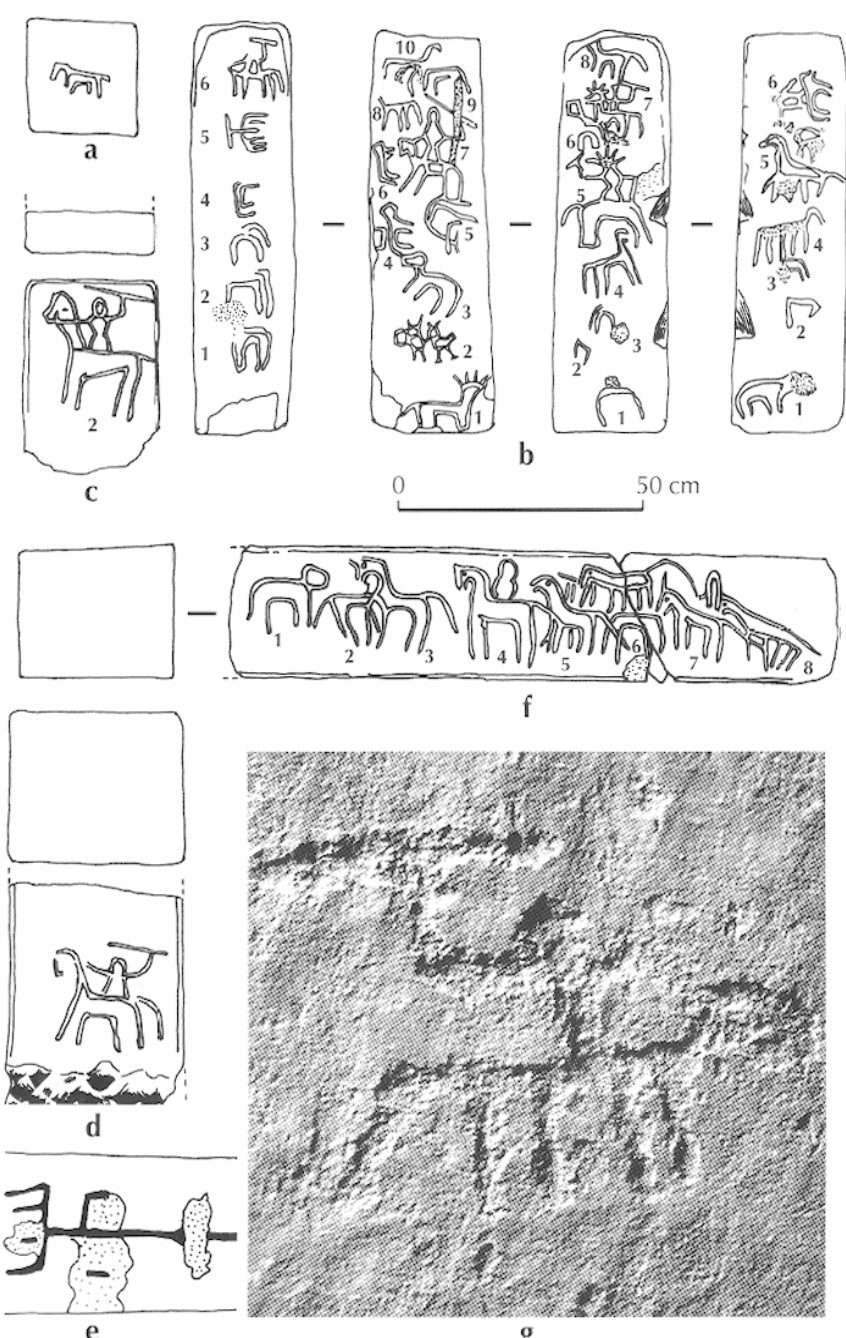

g découverte, ces cippes ne sont pas forcément liés aux agglomérations concernées; ils résultent plus sûrement de lieux cultuels antërieurs, soit sur le site même, soit sur les territoires proches. Il est également probable qu'une part d'entre eux ait été disposée à proximité de certains des portiques cultuels signalés précédemment.

À partir du IV e s., l'offrande individuelle ou familiale d'une stèle en pierre paraît tomber en désuétude (Arcelin et al., 1992, p. 191). La pratique réapparaîtra cependant sous d'autres formes et de façon ponctuelle au $\mathrm{III}^{\mathrm{c}}$ s., telle la dalle dressée sur socle, appuyée contre le parement interne de la fortification de Pech Maho (Solier, 1968; infra notice 6 , p. $234-238$ et fig. 143 c, secteur $17 \mathrm{~b}$ ) ou la statuestèle disposée dans un coffre de dalles immédiatement à l'extérieur de la fortification de Nîmes (fig. 105) (Py et al., 


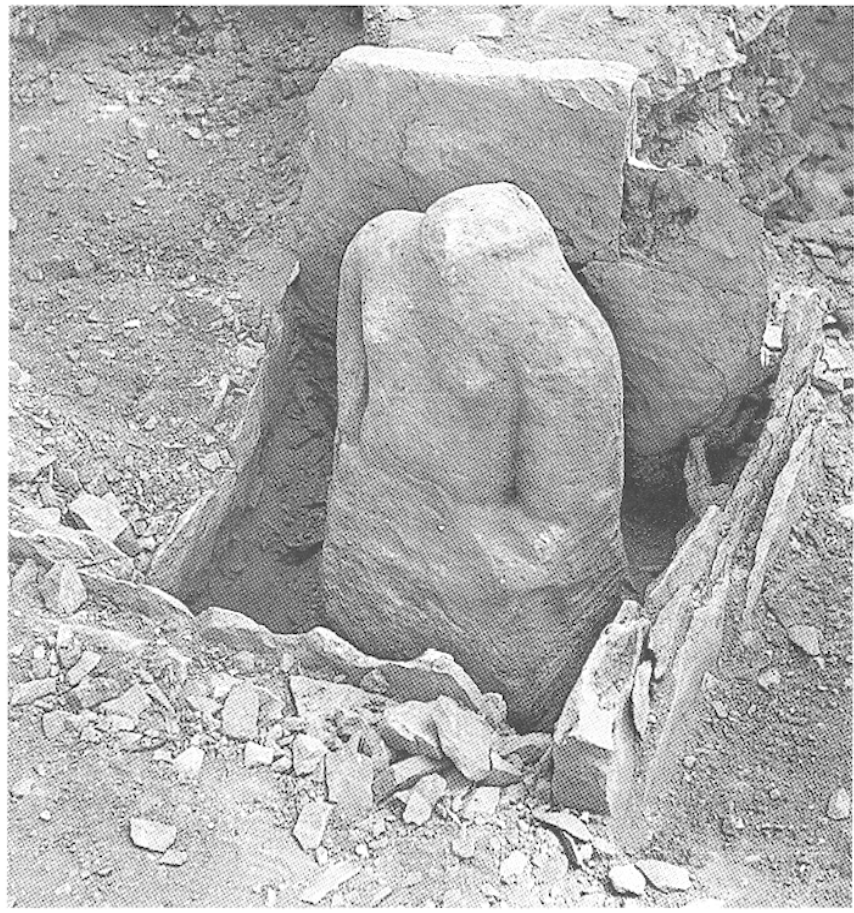

Fig. 105 - Nîmes (Gard), sommet du Mont-Cavalier. À l'extérieur de l'enceinte, sculpture anthropomorphe rudimentaire (sans tête), implantée dans un coffre de dalles. Aucun détail n'est figuré. Le caisson est installé au centre d'une aire marquée par deux petits bétyles frustes. Unique exemple méridional d'un loculus votif périurbain antêrieur à l'époque augustéenne, peut-être du début du II' s. av. J.C.C. (photo G. Roux, SRA Languedoc-Roussillon).

1981, p. 39-40 et 229-230). Dans l'un comme dans l'autre cas, le rapprochement est seulement celui de la similitude morphologique, la fonction n'étant pas forcément la même surtout en ce qui concerne Nîmes où la figuration humaine rattache cet aménagement aux cultes des héros protecteurs (Arcelin, 2000a). D'autres lieux cultuels montrent, aux III $^{e}$ ou II $^{c}$ s. avant J.-C., la présence de stèles chanfreinées, ainsi à Glanon immédiatement à l'extérieur de la porte principale de l'agglomération protohistorique (Rolland, 1968, p. 30-33; infra notice 5, p. $230-235$ et fig. 136 et 137). Mais à l'instar des statues d'accroupis retrouvées sur place, on peut s'interroger sur la date réelle de confection de ces cippes, à l'évidence pour partie au moins remployés. Leur datation au second âge du Fer pourrait être seulement celle de leur réutilisation, avec l'élaboration d'un nouveau revêtement peint, comme d'ailleurs pour le pilier découvert en fondation de la porte tardo-hellénistique (voir infra notice 5 et fig. 141). Avec l'émergence, à partir de la fin du $\mathrm{II}^{\mathrm{e}} \mathrm{s}$. avant J.-C., de l'expression monumentale dans l'architecture, la stèle quadrangulaire est remplacée par d'autres types de supports votifs, piliers et colonnes porteurs éven- tuellement d'un chapiteau et d'une inscription dédicatoire en gallo-grec, de même que par des blocs architecturaux, dalles ou vasques lustrales. Ultérieurement, le transfert se fera vers l'autel de type italique. Dans ce contexte culturel, la dévolution du pilier ou de la colonne relève d'une action plus évergétique qu'individuelle découlant par exemple de la magistrature urbaine exercée par le dédicant. Les découvertes de Nîmes et de sa région ou d'Aumes en Languedoc en sont d'excellents exemples (Lejeune, 1985, p. 250-258, 271-287, 296-299 ; Garcia, 1993, p. 311-312), de même qu'en Provence les autels de Glanon, de la Fontaine d'Arcoule au Paradou ou encore de la source du Groseau à Malaucène (Lejeune, 1985, p. 188-195).

\section{LES IIEUX DE CULTE DANS L'HABITAT}

Si les stèles, jusqu'alors souvent considérées comme liées à la vie cultuelle des agglomérations ou de leur périphérie, apparaissent désormais comme indépendantes du fait de leur probable antériorité chronologique - du moins dans leur état initial -, en revanche un certain nombre d'autres pratiques et de lieux spécifiques peuvent être associés à l'espace de l'habitat. Comme nous l'avons souligné, la multiplication des groupements fortifiés et leur type de structuration planimétrique, dès la fin du premier âge du Fer, ne pouvaient être sans conséquences sur le plan religieux, soit par l'adaptation de rites plus anciens, soit par l'élaboration de modes plus spécifiques et en l'occurrence, aux besoins de leur protection.

\section{Pratiques domestiques}

Les espaces de la vie familiale, du travail artisanal et du stockage vivrier ont été certainement générateurs d'usages religieux intimistes, confinant aux limites de la religiosité, voire de la magie propitiatoire. La lecture des traces relevées n'est pas toujours aisée. Il en est ainsi dans l'interprétation de la richesse décorative de certaines plaques-foyers et de leurs accessoires : chenets zoomorphes, coupes-couvercles percées, etc. À la surinterprétation antérieure de ces réalisations a succédé une approche bien plus prudente qui considère pleinement la part de la création artistique dans un contexte de sédentarisation (Dedet et al., 1968; Roux, Raux, 1996, p. 428-430 ; Nin, 1999, p. 230-232). C'est au niveau des objets du mobilier et des aménagements singuliers, ou encore des dépôts structurés autour d'éléments carnés, que se concentre désormais la réflexion sur les manifestations de pratiques votives domestiques.

On écartera d'emblée de ce propos les inhumations disposées sous les sols des pièces à usage domestique ou artisanal. Il s'agit des restes d'enfants morts en bas âge ou 
périnataux ; disposition qui relève davantage d'un rituel spécifique, celui de l'intimité familiale et de la dissimulation d'un être non encore sociabilisé dans sa communauté. On écartera de même les ensembles monétaires découverts parmi les décombres d'habitats détruits ou abandonnés. Ils correspondent pour l'essentiel à des cachettes de valeurs pécuniaires, bijoux thésaurisés comme à Entremont ou à La Cloche, aussi pécules monétaires plus ou moins importants. Mais on peut être plus dubitatif sur le sens de la découverte majeure de ces dernières années, celle des groupements de plusieurs milliers d'oboles et de drachmes lourdes "fleurs de coin » dans un contexte du début du III $^{\mathrm{e}}$ s. avant J.-C. au sein de l'oppidum de La Courtine d'Ollioules (Brénot, 1989; Bérato et al., 1996, p. 66-67, fig. 10 et 11).

Ce sont les dépôts enfouis sous les sols de circulation ou les aménagements architecturaux, tels les seuils de porte, qui constituent la documentation principale des rites domestiques que l'on qualifiera de propitiatoires. Leurs aménagements, leurs dispositions et leurs contenus caractérisent la spécificité de la mise en place de ces dépôts et suggèrent la nature de leur fonction. On les reliera également à quelques objets isolés mais singuliers, exposés ou en circulation dans l'habitat. Presque tous les contextes connus se placent entre le $\mathrm{IIJ}^{\mathrm{e}}$ et le $\mathrm{I}^{\mathrm{er}} \mathrm{s}$. avant J.-C. (Nin, 1999, p. 268).

Plusieurs agglomérations méridionales montrent de tels aménagements en fosse, parfois complétés d'un entourage de pierres ou de la protection d'une lauze, voire d'un petit tumulus. Le contenu est varié, rarement des vases isolés, plutôt des groupements ou encore des objets sélectionnés, telles les petites haches polies signalées dans plusieurs sites de Provence (id., ibid., p. 264-265). Certains récipients déposés au $I^{\text {er }}$ s. avant J.-C. contiennent des restes d'animaux : serpents à Ambrussum et à Nages-et-Solorgues (Fiches, 1986, p. 122-123, fig. 103-104 ; Py, 1990, p. 803-805, doc. 276B), oiseaux ou rongeurs à Lattes, Ensérune, La Ramasse ou Nages-et-Solorgues (Py, 1990, p. 805). Le sens de tels dépôts est plcincmcnt confirmé par les restes d'un jeune renard disposé sous le seuil d'une porte dans l'habitat de Saint-Blaise : son corps avait été percé d'aiguilles en bronze et en fer (Bouloumié, 1985 et 1992, p. 58).

À l'idée de pratiques magiques que suggère cette dernière découverte venant à l'appui des dires de Pline l'Ancien pour la Gaule ${ }^{20}$, on ajoutera celle des offrandes aux divinités protectrices de la maison et de l'habitat. Elle prend corps aux travers des dépôts d'objets et de faune. Le groupement le plus remarquable est celui de Saint-Pierre à

20. " La Gaule est possédée par la magie " (Histoire naturelle, XXX, 4).
Martigues. Ce site a permis la fouille de plus d'une centaine de telles offrandes, réparties entre le $\mathrm{V}^{\mathrm{e}}$ et le $\mathrm{I}^{\mathrm{cr}} \mathrm{s}$. avant J.-C. (voir infra notice 4, p. 225-230). Un lot de 29 de ces fosses, issucs des premières recherches, a été analysé et publié (Lagrand, 1986, p. 133-134 ; Columeau, 1991, p. 157-161). Elles contiennent presque exclusivement les restes, brûlés ou non, d'animaux d'élevages, dont les deux tiers de moutons et chèvres, le restant étant composé de porcs. La majorité des bêtes abattues sont jeunes ou très jeunes. Le cerf n'est présent que dans une fosse, l'animal sauvage n'étant pas un sujet sacrificiel recherché ${ }^{21}$ (Brunaux, 2000a, p. 134-136). Les animaux peuvent être découpés, parfois mélangés et les éléments carnés disposés en vrac ou au contraire organisés. Dans quelques cas, c'est l'animal complet qui est mis en terre (fig. 131) ou de larges parties qui sont demeurées en connexion (Nin, 1999, p. 267, fig. 56). Ces vestiges peuvent être éventuellement protégés par un récipient en céramique (fig. 132) et accompagnés d'objets métalliques spécifiques : fibules, pointes de flèche, disques perlés...

Avec les informations de plusieurs habitats de la basse vallée du Rhône présentant des similitudes (ainsi à L'Arquet, à Roquefavour, à Teste-Nègre, à Saint-Blaise...), le contenu ritualisé des dépôts carnés de Martigues s'insère pleinement parmi les choix sacrificiels des Celtes comme des cultures gréco-italiques (Méniel, 1992, p. 15-18). À Martigues, avec l'observation des traces de grillage de certains ossements et de découpes en morceaux des animaux abattus, avec la présence également d'un dépôt composé de coupes à boire en céramique (Nin, 1999, p. 265-266), on peut inférer l'existence de repas ritualisés dont une part serait offerte à une divinité tutélaire. Les coupes à boire amplifient cette notion du banquet en suggérant la pratique de libations (Poux, 2000b, p. 311-315). La découverte dans plusieurs habitats de la basse vallée du Rhône (Arles et Martigues, aux $\mathrm{IV}^{\mathrm{e}}$ et II $\mathrm{II}^{\mathrm{e}}$ s. avant J.-C.) de cols d'amphores disposés verticalement dans les sols aménagés de quelques pièces (fig. 130) semble étayer la réalité de telles cérémonies au sein des agglomérations.

D'autres pièces singulières proviennent également des habitats de L'île et de Saint-Pierre à Martigues; elles pourraient s'insérer dans le cortège des rites domestiques (voir infra notice 4, p. 225-230). En revanche, plus problématique est l'interprétation des monolithes en forme de croissant (voir infra la même notice 4), blocs taillés connus dans d'autres habitats régionaux du second âge du Fer : SaintBlaise (Bouloumié, 1992, p. 55, fig. 17a).

21. Arrien (La Chasse, 34) précise même que les Celtes compensent la mort d'un « animal sauvage par le sacrifice d'un d'élevage ". 


\section{Espaces dévotionnels collectifs}

On qualifiera ainsi les aires dans l'habitat groupé qui comportent des dépôts considérés comme offrandes votives et/ou la présence d'une sépulture. Mais on ne perdra jamais de vue qu'à l'exception de Pech Maho (voir infra notice 6, p. 234-238), les modestes aménagements de ces lieux cultuels, peu différents de ceux des pièces d'habitation, laissent planer une interrogation sur leur réelle signification sociale : espaces de familles dominantes dans la communauté ou lieux à fonction véritablement collective ? Quoi qu'il en soit, nous retiendrons que la pratique dévotionnelle se manifeste au sein même des habitats, en complément aux cultes sur les territoires voisins.

La piété exprimée aux divinités dans l'habitat comme les hommages rendus à des héros quasi divinisés du microcosme social transparaissent parfois dans l'iconographie des vestiges archéologiques ou au travers de rares et tardifs témoignages épigraphiques en gallo-grec (Lejeune, 1985 ; Bats, 1988). La référence individuelle ou familiale à des personnages protecteurs est reconnue à l'extrême fin de l'âge du Fcr, par exemple sur les feuilles d'or travaillées au repoussé et incluses dans plusieurs bagues en argent d'Entremont. La même probabilité d'une référence à un héros tutélaire pourrait se retrouver dans l'inscription gallo-grecque composée sur un pavement en opus signinum d'une habitation de Cavaillon, datée de la première moitié du I ${ }^{\text {er }} s$. avant J.-C. Un jeune aristocrate paraît se réclamer du lignage d'un [V]eltuoselo(Lejeune, Lambert, 1996 ; Dufraigne, 2000, p. 201, fig. 4). Sur le site du Baou-Roux, près de Marseille, entre 175 et 125 avant J.-C., une gravure sur le col de cruche se lit comme une dédicace votive à une divinité locale: Aeiouitia (fig. 106) (Boissinot, Bats, 1988). Elle complète le témoignage d'autres, sur pierre, qui pourraient être contemporaines, ainsi celle à Belenos sur le bord d'une vasque de Glanon. Plus généralement, à partir du II ${ }^{e}$ s. avant J.-C., un certain nombre de graffitis répétitifs sur céramique sont sans doute des anthroponymes ; mais dans quelques cas, on peut également penser à des abréviations de théonymes: Martigues, Saint-Blaise, Glanon... (Lejeune, 1981, p. 120-123). Comme dans la plupart des exemples de Nîmes, Montagnac ou Glanon (Lejeune, 1985, p. 75-85, 273-287 et 318-325), l'inscription rupestre gallo-grecque aux Mères découverte au Castellan d'Istres est sans doute très tardive, dans un milieu déjà romanisé (ibid., p. 97-101). Enfin, antérieurement à la conquête, on considérera la scène en bas-relief sur bloc architectural d'Entremont qui représente deux personnages en position d'orants, peut-être un couple offrant des chevreaux (?) en sacrifice (fig. 107) (Salviat, 1987, p. 225).

Les lieux dévotionnels clairement attestés par des offrandes sont peu nombreux. Souvent, les dépôts votifs

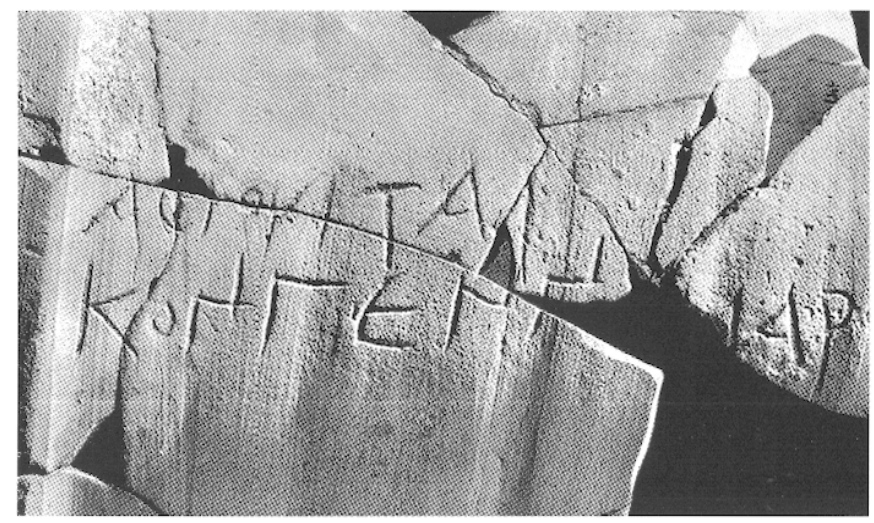

Fig. 106 - Bouc-Bel-Air (Bouches-du-Rhône), Le Baou-Roux. Inscription gravée sur le col d'une cruche régionale tournée. Dédicace votive d'un certain Kongennomaros à une divinité féminine. Aeiouitia. Ce vase à verser, des années 175-125 av. J.-C., laisse envisager une offrande personnelle, lors d'une probable action libatoire (photo P. Foliot et G. Réveillac, CNRS).

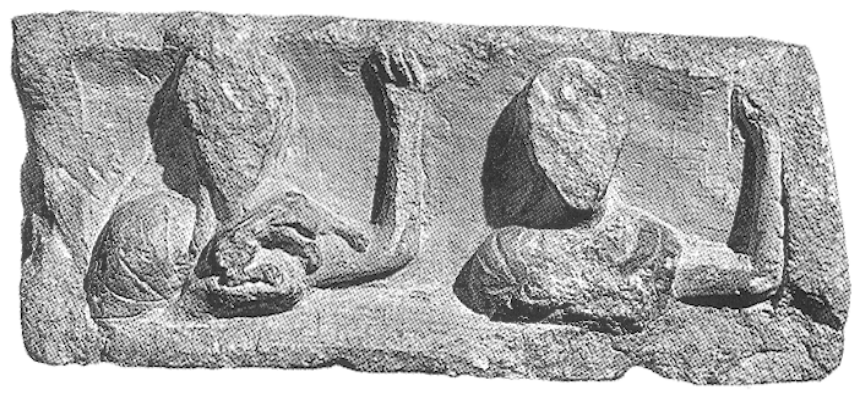

Fig. 107 - Aix-en-Provence (Bouches-du-Rhône), Entremont. Ce bloc architectural, travaillé sur une seule de ses faces, fournit la principale représentation d'orants du Midi ( $L$. de face: $0,51 \mathrm{~m}$ ). Personnages, aux vêtements drapés, saisis lors d'une action sacrificielle, avec l'offrande de petits animaux (photo P. Foliot et G. Réveillac, CNRS).

ont été dispersés et n'ont pas été observés en position d'origine, comme à Entremont, sans doute également à Cavaillon ou à Mauressip. Plusieurs ensembles mieux conservés viennent heureusement compléter notre information dès le premier âge du Fer. On se contentera d'en rappeler quelques caractéristiques.

Sur la partie sommitale de l'habitat perché de SaintVincent à Gaujac, contre le parement interne de la fortification et sur une superficie conservée de $100 \mathrm{~m}^{2}$, des couches de terres cendreuses, avec les vestiges de plaquesfoyers successives, contenaient des céramiques régionales ou importées en grand nombre, entre le deuxième quart du $\mathrm{V}^{\mathrm{e}} \mathrm{s}$. et le début du IV $\mathrm{I}^{\mathrm{c}} \mathrm{s}$. avant J.-C. (Charmasson, 19821986). Elles recelaient aussi des objets métalliques (rondelles percées) ou en terre cuite très spécifiques 

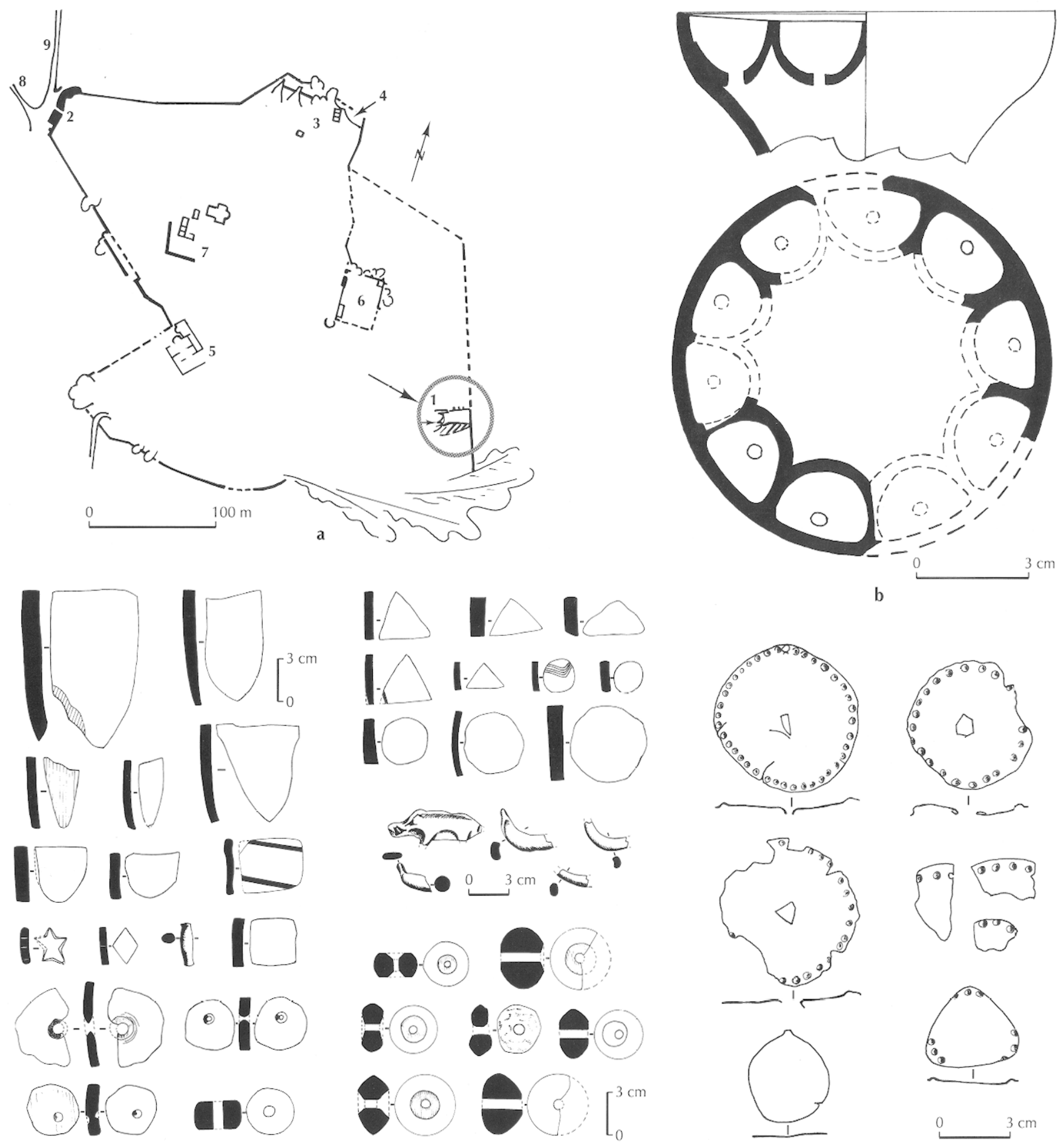

c
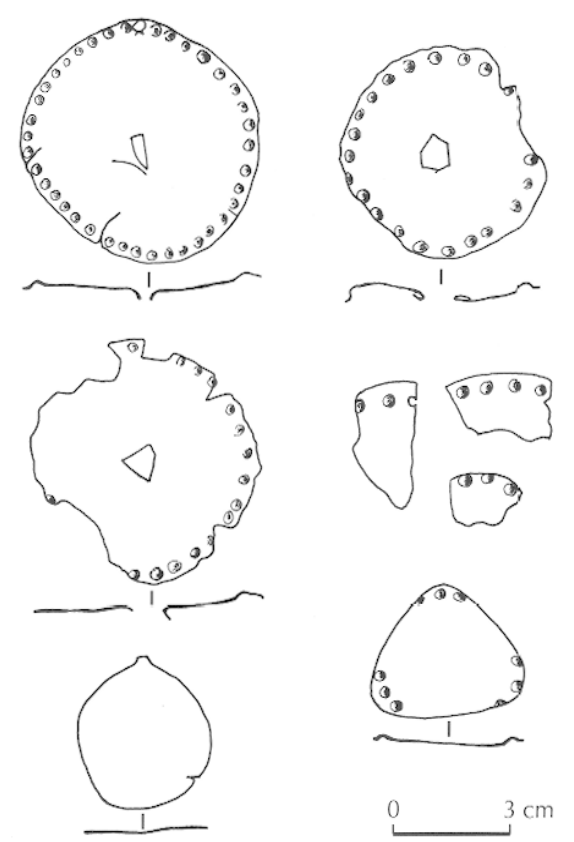

d

Fig. 108 - Gaujac (Gard), Saint-Vincent. Au sommet de l'habitat perché (a), contre le mur d'enceinte (point $n^{\circ}$ I), un aménagement est caractérisé par la présence d'aires de cuisson recouvertes d'une couche cendreuse. Une stèle fruste est disposée contre l'enceinte. Le caractère présumé votif de l'aire est attesté par les vestiges de vases régionaux ou importés, des kernoï (b), un lot conséquent de figurines ou de tessons taillés (c). La présence de rondelles en tôle de bronze vient renforcer la connotation religieuse du lieu $(d)$. Fin du V et début du $I^{P}$ s. av. J.-C. (d'après Charmasson, 1982-1986, fig. 2, 18, 19 et 21). 
(éléments de kernoï, brûle-parfums copiés de modèles méditerranéens, ainsi que des tablettes, des jetons découpés, des figures zoomorphes...) (fig. 108). Une stèle rustique était couchée près de l'enceinte. Plusieurs hypothèses ont été formulées sur le sens de ces associations et quant à l'homogénéité du gisement. Il nous semble qu'au moins dans son premier état le lieu a connu une fonction cultuelle. On observe avec intérêt que la première plaque-foyer n'a plus de surface lissée. Elle semble avoir été détruite ou "tuée " comme celles du témoignage nouveau de La Roque à Graveson. Ce dernier site, très récemment fouillé et en cours d'étude (voir infra notice 3, p. 222-225), a révélé un probable lieu sacrificiel installé contre un mur d'enceinte élevé en plaine dans le dernier quart du $\mathrm{VI}^{\mathrm{e}} \mathrm{s}$. avant J.-C. Il est caractérisé par une succession de plaques-foyers, détruites après usage, et une banquette à soubassement en terre. Peu après, au début $d u \mathrm{~V}^{\mathrm{c}}$ s., la restructuration totale des fortifications place alors le lieu hors de la ligne de défense, près de la porte principale du secteur (fig. 129a, b, c). L'aire cultuelle est volontairement préservée et réaménagée en tant que petit sanctuaire de porte. On rappellera que cette modeste installation est établie à l'emplacement ou à proximité immédiate d'une ancienne aire consacrée avec des offrandes de stèles (voir supra).

Avec la planification structurelle des espaces bâtis qui se généralise dans les habitats fortifiés au second âge du Fer, les lieux dévotionnels vont occuper une pièce dans un îlot, comme à Teste-Nègre vers 200 avant J.-C. (Chabot, 1996, p. 273-276) ou à La Cloche, aux II $^{\mathrm{e}}$ et $\mathrm{I}^{\text {er }}$ s. avant J.-C. (fig. 109a, point $\mathrm{n}^{\circ}$ l) (ibid., p. 238, fig. 6). Dans ces deux exemples, comme à Gaujac, on relève des caractères récurrents quant à l'emplacement de ces aménagements : une implantation sur la partie sommitale du site, contre la fortification, voire à proximité d'une porte dans le cas de La Cloche. Mais nous avons vu à La Roque de Graveson qu'un dispositif similaire pouvait être mis en place dans un secteur bas du site. Le caractère ouranien des cultes peut être un argument dans le choix de l'emplacement d'un espace cultuel, mais c'est le plus souvent la proximité de l'enceinte et le souci de sa protection qui semblent déterminants. Les actions dévotionnelles sont celles de modestes agriculteurs et artisans, si l'on en juge par la simplicité dominante des offrandes déposées à même le sol ou exposées sur des panneaux en bois (fig. 109b).

\section{Restes de défunts parmi les vivants}

Un des modes de structuration des sociétés de la Protohistoire curopéenne est celui de l'intégration au sein d'habitats des restes de personnages célèbres de leur vivant ou de leurs ombres légendaires (Snodgrass, 1982, p. 117-118;
Polignac, 1984, p. 149-151 ; Jost, 1992, p. 62-70 ; Delcourt, 1992 ; Duval, 1993, p. 18-24). C'est le souvenir de leur action pour le groupe social dont ils étaient issus que l'on veut ainsi perpètuer afin d'en conserver l'aura protectrice mais également la dynamique identitaire essentielle au ciment communautaire. Dans le monde celtique, c'est avant tout la valeur spirituelle et le courage guerrier qui priment. Après une "belle mort ", le personnage héroïsé demeure pour les siens un protecteur et la saga de ses mérites est véhiculée par les bardes. Son humanité ancienne lui confère un abord plus aisé qu'en regard d'une divinité, plus abstraite. Une des manières simples et efficaces de conserver un lien avec l'au-delà est de garder dans l'habitat les reliques du disparu.

L'inventaire des cas de probables sépultures dans l'habitat a été réalisé il y a une dizaine d'années. On rappellera que l'exemple le plus ancien, au Cayla de Mailhac (Aude), est à rapporter au début du second âge du Fer, vers le milieu du IVe s. (Arcelin et al., 1992, p. 203-206). Au III ${ }^{\mathrm{c}}$ s., se rattache celui de Pech Maho, également dans l'Aude (voir infra notice 6, p. 234-238 et fig. 143). Les deux autres cas probables sont en Provence, près de Marseille, au Verduron et à La Cloche, entre la fin du $\mathrm{III}^{\mathrm{e}} \mathrm{s}$. et le début du $\mathrm{I}^{\text {er }}$ s. avant J.-C. (Bernard, 2000 ; Chabot, 2000). Les fouilles en cours au Verduron devraient apporter d'ici peu une information renouvelée ou complémentaire aux données anciennes disponibles. Celles du deuxième habitat ne sont guère plus explicites quant aux dispositions initiales des restes humains. Une urne en plomb a été retrouvée jetée dans une ruelle, percée et écrasée ; selon le fouilleur, elle pourrait provenir des pièces du secteur $n^{\circ} 2$ (fig. 109a).

Comme pour les aires à offrandes précédentes, on observe que les espaces funéraires reconnus sont disposés à proximité de l'enceinte (à Mailhac) ou de la porte principale (à Pech Maho et au Verduron). À Pech Maho, l'espace cultuel qui lui est consacré est sciemment mis en valeur, devant un dégagement sans doute cérémoniel.

Il convient de rappeler que la présence de guerriers héroïsés ne concerne pas que les agglomérations. Nous avons suggéré leur valorisation dès le début du premier âge du Fer dans le cadre de domaines ruraux ou d'aires funéraires, au travers de la première statuaire du « type de Sainte-Anastasie ». Pour les côtes de Bretagne, la littérature antique montre la croyance en l'existence d'îles pratiquement désertes et consacrées aux âmes des héros (Plutarque, Euvres morales, 8 ; Sur la disparition des oracles, 18). Sur les rivages méditerranéens, Strabon parle également de la présence d'un hérôon à Lérôn, dans les îles de Lérins, au large de Cannes (Géographie, IV, 1, 10). La découverte, dans une de ces îles (Sainte-Marguerite), d'un couvercle de pyxide dédicacé à Lérôn et Lériné confirme pleinement la réalité d'un tel lieu cultuel (Coupry, Vindry, 1982). Elle 


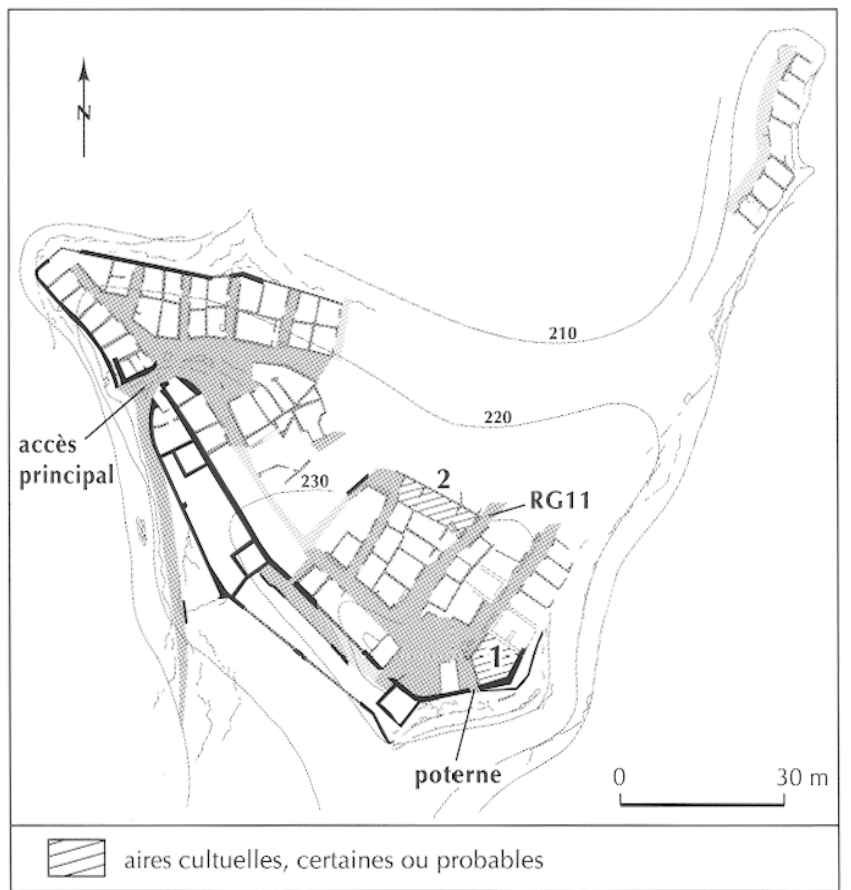

a

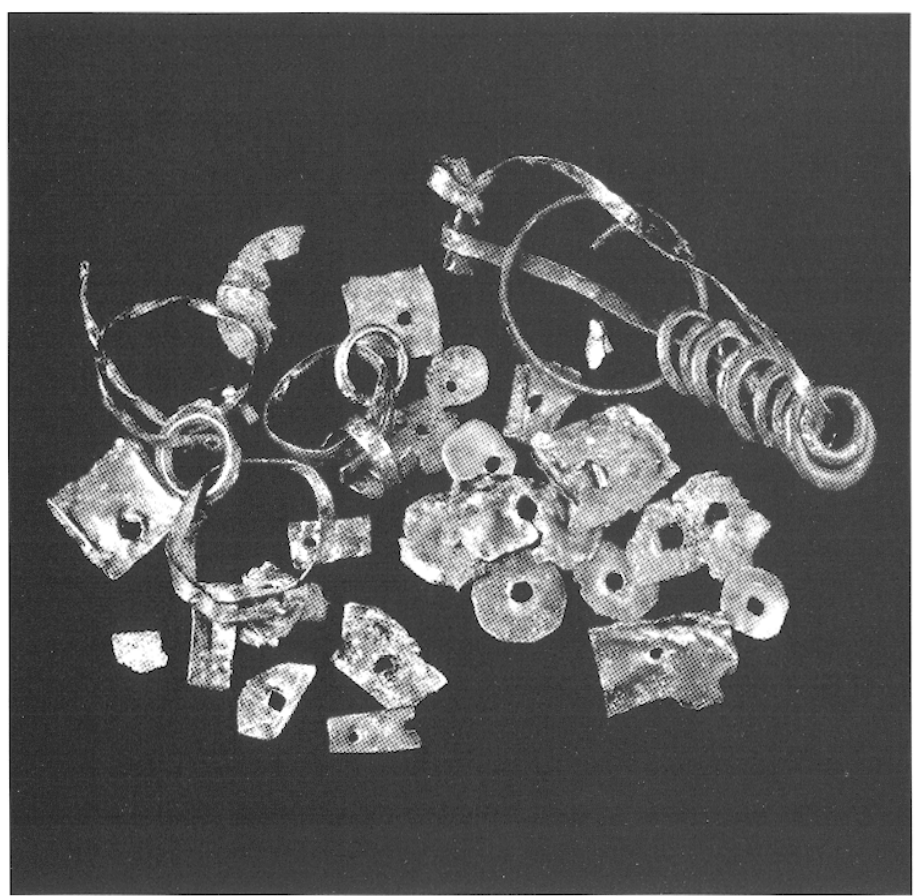

b

Fig. 109 - Les Pennes-Mirabeau (Bouches-du-Rhône), La Cloche. Une aire votive est aménagée sur la partie sommitale dans une salle proche d'une poterne (point $n^{\circ} 1$ ). Elle a foumi un abondant matériel de petites pièces de bronze. Un autre lieu cultuel occupait le même emplacement peut-être dès le début du II ${ }^{e}$ s., avec des éléments métalliques ou céramiques (b) de la fin du IV s. et du III s. av. J.-C. (plan S. Leconte; dessin M. Rétif; photo C. Durand, CNRS).

suggère également une forme de sacralisation des deux îles, et l'origine du dédicant de cette pyxide, Athenaios, un navigateur grec de Neapolis (Naples sans doute), laisse pressentir la renommée de ce couple divinisé comme protecteurs reconnus de la navigation côtière régionale.

\section{Premiers édifices monumentaux}

Le signe majeur de la prime romanisation des agglomérations le long du littoral est celui de l'apparition de lieux collectifs monumentalisés, à vocation politique et religieuse. À l'exception des implantations grecques côlières et peutêtre de l'ancienne colonie d'Arles sur le Rhône, nous avons vu que le caractère premier de l'habitat méridional est, comme dans le restant de la Gaule, d'être foncièrement intégré à ses territoires d'exploitation environnants. Faute d'espaces libres dans l'habitat, les lieux de rassemblements, dont ceux de nature religieuse, sont inévitablement disposés hors de l'enceinte fortifiée. Pourtant dans cette coloration culturelle générale apparaissent quelques points de mutation au contact du monde méditerranéen. Le phénomène, tel que l'archéologie nous permet aujourd'hui de le percevoir, commence à se manifester sur la côte et dans la basse vallée du Rhône. On peut le caractériser comme un double courant transformiste. C'est d'abord celui d'une évolution des concepts ibéro-celtes ou liguroceltes dans l'habitat familial par exemple, avec une rapide amplification des superficies occupées par une multiplication des pièces de l'habitation, regroupées autour d'une cour centrale et sans doute plus spécialisées. Le mouvement semble s'amorcer avec les modifications des rapports de force qui interviennent en Méditerranée lors de la seconde guerre punique, à la fin du III ${ }^{e}$ s. Le repli des Celtes péninsulaires vers la Cisalpine au cours de cette même seconde moitié du siècle et le passage des troupes carthaginoises dans le Sud de la Gaule sont également de puissants catalyseurs de l'évolution, ne serait-ce que par les choix politiques et culturels obligés pour les élites régionales. Avec toutes les nuances intermédiaires, les membres de cette classe sociale, en fonction de leurs acquis antérieurs, seront tentés soit par un repli sur des valeurs " traditionnelles" (une économie agropastorale et les devoirs de la guerre), soit par une amplification des ouvertures au monde méditerranéen désormais à forte connotation gréco-italique. Dès cette époque, la tendance "progressiste " se lit dans l'apparition de plus vastes habitations liées à n'en pas douter à des familles commerçantes. C'est le cas à Lattes sur la côte languedocienne. Il en ira de même à Ensérune, peut-être à Béziers, et 
au coeur de la basse vallée du Rhône, au nord de la ville d'Arles, à partir du II's. Dans ce dernier secteur, au contact de la fédération guerrière des peuples salyens et à la différence de celle-ci, apparaît une zone centro-rhodanienne où l'attrait des valeurs philhellènes se concrétise dès le milieu du siècle par l'amorce d'un véritable phénomène d'urbanisation. Il va se manifester par le regroupement des membres influents de la classe dominante autour de centres politiques et religieux monumentalisés. Cette classe s'y affiche en tant que telle. L'éclosion très probable à Arles, Avignon, Glanon puis Cavaillon, Nîmes, Ermaginon (?), etc. d'une telle mutation sociale conduira à la formation d'un véritable foyer d'hellénisme (Arcelin, à paraître b). Le domaine religieux n'échappera pas à cette dynamique. Ainsi à Glanon, il est probable que des hérôa aient été réaménagés près de la porte basse de l'enceinte protohistorique au début du II $^{\mathrm{e}}$ s. (voir infra notice 5, p. 230-235). S'il s'agit bien de statues très anciennes de guerriers accroupis présentés sur des piliers et entourés de stèles peintes (Rolland, 1968, p. 25-34 ; Barbet, 1991, p. 72), force est de constater que ces monuments sont d'une part des assemblages hétéroclites (statues du $\mathrm{V}^{\mathrm{e}}$ s., pilier et une partie des stèles récentes...) (fig. 137 et infra), d'autre part contemporains ou presque des premières édifications de temples de type gréco-italique (Roth Congès, 1992a, p. 357-360). Hors de ce foyer culturel, l'inventaire anciennement réalisé montre que le phénomène ne se généralisera vraiment sur la rive gauche de la basse vallée du Rhône et en quelques points de la côte qu'après la conquête romaine (Arcelin et al., 1992, p. 196-201).

\section{ENTRE DÉFUNTS ET VIVANTS, UN DIALOGUE RECRÉÉ}

Les auteurs anciens ont à maintes reprises souligné la croyance profonde des Celtes dans l'immortalité de l'âme comme dans sa réincarnation après la mort (ainsi Diodore, Bibliothèque historique, V, 28 ou Valère Maxime, Faits et dits mémorables, II, 6, 10). La pratique d'une communication avec le monde des morts, par exemple en incinérant avec le défunt une part de ses biens ou en jetant dans le bûcher de crémation des messages écrits à l'intention de parents décédés (Diodore, ibid., sans doute d'après Poseidonios), montre la réalité de l'institution d'un dialogue entre les vivants et leurs disparus. Le recours à l'invocation de ces derniers, surtout si leur vie a laissé un sillage de renommée, est pour les hommes qui se réclament de leurs lignages une référence tutélaire et hautement valorisante. De cette manière, les morts glorieux vont continuer à participer à la vie sociale de leur communauté. Nous avons vu plus haut que la puissance passée de guerriers héroïsés peut, du fait de la présence de leurs restes incinérés, aider à la protection d'un habitat. Deux autres modalités d'implication des disparus dans le monde des vivants vont se définir et se structurer dans le Midi au cours de l'âge du Fer. La première est celle de la communication oraculaire, la seconde participe de la valorisation sociale de leur branche familiale.

\section{Portiques et masques-reliquaires}

Dès le tout début du premier âge du Fer, les stèles lisses ou décorées de chevaux et/ou de cavaliers, associés à d'autres rares motifs symboliques, accompagnent des édicules dont l'armature fait appel à des piliers et linteaux monolithes, taillés et abrasés (Benoit, 1969a, p. 69-71; Coignard, Coignard, 1991, p. 33, fig. 8). En soi la forme architecturale est élémentaire : c'est celle du portique largement ouvert, à l'instar de l'ossature de la maison familiale à poteaux porteurs en bois. La couverture, qui fait appel à ce dernier matériau, à des végétaux souples et à la terre, est là pour assurer une protection minimale à la décoration peinte, telle que nous le montrent les éléments ornés des vestiges de Roquepertuse ou de Glanon (Barbet, 1991, p. $69-77$; infra notice 5 , p. $230-235$ et fig. 141). On peut raisonnablement penser que ces constructions à supports de pierre ont succédé ou accompagné des équivalents en bois depuis la fin de l'âge du Bronze. Leur souvenir transparaît encore tardivement dans la réalisation de la salle hypostyle d'Entremont vers la fin du $\mathrm{II}^{\mathrm{c}}$ s. (Arcelin, Blaustein, 1998). La carte de la figure 110 visualise la répartition géographique de l'ensemble des données architecturales régionales disponibles pour l'âge du Fer.

Deux constats s'imposent à l'analyse des vestiges épars et des trois exemples partiellement observés en place. Seul celui de Roquepertuse est véritablement du plein second âge du Fer, de la première moitié du III ${ }^{e}$ s. avant J.-C. (Boissinot et al., 2000). Les deux autres sont tardifs, celui d'Entremont vers la fin du $\mathrm{II}^{\mathrm{e}}$ s. (Arcelin, 1992a) et celui de Nîmes au début du $\mathrm{I}^{\text {er }}$ s. avant J.-C. (Guillet et al., 1992 ; Monteil, 1999, p. 338). Tous les autres éléments ont été découverts isolés ou remployés, parfois bien plus tardivement. Pourtant, les motifs gravés ou sculptés en bas- ou hautrelief peuvent nous fournir des indices quant à leur datation probable et à la teneur des messages délivrés.

Avec les vestiges réutilisés dans les fortifications de Mouriès (fig. 104) ou de Glanon (fig. 136 et 140), plusieurs autres exemples peuvent être attribués à une même date ancienne, entre le VIII ${ }^{c}$ et le $\mathrm{VI}^{\mathrm{e}}$ s. avant J.-C. Style des figures gravées et techniques mises en œuvre (traits réalisés par piquetage, puis cernures dégageant un relief dans le creux) rapprochent fortement certains des piliers et linteaux des stèles décorées. Comme nous l'avons souligné pour ces dernières, les caractères relativement frustes de la 


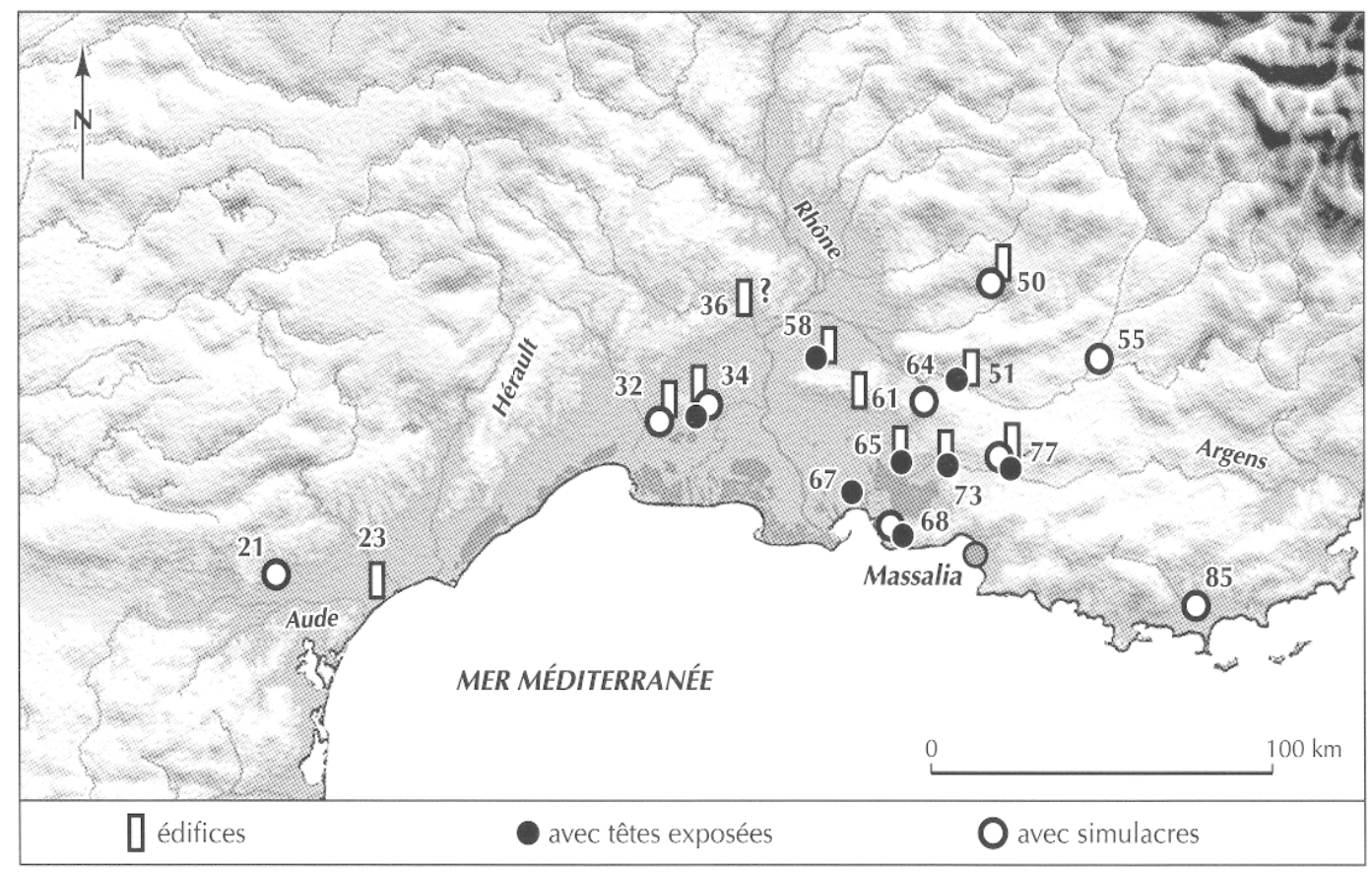

\begin{tabular}{|l|l|l|l|}
\hline$N^{\circ}$ & \multicolumn{1}{|c|}{ Commune } & \multicolumn{1}{c|}{ Lieu-dit } & \multicolumn{1}{c|}{ Département } \\
\hline $\mathbf{2 1}$ & Mailhac & Le Cayla et Le Traversant & Aude \\
\hline $\mathbf{2 3}$ & Nissan-lez-Ensérune & Ensérune & Hérault \\
\hline $\mathbf{3 2}$ & Nages-et-Solorgues & Les Castels & Gard \\
\hline $\mathbf{3 4}$ & Nîmes & agglomération, Grézan et région & Gard \\
\hline $\mathbf{3 6}$ & Saint-Bonnet-du-Gard & Le Marduel & Gard \\
\hline $\mathbf{5 0}$ & Rustrel & Le Pied de l'Aygues & Vaucluse \\
\hline $\mathbf{5 1}$ & Cadenet & Le Castellar & Vaucluse \\
\hline $\mathbf{5 5}$ & Saint-Martin-de-Brômes & Buffe-Arnaud & Alpes-de-Haute-Provence \\
\hline $\mathbf{5 8}$ & Saint-Rémy-de-Provence & Glanon & Bouches-du-Rhône \\
\hline $\mathbf{6 1}$ & Mouriès & Caisses et environs & Bouches-du-Rhône \\
\hline $\mathbf{6 4}$ & Vernègues & Badasset & Bouches-du-Rhône \\
\hline $\mathbf{6 5}$ & Lançon-Provence & Constantine et Calissanne & Bouches-du-Rhône \\
\hline $\mathbf{6 7}$ & Saint-Mitre-les-Remparts & Saint-Blaise & Bouches-du-Rhône \\
\hline $\mathbf{6 8}$ & Martigues & L'île, Saint-Pierre et Tamaris & Bouches-du-Rhône \\
\hline $\mathbf{7 3}$ & Velaux & Roquepertuse & Bouches-du-Rhône \\
\hline $\mathbf{7 7}$ & Aix-en-Provence & Entremont et Terrain Coq & Bouches-du-Rhône \\
\hline $\mathbf{8 5}$ & Hyères & Saint-Michel-de-Valbonne & Var \\
\hline
\end{tabular}

Fig. 110 - Carte de répartition dans le Sud-Est gaulois des portiques et édicules présumés à vocation cultuelle ainsi que des portes-reliquaires pour l'exposition de masques humains ou de leurs simulacres (relevé P. Arcelin et P. Gruat).

figuration plaident en faveur d'une datation haute, bien antérieure pour les premières à la fin du $\mathrm{VI}^{\mathrm{e}}$ s., sans doute même dès les premières décennies de l'âge du Fer. Sans conteste, l'iconographie dominante est celle de la tête humaine (fig. 111) et d'une figuration animalière limitée pour l'essentiel, dans un premier temps du moins, au cheval, compagnon du cavalier, voire à l'expression schématique de scènes de chasse, de combats ou de symboles naturalistes des divinités et de leurs bienfaits (croissants, épis de blé, cerfs, serpents, animaux fantastiques). D'autres formes peintes relevées au début du $\mathrm{III}^{\mathrm{e}} \mathrm{s}$. à Roquepertuse laissent présager des décors plus complexes à vocation didactique et aux discours de nature eschatologique (Barbet, 1991, p. 63-77). Ces représentations ont été parfois reprises dans le système décoratif de céramiques rhodaniennes peintes (Goury, 1995, p. 322-323). On retiendra un cavalier au Pègue (Lagrand, Thalmann, 1973, fig. 11) ou encore ceux de Saint-Laurent à Carnols (Goury, 1989, fig. 2). Autre point singulier, l'existence d'entailles céphaliformes ménagées sur des piliers ou des linteaux, et parfaitement coordonnées avec le restant du système décoratif sculpté ou peint. Les cavités et peintures de Roquepertuse ont été restituées du côté intérieur, sous l'auvent de protection du portique (Coignard, Coignard, 1991, p. 33, fig. 8).

Durant plusieurs décennies, portiques et encoches ont été considérés comme les vestiges d'édifices religieux, au cœur d'un véritable culte des " têtes coupées " (Benoit, $1969 \mathrm{a}$, p. 62-63). Un réexamen récent, mettant en perspec- 


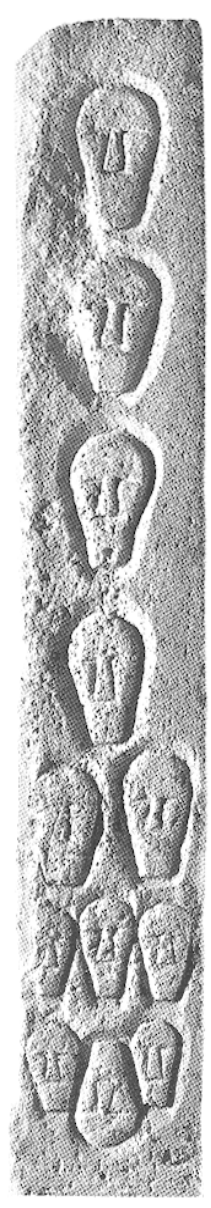

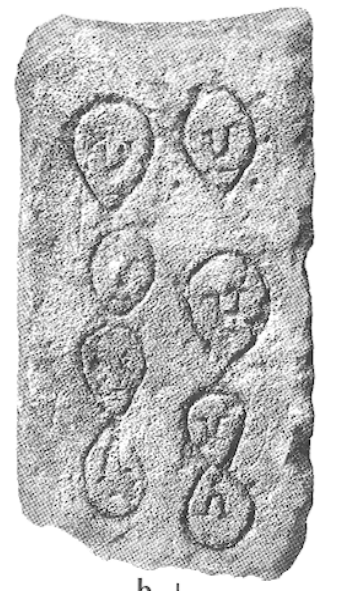

b I

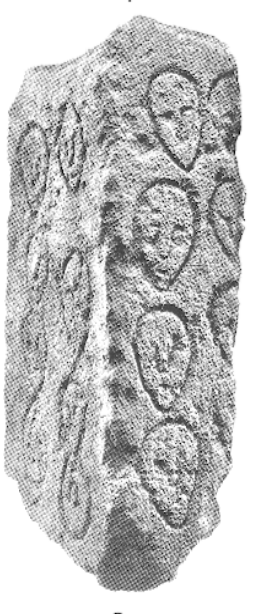

C

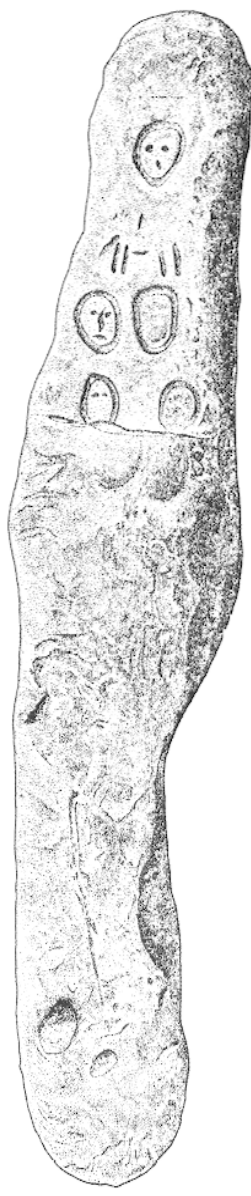

d

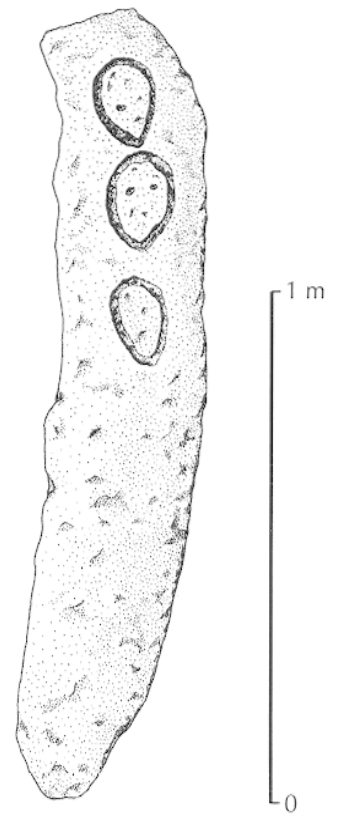

Fig. 111 - Images de la tête humaine dans l'expression cultuelle du premier âge du Fer. Aix-en-Provence (Bouches-du-Rhône), Entremont: a, pilier monolithe complet d'un portique (H.: $2,58 \mathrm{~m} ; l .: 0,35 \mathrm{~m} ;$ ép. : $0,42 \mathrm{~m}$ ) (photo A. Chéné et $G$. Réveillac, CNRS); $b, c$, élément supérieur d'une stèle quadrangulaire (H. conservée: $0,65 \mathrm{~m}$ ) (photos C. Hussy, SRA-PACA). Hyères (Var), Saint-Michel-de-Valbonne : $d$, e, deux exemples plus frustes de grands bélyles ornés de têtes et du motif zoomorphe d'un équidé (d'après Brun, Borréani dir., 1999, fig. 481 et 483).

tive les attestations littéraires des pratiques guerrières des Celtes et les restes humains retrouvés, amène à séparer nettement deux types de manipulation de la tête humaine (Arcelin, à paraître c). Le premier s'inscrit dans les rites de victoire clairement observés et relatés par Poseidonios près de Marseille vers 100 avant J.-C. (ap. Diodore et Strabon). Il ne nous retiendra pas directement ici, de même que la liste des reliquats archéologiques. En revanche, des éléments de crânes humains ont été observés à Roquepertuse à proximité immédiate des alvéoles creusées dans des piliers ou linteaux. Dans ce cas précis, leur présence au sein de réalisations plus pérennes et richement décorées laisse volontiers entrevoir une tout autre finalité à ce rite du prélèvement de la tête. Les restes humains sont ici présentés dans un écrin protecteur et deviennent porteurs d'un discours sur la survie de l'âme, sur un au-delà avec lequel il semble possible de communiquer.
Considérons brièvement les données disponibles. Les portiques les plus anciens ne sont connus qu'au travers de remplois de leurs éléments. Ce sont par exemple les fragments de piliers et linteaux décorés de Mouriès (fig. 104), de Glanon (fig. 116a et 139), de Saint-Michel de Valbonne (fig. $111 \mathrm{~d}$ et e), enfin d'Entremont (fig. 11 la à c). Avec ceux lisses mais en contextes découverts au Marduel de SaintBonnet-du-Gard (Py et al., 1994, p. 259-262), leur style comme les techniques utilisées les reportent au premier âge du Fer, et pour certains même au tout début de la période. Nous avons vu la forte probabilité d'un accompagnement de stèles votives. Parmi les représentations de la tête humaine ou de symboles liés à la mort et au renouveau de l'âme (le serpent, le cheval, des épis de blé...), apparaissent les premières cavités destinées à recueillir des éléments crâniens (fig. 112). Ces pratiques semblent se poursuivre jusqu'au début de l'Empire. À partir du II ${ }^{e}$ s. avant J.-C., le 
style des figurations devient plus réaliste comme sur le linteau de Nages-et-Solorgues (fig. 113b) ou les blocs d'Entremont (fig. $113 \mathrm{c}$ et 114), même si certaines de ces représentations demeurent frustes, comme celles de Nîmes (fig. 113a), Martigues ou Mailhac (Séjalon et al., 2001).

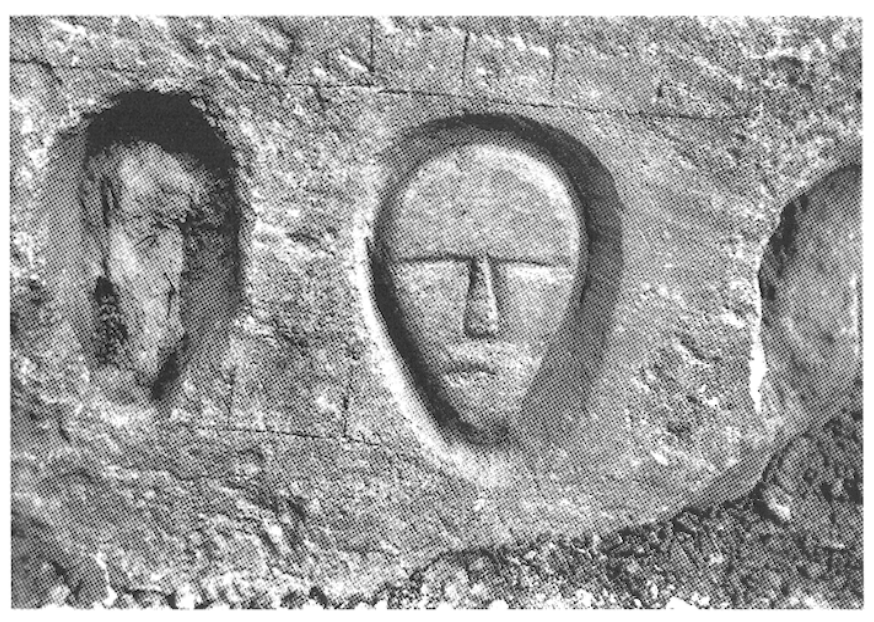

Fig. 112 - Aix-en-Provence (Bouches-du-Rhône), Entremont. Fragment de linteau qui semble appartenir au portique du pilier de la fig. 111a. Allernance d'entailles céphaliformes et de simulacres qui permettent d'espacer les masques exposés $(H$. : 0,45 m). De fines incisions encore lisibles suggèrent un riche décor peint (photo R. Ambard, CNRS).
Parfois, une meilleure lisibilité de l'environnement sculpté des têtes figurées ou enchâssées laisse percevoir les termes d'un discours eschatologique, de la «belle mort » au passage vers un ailleurs par le cycle de la nature, en attendant une éventuelle réincarnation (fig. 114).

Plusieurs interprétations pourraient être avancées pour définir ces lieux d'exposition, certains monumentaux et décorés. Les portiques seraient-ils des espaces de présentation honorifique des têtes de sacrifiés dans un sanctuaire de proximité ? Ne seraient-ils pas plutôt porteurs d'une connotation plus spiritualiste autour du rappel de l'âme des ancêtres? Nous serions davantage tournés vers cette seconde option, en raison de plusieurs arguments forts.

Le principal est lié à la présence de nombreuses figurations entourant les alvéoles. L'image dominante qui s'en dégage est celle de la communauté des âmes du corps social, en un mot de la notion de respect du lignage et du cycle des générations. La tête humaine, isolée ou présentée en frise répétitive, constitue une image récurrente dans l'art celtique laténien depuis le $\mathrm{V}^{\mathrm{e}} \mathrm{s}$. Rappelons à titre d'exemples les représentations sur les célèbres phalères d'Horovicky (Bohême) où les têtes en frise sont auréolées de feuilles de gui à l'image de celles encadrant la tête du prince de Glauberg (Duval, 1977, p. 58-60). On citera de même celles en argent, plus récentes, de Manerbio sul Mella à Brescia en Cisalpine (Arslan, 1991, p. 466-468) et à Entremont même, une applique en forme de croissant rehaussée de la figura-
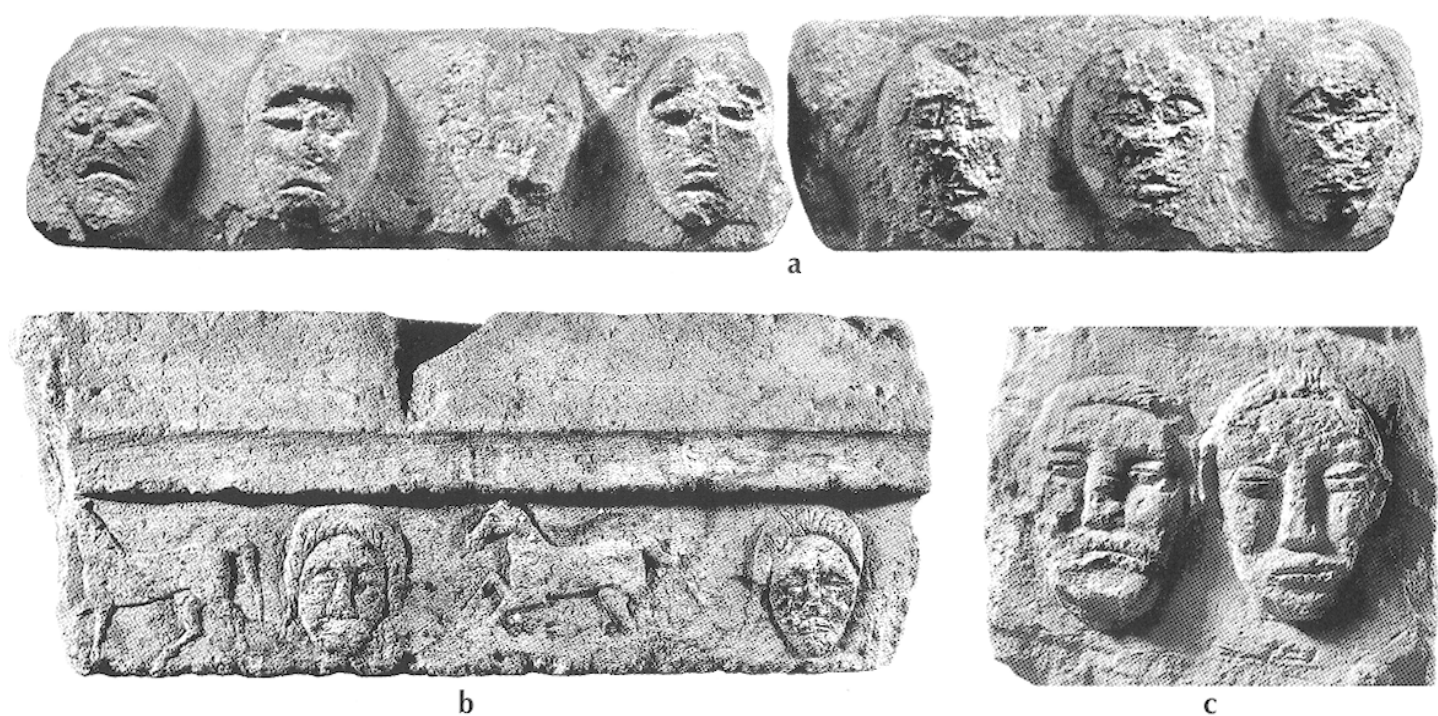

Fig. 113 - Images de la tête humaine dans l'expression cultuelle du second âge du Fer. a, Nîmes (Gard), secteur de l'amphithéâtre: deux blocs architecturaux, issus d'un édifice monumental, portent sur leurs faces visibles des alignements de têtes ou masques de défunts. Fin du II' ou I'r $s$. av. J.-C. (L. : 0,78 et 0,68 m;H. : 0,22-0,23 m); b, Nages-et-Solorgues (Gard), source des Castels : ce linteau, trouvé près d'une source et sans doute du $I^{\text {er }}$ s. av. J.-C., montre sur la face reproduite une figuration en bas-relief de masques-reliquaires et de chevaux; sur l'autre face (sans doute intérieure à l'édicule), ligne de rai-de-cœur et mortaises de fixation (L.: $1,4 \mathrm{~m} ; \mathrm{H} .: 0,52 \mathrm{~m}) ; c$, Aix-en-Provence (Bouches-du-Rhône), Entremont. Deux masques humains sculptés sur un des blocs d'un ensemble de la fig. $114 a(\mathrm{H} .: 0,37 \mathrm{~m})$ (photos $\mathrm{A}$. Chéné et $\mathrm{G}$. Réveillac, CNRS). 
a
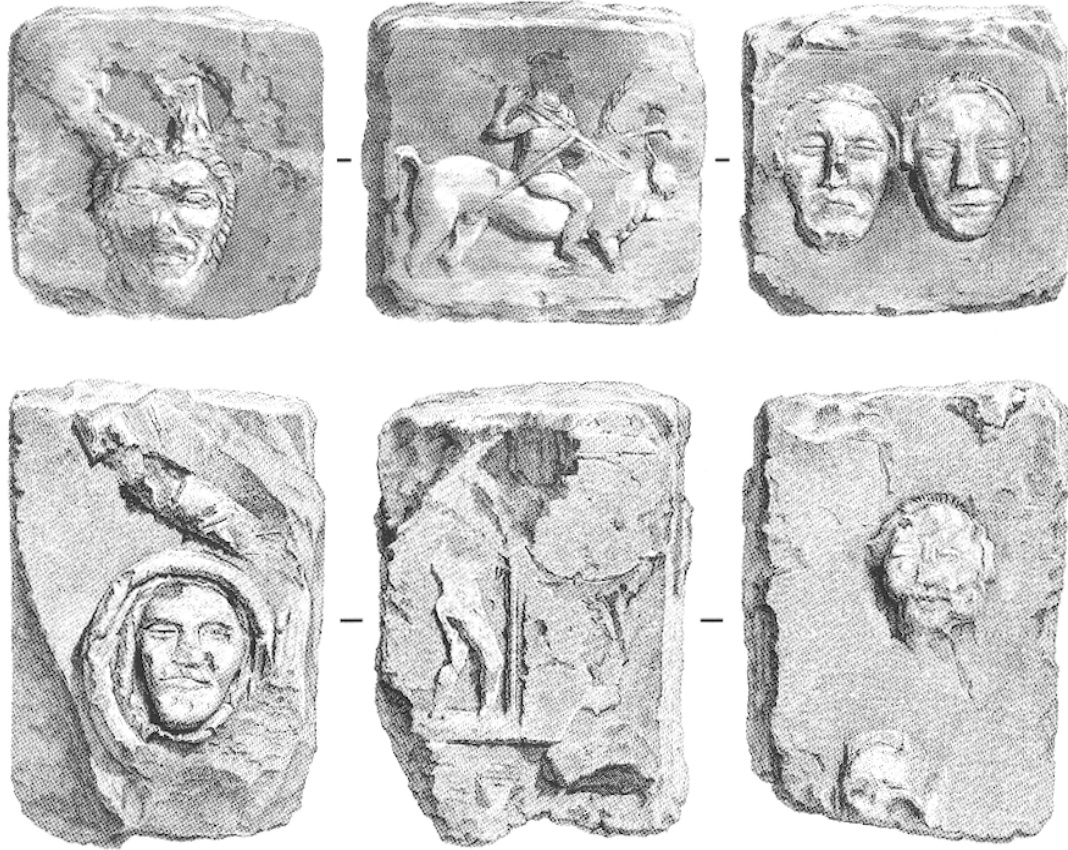

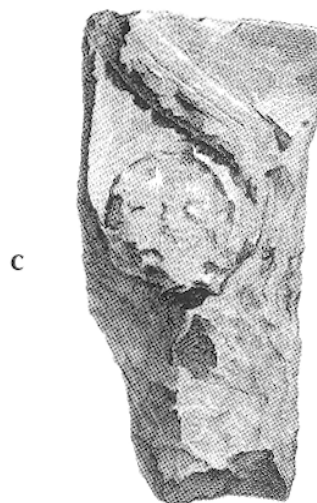

G

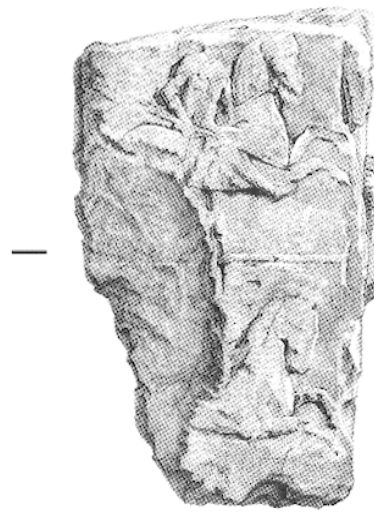

C

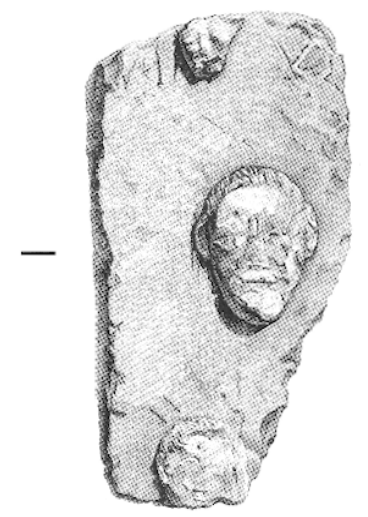

D

Fig. 114 - Aix-en-Provence (Bouches-du-Rhône), Entremont. Les trois faces sculptées en bas-relief de trois blocs appartenant à des piliers saillants ou aux piédroits d'une porte monumentalisée du II s. av. J.-C. (H. respectives: $0,37 \mathrm{~m}, 0,52 \mathrm{~m}$ et $0,54 \mathrm{~m}$ ). Elles présentent des images édifiantes d'aspect réaliste. Ces trois pierres ont un même rythme de répartition iconographique. Sur le plan de la dialectique, on pourrait le décomposer ainsi : valorisation de l'aristocratie dans sa chevalerie ou par des gestes majeurs de la vie sociale (dans l'axe de la porte ?: faces $C$ );

diverses expressions de la rëintégration de l'âme des disparus dans le cycle de la vie, entre autres au travers des rinceaux végétaux: faces $G$; enfin, côtés droits, rappel du lien qui relie les vivants aux valeurs de leurs ascendants par la représentation de "masques-reliquaires ", isolés ou groupés : faces D (d'après Rouard, Reinaud, 1851, pl. 1 à 3).

tion d'une tête isolée (Benoit, 1969b, p. 96, fig. 80). Également dans le Midi, le casque découvert à Montlaurès présente une frise identique de têtes en corail, disposées autour du cabochon sommital (Chazelles et al., 1994). Dans le contexte des portiques, les crânes insérés sous les masques concrétisent cette continuité de façon plus tangible.

I e dêxième argument découle de la sélection et du traitement des reliques exposées. Ainsi le chapiteau de
Nîmes (fig. 115) ou le linteau tardo-hellénistique de Glanon (fig. 116b) montrent non seulement la qualité architecturale de l'environnement des têtes ou l'expression d'une gestuelle respectueuse, mais aussi le caractère incomplet des crânes présentés. La faible profondeur des entailles de Nîmes $(5 \mathrm{~cm})$ ou les excroissances d'accrochage de Glanon n'autorisent que l'encastrement du masque antérieur. Dans le cas présent, il y aurait donc eu décollement de ce dernier sur le 


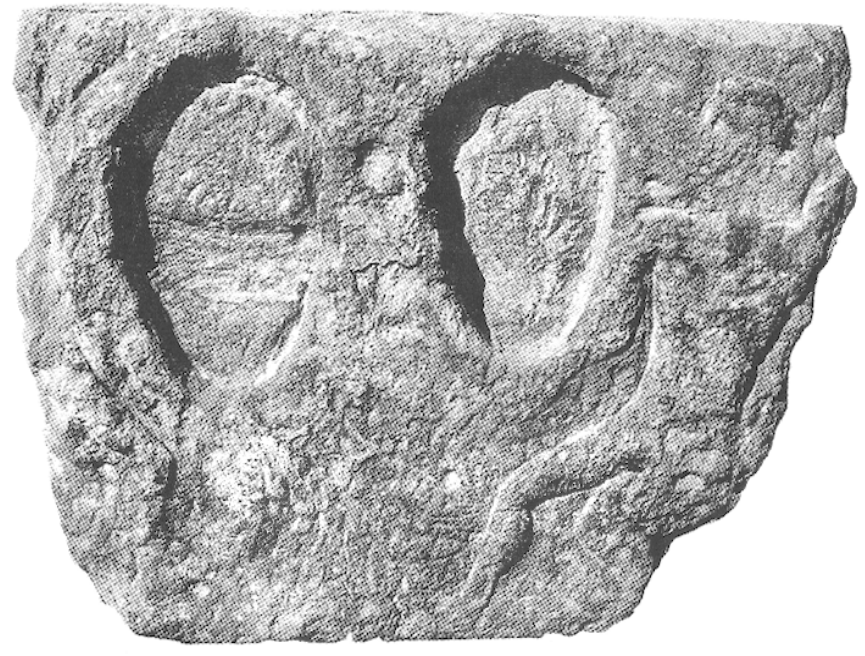

Fig. 115 - Nîmes (Gard), villa Roma. Élément d'un linteau ou d'un chapiteau. Décoré sur son revers de deux chevaux affrontés, c'est un élément majeur pour conforter l'hypothèse d'un vérilable culte des ancêtres par l'exposition de leurs reliques, disposées sous un masque réaliste (voir fig. 117). Écartant l'hypothèse d'une exhibition de trophées guerriers, ces deux alvéoles, profondes de $5 \mathrm{~cm}$, indiquent une insertion de la seule face antérieure des crânes el donc de leur préparation. Deux silhouettes humaines en position de soutien des têtes soulignent le respect qui entoure leur présentation (L. restituée: $0,85 \mathrm{~m} ; H .: 0,50 \mathrm{~m} ;$ ép. : 0,24 m) (photo A. Barbel, (NRS).

crâne décharné. Par ailleurs, les découvertes initiales de Roquepertuse ont montré que les restes osseux exhumés près des entailles étaient, selon le découvreur, liés à de l'argile compacte, alors considérée comme un mastic de calage (Gérin-Ricard, 1927, p. 23, n. 2). Nous sommes aujourd'hui portés à considérer que ces éléments de crânes humains n'étaient pas exposés sous un aspect décharné, hideux et impersonnel, mais présentés derrière une image réaliste de la personne honorée. Les visages étaient certainement reconstitués en argile, peints au naturel, voire pourvus d'un simulacre de perruque ou de barbe (fig. 117). Il s'agirait en définitive de "masques-reliquaires" " ${ }^{22}$ dont les regroupements en des points majeurs des territoires ou à la proximité des habitats sous des portiques paraissent avoir constitué de véritables lieux cultuels ${ }^{23}$. Ces cultes d'ancêtres,

22. Cette idée n'est pas nouvelle. Elle avait été formulée par $\mathbf{F}$. Benoit lors de ses réflexions sur les pratiques méridionales conduisant à l'exposition de têtes humaines (Benoit, 1969a, p. 62-68).

23. La question des emplacements probables de ces portiques, comme de leur environnement, demeure d'actualité, faute de l'observation d'un tel amćnagement en position primaire. La seule découverte, à peu près homogène, est celle dc Roquepertuse au $\mathrm{III}^{\mathrm{c}} \mathrm{s}$. avant $\mathrm{J}$.-C., mais les fouilles initiales sont anciennes et bien des doutes demeurent. Comme nous l'avons suggéré plus haut, il semble qu'un certain nombre de ces
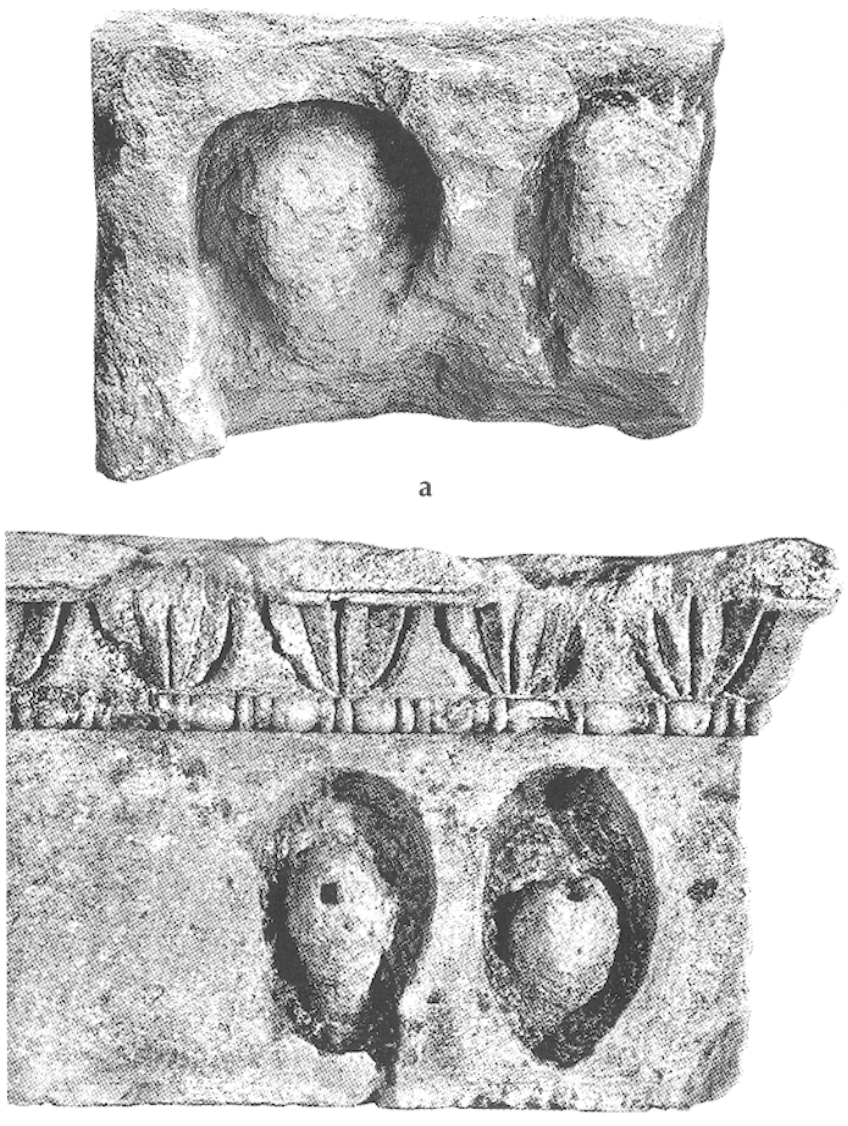

b

Fig. 116 - Saint-Rémy-de-Provence (Bouches-du-Rhône), Glanon. Exemples d'alvéoles céphaliformes dont les proéminences centrales conservées impliquent la seule insertion de la face antérieure des crânes : a, partie supérieure du pilier d'un portique, en remploi dans le monument XXIX (voir fig. 139). Sans doute du premier âge du Fer (photo C. Durand, CNRS) ; b, linteau d'un édicule couronné d'un astragale à perles et pirouettes, avec rai-de-cour qui permet de l'intégrer dans les deux premières phases monumentales du site, à la fin du II' ou au début du Ir s. av. J.-C. (photo G. Réveillac, CNRS).

dans l'ombre des portiques et l'attrait des polychromies, ont sans doute été rapidement accompagnés de pratiques oraculaires telles que les rapporte Nicandre de Colophon en parlant des Gaulois (apud Tertullien, De Anima, 57). Élien précise le goût de ces mêmes Celtes pour la divination par

réalisations aient été édifiées sur les territoires, cn des lieux consacrés ou en relation avec des propriétés domaniales, comme ccla a été formulé à Roquepertuse. Cc dernier exemple suggère un entretien de ces sanctuaires dans la durée et leur exploitation valorisante par l'aristocratie. Le remploi fréquent des piliers et linteaux dans des fortifications ou à proximité immédiate, avec des stèles associées, peut laisser supposer un emplacement sur le sitc même, soit antérieurcment à la présence de l'agglomération comme à Entremont., soit à son immédiat abord lors de l'installation primitive du vaste habitat de Glanon. 


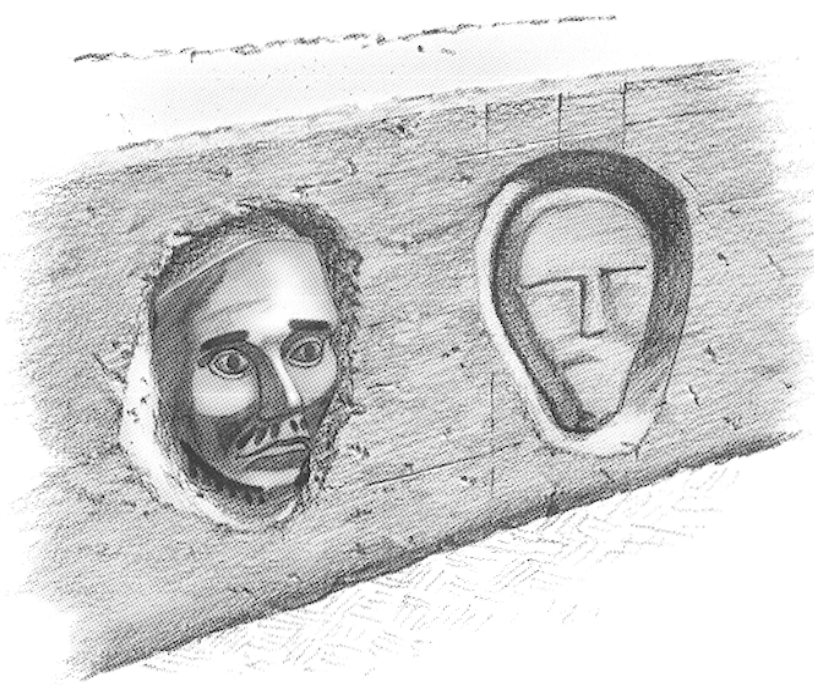

Fig. 117 - Autour du linteau d'Entremont (voir fig. 112), suggestion pour une restitution des "masques-reliquaires", sans doute des modelages réalistes en argile, séchés et peints, sur les parties faciales des crânes honorés (dessin V. Féruglio, pour la MRT du ministère de la Culture et de la Communication).

les rêves (Histoires variées, II, 31). Le phénomène relationnel aux mânes des ancêtres par le songe permet en outre de toucher au divin. Ainsi les Grecs de l'époque hellénistique considèrent que le rêve est un véhicule privilégié de communication avec les dieux (Mangin, 2002, p. 42-43). Comment ne pas envisager de placer ces portiques au centre des journées consacrées aux défunts, celles des trinox Samon du calendrier de Coligny (Lambert, 1994, p. 109-115), les fêtes des trois nuits de Samain de la mythologie irlandaise, celle de l'esprit des morts et des êtres surnaturels (Le Roux, Guyonvarc'h, 1995, p. 35-45).

La fragilité de tels masques n'a guère contribué à leur conservation, dans le Midi comme ailleurs en Gaule (Brunaux, 1997, p. 206-207). Ce sont les témoignages indirects de la sculpture en ronde-bosse qui viennent renforcer cette proposition. D'abord celui du monstre allégorique de Noves. Comme nous l'avons vu plus haut, la bête tient sous ses pattes deux têtes humaines d'aspect singulier (fig. 90c). La lecture de ces parties sculptées montre une séparation volontaire des visages d'avec l'arrière des crânes, soulignée par un ressaut dans la pierre. On peut fort bien lire dans cette réalisation la transcription sur pierre de deux masques surmodelés et décorés (ici disposés sur des crânes complets), tels qu'ils étaient exposés sous les portiques. On s'interrogera ensuite, et après d'autres, sur quelques caractères sculpturaux singuliers de la rcprésentation bicéphale de Roquepertuse (Coignard, Coignard, 1991, p. 30-31; Barbet, 1991, p. 77). Les séparations anguleuses comme les

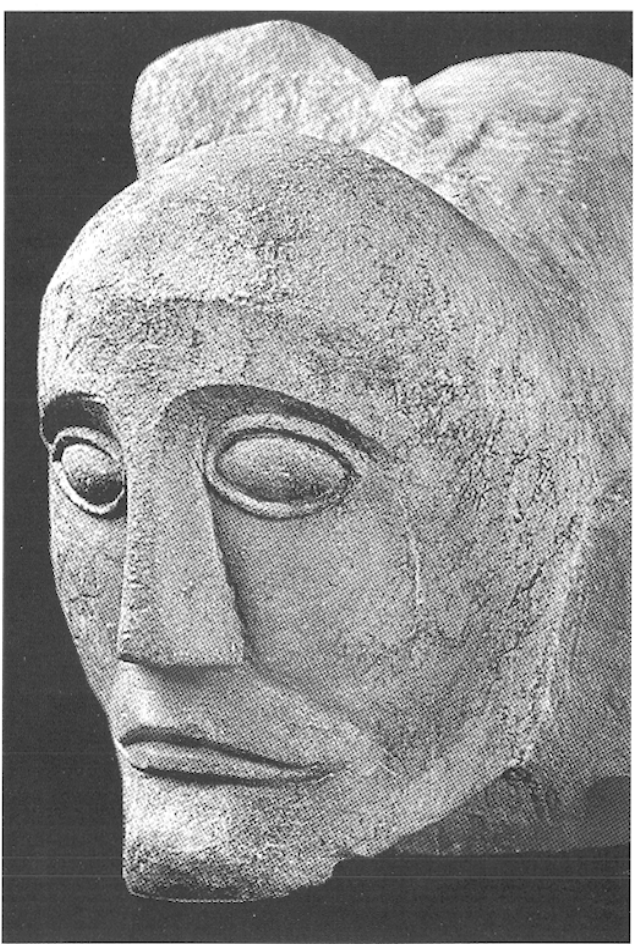

Fig. 118 - Velaux (Bouches-du-Rhône), les visages opposés de l'« hermès " de Roquepertuse présentent une rupture de traitement au niveau du front, avec la formation d'un pli brutal. Au visage régulièrement fini s'oppose un sommet de crâne plus rustique, comme inachequé. Nous serions enclins à yoir dans ces têtes accolées la transposition, sur calcaire peinl, de "masques-reliquaires " modelés par ailleurs sur des restes osseux. La pliure correspondrait à l'arrêt du surmodelage dans le haut du crâne, à l'instar des deux têtes liées à la Tarasque de Noves (fig. 90c). Les "feuilles de gui ", restituées entre les deux têtes, accentueraient le caractère héroïque de ces simulacres de masques (photo A. Chéné et G. Réveillac, CNRS).

différences de traitement entre les visages (lisses) et le sommet des têtes (plus frustes) suggèrent la probabilité d'une simulation en pierre de deux « masques-reliquaires " peints, suspendus et opposés (fig. 118) (Arcelin, à paraître c). Ces deux visages, moustachus et barbus, pourraient être surmontés des feuilles de gui honorifiques (Guillaumet, Rapin, 2000, p. 82).

Qu'elles soient ou non à la source du développement de ces pratiques cultuelles dès le premier âge du Fer, on perçoit tout l'intérêt que les familles aristocratiques ont pu porter ultérieurement à la réalisation et à l'entretien de tels sanctuaires pour consolider leur autorité morale sur les populations dépendantes. Faute de découvertes homogènes en position primaire, on en est réduit à considérer que ces portiques pouvaient être disposés en des points sensibles du territoire ou liés à des propriétés domaniales. Certains ont pu précéder, au premier âge du Fer, de futures agglomé- 


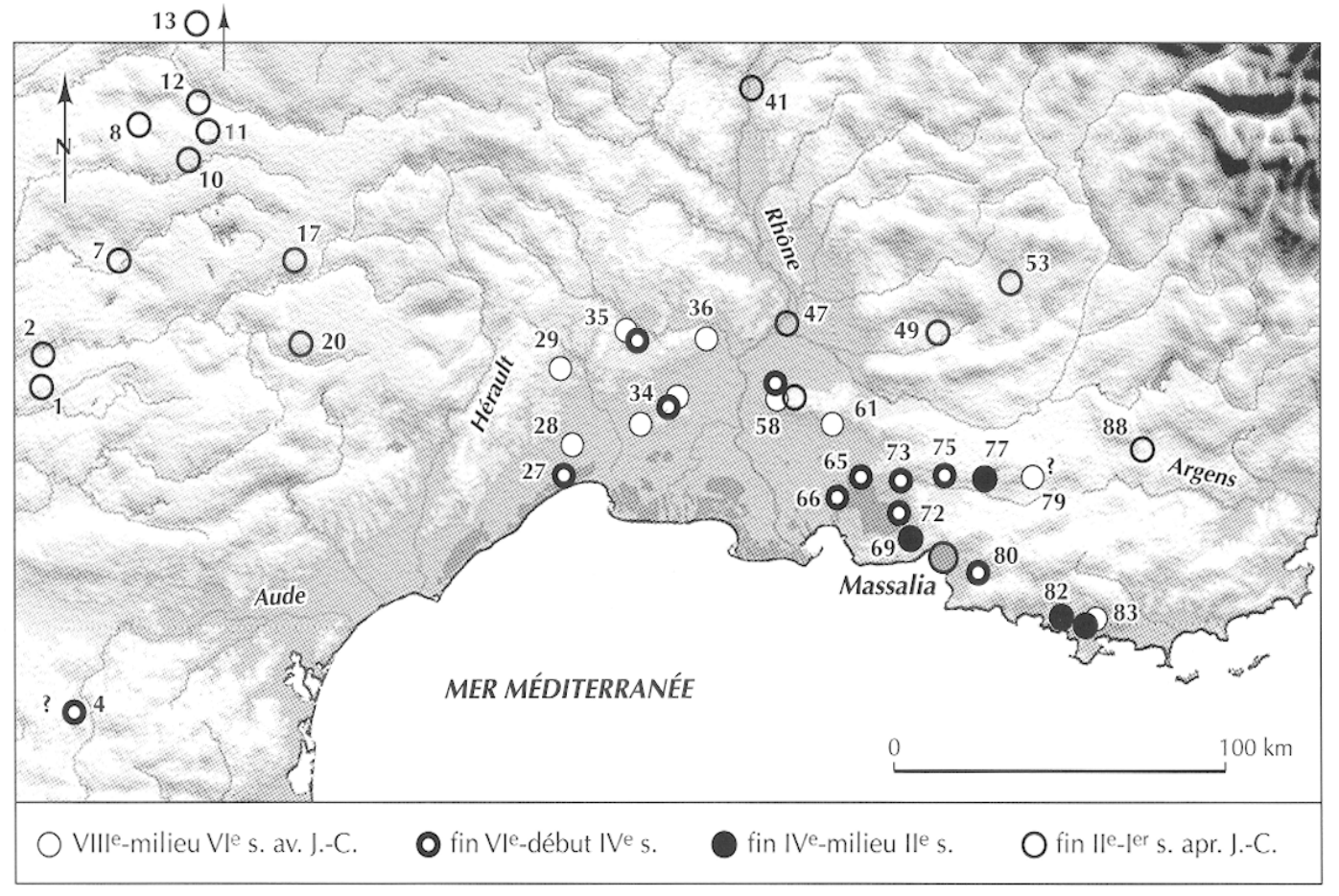

\begin{tabular}{|c|c|c|c|}
\hline$N^{0}$ & Commune & Lieu-dit & Département \\
\hline 1 & Poulan-Pouzols & Le Coutarel & Tarn \\
\hline 2 & Albi & & Tarn \\
\hline 4 & Bouriège & Le Carla & Aude \\
\hline 7 & Centrès & Miramont-la-Calmésie & Aveyron \\
\hline & Saint-Just-sur-Viaur & Miramont-la-Calmésie & \begin{tabular}{|l|} 
Aveyron \\
\end{tabular} \\
\hline 8 & Salles-la-Source & La Robertie & Aveyron \\
\hline 10 & Rodez & & Aveyron \\
\hline 11 & Bozouls & La Devèze d'Ayrebesque & Aveyron \\
\hline 12 & Rodelle & Sainte-Eulalie-du-Causse & Aveyron \\
\hline 13 & Taussac & Passevanneau & Aveyron \\
\hline 17 & Viala-du-Tarn & Valencas & Aveyron \\
\hline 20 & Marnhagues-et-Latour & Le Plô de Maroui & Aveyron \\
\hline 27 & Lattes & Saint-Sauveur & Hérault \\
\hline 28 & Castelnau-le-Lez & Sextantio & Hérault \\
\hline 29 & Corconne & Le Valat de Cremal & Gard \\
\hline 34 & Nîmes & agglomération, Grézan et région & Gard \\
\hline 35 & Sainte-Anastasie & Camp-Guiraud et Castelvielh & Gard \\
\hline 36 & Saint-Bonnet-du-Gard & Le Marduel & Gard \\
\hline 41 & Mondragon & & Vaucluse \\
\hline 47 & Avignon & & Vaucluse \\
\hline 49 & Apt & quartier de La Doa & Vaucluse \\
\hline 53 & Vachères & & Alpes-de-Haute-Provence \\
\hline 58 & Saint-Rémy-de-Provence & Glanon & Bouches-du-Rhône \\
\hline 61 & Mouriès & Caisses et environs & Bouches-du-Rhône \\
\hline 65 & Lançon-Provence & Constantine et Calissanne & Bouches-du-Rhône \\
\hline 66 & Istres & Le Castellan & Bouches-du-Rhône \\
\hline 69 & Les Pennes-Mirabeau & La Cloche & Bouches-du-Rhône \\
\hline 72 & Rognac & Le Clapier et Le Castellas & Bouches-du-Rhône \\
\hline 73 & Velaux & Roquepertuse & Bouches-du-Rhône \\
\hline 75 & Éguilles & Pierredon & Bouches-du-Rhône \\
\hline 77 & Aix-en-Provence & Entremont et Terrain Coq & Bouches-du-Rhône \\
\hline 79 & Puyloubier & Mas du Jasmin & Bouches-du-Rhône \\
\hline 80 & Marseille & Les Baou de Saint-Marcel & Bouches-du-Rhône \\
\hline 82 & Sanary-sur-Mer & Le Mont-Garou & Var \\
\hline 83 & Ollioules & La Courtine & Var \\
\hline 88 & Fox-Amphoux & La Bresque & Var \\
\hline
\end{tabular}

Fig. 119 - Carte de répartition dans le Sud-Est gaulois des expressions de la figuration humaine hérö̈sée et, tardivement, des premières représentations anthropomorphes de divinités (relevé P. Arcelin et $P$. Gruat). 
rations ou les accompagner à leurs périphéries immédiates, près des voies d'accès ou d'un lieu sacré. Dans le cas de Glanon et des aménagements présumés en activité au $\mathrm{II}^{\mathrm{e}} \mathrm{s}$. avant J.-C. à l'extérieur de la porte connue, on pourrait se demander s'il ne s'agit pas de reconstructions résultant du déplacement de familles aristocratiques de leurs domaines ruraux vers ce centre urbain en formation (voir supra).

\section{Statuaire et cultes héroïques}

Nous avons déjà abordé la question de l'apparition d'une figuration humaine naturaliste en ronde-bosse en nous interrogeant sur son rapport probable aux aires consacrées sur les territoires. En effet, aucune de ces pièces sculptées n'a été découverte dans un contexte que l'on pourrait estimer être celui de sa fonction initiale. La quarantaine d'exemples que l'on peut aujourd'hui recenser près de la façade méditerranéenne est composée de portraits en buste et de personnages debouts ou assis, généralement masculins (fig. 119). Ils ont déjà fait l'objet d'inventaires commentés sur lesquels nous ne reviendrons pas directement (Arcelin et al., 1992, p. 220-225 ; Boudet, Gruat, 1992 et 1993; Gruat, 1998, p. 109 ; Arcelin, 2000b, p. 283-286; Arcelin, Rapin, 2003). Toutes les pièces ont été découvertes en position secondaire, soit isolées de tout contexte archéologique relaté, soit en remploi dans un lieu cultuel en tant qu'objets honorćs ou commc simples matériaux de construction, souvent volontairement brisés. Quel que soit le cas de figure, l'analyse de ces expressions anthropomorphes dans la pierre, mais certainement aussi dans le bois et plus modestement dans le métal, peut dorénavant s'appuyer sur les données récentes de l'archéologie, découvertes contextuelles nouvelles (au Marduel) ou reprises de sites anciennement fouillés (à Roquepertuse). Cette approche, toujours en cours, inclut parallèlement un nouveau descriptif comparatif des objets figurés sur les statues où le souci de réalisme des artistes ira croissant tout au long de l'âge du Fer. Grâce à une meilleure connaissance des originaux européens, les pièces de l'armement défensif ou offensif représentées, mais aussi lés bijoux ou les motifs zoomorphes figurés, concourent plus efficacement à la compréhension du discours retransmis par cette statuaire ainsi qu'à sa répartition chronologique. La vision qui en résulte bouleverse désormais bien des certitudes antérieures.

Le meilleur exemple de renouvellement stylistique et chronologique intervenu ces dernières années est lié à la reprise des recherches sur le célèbre "sanctuaire " de Roquepertuse à Velaux, en parallèle au réexamen des découvertes anciennes. Depuis la monographie initiale des premières recherches (Gérin-Ricard, 1927), le site était perçu, voici seulement une décennie, comme un lieu cultuel sur le territoire, établi au cours du second âge du Fer. Détruit vers 200 avant J.-C., il aurait succédé à des habitats plus anciens, du Néolithique au premier âge du Fer. L'implantation singulière sur un ëtroit plateau et dans un vallon mitoyen, peu défendable, paraissait s'expliquer par la nature spécifique de l'implantation, un lieu cultuel établi en un milieu relativement ouvert. La reprise des fouilles en 1994 par B. Lescure, puis P. Boissinot (voir infra notice 7, p. 238-241), apporte désormais une tout autre vision du site, à la fois mieux précisée sur le plan des séquences stratigraphiques et de leur chronologie, mais aussi bien plus complexe si l'on tente de concilier les données archéologiques et celles de la stylistique, apparemment contradictoires. De plus les statues de personnages assis en tailleur, comme les éléments d'un portique décorés et d'autres sculptures anthropomorphes ou zoomorphes, ne sont pas sans poser de problèmes pour leur insertion dans la phase majeure de l'habitat fortifié reconnue au III ${ }^{\mathrm{e}} \mathrm{s}$. avant J.-C. (Boissinot, Lescure, 1998; Boissinot et al., 2000 ; Guillaumet, Rapin, 2000). Sans discuter ici de l'interprétation du site au second âge du Fer, des dissensions sc font jour autour des pièces sculpturales et architecturales découvertes au début du siècle mais qui malheureusement n'ont pas pu être totalement résolues par les nouveaux contextes stratifiés. Une double proposition se fait jour à la croisée des informations disponibles. Un premier ensemble est à rapporter au $\mathrm{V}^{\mathrm{e}} \mathrm{s}$. de par l'iconographie, en particulier l'armement défensif. Il inclut les statues de personnages masculins assis (quatre anciennement découvertes, fig. 121b ; et au moins les fragments de quatre à cinq autres) et, sans doute, les têtes jumelées. Un second ensemble serait à rattacher aux aménagements reconnus de la première moitié du III ${ }^{c}$ s. : les éléments du portique peint, des figurations zoomorphes en bas-relief ou en ronde-bosse. Si les statues de personnages princiers assis étaient toujours exposées dans l'installation domaniale du III' s., comme le supposent les fouilleurs, il nous faut admettre leur conservation et leur usage durant près de deux siècles !

Ciette dernière proposition qui peut choquer la vision parfois trop séquentielle de l'archéologue, n'en est peutêtre pas moins une réalité si l'on considère deux autres exemples dans l'iconographie méridionale récemment publiés (Guillaumet, Rapin, 2000, p. 81-83 ; Rapin, 2002 ; Arcelin, Rapin, 2002, 2003). L'analyse des productions sculptées du second âge du Fer passe inévitablement par l'ensemble majeur d'Entremont dont l'essentiel des pièces a été publié (Benoit, 1969a, p. 40-44 et 1969b, p. 51-99; surtout Salviat, 1987). Les statues découvertes concassées, en remblai dans le dernier radier de voie en arrière de la porte principale du second habitat (123-100 avant J.-C.) (Arcelin et al., 2001), sont au nombre de plusieurs dizaines 
et grandeur nature. Elles étaient peut-être exposées dans ce secteur du site, en bordure de la voie d'accès relativement monumentalisée. L'iconographie comporte la désormais traditionnelle représentation de personnages masculins assis en tailleur (ou position du Bouddha), mais aussi le thème du cavalier et la présence de femmes assises sur des sièges bas. Un adolescent en pied est possible. Avec cette diversification des figurations, l'autre grande nouveauté de ce groupement majeur de sculptures est le réalisme poussé des rendus, tant physiques que vestimentaires, ainsi que dans la parure et l'armement, désormais aussi offensif. Cette statuaire parait détruite à l'issue d'un premier siège de l'agglomération, vers 123. Même en admettant que ces sculptures soient présentes sur le site dès le premier habitat, elles ne pourraient remonter au-delà des premiers documents archéologiques datés des années 180-170 avant J.-C. Cette fourchette chronologique probable de l'exposition des statues (180-123 avant J.-C.) avait inféré celle de leur création. Un réexamen complet de l'équipement figuré sur ces œuvres montre désormais sans ambiguité que l'âge de leur fabrication est bien antérieur, étalé entre le début du III $^{e}$ s. et le début du suivant. Deux conclusions s'imposent : ces représentations sont celles de l'aristocratie du $\mathrm{III}^{\mathrm{e}} \mathrm{s}$., equiles mais aussi leur famille. À côté des accroupis désormais entourés de têtes coupées, trophées de leurs victoires, cette élite se fait représenter en position de réception (de leurs ambacts) et en couple, ou pour les hommes, à cheval et en armes.

Un deuxième exemple vient pleinement conforter la réalité des forts décalages chronologiques qui peuvent exister entre le moment du travail sur l'œuvre puis son utilisation initiale, et celui de son éventuelle réutilisation, puis de sa destruction. Le petit village perché de La Cloche aux Pennes-Mirabeau, près de Marseille, est précédé d'une occupation cultuelle et sporadique au III $\mathbf{s}$. (Chabot, 1996). L'habitat d'environ 0,5 ha est implanté au début du $\mathrm{II}^{\mathrm{e}} \mathrm{s}$., suivi d'une reconstruction et d'un agrandissement global au début du I ${ }^{\text {er }} \mathrm{s}$. C'est une destruction violente qui scelle le gisement archéologique vers 50 avant J.-C. De larges fragments d'une statue représentant un personnage masculin assis ont été retrouvés dans l'horizon de cette ultime destruction (Chabot, 1983, p. 74, fig. 55). Dans un tel contexte bien daté, l'attribution de la statue à la fin du II $^{\mathrm{e}}$ ou au début du I ${ }^{\text {er }}$ s. avant J.-C. semblait évidente il y a encore quelques années. Pourtant, une des mains de cette œuvre porte la représentation d'une bague serpentiforme d'un type bien connu à Münsingen-Rain au début du $\mathrm{III}^{\mathrm{e}} \mathrm{s}$. (Chabot, 2000, p. 165, fig. 9 ; Hodson, 1968, 24, tombes 84, 102,126 , etc.) ! Il convient désormais de rattacher cette pièce à un même horizon chronologique que celui d'Entremont. Récupérée sans doute dans l'habitat du $\mathrm{II}^{\mathrm{e}} \mathrm{s}$. ou hors du site au moment du dernier réaménagement, cette œeuvre vieille de deux siècles est conservée (mais dans quel état?) au sein d'une communauté villageoise implantée aux marges de la chôra marseillaise. Sans doute sa signification n'est-elle plus tout à fait la même ici que lors de sa première exposition. Mais son contenu spirituel est tel que la prégnance de son pouvoir a dû se maintenir suffisamment fort en regard des croyances traditionnelles de la communauté pour continuer à symboliser le lignage prestigieux d'une famille de l'aristocratie régionale.

Des cas précédents, la recherche archéologique doit prendre acte de la "normalité " de telles distorsions et l'intégrer dans son mode de raisonnement. Les objets cultuels à forte connotation "politique " que sont les œuvres de cette nature ont été conservés le plus longtemps possible. Cette durée rend compte en elle-même de la puissance contraignante de ces représentations et de la réalité de leur impact sur les populations concernées.

Les publications récentes mettent en valeur quatre grandes étapes dans l'évolution de la sculpture anthropomorphe du Midi méditerranéen. Nous les résumerons brièvement.

- La première phase est celle de l'éclosion d'une figuration réaliste de guerriers héroïsés, peut-être dès la transition bronze-fer ou le début du premier âge du Fer (du milieu du VIII au milieu du VI ${ }^{e}$ s. avant J.-C.). La filiation aver la Préhistoire récente pourrait être assurée par les représentations de cavaliers de Mouriès ou de Glanon, mais aussi la stèle en micaschiste de Durenque (Aveyron). Par les objets représentés, elle évoque les statues-menhirs du

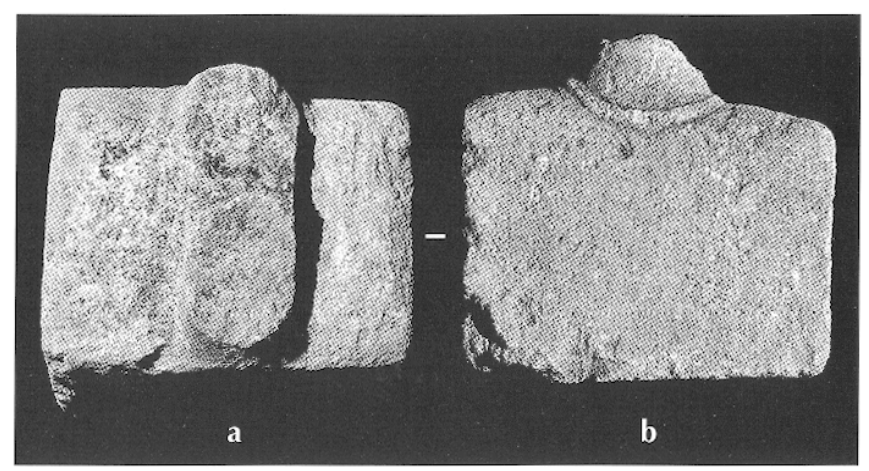

Fig. 120 - Saint-Bonnet-du-Gard (Gard), Le Marduel. Buste et amorces des cous de deux têtes humaines géminées. Présence d'un torque fermé à la base de l'un des cous. Sous le socle, un trou de mortaise laisse envisager la présentalion du buste au sommet d'un pilier. Découvert en remploi au début du $V^{k}$ s. av. J.-C., ce bloc offre pour la première fois un terminus ante quem au moment des premières manifestations de l'iconographie monumentale à caractère réaliste ( $L$. : 0,34-0,36 m; H. cons. : 0,28 m;ép. : 0,25-0,26 m) (photos musée archéologique de Nîmes). 


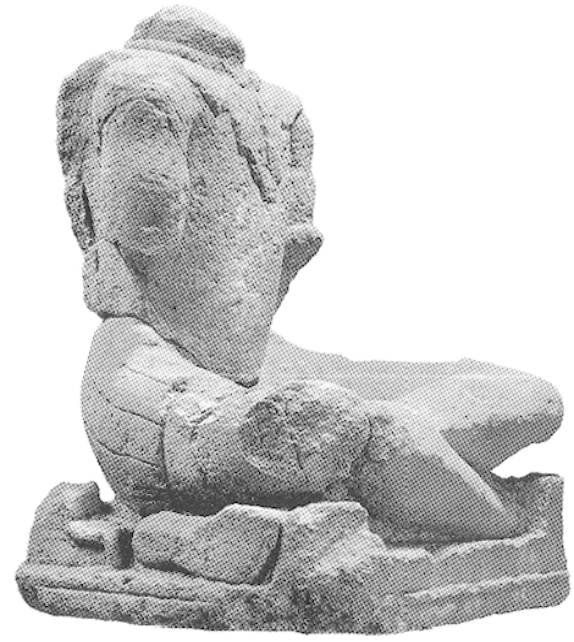

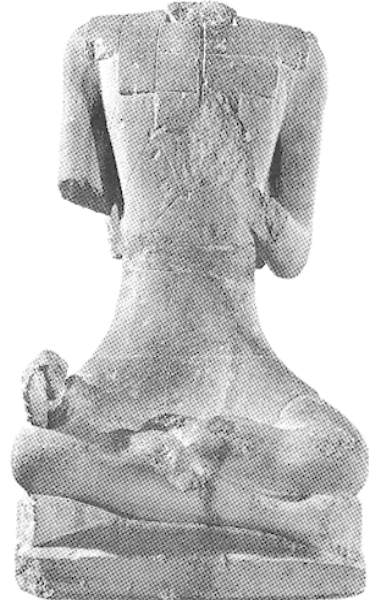

b

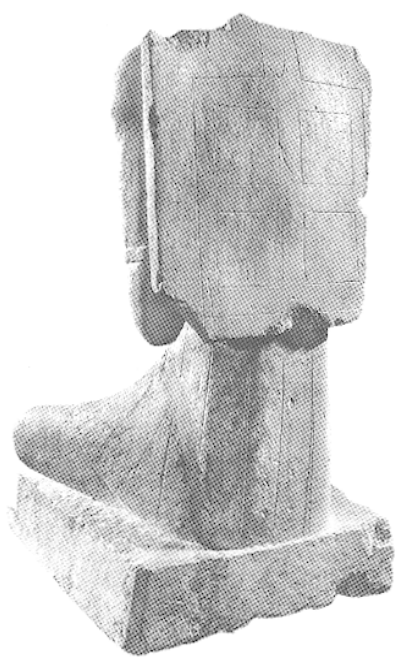

Fig. 121 - Deux des statues de personnages assis, portant une cuirasse dorsale à dossière et couvre-nuque. Celle de Glanon à Saint-Rémyde-Provence (a) fail partie d'un lot de trois découvertes à proximité de deux édicules cultuels (voir fig. 137 et 138). De par leurs socles à acrotères, elles peuvent dater des dernières années $d u V^{*} s$. ou de l'amorce du V s. (H. : 0,80 m). D'autres représentations de Roquepertuse, à Velaux $(b)(H .: 0,98 \mathrm{~m})$, sont plus simples, avec une base plane et un sexe désormais voilé. Courant du V' s. av. J.-C. (photos A. Chéné et $G$. Réveillac, CNRS).

groupe chalcolithique du Rouergue. Mais la tête est ici bien dégagée, assez proche des stèles nord-italiques de Lunigiane, notamment des groupes B ou C d'Ambrosi, datés désormais de la fin de l'âge du Bronze (D'Anna, 2002, p. 202-203 et 216-217). Ce sont les représentations en buste qui apparaissent au cours de cette première phase. Ce mode iconographique est un phénomène bas-rhodanien, réparti pour l'essentiel sur la rive droite du fleuve (fig. 119). Cette émergence régionale n'est pas strictement côtière mais répartie sur le pourtour des plaines. Le savoir-faire des artisans, s'il se veut précis dans les représentations, demeure encore malhabile, sans doute dans la continuité du travail sur bois. Les exemples publiés de Sainte-Anastasie (voir supra, fig. 97) (Py, 1990, p. 816-819), de Corconne (Chazelles, 1991, fig. 3 à 5) ou du Marduel (fig. 120) (Py et al., 1994, fig. 55) montrent un large éventail chronologique depuis l'extrême fin du Bronze (Corconne), et stylistique (dans les casques en particulier). La dignité comme le haut rang des personnages sont soulignés par la figuration des torques, de leurs cuirasses ou l'adjonction de symboles forts comme celui du cheval ou de la trompe de guerre. La polychromie est clairement attestée. La découverte du Marduel est non seulement majeure par son information de nature chronologique, mais aussi par le caractère double du portrait. Ce dernier trait permet de relier la pièce au groupe septentrional européen du début de l'âge du Fer et de la rapprocher de l'œuvre du Holzgerlingen, Bade-Würtemberg (Bittel, Kimmig, Schiek dir., 1981, pl. 32). Un autre type morphologique apparaît certainement avant le milieu du VI' s., c'est celui du guerrier debout. Il est magnifiquement illustré par l'œuvre hiératique découverte au Grézan, près de Nîmes. Le personnage est revêtu d'une cuirasse à cardiophyllax et d'une large ceinture à crochet proche de formes italiques (Py, 1990, p. $813-815$, doc. $280-281$ ).

Ce premier groupe méridional s'insère désormais bien mieux dans le courant iconographique de l'âge du Fer ancien de l'Europe occidentale (Bonenfant el al., 1998, p. 43-65 ; Frey, 2002).

- La deuxième grande rupture est marquée par la transformation formelle de l'iconographie, dans ses thèmes et ses acquis technologiques, et un déplacement des régions concernées par le phénomène (fig. 119). Ce mouvement, encore très mal cerné, doit sans doute se situer vers la fin du $\mathrm{VI}^{\mathrm{e}} \mathrm{s}$. avant J.-C. et recouvrir tout le $\mathrm{V}^{\mathrm{c}} \mathrm{s}$. (Rapin, 1999, p. 37 ; Guillaumet, Rapin, 2000, p. 80 ; Rapin, 2002 ; Arcelin, Rapin, 2003). Il est sans conteste lié au développement des relations entre les sociétés de la basse vallée du Rhône et le monde grec de Marseille, alors en pleine expansion commerciale. Les artisans celtes maîtrisent désormais plus complètement un outillage métallique évolué. Une certaine connotation allochtone est perceptible dans les acrotères encadrant le support servant de siège honorifique aux personnages héroïsés, dès lors systématiquement représentés assis en tailleur, signes du pouvoir en main, une position hiératique et idéalisée. Comme l'a souligné A. Rapin, 


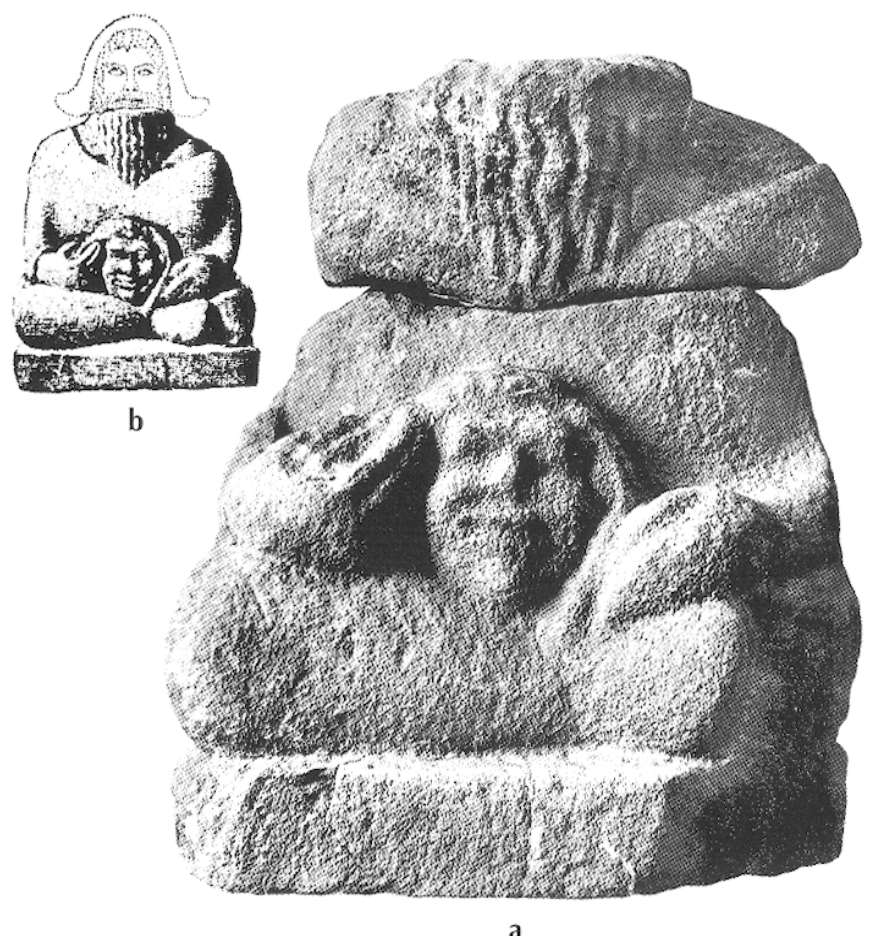

a

Fig. 122 - Sculpture découverte à Bouriège (Aude), au lieu-dit Devant la Ville, au pied du Carla (a) (H. cons. : 0,55 m). Elle était profondément enfouie dans un secteur de forte occupation aux $V^{P}$ et $I^{P}$ s. av. J.-C., puis durant la période protoromaine. Exhumée en totalité vers 1.920, l'cuurre possédait une tête portant moustache et longue barbe, aux cheveux bouclés et recouverte d'une "coiffe enveloppante "; elle a depuis disparu ( $b$; d'après Barruol et al., 1961, fig. 2). Fin du premier âge du Fer ou début du second (photo G. Barruol, CNRS; dessin N. Calabro).

plusieurs critères suggèrent une évolution entre la fin du $\mathrm{VI}^{\mathrm{e}}$ s. et le courant du $\mathrm{V}^{\mathrm{e}}$ s. Les accroupis de Glanon (fig. 121a), avec socle à acrotères et sexe apparent sous la tunique entrouverte, pourraient illustrer la production ancienne. On a déjà largement souligné les caractères très celtisants du couvre-nuque de la cuirasse dorsale et ses parallèles avec celle du prince du Glauberg. D'autres exemplaires de Roquepertuse semblent plus évolués, sexe couvert et suppression des acrotères facilitant le positionnement des jambes repliées (fig. 121b). Plus d'une vingtaine de statues de ce type sont connues dans la basse vallée du Rhône, sans contexte d'origine assuré (Arcelin et al., 1992, p. 221-225, groupe I). Gravures de repérage et polychromie conservées permettent de restituer aisément le rendu de la richesse décorative des tissus celtiques et du dosseret de la cuirasse. Elles illustrent à merveille les progrès de l'artisanat indigène et l'existence d'une élite puissante, fortement enrichie par son implication dans le commerce méditerranéen. On pourrait être tenté de rattacher à la fin de cette période (ou au début du second âge du Fer) la figuration du personnage assis en tailleur, exhumée près du Carla de Bouriège (fig. 122) (Barruol et al., 1961). C'est un exemple non seulement très isolé en Languedoc occidental, mais aussi singulier par la tête figurée qui n'est pas forcément le reliquat d'un rituel de victoire (voir supra). Anciennement découverte hors de tout contexte archéologique, cette cuvre originale est peut-être plus archaïsante qu'archaïque. Le type du casque la rattacherait volontiers aux réalisations de la phase primitive, mais la position accroupie est celle qui prévaut à partir de la fin du premier âge du Fer. La récente découverte de traces d'un habitat du $\mathrm{V}^{\mathrm{e}} \mathrm{s}$., non loin du lieu de la découverte, pourrait faire préférer la seconde proposition.

- Après un siècle au moins de restructuration des rapports entre Grecs et communautés celtiques du Midi, l'affirmation d'une classe aristocratique et guerrière se lit pleinement autour de la ville grecque par le renouveau d'une statuaire héroïque dès les alentours de 300 avant J.-C. (fig. 119). Secteur de création circonscrit à l'arrière-pays de Marseille et du proche littoral provençal, période de production limitée aux III $^{\mathrm{e}}$ et début du $\mathrm{II}^{\mathrm{e}}$ s. avant J.-C., semblent rattacher cette statuaire à la seule confédération des Salyens. Mieux, plus des deux tiers des œuvres inventoriées proviennent du seul habitat d'Entremont. Une récente analyse critique de ces dernières statues (Arcelin, Rapin, 2002) montre le souci du réalisme dans ces représcntations dc héros assis, désormais armés et entourés de trophées humains (fig. 123). Elle montre d'autre part le glissement manifeste du concept héroïque à connotation religieuse, qui était celui de la phase précédente, vers une valorisation plus directe des familles aristocratiques. Nous sommes désormais en présence de dunastai, assis en position de réception ou à cheval, en simulacre de leur fonction guerrière; ils sont entourés de leurs compagnes assises, voire peut-être même d'un jeune héritier désigné. La part du profane et du pragmatisme politique, aspect hérité des contacts développés de longue date avec le monde méditerranéen, prend désormais le pas sur l'idéalisation plus spiritualiste antérieure.

- Les guerres de la seconde moitié du $\mathrm{II}^{\mathrm{e}} \mathrm{s}$. contre Marseille et Rome, la décapitation de l'aristocratie salyenne traditionaliste après 123 avant J.-C., marquent du même coup la fin de ce mode de valorisation. L'importance des transformations qui se font jour alors accompagne une véritable protoromanisation culturelle qui durera jusqu'aux installations coloniales du troisième quart du $\mathrm{I}^{\mathrm{er}} \mathrm{s}$. avant J.-C. Partout et par étapes, les caractères celtisants seront recouverts par une expression formelle plus gréco-italique des pratiques religieuses, même si la part indigène reste vivace, présente en symbiose avec elle (fig. 124). La statuaire $\mathrm{du} \mathrm{I}^{\mathrm{cr}}$ s. avant $\mathrm{J}$.-C. et ses prolongements au $\mathrm{I}^{\mathrm{er}} \mathrm{s}$. de notre ère 


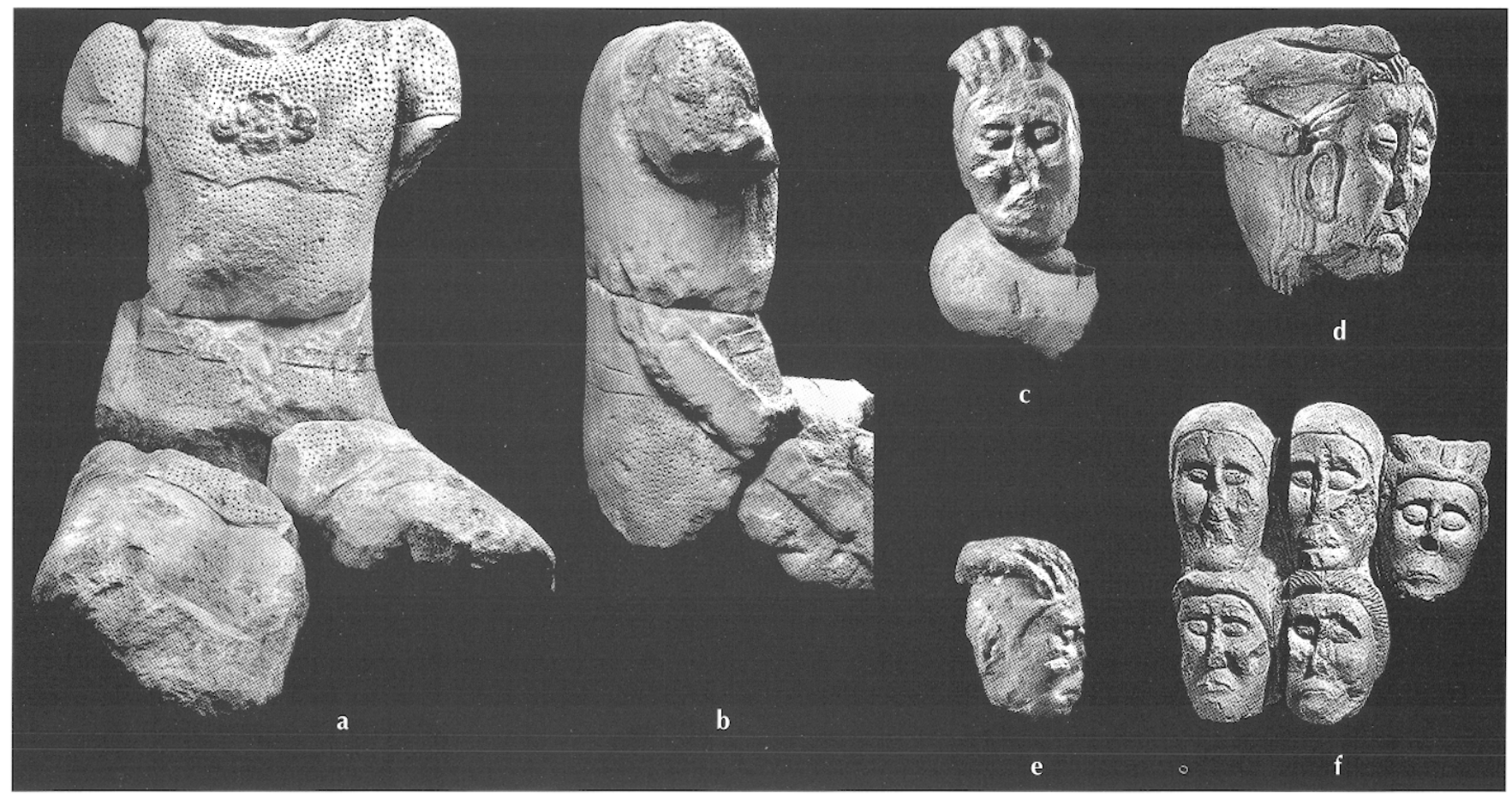

Fig. 123 - Aix-en-Provence (Bouches-du-Rhône), Entremont : les torses de personnages assis (a) (H.: 0,83 m), associés à l'observation du détail de leur armement (b) et des trophées humains accumulés ( $c$ à $)$, aident à comprendre le sens de la représentation du héros dans les sociétés méridionales. En Provence occidentale, au III s. av. J.-C., c'est le réalisme baroque de l'iconographie et l'exallation récurrente de la bravoure guerrière qui prévalent (photos $M$. Olive, SRA PACA et A. Chéné, G. Réveillac, CNRS).

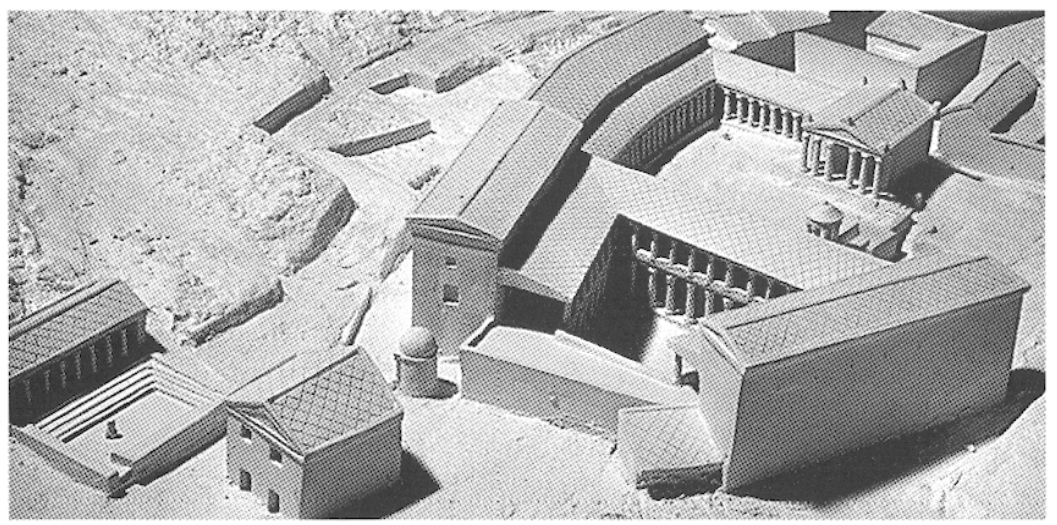

a

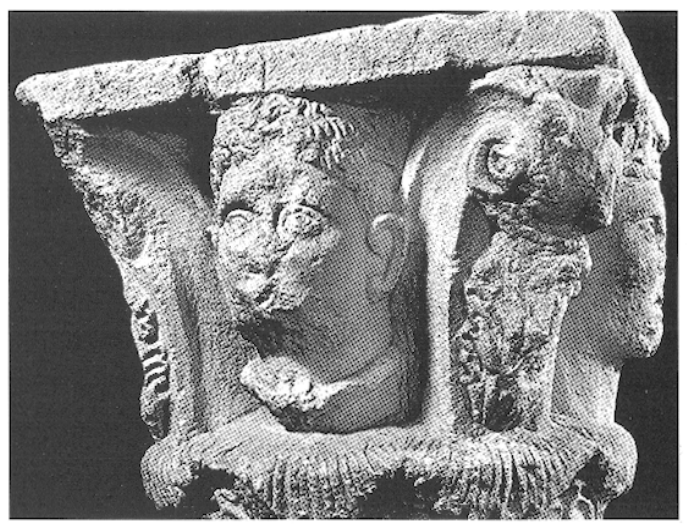

b

Fig. 124 - De profondes mutations interviennent au sein des populations indigènes du centre de la basse vallée du Rhône après le milieu du II ${ }^{e}$. av. J.-C. Elles se manifestent en particulier par l'émergence des premiers centres urbains, avec les signes architecturaux d'une affirmation politique sur les territoires de proximité. L'exemple incontournable est celui du centre monumental de Glanon à Saint-Rémy-de-Provence (Bouches-du-Rhône) (maquette a). L'érection de plusieurs temples hexastyles de type toscan ou les premières représentations anthropomorphes de divinités celtiques, comme ici dans l'iconographie des chapiteaux (b), montrent une transformation au moins formelle des pratiques culluelles, sans préjuger du degré de renoncement aux croyances naturalistes antérieures (photos A. Chéné et G. Réveillac, CNRS).

vont perdre leur originalité antérieure. La frange littorale, soumise à une forte emprise coloniale italienne dès l'extrême fin du $\mathrm{II}^{\mathrm{e}} \mathrm{s}$. ou le début du suivant, devient par excellence l'aire de la romanisation la plus active, dans ce domaine comme en d'autres. Ce sont les régions plus reculées qui conservent les traits les plus celtisants dans l'expression sculpturale d'alors (Boudet, Gruat, 1992 et 1993). La figuration du héros persiste même si elle est 
condamnée à être recouverte par celle d'une divinité qui pourra, à son tour, s'insérer quelques décennies plus tard au sein des premiers fana. En reprenant la forme ancienne de la stèle, l'excmplairc du Coutarel à Poulan-Pouzols, de 0,91 m de hauteur, présente une coiffure faite de nattes torsadées et le sujet porte un torque à tampons dissymétriques autour du cou. Les scènes animales sculptées sur le dos évoquent celles de la statue d'Euffigneix (HauteMarne). Les autres représentations, parmi les plus complètes, constituent un groupe relativement homogène. Elles prennent appui sur un dé grossièrement équarri, ainsi à Bozouls (fig. 98), à l'hôpital de Rodez (fig. 96a) ou au Plô de Maroui (fig. 96b). Seule la partie supérieure est figurée et l'on relève des traits stylistiques communs et récurrents : yeux en amande, nez trapézoidal, coiffure et parfois moustaches soignées, attributs symboliques (torque, poignard). Les contextes, lorsqu'ils sont documentés, sont postérieurs à la fin du II ${ }^{\mathrm{e}}$ s., sauf peut-être pour la stèle de Bozouls.

Dans l'amorce de la moyenne vallée du Rhône et l'intérieur de la Provence, le thème du guerrier va persister mais dans une esthétique plus romanisée. Les représentations en armes de Fox-Amphoux, de Mondragon ou de Vachères sont celles d'auxiliaires figurés en pieds, revenus sur leurs domaines ruraux après leur temps de service dans l'armée (Barruol, 1996). Le thème ancien du héros artistocratique d'Entremont survit ici, certes dans une version romanisée sur le plan du maintien et de l'équipement, mais dans la tradition des sanctuaires domaniaux plus anciens que nous avons pressentie.

\section{DE LA PIÉTÉ À L'IMPLICATION SOCIALE}

Des images qui prennent corps de l'inventaire qui précède, les Celtes méridionaux apparaissent tout autant respectueux des divinités que le sont les populations plus septentrionales, mêlant comme ces dernières la piété et la dévotion aux démarches propitiatoires circonstancielles, voire à la magie. Aux cultcs voućs aux dieux en des lieux désignés par ces derniers s'adjoignent ceux rendus aux hommes divinisés. La place du héros, sans être nouvelle au premier âge du Fer, prend une ampleur en rapport avec le développement social de l'époque, la structuration hiérarchisée des sociétés et l'émergence d'une élite enrichie près du littoral comme dans les basses vallées de l'Aude et du Rhône. Dans ce processus, l'implication de la part économique et des réseaux de commercialisation avec le monde méditerranéen est essentielle pour juger de l'importance et de la localisation des transformations intervenues ou non dans la nature de l'expression cultuelle, de ses choix formels, voire de la portée de sa monumentalisation. Le second âge du Fer est l'époque de l'aboutissement des tendances amorcées antérieurement, marquée cependant par de plus grandes différenciations entre régions dans la manifestation concrète d'une réelle dichotomie culturelle entre conservateurs et progressistes au sein des élites dirigeantes.

Si l'on tente de résumer les traits dominants de ce bilan, on dégagera d'abord une série de caractères qui vont dans le sens d'une permanence des traditions depuis la fin de la Préhistoire, avec une adaptation élémentaire aux évolutions sociales, économiques et politiques des sociétés jusqu'à la romanisation du $\mathrm{I}^{\mathrm{er}} \mathrm{s}$. avant J.-C. À partir de la seconde moitié du VIc s., l'amplification des ressources technologiques dans l'artisanat, près des zones de contact avec le monde méditerranéen, sera déterminante dans l'évolution des savoir-faire antérieurs, ainsi dans le travail de la pierre pour la formalisation des représentations anthropomorphes ou zoomorphes qui révèlent le goût d'un réalisme accru. Mais par-delà cette osmose de contact, un des caractères récurrents jusqu'au $\mathrm{II}^{\mathrm{c}} \mathrm{s}$. avant J.-C. est celui de la persistance affirmée des traits celtiques dans les croyances religieuses et leurs diverses implications dans la vie sociale.

Sur cette continuité des cultes et de leurs expressions, se superposent par étapes, sans les remplacer totalement, des évolutions plus radicales répondant aux mutations sociales des peuples et des communautés qui vivent en agglomérations. Mais si l'on saisit mieux désormais que ces dernières deviennent les vecteurs de la transformation des pratiques cultuelles anciennes, seules celles pleinement insérées dans la dynamique culturelle méditerranéenne seront les moteurs du processus évolutif.

\section{DES PERMANENCES SOGIOCULTUELLES}

La pratique des cultes recouvre pleinement les caractères des sociétés et en l'occurrence leur structuration fondamentalement rurale, c'est-à-dire, chez les Celtes méridionaux, la place majeure qu'occupent les territoires entre les habitats groupés. Même si ces derniers composent une part importante dans l'organisation socio-économique, de même que les ports et les comptoirs de redistribution des produits méditerranéens, la grande majorité des habitats méridionaux conserve tous les traits de la ruralité, en perpétuant les caractères de bourgades ou de bourgs constitués pour l'essentiel de paysans et de petits artisans. On recherchera en vain dans ces agglomérations des lieux de regroupements à connotation politique (concilia) ou religieuse. C'est au mieux sur les territoires proches que l'on peut espérer découvrir les vestiges de tels espaces indispensables tant aux foires de l'échange (futurs fora de l'époque romaine) qu'aux décisions politiques et aux manifestations 
des pratiques religieuses et/ou festives. L'importance relatée par les récits anciens de ces grands enclos entre les agglomérations et près des voies les reliant recoupe pleinement le silence dominant de ce point de vue dans l'habitat jusqu'au $\mathrm{II}^{\mathrm{e}}$ s. avant J.-C. On perçoit mieux également, ici comme dans l'ensemble de la Gaule, que les centres décisionnels ne recouvrent pas directement la distribution des plus vastes de ces agglomérations, encore une fois avec les réserves précédemment énumérées. Les caractères propres aux élites aristocratiques du $\mathrm{V}^{\mathrm{e}}$ au $\mathrm{II}^{\mathrm{c}} \mathrm{s}$. avant J.-C., familles tirant leur profit du commerce mais tout autant que des ressources foncières, hommes dévolus aux fonctions guerrières dans la cavalerie, les obligent à demeurer au plus près de leurs propriétés de rapport et de leurs dépendants, du stockage pour l'échange et des haras indispensables. En balance avec le poids de l'économie des agglomérations, une large part du pouvoir décisionnel devait résider dans ces propriétés domaniales, pour certaines seulement de grosses fermes, pour d'autres de véritables villages regroupant les dépendants immédiats de la maisonnée.

Dans cette vision globalement rurale du mode de vie des populations, les sites naturels remarquables des territoires sont par excellence des lieux cultuels potentiels pour peu qu'ils aient été marqués par l'empreinte d'une divinité. Nous avons vu l'importance que revêtent les sources et cours d'eau ou encore les emplacements de hauteur. Les lieux cultuels sont généralement modestes, de même que les offrandes déposées. Ces pratiques dévotionnelles concernent tout autant les puissances ouraniennes que chthoniennes. Nous avons illustré, par exemple en Aveyron, les offrandes cachées loin de la lumière du jour, en grotte et en aven. Ces rituels se poursuivent au long de l'âge du Fer. Si les dépôts sont parfois plus discrets au début du second âge du Fer, moment de grand développement des habitats groupés, les transformations qui interviennent à partir de la fin $\mathrm{du} \mathrm{II}^{\mathrm{e}}$ s. dans la nature de l'occupation des sols (redéploiement rural incluant par zones une part coloniale italienne) pourront parfois redynamiser des sanctuaires ruraux antérieurs. Nombre de ces derniers survivront sous le Haut-Empire, voire jusqu'à la fin de l'Antiquité tardive.

Au côté des lieux étranges ou inquiétants, les hommes protohistoriques ont consacré à leurs dieux des aires matérialisées, du modeste nemeton à de bien plus vastes, capables de recevoir d'amples populations. C'est généralement sous la forme d'enclos palissadés et fossoyés que ces espaces sont matérialisés. Bien connues en Gaule depuis le Néolithique, remarquablement développées au cours du Bronze, ces pratiques se poursuivent à l'âge du Fer. Le Midi méditerranéen montre des comportements similaires pour des actions cultuelles les plus diverses, en relation avec le milieu funéraire ou non. Mieux, cette tradition très celtisante de délimitation d'une aire circulaire ou plus grossièrement ovalisée en fonction de la nature du terrain peut être reprise dans des aménagements tardo-hellénistiques en grand appareil monumentalisé, phénomène d'osmose culturelle très signifiant des évolutions au cours de la période « protoromaine " du I ${ }^{\mathrm{er}} \mathrm{s}$. avant J.-C. Le cas brièvement analysé de l'enclos bâti autour de l'ouverture d'un aven sur le plateau de Constantine et au sein d'une agglomération demeure assez exceptionnel. On retiendra seulement ici la pérennisation d'un système de délimitation traditionnelle de l'aire consacrée et, par-delà cet exemple exceptionnel, le témoignage de la vivacité d'une telle pratique sur le plan régional jusqu'à la pleine romanisation. D'ailleurs au travers des récits de Poseidonios, nous avions rappelé le rôle majeur de ces enclos, parfois très vastes, ainsi que la diversité de leur fonction.

Le réexamen de la question des stèles, à défaut de préciser leur fonction exacte, confirme globalement leur rôle votif et leur chronologie haute dans l'âge du Fer, sans doute pour la plupart avant la fin du $\mathrm{VI}^{\mathrm{e}}$ s., voire bien plus tôt pour certaines, dès la transition avec l'âge du Bronze. Elles devaient être assemblées sur des aires consacrées en divers points du territoire. Les cas de Glanon et de Graveson, près de résurgences pérennes, laissent présager une dévolution à la divinité des eaux, Belenos/Bellinto.

\section{LE PASSAGE DU CULTUEL À LA VALORISATION SOCIALE}

Sur les territoires mêmes, la définition d'une élite sociale dans la formation des communautés du premier âge du Fer, puis sa structuration en classe dominante aristocratique à partir du IV ${ }^{\mathrm{e}}$ s., vont engendrer l'apparition de sanctuaires qui, sans être totalement nouveaux, n'en sont pas moins désormais conceptualisés en tant qu'outil social. Nous avons séparé deux ensembles de pratiques qui, l'un comme l'autre, apparaissent très tôt liés aux familles possédantes et à leur valorisation.

Ce sont d'abord les portiques à piliers et linteaux monolithes en pierre qui, dès le tout début du premier âge du Fer, doivent accueillir des reliques d'ancêtres sous la forme de crânes complets ou, plus sûrement, de masques faciaux reconstitués et peints au naturel. Ces véritables « masquesreliquaires " étaient enchâssés dans des entailles céphaliformes, disposées au sein de décors géométriques et zoomorphes polychromes, hautement symboliques et édifiants. Des stèles semblent avoir participé de leur accompagnement dévotionnel. La séparation de cette pratique d'avec celle des trophées de victoire prélevés sur le champ de bataille doit être clairement soulignée. 
Ces mêmes familles dominantes sont certainement à l'origine d'une statuaire héroïque, tôt dans le premier âge du Fer et dans l'aire de la basse vallée du Rhône. Comme pour lcs portiques contemporains, ces réalisations en rondebosse, désormais mieux réparties sur le plan chronologique, n'ont jamais été observées dans leurs contextes initiaux qui semblent pourtant essentiellement ruraux. Plusieurs exemples permettent d'affirmer une longue utilisation de cette iconographie, éventuellement pendant plus de deux siècles et, dans le cas d'Entremont au moins, d'envisager le déplacement des œuvres de domaines ruraux vers cette agglomération puissamment fortifiée et mieux sécurisée pour répondre aux menaces militaires d'alors. Les premières analyses du développement stylistique montrent une réelle évolution dès la fin du premier âge du Fer sous l'influence des savoir-faire du monde méditerranéen qui insuffle parallèlement le facteur qualitatif au goût du réalisme figuratif. Dans la région très circonscrite à la population des Salyens, les dernières productions du monde méridional indépendant sont pour l'essentiel à rapporter au $\mathrm{III}^{\mathrm{e}} \mathrm{s}$. Elles caractérisent alors magnifiquement le glissement de l'iconographie héroïque primitive vers une apologie pure et simple des princes aristocratiques et de leurs familles.

La généralisation marquée des habitats groupés et leur structuration spatiale mieux définie vont être accompagnées d'une présence plus affirmée de pratiques cultuelles en leur sein. Bien sûr, dès les débuts de la Protohistoire, l'habitat groupé est le lieu de rites domestiques propitiatoires. Ces derniers sont liés à la protection des familles, comme de la collectivité. À partir de la fin du VI ${ }^{\mathrm{e}}$ s., de petits espaces cultuels et votifs apparaissent dans l'organisation planimétrique existante (Graveson). Ils se maintiendront jusqu'à la fin de l'âge du Fer (Entremont). C'est en réponse à l'amplification de la surface des plus vastes habitats au cours du second âge du Fer, de leur besoin de protection, cornme de celle des activités économiques en développement, que l'on constate un accroissement du nombre et de la valeur contenue des dépôts votifs. C'est surtout à proximité des agglomérations qu'apparaissent dès le II ${ }^{e}$ s. de vastes aires cultuelles et de libations collectives, avec dépôts dans des fossés et dans des puits (Rodez, Aix-en-Provence). Dans la même perspective, nous nous sommes interrogés sur le sens des restes humains découverts dans des fossessilos, accompagnés ou non d'offrandes (La Lagaste, Ensérune, Cavaillon). Bien que d'interprétation complexe, le caractère propitiatoire de ces vestiges ne doit pas être a priori écarté.

En définitive, il transparaît que la spécificité cultuelle des agglomérations protohistoriques méridionales est très tardive et liée au mouvement de proto-urbanisation. C'est en effet après la fin du $\mathrm{III}^{\mathrm{e}}$ s., et en ce qui concerne le centre de la basse vallée du Rhône vers le milieu du $\mathrm{II}^{\mathrm{c}}$ s., que le phénomène commence à prendre corps, puisant dans la présence romaine aux sources du monde gréco-italique. Ainsi, les premiers temples hexastyles de Glanon, même s'ils ne sont peut-être adoptés que de façon formelle, révèlent le long cheminement culturel préalable d'une partie des élites indigènes. Ce courant progressiste et philhellène de l'aristocratie méridionale est à l'origine, bien avant l'intervention militaire romaine de 125-123 avant J.-C., des grandes mutations qui interviennent dans l'habitat et ses rapports aux territoires de proximité. La religion et ses réalisations cultuelles ostentatoires s'intègrent dès lors pleinement aux outils du pouvoir de l'oligarchie dirigeante. 


\section{NOTICES}

\section{NOTICE 1}

\section{TRACES D'EXPRESSIONS CULTUELLES AUPRÈS DES TOMBES PROTOHISTORIQUES}

Les fouilles des sépultures et des nécropoles protohistoriques du Sud-Est de la France mettent au jour des vestiges immobiliers ou mobiliers qui ne paraissent pas correspondre à des gestes ayant une utilité pratique dans la gestion de la mise au tombeau. $\mathrm{Vu}$ le contexte funéraire, tout au plus peut-on proposer des interprétations plausibles que suggère le comparatisme historique et ethnologique. Ces traces sont diverses. Certains sites n'en ont livré qu'une catégorie, d'autres en associent plusieurs. Les unes sont liées à la tombe ou à son environnement immédiat, d'autres paraissent concerner l'ensemble d'un groupement de sépultures.

\section{DES DÉPÔTS SUR LA TOMBE...}

Des tessons de vases ont été repérés en surface de la tombe, dont la datation est compatible avec celle des objets enfermés dans la sépulture, parfois accompagnés d'os d'animaux. La rareté des cas signalés, liée aux sépultures les moins endommagées, peut s'expliquer aisćment par la situation elle-même, qui rend la conservation aléatoire. Un recensement montre cependant une répartition chronologique et géographique large, qui laisse penser à une pratique répandue durant la Protohistoire. Ainsi au Moulin de Mailhac, dès la transition bronze-fer, la présence d'un gobelet a été reconnue au sein des restes des petits tumulus de pierres recouvrant les sépultures 36 et 48 . Au début du premier âge du Fer, même remarque pour la tombe 41 du Grand-Bassin I (fig. 125), et, au VII ${ }^{\mathrm{c}}$ s., pour une urne sur la tombe 135 du Peyrou d'Agde. Des tessons de vases ont aussi été observés en surface de tumulus des serres et plateaux rocheux de Provence, du Languedoc oriental ou du sud du Massif central, comme à Peyraube 6 dans les Cévennes, aux Pouzettes sur le Causse Noir ou aux Barracs sur le Causse de Séverac, tous du premier âge du Fer. Sur le Causse Comtal, un vase renfermant des dents de suidés était écrasé en surface d'un coffre réutilisé au premier âge du Fer (T. XII) dans la nécropole de Floyrac. Il est séduisant de rapporter ces vestiges à des contenants d'offrandes ou de libations répandues sur le sépulcre, mais l'on est dans l'incapacité d'en préciser le moment. Au Grand-Bassin I et à Agde, tout au plus a-t-on la preuve que ce dépôt a été effectué avant que la charpente ou les bords de la fosse ne cèdent.
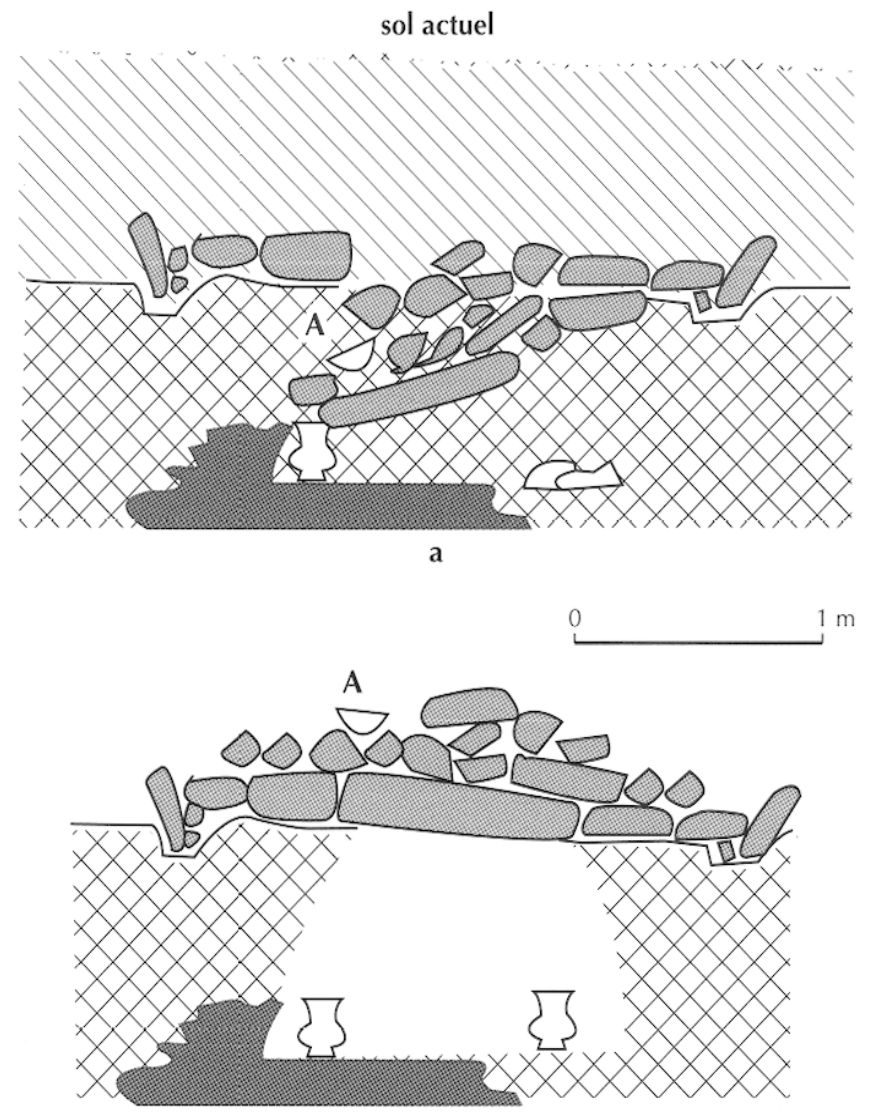

b

Fig. 125 - Mailhac (Aude), Le Moulin, le Grand-Bassin I: a, coupe schématique des vestiges de la tombe $41 ; b$, reconstitution de la disposition primitive. En A, écuelle déposée sur le dessus du tumulus (d'après Louis et al., 1958).

\section{...OU À CÔTÉ DE LA TOMBE}

De tels dépôts se rencontrent aussi à proximité de la tombe, sur le sol ou dans une structure spécialement aménagée. Des morceaux de vases, surtout des urnes, étaient écrasés sur le sol aux abords de plusieurs sépultures de la nécropole du Camp de l'Église-Sud, dans le Quercy, à la transition bronze-fer. Ces vases fermés semblent compléter ceux essentiellement ouverts disposés dans les tombes et qui servent d'ossuaires, de couvercles et de plats à offrande, ou exceptionnellement de petits gobelets. À Vestric-et-Candiac, au début du premier âge du Fer, trois vases ont été déposés isolément sur le sol, non loin des tombes, et là encore une correspondance existe entre l'un d'eux, un gobelet et l'urne placée dans la tombe la plus proche, dont il est le modèle réduit. À la même époque, les sépultures 19 et 32 de la nécropole de Pradines à Causses-et- 


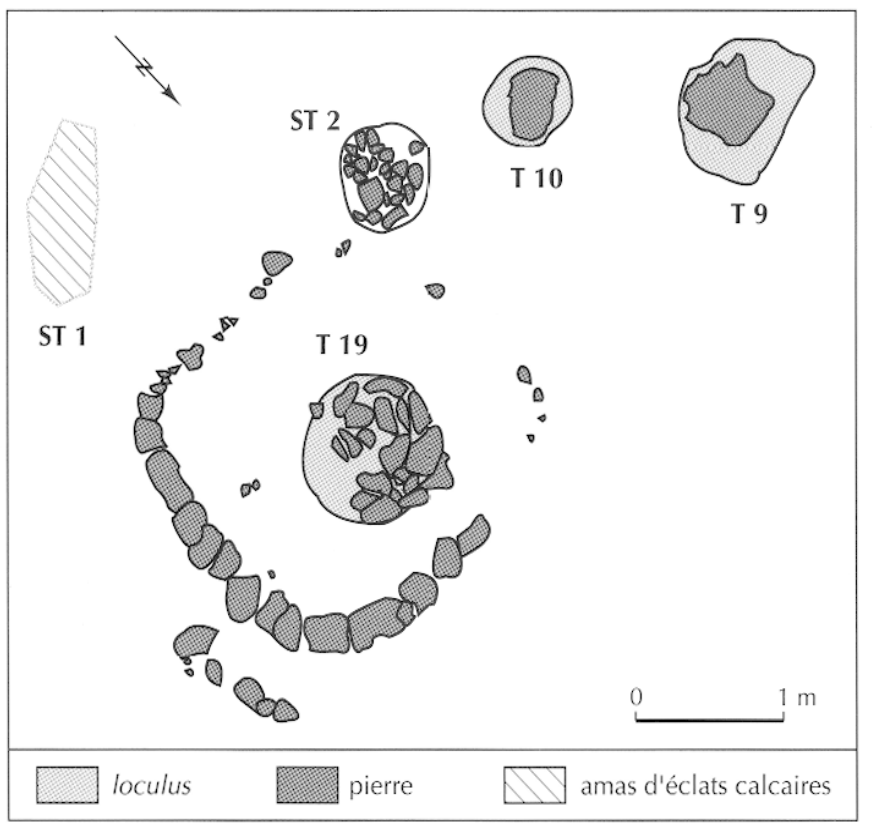

Fig. 126 - Causses-et-Veyran (Hérault), Pradines. Plan de la tombe 19 et de sa périphérie; ST 2, petite plate-forme circulaire empierrée, aménagée contre l'angle du dispositif d'entourage de la sépulture (d'après Mazière et al., 2002).

Veyran (Hérault), dans la moyenne vallée de l'Orb, offrent un dispositif particulier pour accueillir de tels objets. Toutes deux sont pourvues, après leur édification, contre un des angles de leur enclos, d'une plate-forme de pierres, d'environ $80 \mathrm{~cm}$ de diamètre. Sur celle de la tombe $19 \mathrm{ont}$ été découverts deux vases et une fusaiole, ce dernier ustensile n'est pas sans rappeler son homologue déposé dans le loculus (fig. 126). Sur ces trois sites, les liens apparaissent entre le mobilier des tombes et les dépôts de surface, complémentarité d'usage ou rappel. Mais l'établissement d'une relation entre vivants et défunts peut prendre d'autres formes qui ont laissé des traces archéologiques, tels les dispositifs mettant en communication l'intérieur et l'extérieur de la tombe.

\section{LeS CHEMINÉES À OFFRANDES deS TUMULUS DE SADOULET}

Deux tumulus du début du premier âge du Fer des Garrigues, Sadoulet 1 et 4 à Pompignan (Gard), présentent un dispositif interne affleurant la surface du tertre. Il permet depuis l'extérieur d'atteindre les parties profondes de la tombe, mais non la région sépulcrale proprement dite. À Sadoulet 1 , un petit puits cylindrique aux parois de pierres sèches, de 0,80 à $0,85 \mathrm{~m}$ de diamètre et $0,60 \mathrm{~m}$ de profondeur, a été construit à côté de la zone sépulcrale jusqu'au substratum. Il renfermait les tessons de trois vases non tournés et une offrande carnée dont témoigne un os d'oviné. Ce dépôt n'est pas forcément contemporain des funérailles; il peut tout aussi bien témoigner d'un apport ultërieur. On peut rapprocher ce type de puits des conduits à libations, bien attestés dans l'Antiquité classique. Sadoulet 4 comportait le même dispositif, mais ici ce dernier a été retrouvé vidé de son contenu. Des cas semblables ont dû exister ailleurs, que les méthodes d'investigations anciennes n'ont pas permis d'observer. ¿̀ Sadoulet pourtant, ces faits ne concernent que deux des cinq tertres soigneusement explorés. Ce dispositif n'a donc rien de systématique. Mais il en existe un autre à Peyraube 6, de forme différente, posant d'autres questions sur la communication avec les défunts.

\section{PeYraube 6 : UN POSSIBLE DISPOSITIF POUR LA NÉCROMANCIE ?}

$\mathrm{Au}$ VIII ${ }^{\mathrm{e}}-\mathrm{VII}^{\mathrm{e}}$ s., le tumulus de Peyraube 6 à Lamelouze (Gard) possède un aménagement autorisant aussi la transmission entre le monde extérieur et le sous-sol du tertre. Le substrat rocheux micaschisteux est creusé, à $2 \mathrm{~m}$ de la région sépulcrale, d'une fosse peu profonde $(1,80 \mathrm{~m}$ de long sur 0,35 à $0,55 \mathrm{~m}$ de large), sur les bords de laquelle prend appui une série de lauzes micaschisteuses disposées en bâtière. Le faîte de ces dalles affleure la surface de la calotte tumulaire, et dans cette partie est taillé un orifice ovalaire de 15 à $20 \mathrm{~cm}$ de diamètre, échancrant les sommets de deux lauzes en vis-à-vis. À son aplomb, le comblement du fond de la fosse recèle un morceau de mandibule humaine non brûlé, d'un adulte robuste, âgé d'au moins 25-30 ans, associé à un os non brûlé également de mouton ou chèvre et une pendeloque aménagée dans une plaquette de micaschiste. La partie sommitale du coffre était vide au moment de la découverte. La mandibule ne parait pas appartenir au défunt incinéré, de taille adulte, dont des restes osseux et fragments de calotte crânienne brûlés ont été éparpillés, à $2 \mathrm{~m}$ de cette fosse. Le morceau de mandibule non brûlé pourrait correspondre à la " relique » d'un autre mort; don fait au défunt incinéré ou " objet " lui appartenant.

Ce dispositif, on le voit, ne renferme pas de traces tangibles de pratiques postsépulcrales. Toutefois, l'agencement de l'ensemble, creusé dans le sous-sol et ouvert vers le monde extérieur, peut avoir eu une fonction similaire à celle des petits puits précédents ; mais il a pu aussi favoriser des communications moins matérielles. Peut-être avonsnous là la trace d'un rite de nécromancie. Cet usage des vivants qui interrogent les morts et conversent avec eux est bien connu dans la Grèce ancienne. D'ailleurs cette pratique est bien attestée dans la région à la fin du $\mathrm{I}^{\mathrm{er}} \mathrm{s}$. de notre ère, avec la tablette de plomb inscrite en langue 
gauloise et déposée dans l'urne cinéraire de la tombe 71 de la nécropole de L'Hospitalet-du-Larzac (Aveyron). Plusieurs femmes, des sorcières ou des druidesses, écrivent à l'une d'entre elles qui est morte, et elles invoquent sur sa tombe " la magie des femmes " pour attirer de bons et de mauvais sorts. Il n'est peut-être pas indifférent de constater que le reste humain placé dans le dispositif de Peyraube 6 est une mandibule, cet os étant, dans de nombreuses sociétés traditionnelles, symbole de la parole.

\section{DES STRUCTURES SANS RESTES OSSEUX HUMAINS}

À côté des tombes on rencontre souvent des dispositifs bâtis ou aménagés dans le sol, qui posent d'autres problèmes d'interprétation. Ainsi, il est fréquent de relever, au sein des champs tumulaires du premier âge du Fer qui parsèment les plateaux et montagnes du Sud-Est, des constructions semblables par leur structure et leurs dimensions aux tumulus qui abritent une sépulture, mais qui ne renferment que des objets contemporains des tombes voisines, sans aucun reste osseux humain. C'est le cas de $13 \%$ des tertres des Garrigues et de $20 \%$ de ceux du Rouergue. Certains de ces édifices témoignent même d'un grand soin dans la construction ou de dispositions particulières. Ainsi, par exemple, dans les Hautes-Alpes, au sein de la nécropole de Ventavon, la masse du tertre 19 inclut un système de murets orthogonaux sans équivalent ailleurs. Sur le Causse du Larzac, le tertre 10 du Blacas (Aveyron), au centre d'une forte concentration de tumulus, est bordé par un parement très soigné, décrivant un cercle parfait de $9 \mathrm{~m}$ de diamètre, et il n'abritait qu'un maigre dépôt de charbons de bois (datés du premier âge du Fer par le $\left.{ }^{14} \mathrm{C}\right)$. S'agit-il de monuments commémoratifs, érigés en l'absence de la dépouille du mort, comme cela est attesté alors en Grèce (Homère, Odyssée, IV, 595) ? Dans les Grands Causses du Gévaudan, ces tertres sans os humains sont en moyenne plus petits que ceux qui en ont livrés, et le mobilier est, en général, plus réduit. Ils s'inscrivent à la limite inférieure d'une progression des diamètres moyens qui s'établit en fonction du degré d'encombrement des restes osseux, ce peut être là la marque d'un rituel affaibli ou différent.

Dans plusieurs nécropoles de plaine du Languedoc occidental, entre les loculus des tombes creusés dans la terre, prennent place des fosses semblables à ceux-ci, contenant du mobilier mais dépourvues d'os humains. Au Moulin de Mailhac, au Bronze final IIIb, huit fosses renfermaient des vases et parfois des objets métalliques ou des offrandes carnées, et ne se distinguaient des sépultures que par l'absence de tout reste osseux humain et du petit tumulus de surface. Des faits semblables ont été observés

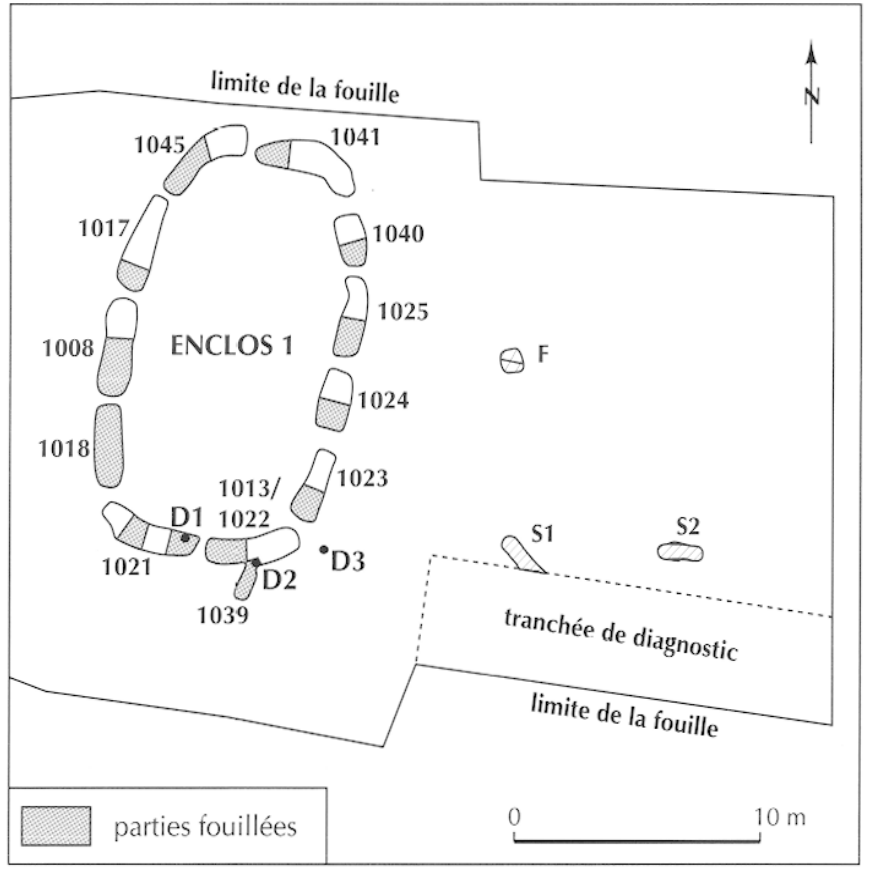

Fig. 127 - Vestric-et-Candiac (Gard). Plan de la partie fouillée du complexe funéraire et cultuel : D1, D2 et D3, dépôts de vases; $F$, fosse à galets chauffés; $S 1$ et S2, sépultures 1 et 2 (relevé B. Dedet et M. Coutureau, CNRS).

pour le premier âge du Fer dans les cimetières des Coudoumines à Caramany (Pyrénées-Orientales) et de Pradines. On y voit volontiers des structures annexes des tombes, par exemple pour recevoir des offrandes, pendant les funérailles ou lors de commémorations.

\section{VESTRIC-ET-CANDIAC : COMPLEXE FUNÉRAIRE ET CULTUEL ?}

La fréquentation de la Carrière du Moulin à Vestric-etCandiac se place au VIII $-\mathrm{VII}^{\mathrm{e}}$ s. En sa partie fouillée le site comporte un fossé ovalaire discontinu, délimitant un espace de $14,5 \mathrm{~m} \times 8,6 \mathrm{~m}$, orienté nord-sud (fig. 127). Sur son comblement, qui inclut de rares objets dont un bracelet en fer, intervenu peu de temps après le creusement, deux urnes ont été déposées. À l'extérieur, vers le sud-est, on rencontre un troisième récipient écrasé sur le sol, une fosse à galets chauffés de $1 \mathrm{~m}$ de diamètre et deux tombes à inhumation d'adultes, dont celle d'une femme. À environ $50 \mathrm{~m}$ vers l'ouest, deux fossés circulaires concentriques (30 et $24 \mathrm{~m}$ de diamètre) ont été partiellement reconnus, mais on ignore tout de leur environnement immédiat. On peut interpréter la fosse à galets chauffés, faute de déchets, comme un four destiné à la cuisson à l'étouffée, structure culinaire non attestée alors dans les habitats régionaux, et dont divers exemples ethnologiques montrent le caractère cérémoniel 
et festif. Les dispositifs parafunéraires paraissent ici prendre le pas sur les tombes elles-mêmes, et le fossé semble jouer un rôle central. On pourrait envisager un lieu consacré à des cérémonies religieuses près des tombeaux de deux défunts particuliers, avec cuisson et dépôt d'offrandes. Mais cette dernière structure, orientée, segmentée, avec ses onze interruptions, ne pourrait-elle traduire des préoccupations dépassant le cadre d'un simple hommage à des disparus?

Les sépultures ne nous renseignent pas que sur les faits et gestes permettant de gérer les corps des défunts. De même qu'elles fournissent un certain reflet de l'organisation sociale de la communauté, elles procurent aussi l'écho de conceptions concernant l'au-delà et ainsi participent pleinement du religieux. Une étude des tombes protohistoriques des Grands Causses nous a permis de soupçonner l'existence de la croyance à deux " goulets " de la mort, le décès physique, qui ouvre sur un séjour temporaire dans et autour du tombeau, et qui est suivi par un départ vers un ailleurs. Marquée en surface par un dispositif plus ou moins persistant, tumulus, enclos, pierre dressée (voire poteau ?), la tombe apparaît dans un premier temps comme un lieu de rendez-vous avec le défunt, que l'on a pourvu lors des funérailles, du moins symboliquement, des objets et offrandes nécessaires à sa survie. C'est sans doute alors le moment des différents dépôts et structures évoqués ici, sur ou à proximité des tombeaux, et dont les datations sont tout à fait compatibles avec celles des objets placés dans le sépulcre même. Mais cette fréquentation des tombes par les survivants paraît n'avoir qu'un temps et cesser assez vite. À cet égard, le cas d'Ensérune est exemplaire, où l'extension de l'habitat dans le courant du $\mathrm{II}^{\mathrm{e}} \mathrm{s}$. avant J.-C. recouvre le cimetière établi là du $\mathrm{V}^{\mathrm{e}}$ au $\mathrm{III}^{\mathrm{c}} \mathrm{s}$. Ici on remblaie, ailleurs on abandonne, mais nulle part on ne détruit. À l'évidence persiste un souvenir respectueux.

Bibliographie : Louis et al., 1958 ; Gascó, 1980 ; Gruat, 1988, 1994 ; Nickels et al., 1989 ; Nickels et al., 1989 ; Dedet, 1992 , 2001 a ; Dedet, Gauthey, 1994 ; Janin et al., 1994 ; Lambert, 1994 ; Porra, 1995 ; Dedet et al., 1997 ; Gruat, Poujol, 1997 ; Taffanel et al., 1998 ; Mahieu, Boisseau, 2000 ; Pons et al., 2001 ; Mazière et al., 2002.

\section{B. DFDET}

\section{NOTICE 2}

\section{AIX-EN-PROVENCE (BOUCHES-DU-RHÔNE)}

\section{LE Fossé dU TerRaIN CoQ}

Les recherches conduites depuis 1991 en périphérie méridionale d'Aix-en-Provence, non loin de la ville antique, ont permis d'explorer une vaste zone où la majorité des vestiges antiques exhumés réfère à la mise en valeur des sols. Il s'agit, pour l'essentiel, d'un important réseau de drains et de fossés, dont l'installation résulte tout d'abord du besoin d'assainir un cirque naturel, situé en bas des pentes qui descendent depuis les hauteurs d'Entremont, mais vraisemblablement aussi du souci d'organiser l'occupation des terrains.

De tous les dispositifs présents dans cette zone, le fossé découvert à l'emplacement de l'ancienne fonderie Coq est sans conteste le plus énigmatique. Reconnu sur $120 \mathrm{~m}$ de long et suivant une direction ouest-nord-ouest - est-sud-est, parfaitement rectiligne, ce fossé, creusé dans le substrat, mesure, dans sa plus grande dimension, 1,50 m de large pour $1,20 \mathrm{~m}$ de profondeur ; il présente un profil en $\mathrm{V}$, très régulier (fig. 128a et c). Il pourrait apparaître comme un banal aménagement des sols, n'étaient la fraîcheur de ses parois qui ne portent aucune trace de ravinement, preuve d'une brève exposition à l'air libre, et surtout la nature et les modalités surprenantes de son comblement (fig. 128b et c). Réalisé très rapidement, le remplissage se singularise, en effet, par sa relative homogénéité et surtout par la répartition spatiale très particulière des éléments qui le composent ; l'analyse de leur distribution suggère sélection et choix dans leur disposition.

\section{Un mobilier atypique}

Parmi le mobilier recueilli compte au premier chef un lot exceptionnellement abondant d'amphores vinaires italiques : plus de 9000 fragments représentant au moins 206 individus $(87,5 \%$ des artefacts). Hormis quelques importations de la côte adriatique (Lamb. 2 et amphores de Brindes) ou de Méditerranée orientale (amphores de type rhodien), il réunit essentiellement des amphores Dressel 1A de la côte tyrrhénienne (94,7\% des individus) (fig. 128d). L'analyse des pâtes a permis de dénombrer une dizaine d'origines différentes, parmi lesquelles dominent largement les productions à pâte volcanique de type Eumachi, originaires de Campanie (environ $60 \%$ ). L'homogénéité de composition du lot se traduit aussi sur le plan morphologique avec des amphores présentant des caractéristiques typologiques identiques, qui renforcent l'hypothèse d'arrivages de cargaisons entières, tels qu'on les connaît pour le fossé Aval du Verbe-Incarné à Lyon : lèvres généralement très courtes, à profil triangulaire, anses cintrées, pieds effilés et droits ou bien courts " en bouton ".

Minoritaire $(13,5 \% \mathrm{du}$ lot), le matériel céramique d'accompagnement comprend des céramiques italiques (campaniennes $\mathrm{A}$ et $\mathrm{B}$; récipients culinaires), quelques productions de céramique indigène non tournée (ateliers 
des Alpilles), de la céramique à pâte claire de Marseille, des dolia en nombre relativement abondant $(9 \%)$ et un ensemble de meules rotatives en basalte dont certaines sont apparues très peu usées (fig. 128f).

Globalement, le matériel évoque bien le dernier tiers du II $^{\mathrm{e}} \mathrm{s}$. avant J.-C., notamment les amphores au sein desquelles on note l'absence totale de Dressel 1B et un unique exemplaire de Dressel 1C.

\section{Des modalités de dépôt singulières}

La distribution des objets dans le fossé s'est par ailleurs révélée très inégale, laissant voir des concentrations ponctuelles qui semblent avoir répondu à une logique de regroupement par type de fragments tels les cols d'amphores - une cinquantaine environ (fig. 128e) -, mais aussi par type d'objets, telles les meules, réparties sur trois secteurs

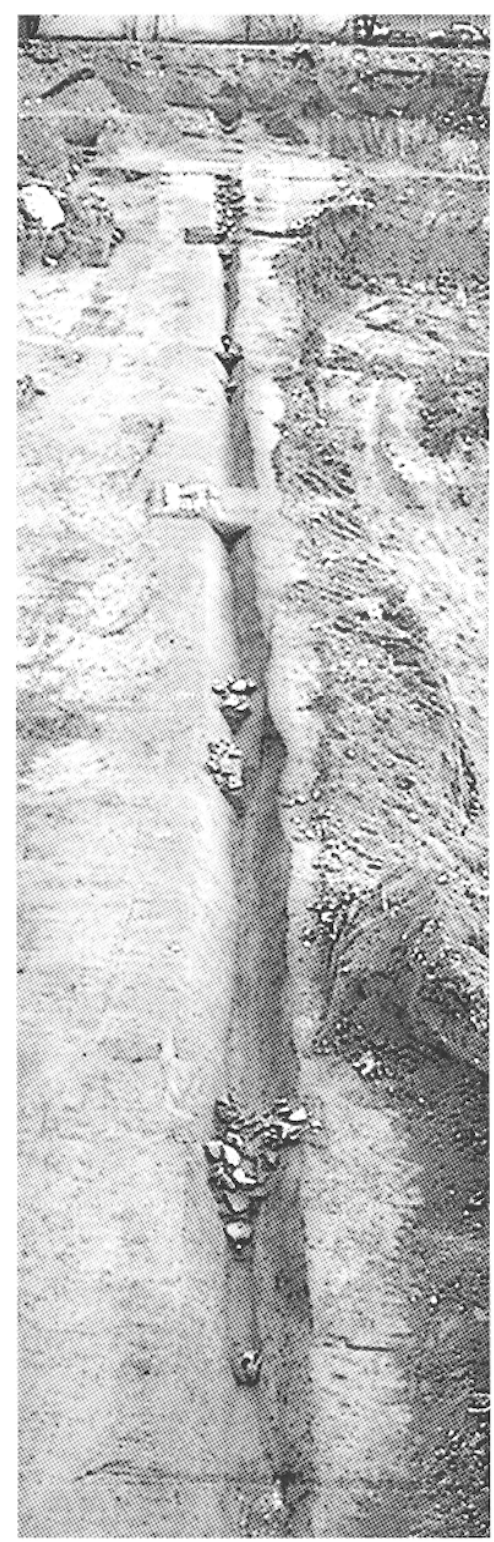

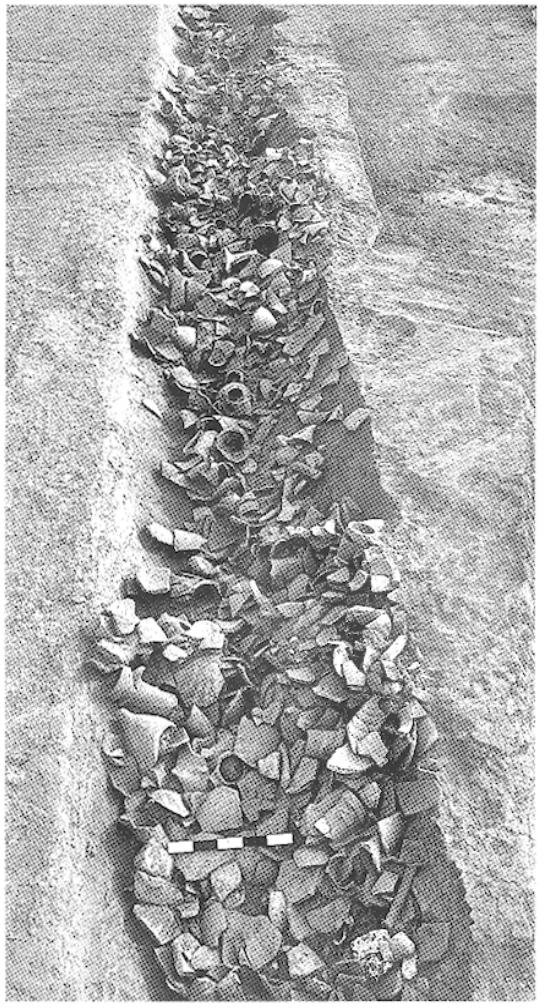

b

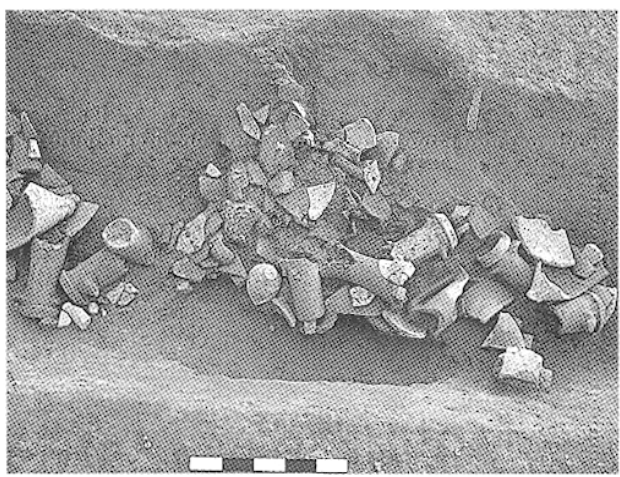

e
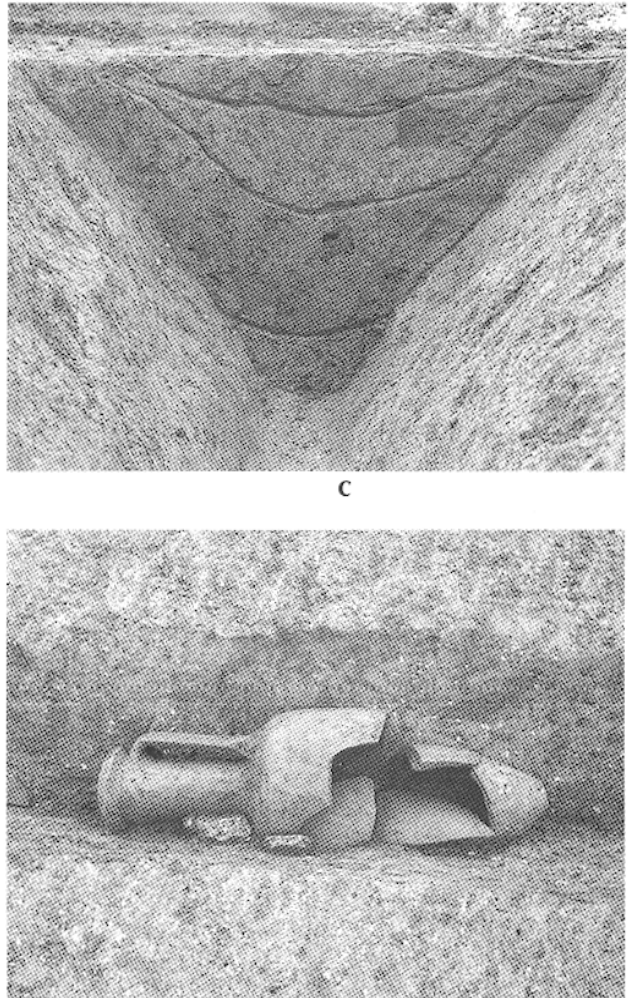

d

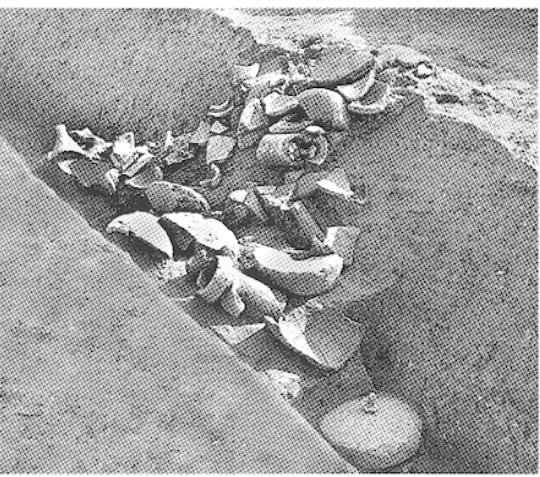

Fig. 128 - Aix-en-Provence (Bouches-du-Rhône), Terrain Coq : a, perspective du fossé découvert en 1991 ; $b$, aspects des morceaux d'amphores italiques qui comblaient certains segments du fossé (vus depuis le nord-ouest), on distingue les points de déversement; c, coupe du fossé, large de $1,50 \mathrm{~m}$ et profond de $1,20 \mathrm{~m}$; $d$, amphore italique du type Dressel $1 \mathrm{~A}$ dont les fragments ont été retrouvés en connexion; $e$, un des regroupements de cols d'amphores; $f$, meules rotatives en basalte rejetées avec les amphores italiques (photos $N$. Nin, ville d'Aix). 
distincts et toujours rassemblées (fig. 128f), ou encore le matériel amphorique qui est localisé sur de courts tronçons correspondant aux principaux cônes de déversement (fig. $128 \mathrm{~b}$ et e), séparés parfois par des vides importants (jusqu'à $15 \mathrm{~m}$ ).

La répartition spatiale des tessons montre également que la fragmentation des vases ne peut être imputée aux seuls chocs postdépositionnels. Elle suppose au contraire la dispersion des tessons appartenant à un même objet, que seul peut expliquer un bris avant enfouissement. Autant d'observations qui pourraient rendre compte d'une mise en scène des dépôts : processus de sélection des éléments avant leur rejet et leur enfouissement, segmentation du fossé, dont le rythme n'est peut-être pas fortuit, mais dont la signification nous échappe.

\section{Un dépôt rituel ?}

La datation de ce fossé nécessite d'être replacée dans le contexte de l'histoire d'Aix antique et plus particulièrement de sa fondation (122 avant J.-C.). La nature très spécifique des dépôts comme la dynamique de comblement conduisent à rejeter d'emblée l'hypothèse d'un dispositif défensif, initialement évoquée. On pourrait davantage arguer de la consommation d'une population particulière, en l'occurrence ici la garnison romaine qui, selon Strabon et Pline l'Ancien, accompagna la création de l'établissement indigène à l'origine de la ville. Mais à considérer la sélection du mobilier et, plus encore, sa disposition dans le fossé, l'opération de remplissage paraît avoir répondu à une logique précise qui cadre mal avec l'hypothèse d'une simple entreprise de nettoyage. Ceci dénote surtout la qualité et la quantité des vins consommés (estimation proche de 5000 l) auxquelles répondent le nombre de meules rotatives, ainsi que celui élevé des dolia. Ils évoquent la consommation d'une grande quantité de denrées céréalières et pallient d'une certaine manière la rareté de la faune. Autant d'aspects qui ne sont pas sans rappeler les "fossés à amphores" de la région lyonnaise. Les analogies entre ces dispositifs sont en effet très nombreuses. Elles touchent aussi bien la forme des aménagements eux-mêmes que la répartition, la composition et l'importance des dépôts, essentiellement composés de résidus de consommation et qui relèvent de pratiques spécifiques. L'abondance et la qualité des produits suggèrent les restes d'un banquet, pratiques collectives relevant tout autant du politique que du cultuel.

Les recherches archéologiques conduites sur l'environnement du dispositif ont déterminé une zone relativement éloignée de l'aire urbanisée durant le Haut-Empire et longtemps vouée à des occupations rustiques. La forme, l'emplacement et l'orientation du fossé concerné invitent à le rattacher à un important réseau d'aménagements répondant à la mise en culture et au découpage des sols. Parmi les hypothèses avancćcs sur sa dćvolution a été proposée celle du rôle fondateur dans la mise en place d'un nouveau parcellaire, à l'issue de la conquête. Car si ce dispositif a rapidement disparu du paysage, la direction qu'il a fixée s'est en revanche maintenue longtemps après lui.

Bibliographie : Mandy et al., 1989, 1990 ; Nin, 1991, 2000 ; Guyon et al., 1998.

G. MAZA et N. NiN

\section{NOTICE 3}

\section{GRAVESON (BOUCHES-DU-RHÔNE)}

\section{Le Mourre Pela et la RoQue}

\section{Stèles et lieu sacrificiel près de l'enceinte basse}

L'habitat perché du Mourre Pela s'est constitué sur la première éminence située à l'extrémité nord-est de la chaîne de la Montagnette, entre la petite Crau, le Rhône et la Durance. Il domine d'environ $55 \mathrm{~m}$ la dépression des Duransoles, terre basse humide, voire épisodiquement inondée au cours de la Protohistoire.

\section{Un lieu de culte près d'une voie fréquentée}

Le Mourre Pela a des pentes abruptes sauf du côté oriental où plusieurs vallons descendent vers la plaine des Duransoles. D'importantes résurgences jaillissent à la base des écailles rocheuses qui encadrent les piémonts. Le site est fréquenté durant l'âge du Bronze. Mais c'est au premier âge du Fer, vers 525 avant J.-C. ou peu après, qu'une communauté se rassemble pour constituer un ample habitat d'environ 5 ha. Les lieux seront abandonnćs tout aussi spontanément deux générations plus tard, au cours du deuxième quart du $\mathrm{V}^{\mathrm{e}} \mathrm{s}$., sans destruction violente perceptible. Des recherches entreprises de 1998 à 2001 montrent que l'occupation sur Le Mourre Pela se prolonge en fait dans les vallons orientaux et jusqu'au contact avec la plaine, au lieu-dit La Roque. Si les quartiers de pente et de périphérie sont fréquents autour des oppida méridionaux dès la fin de l'âge du Bronze, il s'agit dans le cas présent d'une intégration des piémonts à l'oppidum, impliquant une descente de l'enceinte défensive du site de hauteur jusqu'au contact avec la plaine. Le phénomène observé à Glanon, dans les proches Alpilles (voir infra notice 5, p. 230-235), se 
reproduit ici. Le site paraît avoir eu très tôt une vocation cultuelle, si l'on suit l'indication transmise par le nom de la proche agglomération de plaine d'époque romaine, la mulatio Bellinto de l'Itinéraire de Bordeaux à Jérusalem ou de la Table de Peutinger. Elle révèle le souvenir ou le maintien d'un culte des eaux établi autour du dieu guérisseur Bellinos ou Belenos, bien attesté par ailleurs dans le Midi celtique et l'Italie du Nord. Cette probabilité est confortée par la puissance toujours actuelle des résurgences de La Roque.

Les investigations se sont concentrées sur la compréhension du mode d'intégration des composantes de la ligne de défense à la topographie du quartier bas de La Roque. Des éléments de stèles travaillées ont été découverts en remploi, de même qu'un espace aménagé qui est accolé à deux fortifications qui se succèdent dans le temps. Malgré le caractère récent des recherches, il nous paraît utile de communiquer un premier aperçu sur leur composition et d'entrevoir les implications chronoculturelles qu'ils suggèrent.

\section{Des lignes de défense et des stèles}

L'habitat du dernier quart du $\mathrm{V}^{\mathrm{c}} \mathrm{s}$. avant J.-C. descend jusqu'au contact avec la plaine orientale. À l'amorce de celle-ci, il est délimité par un mur épais de 1,10 m (Us 26, fig. 129a à c). Reconnu sur $5 \mathrm{~m}$ de longueur, il semble avoir été démantelé ailleurs lors de l'édification de la seconde ligne de défense, aménagement plus élaboré et complexe. Cette dernière fortification, bâtie au tout début $\mathrm{du} \mathrm{V}^{\mathrm{c}} \mathrm{s}$., est renforcée par deux bastions quadrangulaires dont un protège l'accès repéré à l'agglomération (bastion 1 et porte). Le site est abandonné une génération plus tard et le démantèlement systématique de ces élévations commence au second âge du Fer pour se poursuivre jusqu'au début de l'Antiquité tardive. C'est dans la construction du bastion 1 que des éléments de stèles, de section quadrangulaire ou aplatie, ont été remployés (fig. 129c à e). $\mathrm{Au}$ total, 16 stèles complètes et fragmentaires ont été recueillies dans les deux seules assises du bastion 1 demeurées en place ou à ses abords immédiats, sur un total inventorié de 31 exemplaires.

Si aucun pilier-support n'a été reconnu malgré l'existence de fûts massifs et de section carrée (comme le i, fig. 129), le restant des stèles présente une assez grande variété de dimensions (de l'ordre de 0,40 à $0,50 \mathrm{~m}$ de hauteur estimée pour les plus petites à $1,83 \mathrm{~m}$ pour la plus grande reconstituée : f, fig. 129), de formes (les sommets plats sont majoritaires, $\mathrm{f}, \mathrm{g}$ ou $\mathrm{k}$, et les angles presque toujours chanfreinés, fig. 129) et de traitements de finition (surfaces des fûts abrasées, mais parfois des cadres laissés bruts ou presque : h et j, fig. 129). La plupart ont des bases brutes ou seulement dégrossies, pour ancrer le mégalithe en terre. Proportions et modes de finition ne dénotent pas de fabrications en série mais autant de cas particuliers que d'individus. À une exception près, le matériau est du calcaire burdigalien importé de la chaîne des Alpilles, distante de $14 \mathrm{~km}$ à vol d'oiseau. Un large fragment de stèle ou des faces inachevées dans leur traitement montrent que la taille et le traitement final des blocs sont réalisés sur place (j et k, fig. 129). Aucune décoration, gravée ou peinte, n'a pu être observée.

Deux constatations transparaissent du relevé de terrain et de l'analyse des blocs. C'est d'abord le phénomène de regroupement des découvertes dans la construction du seul bastion 1 et, pour un cas, dans le parement externe du mur 26 voisin. C'est ensuite le peu de " respect » observé dans les traitements qui leur sont imposés : les pierres sont brisées à la masse ou retaillées pour des besoins divers et l'on observe les traces de l'outillage spécialisé des réutilisateurs, celles de la polka, du marteau taillant et de la sciotte. La première conclusion qui s'impose sur ces vestiges lapidaires est celle de leur désacralisation au moment des remplois. Sur le plan chronologique, cette simple remarque devient majeure. Elle souligne que ces monolithes sont au moment de l'édification de la première enceinte, dans le dernier quart du $\mathrm{VI}^{\mathrm{e}} \mathrm{s}$., déconnectés de la population qui les a érigés. Ils seraient donc bien antérieurs à cette fin de siècle, de la première moitié du premier âge du Fer, voire de la transition bronze-fer.

En 2001, un lot de 15 nouveaux éléments de stèles a été découvert, rassemblé au point $S$ (fig. 129a), dans les terres limoneuses sous-jacentes aux fondations du mur 26 et des parements du bastion 1. Cet ensemble ne rend pas compte de leur position initiale sur une aire sacrée, mais davantage du lieu de leur entrepôt comme matériaux à retailler, avant ou au début des travaux du premier mur défensif 26 .

\section{Un lieu sacrificiel à une divinité protectrice?}

La découverte du tronçon de mur épais 26, qui paraît être un premier mur de défense, s'est accompagnée du dégagement d'un espace délimité connexe, noyé sous les limons déposés lors des débords pluriséculaires des Duransoles. Le lieu a été malheureusement endommagé par la présence d'une ferme aux $\mathrm{IJ}^{\mathrm{e}}$ et $\mathrm{I}^{\mathrm{er}} \mathrm{s}$. avant J.-C., puis par un drain creusé à l'ouverture des fouilles. Entre cet ancien mur 26 et le bastion 1 qui lui succède, s'étend une surface en terre battue, pauvre en vestiges mobiliers. Ce sol est également délimité par les bases de deux autres petits murs, trop dégradés pour repérer une possible trace de porte (fig. 129a). Sous une épaisse couche de terre cendro-charbonneuse de 0,10 à $0,30 \mathrm{~m}$ d'épaisseur et qui 


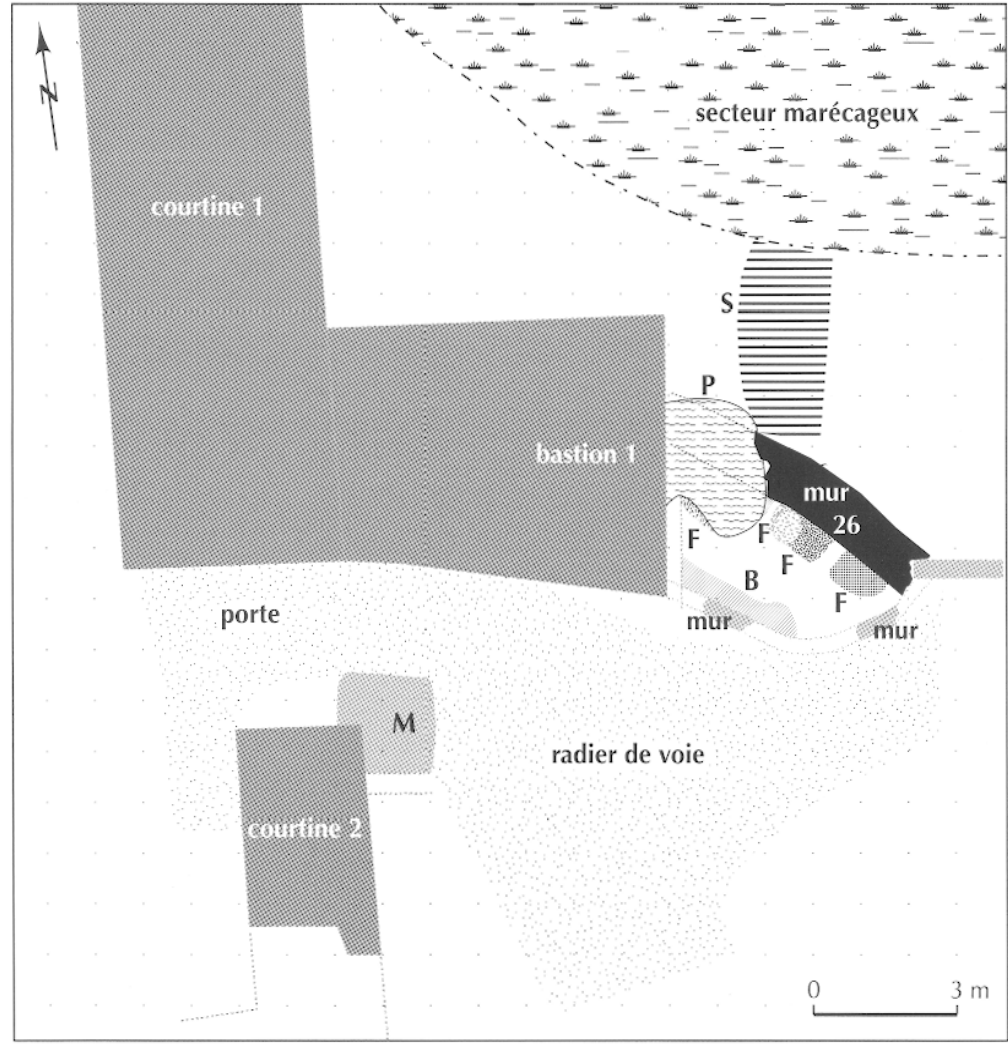

a
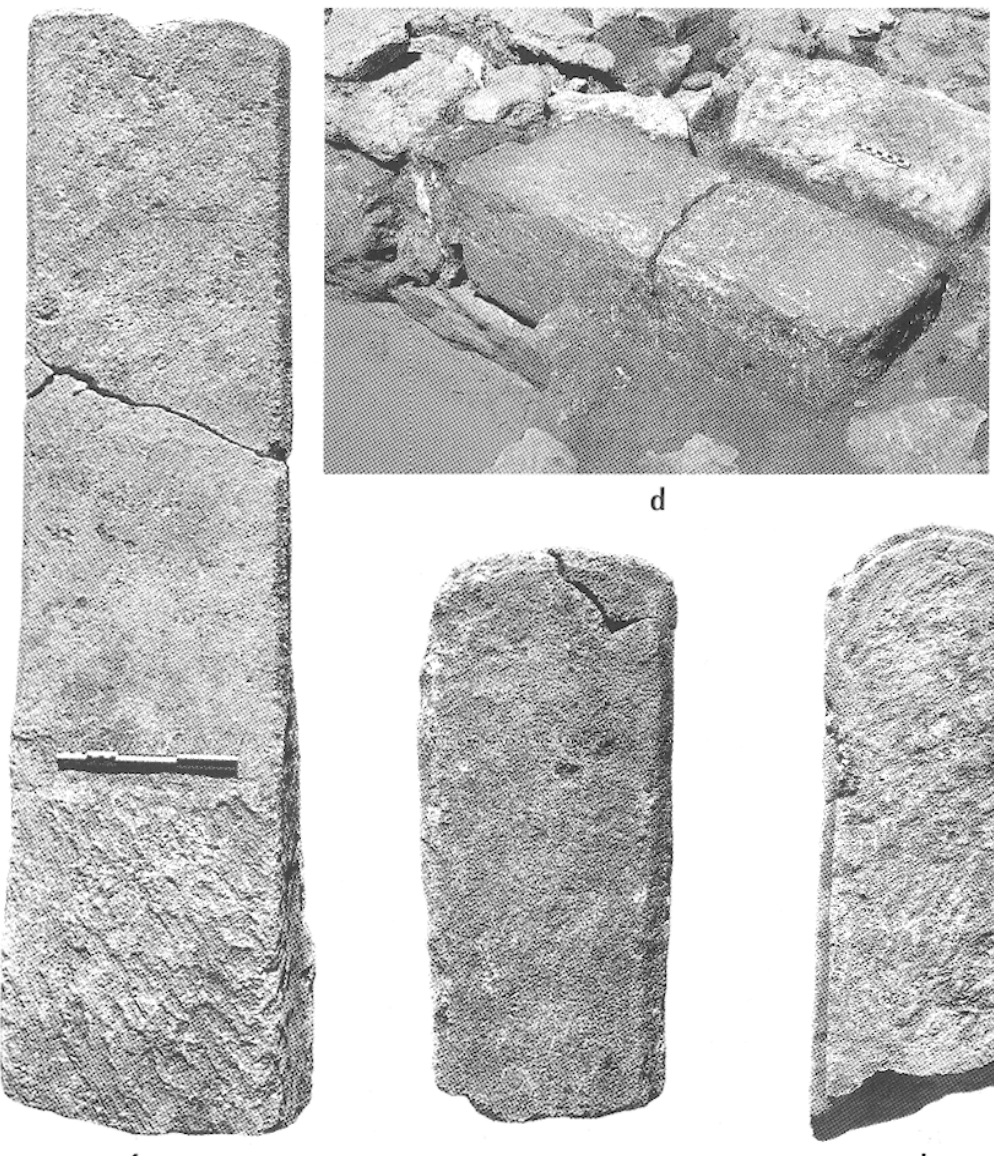

d

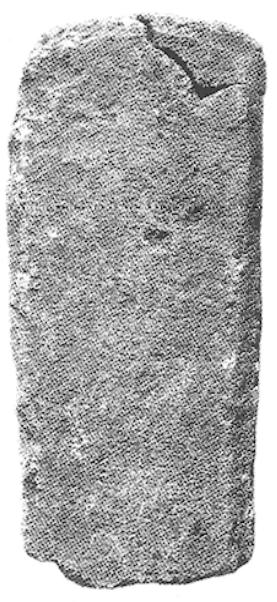

g

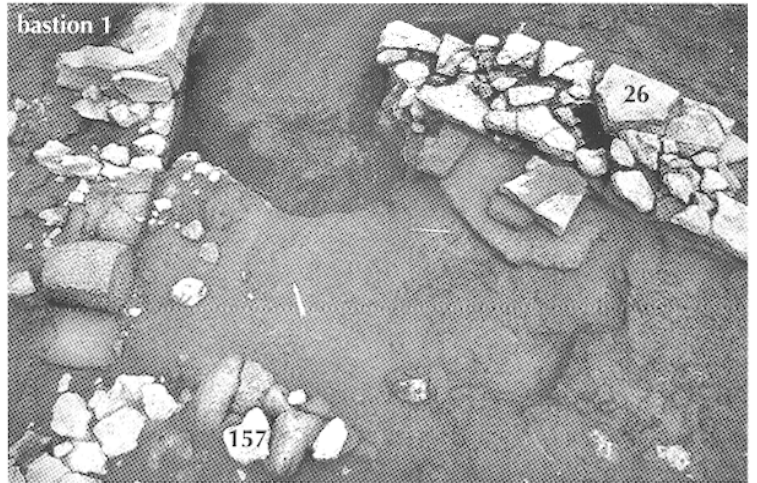

b

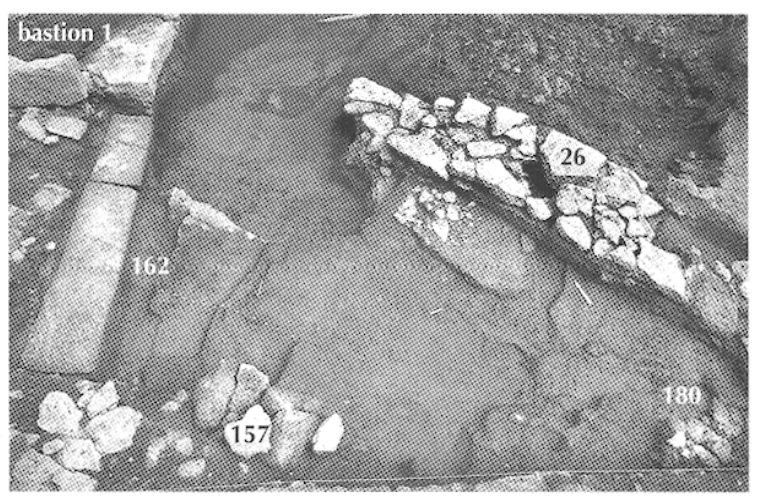

C

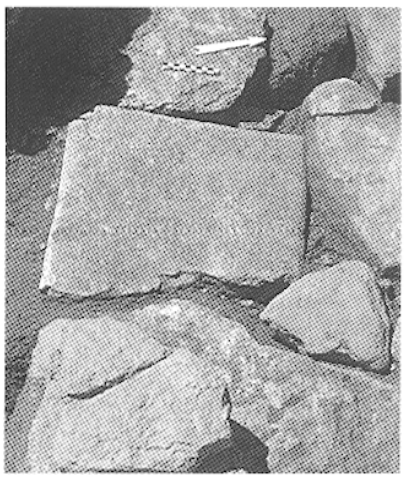

e

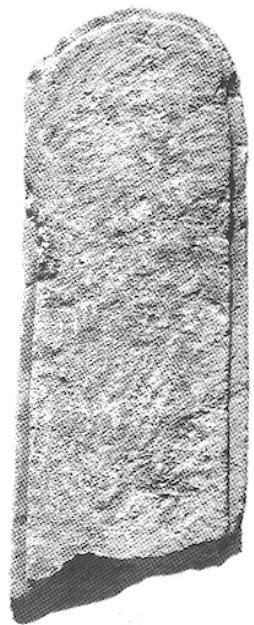

h

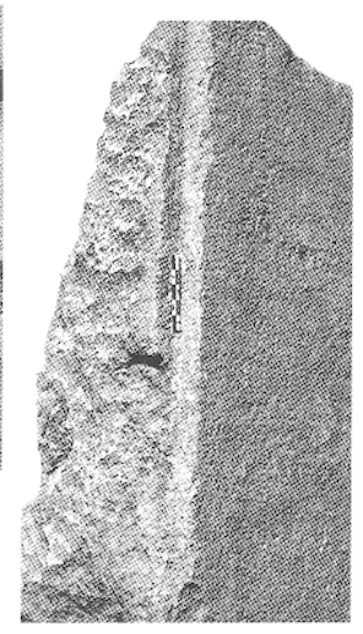

j

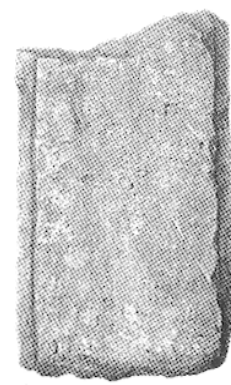

i

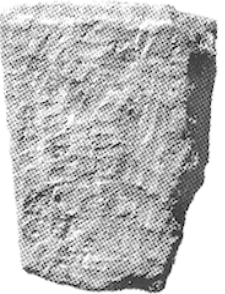

k

Fig. 129 - Craveson (Bouches-du-Rhône), La Roque : a, plan-masse du mur épais 26 et de la ligne de défense ullérieure (courtines et bastion 1) autour de la porte explorée. Contre le mur 26, plan de l'espace présumé cultuel, coupé par un puisard contemporain $(P)$, avec indications d'une banquette $(B)$ et des foyers $(F)$. Emplacement d'un lot d'éléments de stèles $(S) ; b$, l'espace cultuel au niveau du dernier sol d'utilisation; $c$, le même emplacement coupé par la tranchée de fondation du bastion 1 (Us 162); d, e, deux éléments de fûts de stèle remployés dans le parement méridional du bastion $I ; f$, la seule stèle complète, réutilisée en fondation du bastion $(H .: 1,83 \mathrm{~m}) ; g, h, i$, trois éléments de fûts, chanfreinés ou à feuillures; $k, h, j$, trois exemples de stèles, soit juste ébauchées ( $k$ ), soit avec un panneau à peine dégrossi ( $h$ et $j)$ (relevés et photos $P$. Arcelin, CNRS). 
contient pour l'essentiel de petits os d'animaux broyés ${ }^{24}$, sont apparus, le long du mur sud-est, les restes dégradés d'une banquette en terre argileuse (B). D'autres l'avaient précédée dans le temps. De même, au fur et à mesure de la fouille des sols, 13 foyers successifs ont été relevés (F). Ils sont tous construits sur radiers de petites pierres et/ ou tessons étalés, les uns sur les autres, avec de légers déplacements, mais toujours le long du mur 26. L'espace total est d'environ 9 à $10 \mathrm{~m}^{2}$, avec en son milieu une aire plus cendreuse et déprimée par une stabulation humaine récurrente. À l'exception du dernier sol, tous les autres sous-jacents sont rigoureusement nettoyés de tout déchet et les surfaces des plaques de cuisson, détruites (fig. $129 \mathrm{~b}$ ou c).

Tout aussi intéressant est l'apparition de la tranchée de fondation du bastion 1 qui confirme que cet espace est initialement contemporain du mur 26, et donc du premier état de la fin du $\mathrm{VI}^{e} \mathbf{s}$. Surtout que ces aménagements se sont maintenus postérieurement et au même emplacement, forçant les concepteurs de la seconde enceinte à conserver la portion mitoyenne du mur 26 et à déformer en un parallélogramme irrégulier la forme conceptuellement rectangulaire du bastion 1 . Cette disposition singulière répond à un impératif de protection du modeste petit local en induisant le courant de la circulation voisine un peu plus au sud.

Dans l'attente des résultats des analyses carpologiques, anthracologiques et ostéologiques en cours, on relèvera que la présence antérieure de stèles, la proximité immédiate d'une ample zone humide, la spécificité des aménagements récurrents et le souci de leur pérennisation même au prix d'une distorsion architecturale paraissent être autant d'arguments pour une caractérisation comme lieu cultuel. L'espace serait dans un premier temps intra-muros, lié à l'eau et à la protection d'un mur de défense, évoluant ensuite vers un petit sanctuaire de porte extra-muros. L'absence d'offrandes manufacturées, l'usage constant de plaques-foyers et leur destruction systématique, comme l'entretien régulier de la propreté des lieux jusqu'à leur désertion, pourraient laisser penser à un lieu sacrificiel où seraient brûlées des offrandes carnées.

Bibliographie : Lejeune, 1985 ; Gateau, Gazenbeek dir., 1999 ; Arcelin, Ferrando, 2000 ; Arcelin, 2001 ; Jufer, Luginbühl, 2001.

\section{P. ARCELIN et P. Ferrando}

24. L'analyse ostéologique mais aussi anthracologique et carpologique de plusieurs dizaines de litres de sédiments conservés pourra sans doute nous offrir une argumentation mieux étayée pour tenter de caractériser la nature des rites pratiqués.

\section{NOTICE 4}

\section{MARTIGUES (BOUCHES-DU-RHÔNE)}

\section{L'HABITATION COMME LIEU D'EXPRESSION DES CROYANCES POPULAIRES}

Plusieurs habitats protohistoriques de Martigues fournissent une documentation à la fois abondante et originale sur le rôle de l'habitation comme cadre privilégié des pratiques rituelles à vocation domestique et familiale. Même s'il est parfois hasardeux d'attribuer un usage précis aux vestiges à qui l'on confère une destination votive ou religieuse, nous rangeons dans cette catégorie les objets ou aménagements dont les critères de fonctionnalité et d'utilisation ne sont pas opérants pour expliquer leur présence à l'intérieur des habitations.

\section{Des objets porteurs d'une charge spirituelle}

Dcs éléments isolés peuvent relever de pratiques de magie ou de superstition. De rares objets insolites présents dans les maisons, hors de tout contexte utilitaire, peuvent être assimilés à des porte-bonheur ou gris-gris. Ainsi les fossiles et minéraux ou les haches de pierre polie du Néolithique, objets ramassés par des agriculteurs ou exploitants forestiers.

À côté d'objets à la fonction ubiquiste, comme les disques perlés en bronze, les rondelles taillées dans des tessons de céramique ou les statuettes d'animaux, d'autres éléments miniatures, le plus souvent métalliques, relèvent à l'évidence de cette sphère magico-religieuse. C'est le cas de deux haches miniatures et d'une petite herminette factice en bronze issues respectivement de Saint-Pierre et Tamaris ou encore d'un murex transpercé par un clou en fer dans le premier village du quartier de l'île. Sa découverte près du seuil d'une maison permet de restituer son enclouage sur la porte de l'habitation et de l'interpréter comme une amulette prophylactique pour la maison concernée.

\section{La ritualisation de l'espace domestique}

Dans d'autres cas, la charge spirituelle des objets mobiliers n'est pas intrinsèque, mais s'affirme par le contexte de découverte qui traduit alors une mise en scène particulière au sein de l'espace domestique quotidien. C'est le cas de deux dépôts de poteries que l'on trouve sur

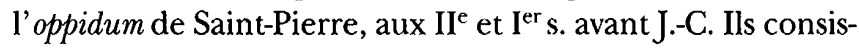
tent soit dans le regroupement de céramiques miniatures, soit dans la mise en place d'une grande urne en céramique non tournée, en position debout, sous le sol de l'habitation. 


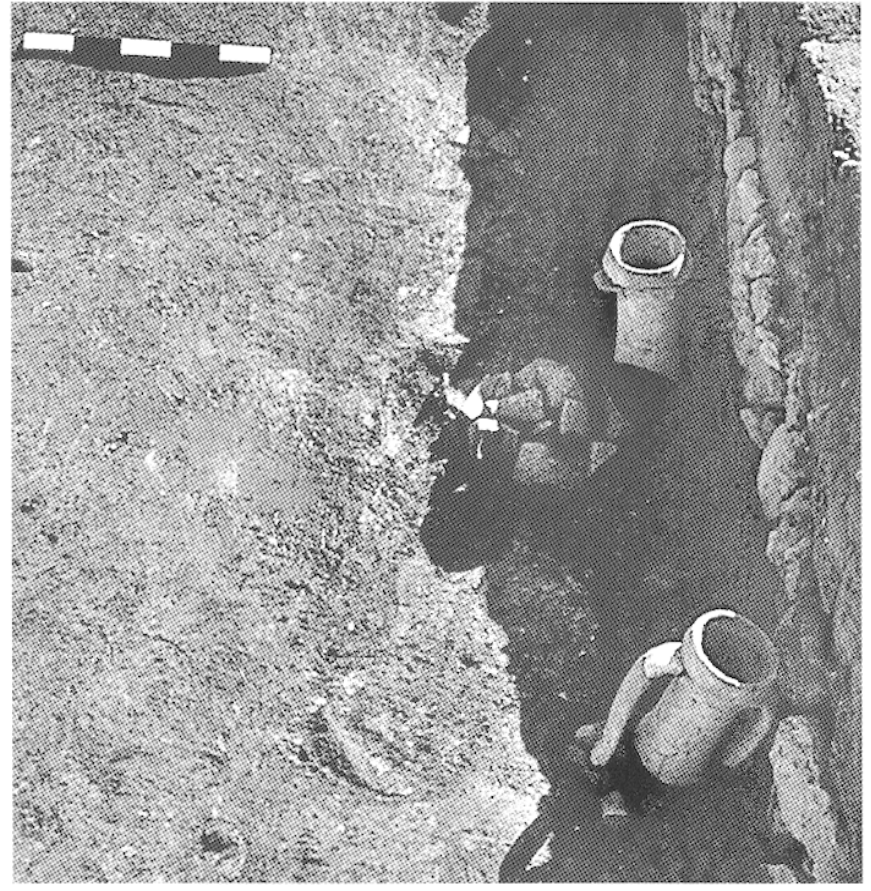

Fig. 130 - Martigues (Bouches-du-Rhône), L'Tlle. Cols d'amphores italiques servant de réceptacles ou de conduits à libation dans une habitation (II s. av. J.-C.) (photo J. Chausserie-Laprée, ville de Martigues).

La singularité du dépôt tient d'une part au contenu du vase, qui ne renfermait que du sable fin déposé sur le fond, avec une coupelle en pâte grossière, d'autre part au fait que le col de cette urne soit proprement et volontairement transpercé par un coup de lance ou de javelot.

On peut sans doute rapprocher ces vestiges des pratiques de libations attestées à Saint-Pierre et dans l'île par la découverte de portions de vases (cruche ou amphore) plantés verticalement pour servir sans doute de conduit ou réceptacle à des liquides versés dans le sol de l'habitation (fig. 130). La ritualisation de l'espace domestique s'exprime surtout par les très nombreux dépôts en fosse de restes animaux que l'on trouve dans lcs bourgades protohistoriques du territoire de Martigues.

Qu'ils soient limités à quelques exemplaires comme à l'Arquet et dans les deux villages du quartier de l'île, ou présents par centaines comme à Saint-Pierre, ces dépôts ne concernent strictement que le domaine intérieur de la maison à l'exclusion de tout autre. Actuellement en cours, la recension et l'étude de ces structures montrent que ces dépôts échelonnés entre le $\mathrm{V}^{\mathrm{e}}$ et le $\mathrm{I}^{\mathrm{er}} \mathrm{s}$. avant J.-C. renferment majoritairement des ossements d'ovicapridés, moutons et chèvres (près de $75 \%$ du total des ossements), et de suidés (de l'ordre de $20 \%$ ). D'autres particularités fauniques concourent à distinguer ces dépôts de simples

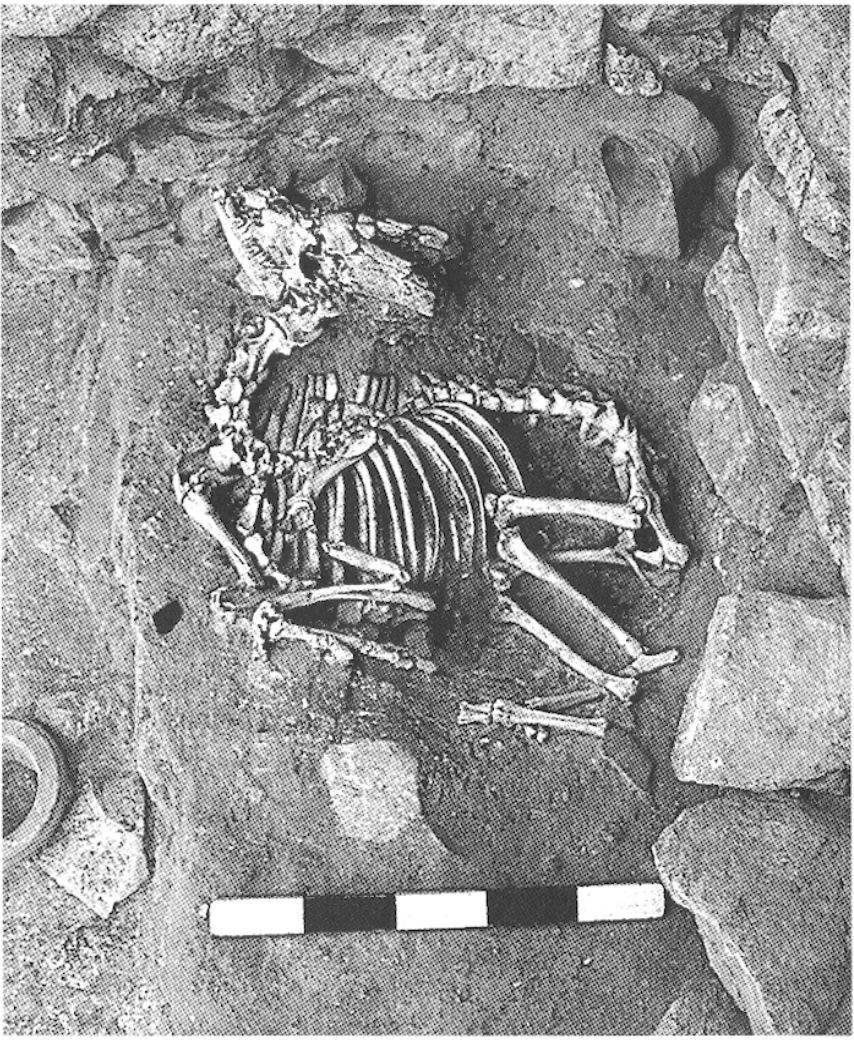

Fig. 131 - Martigues (Bouches-du-Rhône), Saint-Pierre. Squelette complet d'une chèrre disposé dans une fosse à l'angle d'une habitation (IV s. av. J.-C.) (photo J. Chausserie-Laprée, ville de Martigues).

poubelles alimentaires. Elles concernent d'abord l'âge des animaux abattus qui sont le plus souvent des animaux jeunes, voire très jeunes. Selon les premiers résultats recueillis à Saint-Pierre, plus de $80 \%$ des animaux ont moins de trois mois. Si l'on trouve souvent les ossements d'un seul animal, soit sous la forme de l'essentiel du squelette, soit représenté par un seul ou quelques éléments significatifs, la tête par exemple, il existe également des cas de dépôts beaucoup plus considérables qui voient l'accumulation d'un grand nombre d'individus dans des ensembles qui peuvent occuper plus de $1 \mathrm{~m}^{2}$. Enfin la présence de restes de cendres et charbons de bois, comme les traces de découpe et de carbonisation de certains ossements montrent que parfois les animaux étaient préalablement découpés, cuits, voire mangés avant d'être mis dans la fosse. Pourtant, la consommation préalable de la viande ne semble pas être la règle, comme l'indiquent, d'une part, l'existence de connexions anatomiques dans certains dépôts, d'autre part la découverte des squelettes de deux ovicapridés entiers ou presque entiers dans des maisons de Saint-Pierre des $V^{e}$ et $I^{e}$ s. avant J.-C. (fig. 131). Nous sommes ici en présence de vestiges relatifs à des sacrifices 


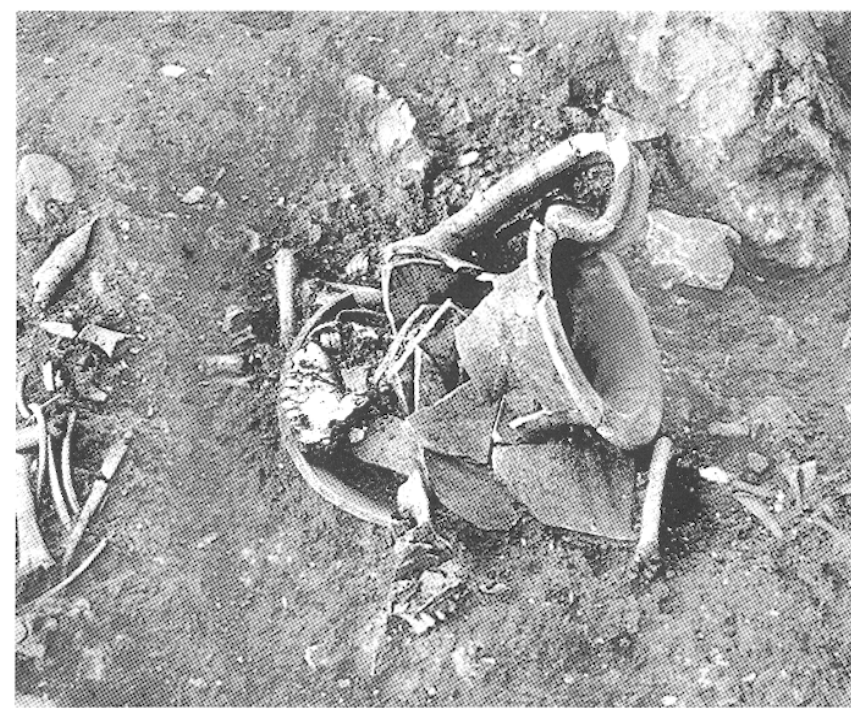

a

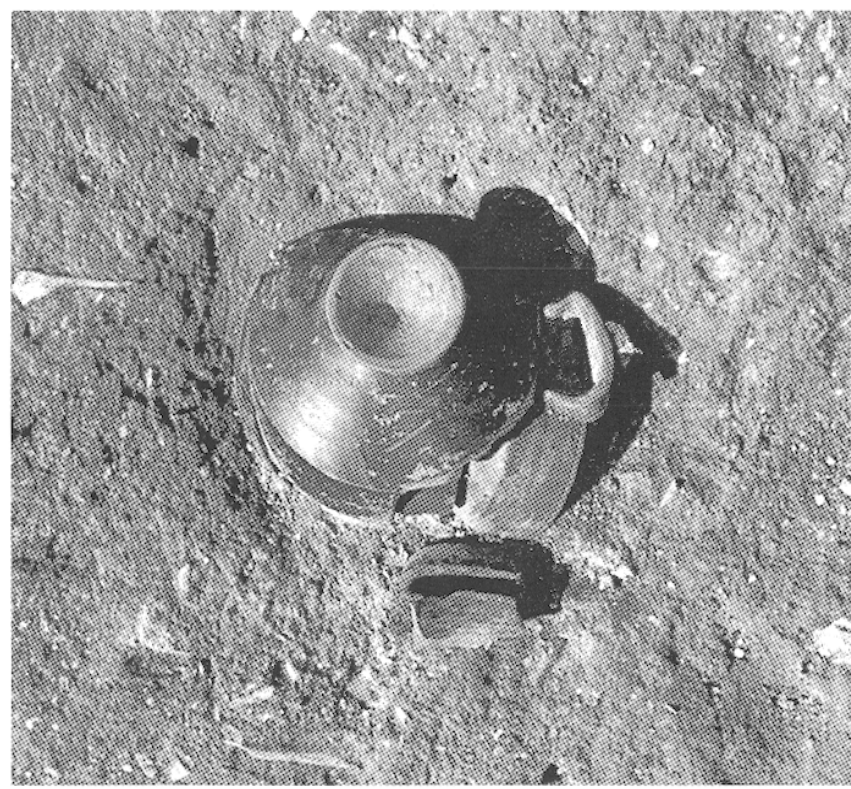

b

Fig. 132 - Martigues (Bouches-du-Rhône), Saint-Pierre : a, cruche en céramique claire au sein d'un dépôt mis au jour sous le sol d'une habitation; $b$, autre dépôt avec un bol italique à vernis noir utilisé comme couvercle (début du II s. av. J.-C.) (photos J. ChausserieLaprée, ville de Martigues).

d'animaux sans traces d'ignition et de consommation qui ne trouvent pas d'équivalent dans les autres habitats du Midi gaulois. Rarement protégés par un entourage de pierres, ces dépôts sont parfois aussi accompagnés de rares offrandes métalliques et poteries, généralement des cruches, bols et coupes, qui servent de réceptacle, couvercle ou simplement de vases d'accompagnement (fig. 132).
Ces fosses paraissent pour la plupart le produit de rites familiaux qui s'expriment par le sacrifice d'animaux domestiques et le dépôt d'objets usuels. Elles résultent de repas liturgiques, accompagnés ou non de libations, et de ce fait peuvent être qualifiées de votives. Si nous ignorons tout des cérémoniels qui les entourent, on peut penser qu'elles répondent aux manifestations des événements de la vie familiale et de celles des festivités du cycle saisonnier des activités agropastorales.

\section{SYMBOLES CULTUELS EN PIERRE}

Les villages de l'île et de Saint-Pierre à Martigues ont livré une documentation importante relative à des pratiques religieuses dont l'expression matérielle se traduit par l'érection ou la mise en scène d'éléments en pierre taillée. On distingue ici deux types de documents qui ne paraissent pas répondre aux mêmes pratiques religieuses.

\section{Les croissants}

Il s'agit de monolithes en forme de croissant dont l'existence apparaît limitée à la région de Martigues. Ils évoquent des pratiques cultuelles en milieu domestique.

Dans le quartier de l'île tout d'abord, deux pierres de calcaire local très volumineuses (L. : $1 \mathrm{~m}$; ép. : 0,25-0,30 m ; H. : 0,11-0,72 m), taillées en croissant de lune, ont été découvertes dans une rue, appuyées de chant contre le mur de façade d'une maison. L'une comme l'autre offrent une grande face arrière brute d'arrachage, alors que la seconde grande face latérale se trouve dégrossie au moyen d'un outil tranchant du type marteau taillant (fig. 133). Seule la face supérieure, au profil concave très incurvé, est finement travaillée à l'abrasif. La présence d'un chanfrein sur l'arête commune aux faces avant et haute dénote une volonté d'exposition de ces deux côtés au détriment de la face arrière. Les fouilles de l'oppidum de Saint-Pierre ont livré quatre pierres similaires, de dimensions cependant plus modestes. Dans un cas, le croissant, daté du $\mathrm{II}^{\mathrm{c}}$ s. avant J.-C., a pu être retrouvé en situation, dans une maison de la partie haute du site. Il reposait à plat sur une grande dalle calcaire, elle-même assise sur un lit de sable jaune (fig. 134).

L'hypothèse d'une vocation cultuelle est suggérée par la forme même des blocs, et les rapprochements que l'on ne manque pas de faire avec d'autres civilisations où des documents de nature proche sont connus en contexte indiscutablement religieux.

L'exhibition des croissants de pierre au sein de l'espace domestique est supposée, d'une part, en raison de l'absence de traces d'usure sur les pierres indiquant une fonction artisanale ou utilitaire, d'autre part, par l'existence d'une dalle 


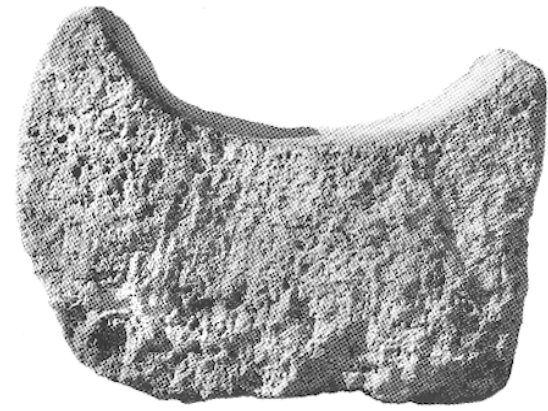

a

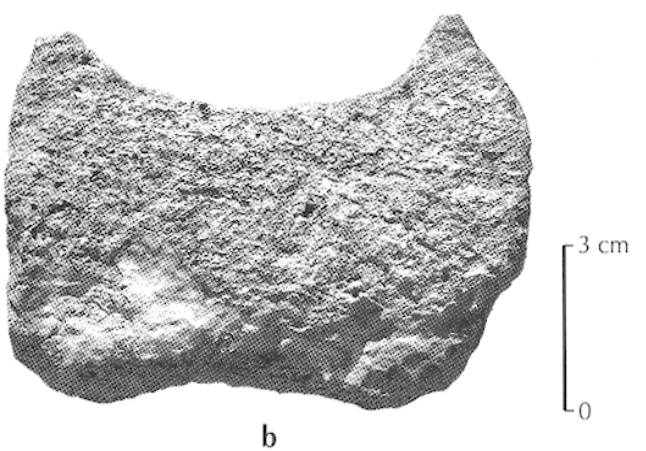

Fig. 133 - Martigues (Bouches-du-Rhône), LÎle. Les deux faces du plus grand des deux croissants en pierre découverts en remploi dans une ruelle du village (IVk s. av. J.-C.) (photos J. Chausserie-Laprée, ville de Martigues).

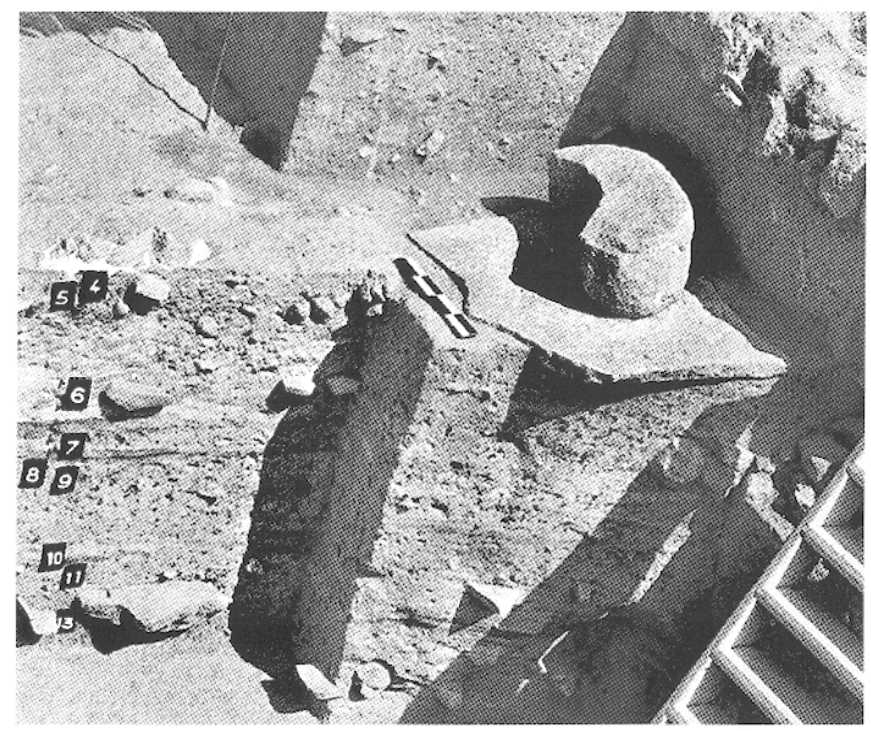

Fig. 134 - Martigues (Bouches-du-Rhône), Saint-Pierre. Croissant de pierre retrouvé couché sur sa dalle de présentation au sein d'une habitation du village (II' s. av. J.-C.) (photo C. Lagrand, CNRS). de présentation associée à un des croissants. Pour les pierres les plus importantes, la finition de la face supérieure pourrait aussi s'accorder à l'utilisation ou la mise en scène symbolique de ces monolithes comme sièges. Mais l'existence ponctuelle et trop peu explicite de ces formes de pierre nous incite à la prudence sur leur vocation précise.

\section{Les stèles}

D'autres documents permettent d'approcher la vie religieuse et politique qui s'exprimait plutôt hors de l'agglomération. Il s'agit des nombreuses stèles en pierre mises au jour hors contexte ou en remploi dans la construction de remparts, de murs ou d'aménagements intérieurs d'habitations des villages de l'île et de Saint-Pierre. Ce sont des monolithes de petite ou moyenne dimension, taillés dans des roches locales tendres ou fermes. Leur forme générale dessine un fût de section rectangulaire aminci vers le haut dont les arêtes sont le plus souvent chanfreinées et la base laissée brute ou sommairement dégrossie. Elles possèdent un sommet arrondi, biseauté ou déprimé. La réalisation des cippes est effectuée principalement à l'aide d'un outil du type polka. La finition, souvent très poussée, montre l'emploi constant d'outils abrasifs dont l'usage hérité des techniques de taille préhistorique ne laisse pas encore la place aux outils issus des techniques grecques, du type marteau-taillant.

À Saint-Pierre, les recherches entreprises dans la partie sud de l'oppidum, et tout spécialement celles qui ont concerné le dégagement du système de fortification, ont permis de mettre au jour une trentaine de monolithes pouvant être interprétés comme des stèles (fig. 135). Le contexte de découverte de certaines d'entre elles vient confirmer les données acquises sur quelques autres habitats protohistoriques du Midi, qui tendent à placer leurs remplois aux $\mathrm{VI}^{\mathrm{e}}$ et $\mathrm{V}^{\mathrm{c}} \mathrm{s}$. avant J.-C. Le fait le plus remarquable concernant les stèles de Saint-Pierre est celui de la présence d'un décor gravé sur de nombreux exemplaires connus. Il s'agit le plus souvent d'incisions, plus ou moins profondes, formant des figures géométriques diverses à base de lignes brisées ou de lignes parallèles disposées de manière symétrique ou inscrites dans un bandeau. Ce type de décor doit être rapproché des motifs incisés sur les céramiques non tournées de la fin du VII ${ }^{\mathrm{c}} \mathrm{s}$. ou de la première moitié du $\mathrm{VI}^{\mathrm{c}} \mathrm{s}$., attestées par exemple à SaintBlaise. Sur quelques stèles, on note également des figures en creux obtenues par évidement et polissage de cannelures peu profondes. Sur la stèle la mieux conservée, le décor dessine des motifs variés: triangles, quadrilatères losangiques, cercles, traits qui s'assemblent de manière asymétrique et non répétitive (fig. $135 \mathrm{c}$ et $\mathrm{d}$ ). Ce type de déco- 

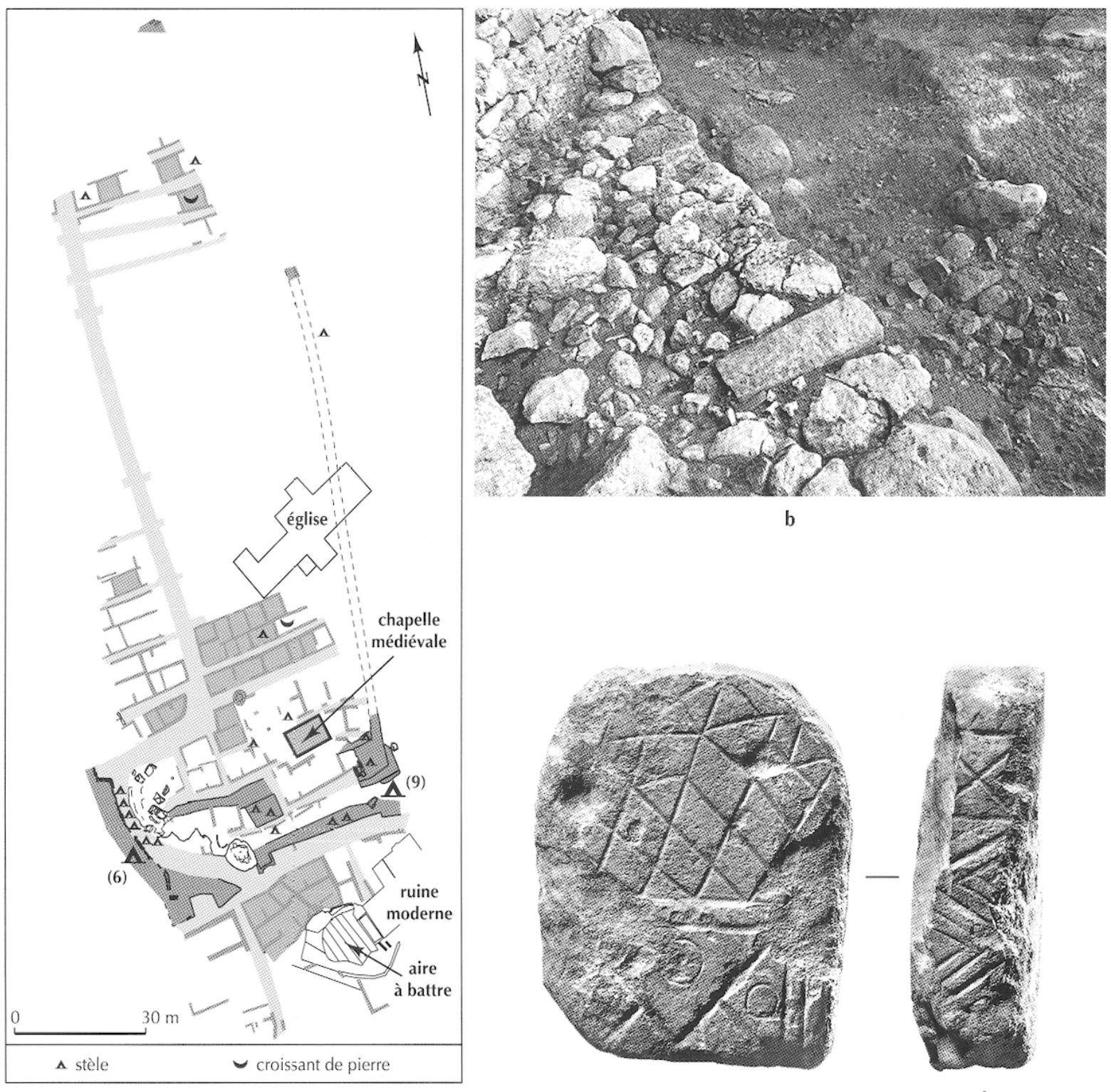

b

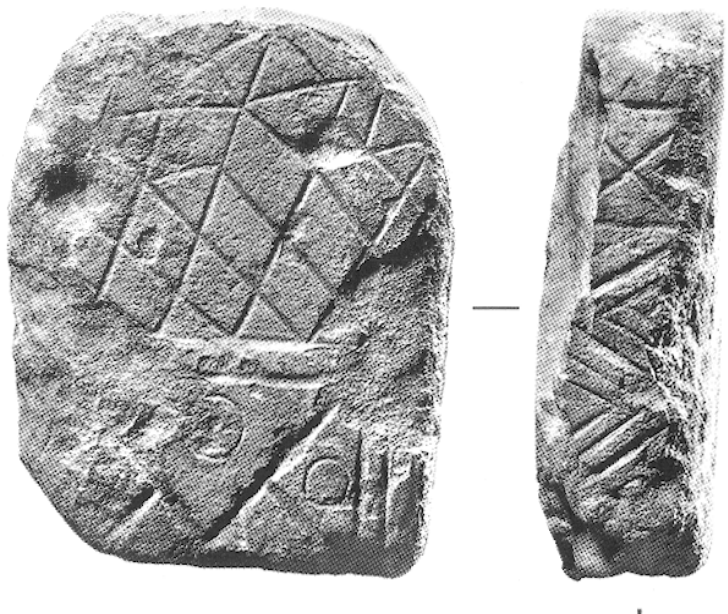

d

Fig. 135 - Martigues (Bouches-du-Rhône), Saint-Pierre :

$a$, plan de répartition des stèles au sein du village protohistorique; $b$, stèles remployées dans la fortification sud-ouest;

$c, d$, face et profil d'une stèle à décor géométrique (dessin M. Rétif; photos J. Chausserie-Laprée, ville de Martigues et C. Durand, CNRS).

ration apparaît original dans le corpus des stèles préromaines du Midi de la Gaule et semble plus facilement se rattacher aux stèles richement décorées du Bronze final découvertes à Buoux dans le Vaucluse et Sextantio en Languedoc. Mais le décor le plus singulier concerne une stèle fragmentaire, en remploi dans la fortification du début $\mathrm{du} \mathrm{V}^{\mathrm{e}}$ s. avant J.-C., dont l'une des faces montre la représentation incisée à la pointe fine de la partie centrale ainsi que de la poupe relevée d'un bateau avec gouvernail, rames et gréement.
Les pierres du second village du site de l'île, au nombre de 18 , sont plus homogènes que les précédentes. L'un des apports importants de ces derniers blocs concerne la présence de trois supports de stèles, taillées dans un calcaire local très semblable à celui des cippes. Ils permettent de visualiser la manière dont une partie des stèles était présentée dans ses emplacements d'origine. Ils supposent une certaine mise en scène des pierres elles-mêmes qui pouvaient, comme l'indique un support double, être disposées dos à dos. 
Pour apprécier la période d'utilisation de ces stèles, à laquelle doit être associée celle du démantèlement des lieux où elles étaient exposées, nous manquons à Martigues, commc sur presque tous les sites du Midi, de documents mis au jour en position et contexte originaux. Les cippes découverts à Saint-Pierre, par leur technique de façonnage, leur décoration et la chronologie de leur remploi tendent cependant à renvoyer leur utilisation primaire à une phase haute de l'âge du Fer méridional, voire de la fin de l'âge du Bronze.

Bibliographie : Lagrand, 1979; Columeau, 1991 ; Bessac, Chausserie-Laprée, 1992 ; Duval, 1998 ; Nin, 1999 ; Arcelin, 2000a ; Rétif, 2000.

\section{J. Chausserie-Laprée}

\section{NOTICE 5}

\section{SAINT-RÉMY-DE-PROVENCE (BOUCHES-DU-RHÔNE)}

\section{GLANON}

\section{Aires cultuelles à l'extérieur de la première enceinte}

Au débouché nord d'un vallon, voie de franchissement des Alpilles, une source pérenne a suscité une fréquentation dès l'âge du Bronze, puis une occupation aux $\mathrm{VI}^{\mathrm{c}}-\mathrm{V}^{\mathrm{e}} \mathrm{s}$. avant J.-C. Un rempart protège alors sur 20 ha le vallon et les collines avoisinantes, dont la plus haute, le mont Gaussier, culmine à près de $200 \mathrm{~m}$ au-dessus de la source. Vers 100 , un second rempart double du côté nord la superficie du site. $\mathrm{Au} \mathrm{II}^{\mathrm{e}}$ s. avant J.-C., Glanon fait l'objet d'un programme urbanistique et monumental remarquable, notoirement hellénisé, mais la culture indigène s'y affirme avec une égale vigueur. La ville est détruite à deux reprises, à une époque qui en fait chercher la cause dans les deux campagnes de la conquête romaine en pays salyen (125-122 et 90 avant J.-C.). Dans les années quarante, Glanum reçoit le titre d'oppidum Latinum ct plus tard, pcut-être, celui de colonie latine. Le site est abandonné vers 260 après J.-C.

\section{Un ensemble cultuel près de l'accès au vallon}

Les structures décrites plus loin (monument XLV), que leur fouilleur $\mathrm{H}$. Rolland qualifiait $\mathrm{d}^{\prime}$ " oratoires " et les auteurs récents d' "hérôa", se situent à l'extérieur du premier rempart, à une dizaine de mètres au nord-ouest de la porte (fig. 136 et infra, p. 233-234). Elles s'adossent à la paroi rocheuse du vallon, au pied d'une terrasse en pierres sèches qui est peut-être la courtine du rempart, percée d'une porte à laquelle un escalier donnait accès. Dans le troisième quart du $\mathrm{I}^{\mathrm{er}}$ s. avant J.-C., ces monuments préalablement détruits sont recouverts par un dallage supportant un monument corinthien.

Le premier monument, le mieux conservé, se trouvait immédiatement au sud de l'escalier d'accès à la terrasse (fig. 137a). Quatre blocs de calcaire tendre servaient de fondations, disposés en un carré d'à peu près 1,70 m de côté. Au centre, un autre de $60 \mathrm{~cm}$ de côté portait un pilier de section quadrangulaire $(30,5 \mathrm{~m} \times 36 \mathrm{~cm})$, conservé sur une hauteur de $63,5 \mathrm{~cm}$, aux angles chanfreinés concaves et à la base décorée de postes peintes. Il paraît avoir servi de socle à la statue d'un homme assis en tailleur, dont la partie inférieure a été trouvée à terre (H. conservée : $41 \mathrm{~cm}$ ), à l'angle nord-ouest du monument (fig. 138a). La statue était solidaire d'un socle de $57 \mathrm{~cm}$ de côté, flanqué de quatre acrotères et comportant au lit de pose une mortaise d'encastrement sur le pilier; il n'en reste que les jambes croisées et le bassin, vêtu du bas d'une tunique (fig. 138b et c) (Gallia, XXVII, 2, 1969, p. 443, fig. 27). Derrière le pilier, de part et d'autre, se dressaient deux stèles aux angles arrière chanfreinés concaves, de $20 \mathrm{~m}$ x $35 \mathrm{~cm}$ de section et $70 \mathrm{~cm}$ de hauteur conservée; leurs quatre faces étaient peintes de motifs géométriques, de postes et de chevaux (fig. 138c). Entre ces stèles verticales et sur le côté sud du monument se trouvaient trois blocs parallélépipédiques couchés, dont deux à sommet arrondi pourraient être des stèles.

À $2 \mathrm{~m}$ au nord-ouest, les vestiges d'un autre pilier suggèrent l'existence d'un second aménagement de même type, mais réduit à son seul élément central : un pilier enfoncé de $45 \mathrm{~cm}$ dans le sol, ne dépassant plus que de $18 \mathrm{~cm}$ au-dessus du socle fait de deux blocs mortaisés entre lesquels il s'encastrait. À proximité immédiate ont été retrouvés d'autres éléments de statuaire : une autre partie basse de personnage assis sur un socle à acrotères et vêtu d'une tunique laissant apparaître le sexe ; un buste voisin s'y adapte (fig. 121a). Un troisième socle à acrotères se trouvait dans le blocage du mur de l'égout principal, devant le «bouleuterion».

$\mathrm{Du}$ même secteur proviennent plusieurs fragments de piliers et un linteau à alvéoles céphaliformes, découverts en remploi (fig. 116a et 139). Le linteau, ceint sur ses quatre côtés d'un couronnement à rai-de-cœur, montre quatre cavités sur la face et une sur le côté droit (fig. 116b). Les piliers étaient en remploi dans les fondations de la tour du rempart XXXIII, de la salle hypostyle XXXII, et du «bouleuterion »XXIX (fig. 136b). Deux crânes trépanés ont été trouvés sur le sol d'abandon d'une salle de l'édifice à péristyle trapézoïdal LVII, en compagnie d'un fragment de stèle et de bols campaniens gravés EПO après cuisson. D'autres stèles ont été découvertes, abandonnées ou en 


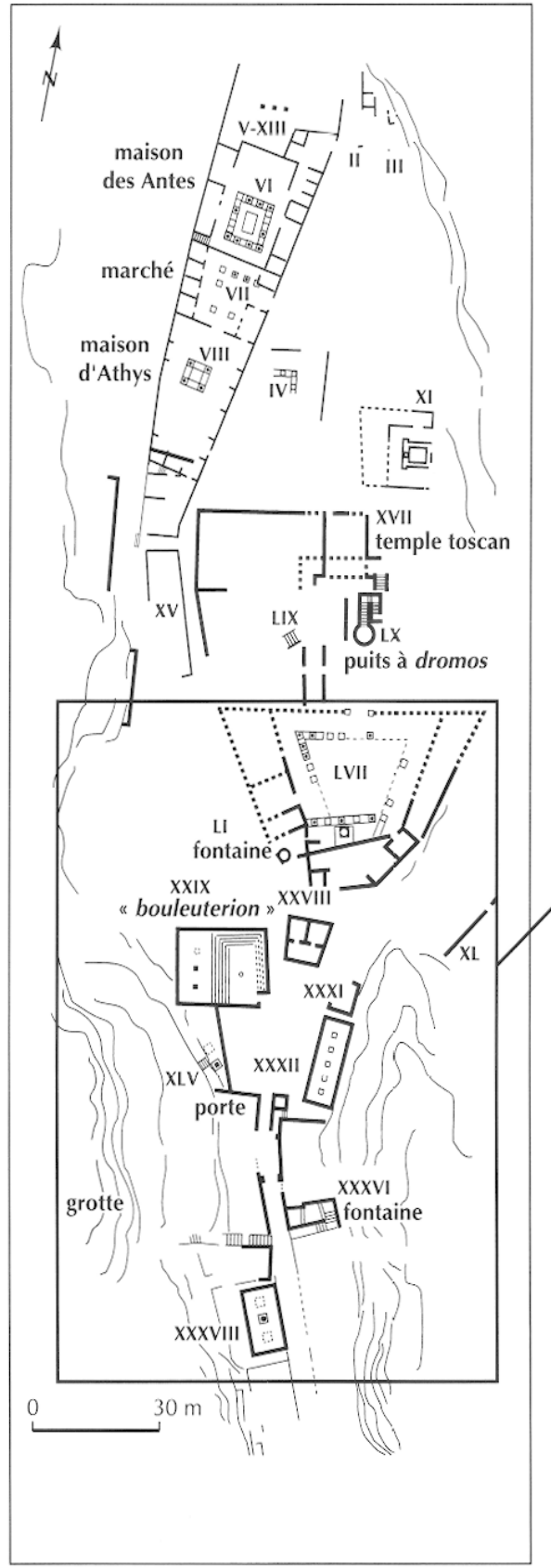

a

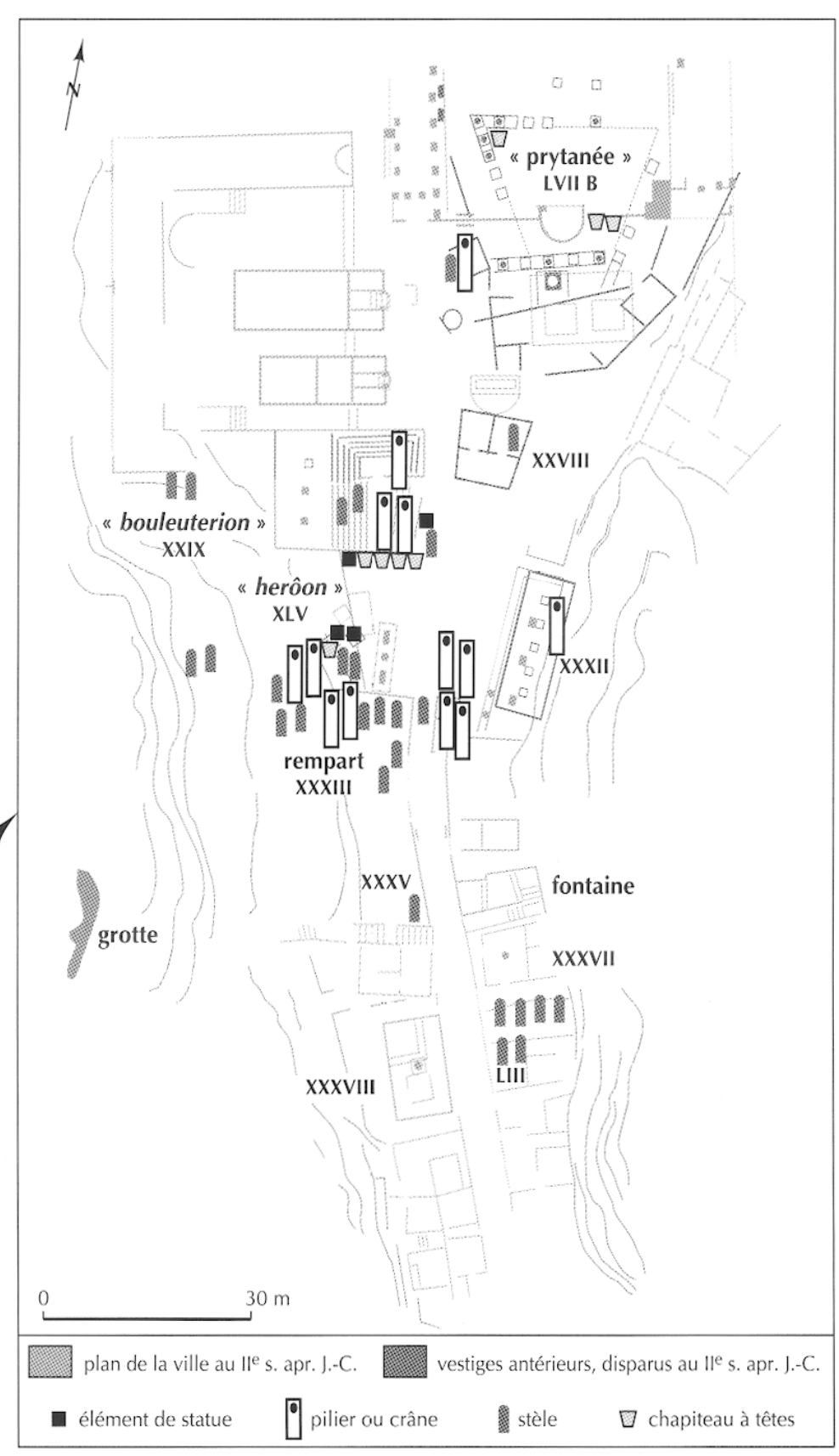

b

Fig. 136 - Saint-Rémy-de-Provence (Bouches-du-Rhône), Glanon. Plan général de l'agglomération tardo-hellénistique, fin du II s.début du $I^{\text {er }}$ s. av. J.-C. : a, emplacement délimité du secteur de concentration des éléments architecturaux et sculptés antérieurs à 125 av. J.-C. ; b, détail de la zone concernée, avec l'indication de l'emplacement des différents remplois, selon leur nature (relevé A. Roth Congès, CNRS).

remploi, dans le quartier au nord du rempart (édifices LVII, XXVIII, XXIX, XLV), dans le rempart lui-même (XXXIII) (voir infra, p. 233-234), dans le vallon, et sur les terrasses qui dominent à l'ouest ce quartier.

\section{La destruction du sanctuaire salyen}

$\mathrm{H}$. Rolland considère que les deux monuments aux statues assises étaient en usage lors de la destruction générale du site à la fin du $\mathrm{II}^{\mathrm{e}} \mathrm{s}$. avant J.-C., qu'il attribuait 


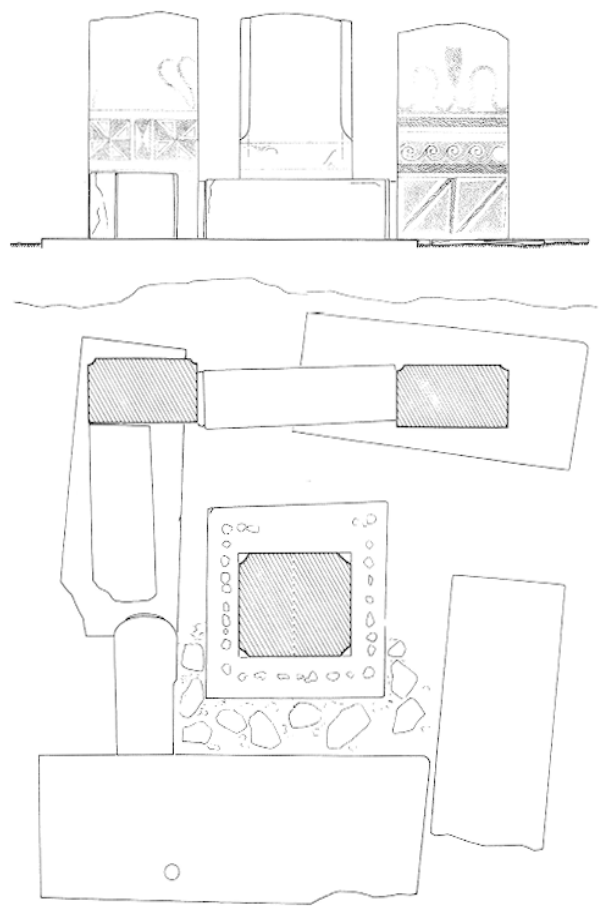

a

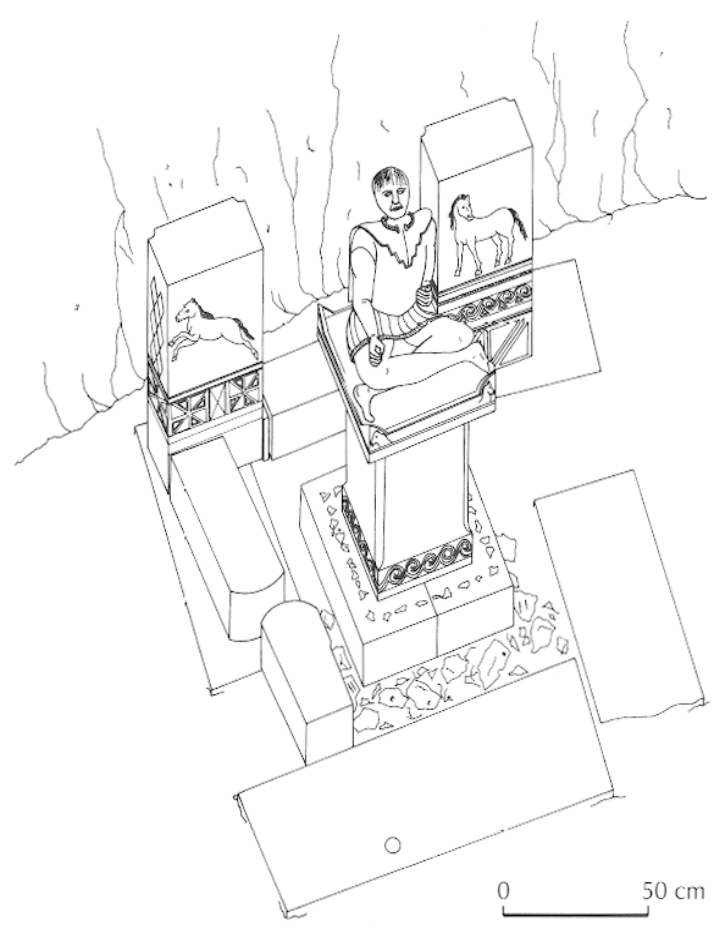

b

Fig. 137 - Saint-Rémy-de-Provence (Bouches-du-Rhône), Glanon : a, relevé du monument XLV-sud en 1968 par J. Bruchet (Gallia, XXVII, 2, 1969, p. 445); b, proposition de restitution de lhérôon (d'après Barbet, 1991, p. 72, fig. 15).

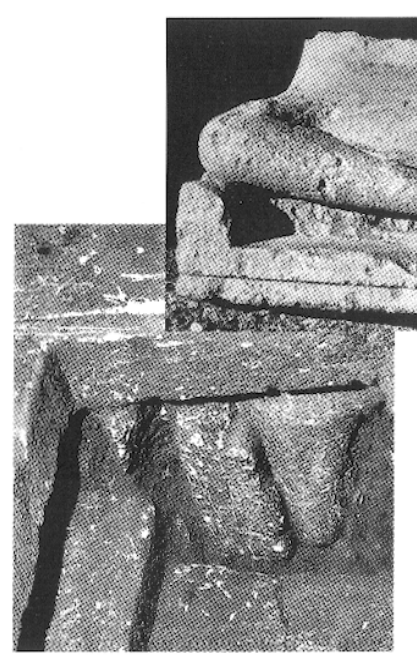

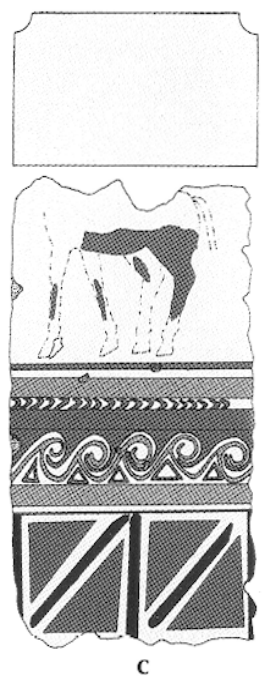

Fig. 138 - Saint-Rémy-de-Provence (Bouches-du-Rhône), Glanon : $a, b$, base de la sculpture d'un personnage assis découvert en 1968 contre le monument XLV-sud (l. du socle: $57 \mathrm{~cm}$ ) (photo H. Rolland); $c$, une des stèles à décor polychrome encadrant le pilier-support, à la droite du monumenl de la fig. $137 b$ (d'après Barbet, 1991, p. 62, fig. F).

Fig. 139 - Saint-Rémy-de-Provence (Bouches-du-Rhône), Glanon. Deux éléments de piliers portant des alvéoles céphaliformes, remployés comme gradins dans le monument XXIX ou bouleuterion (voir fig. 116a) (relevés J.-L. Paillet, CNRS).
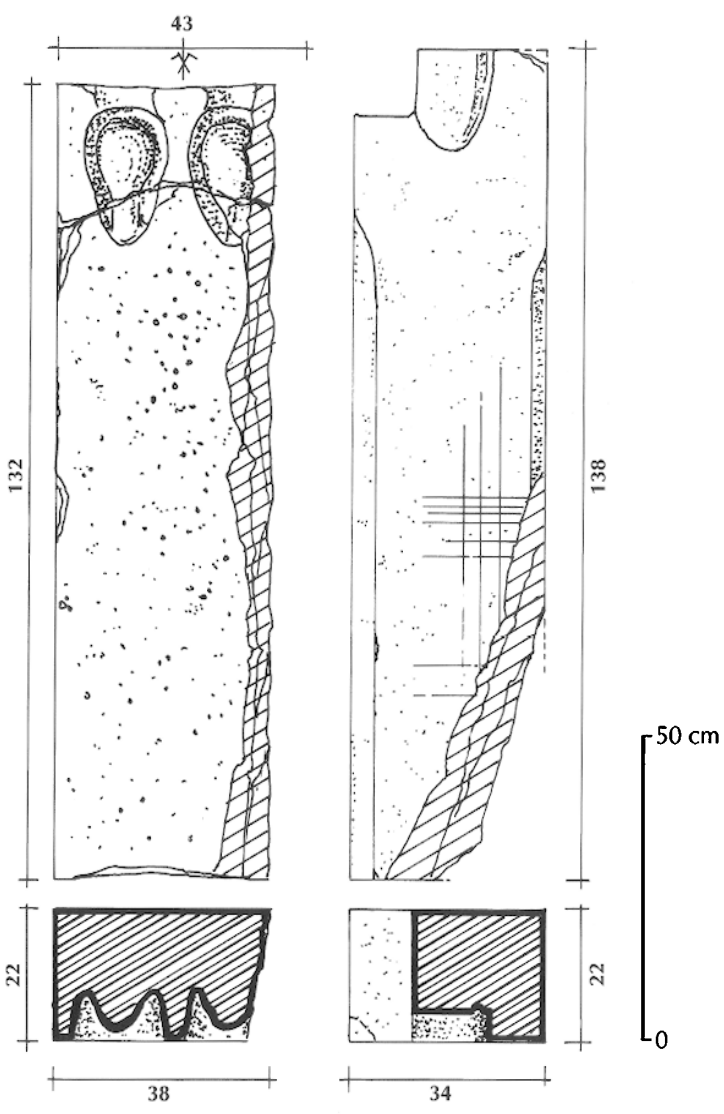

b 
aux invasions germaniques ; j'ai proposé de la rapporter à la dernière campagne romaine en pays salyen (90 avant J.-C.), ce qui reste compatible avec le matériel archéologique associé à ce niveau d'abandon. Il en va de même pour les crânes de l'édifice LVII. Mais des éléments de statuaire et piliers ont été trouvés en remploi dans les états les plus anciens du "bouleuterion" XXIX et de la salle hypostyle XXXII, qui paraissent contemporains du rhabillage en grand appareil du rempart XXXIII, lequel réutilise également des piliers à alvéoles (fig. 139). Ces édifices, qui semblent relever du même programme édilitaire que le monument LVI, dateraient comme lui du dernier quart du II $^{\mathrm{e}}$ s. avant J.-C., et auraient été bâtis avec des éléments provenant d'une destruction de la ville qu'on peut mettre en relation avec la conquête romaine de 125-122 avant J.-C. Le culte salyen remonterait donc au moins au milieu du $\mathrm{II}^{\mathrm{c}} \mathrm{s}$. L'existence des statues et des rites de décapitation à l'époque archaĩque n'est attestée par aucun vestige en place ou en remploi, mais d'assez nombreux sondages ont montré une occupation importante du site dès le tout début du premier âge du Fer.

Bibliographie : Rolland, 1968 ; Salviat, 1969 ; Barbet, 1991 ; Roth Congès, 1992b.

\section{A. ROTH CONGÈS}

\section{Éléments cultuels de la porte charretière de Glanon}

\section{La fouille}

Les fouilles de 1992 à 1996 ont mis en évidence au moins six phases différentes de la porte qui ferme le débouché du vallon de Notre-Dame de Laval sur la plaine (point XXXIII, voir fig. 140). Les constructions défensives se succèdent ainsi : 1) premier rempart en pierres sèches, mal conservé, non daté ; 2) deuxième rempart, dont le parement externe coupe une tombe du Bronze moyen à récent (terminus post quem) ; 3) troisième rempart, daté par un fragment de coupe attique vers 500 (terminus post quem), sans doute du $\mathrm{V}^{\mathrm{e}}$ ou du IV ${ }^{\mathrm{e}}$ s. avant J.-C. ; 4) rempart à deux tours quadrangulaires (IVe-II ${ }^{e}$ s. ?) ; 5) tour polygonale et terrasse ouest (II ${ }^{\mathrm{c}}$ s. avant J.-C.) ; 6) rempart de type hellénistique, en grand appareil.

La construction du mur 6 s'accompagne d'un déplacement de la porte et de la route ainsi que d'un détournement du torrent qui est canalisé plus à l'est. Elle est sans doute contemporaine de la construction de la salle d'assemblée XXIX (ou "bouleuterion") et du bâtiment trapézoïdal aux chapiteaux à têtes LVII (phase Ic de A. Roth Congès, quelque part entre le dernier quart du $\mathrm{II}^{\mathrm{e}} \mathrm{s}$. et le premier quart du I ${ }^{\text {cr }}$ s. avant J.-C.) et sans doute peu après l'abandon du « sanctuaire aux accroupis ».

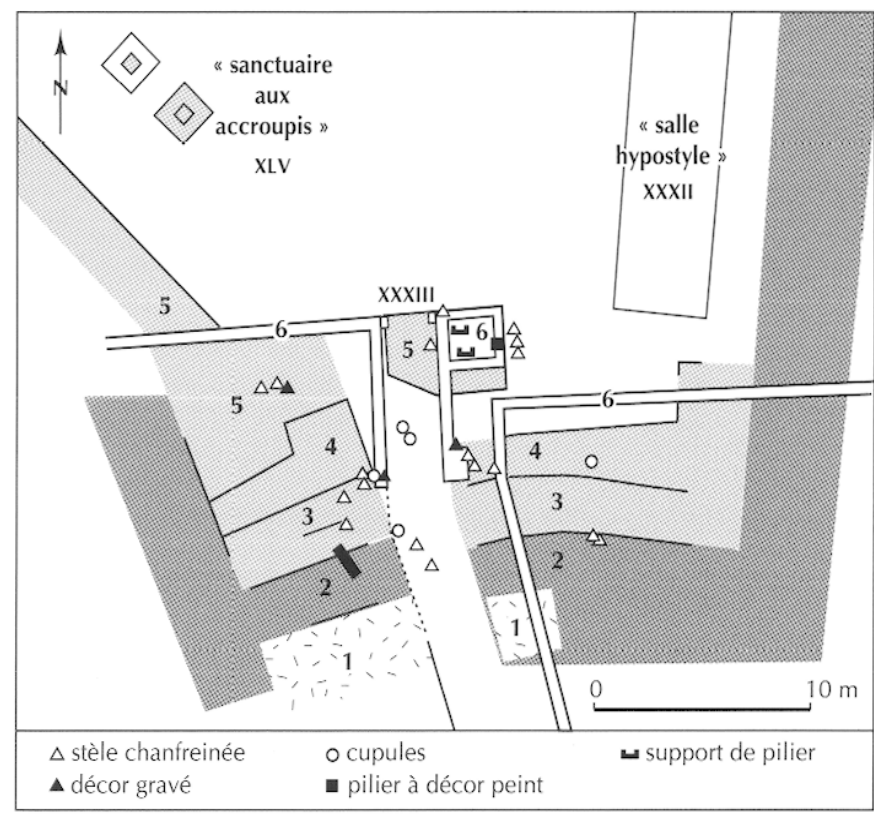

Fig. 140 - Saint-Rémy-de-Provence (Bouches-du-Rhône), Glanon. Plan schématique des six états successifs de la fortification (numérotés) autour de la porte au débouché du vallon de Notre-Dame de Laval (XXXIII). Répartition des stèles, bases et piliers sculptés (relevé J.-L. Paillet et H. Tréziny, CNRS).

\section{Les éléments de nature cultuelle}

Dans la fouille des fortifications autour de la porte charretière ont été recueillis des éléments cultuels en pierre : un pilier complet et un fragmentaire dans le remplissage de la tour (phase 6) ; un pilier incisé et peint pris dans la fondation orientale de la tour hellénistique (phase 6), il a été dégagé sur son côté est par H. Rolland en 1964 (relevé J. Bruchet), puis par nous en 1994 sur son côté ouest à l'intérieur de la tour (fig. 141) ; une stèle à décor piqueté et à chanfreins plats (fig. 142) composée de cinq fragments provenant du remplissage de la terrasse occidentale (phase 5 de la muraille ?). L'un d'eux est décoré, sur sa face principale, d'un cavalier brandissant une lance (inv. PC 58). La face opposée présente un rectangle cloisonné et l'une des faces latérales un autre cavalier suivi par un homme à pied (fig. 142b). Un autre fragment, l'élément sommital, porte vraisemblablement une ramure de cervidé (PC 48). Les cinq fragments suggèrent une restitution pyramidale à base rectangulaire haute d'environ 2,80 m (fig. 142c) ; un autre fragment de stèle portant des gravures de chevaux ou cervidés (PC 79) a été retrouvé dans les fondations du mur hellénistique, à l'intérieur de la poterne. Il n'a pu être dégagé.

Tous les décors de ces stèles, chevaux, cavaliers, rectangle cloisonné et cervidé, ont été exécutés à l'aide d'un 


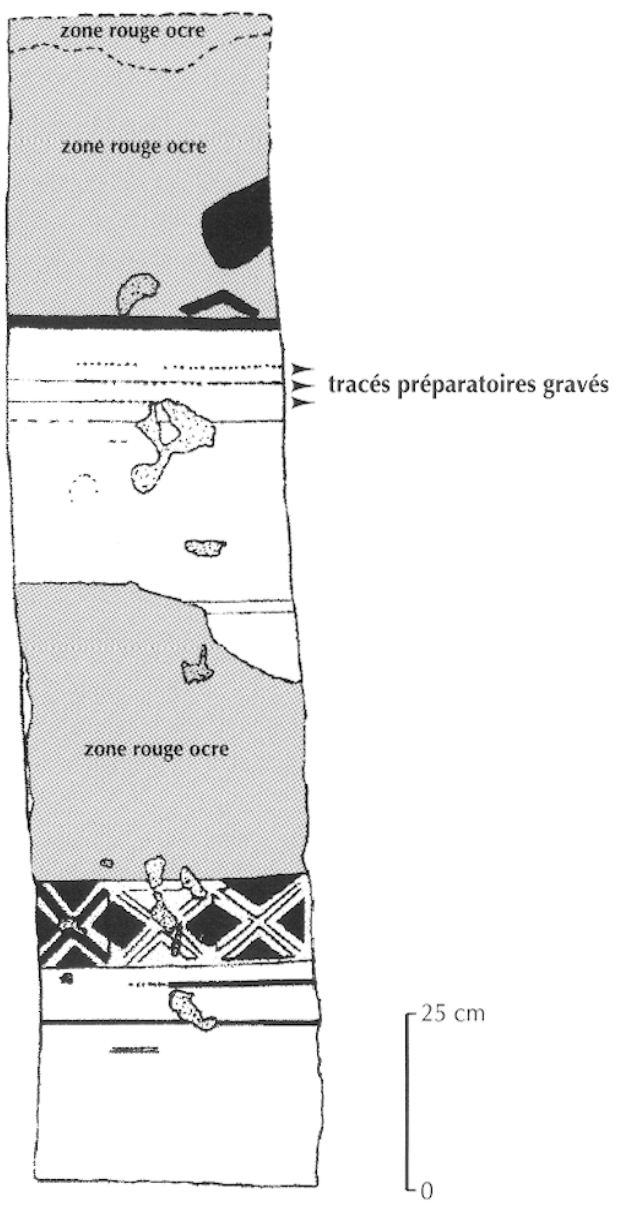

Fig. 141 - Saint-Rémy-de-Provence (Bouches-du-Rhône), Glanon. Relevé du pilier incisé et peint (ocre rouge), découvert en fondation de la tour hellénistique (phase 6) (relevé A. Barbet, CNRS).

outil à la pointe émoussée. Les traces laissées par cet outil ont la forme de petites cupules (fig. 104g). Si le percuteur avait été métallique, les marques auraient été beaucoup plus profondes et prismatiques; de plus, les contours des dessins seraient plus précis et linéaires. Il ne s'agit donc pas de dessins réalisés au « pic » mais à l'aide d'un percuteur lithique à extrémité plus ou moins émoussée.

Deux grandes stèles à cupules (PC 78 et 102) proviennent du secteur ouest de la porte. Plusieurs autres éléments de stèles chanfreinées sans décor visible sont issus de divers secteurs du rempart (fig. 140), du blocage de la couverture de l'égout dans son état récent (romain ?), et de la terrasse du temple de Valetudo.

\section{Quelques repères chronologiques}

Au total, seule la phase 1 du rempart ne comporte pas de stèles en remploi. Encore faut-il admettre que ce premier rempart n'est conservé que sur une faible élévation, sur le côté ouest de la porte. Dès la phase 2 (côté oriental) se trouvent des remplois en parement. La grande stèle de la figure 142 est remployée dans le blocage de la terrasse de la phase 5, alors que le pilier peint de la figure 141 et les supports de piliers ne se trouvent que dans la phase 6 , peutêtre liée à la destruction du "sanctuaire aux accroupis " fouillé par H. Rolland plus au nord-ouest (voir supra, p. 231).

Dans l'état actuel de la recherche, on restera donc très prudent sur l'interprétation des stèles (funéraire ou votive ?). À propos de leur chronologie, on peut déjà affirmer que celles remployées en tant que matériau de construction pour les remparts 2 et 3 avaient perdu leur fonction initiale au $\mathrm{V}^{\mathrm{e}}-\mathrm{VI}^{\mathrm{c}} \mathrm{s}$. avant J.-C. D'autre part, on peut penser que le "sanctuaire aux accroupis ", qui remploie à l'évidence des éléments plus anciens, pourrait être contemporain de la phase 5 ( $\mathrm{II}^{\mathrm{c}} \mathrm{s}$. avant J.-C.). Notons enfin l'absence dans la muraille des piliers et linteaux à alvéoles céphaliformes pourtant présents à proximité immédiate. Au grand linteau découvert par $\mathrm{H}$. Rolland contre le flanc nord de la tour de la poterne (fig. 116b), il faut ajouter plusieurs découvertes récentes dont celles de deux piliers à alvéoles céphaliformes remployés comme gradins dans le "bouleuterion » (fig. 139).

Bibliographie : Paillet, Tréziny, 2000.

J.-L. PAILlet et H. TrÉZinY

\section{NOTICE 6}

\section{SIGEAN (AUDE)}

\section{Рech Мано}

\section{Un ensemble à caractère public et cultuel dans l'habitat}

L'habitat protohistorique de Pech Maho a été occupé entre le milieu du $\mathrm{VI}^{\mathrm{e}}$ et la fin du $\mathrm{III}^{\mathrm{c}} \mathrm{s}$. avant J.-C. Les fouilles anciennement menées par J. Campardou, puis Y. Solier, ont permis de reconnaître l'existence de trois phases d'occupation successives, soit Pech Maho I (v. 575/550-475/450), II (v. 450-325/300) et III (v. 300$225 / 200)$. L'histoire du site s'achève brutalement dans le dernier quart du $\mathrm{III}^{\mathrm{e}} \mathrm{s}$. par une destruction généralisée, accompagnée de traces de combats violents.

La découverte en 1959 d'une sépulture à incinération, localisée dans le périmètre de l'habitat, a attiré l'attention des fouilleurs sur le possible caractère cultuel que pouvait revêtir le secteur adossé à l'enceinte dite intérieure, et situé à proximité de la porte principale (fig. 143). Par la suite, les travaux ont permis à la fois d'élargir la vision en plan de ce 

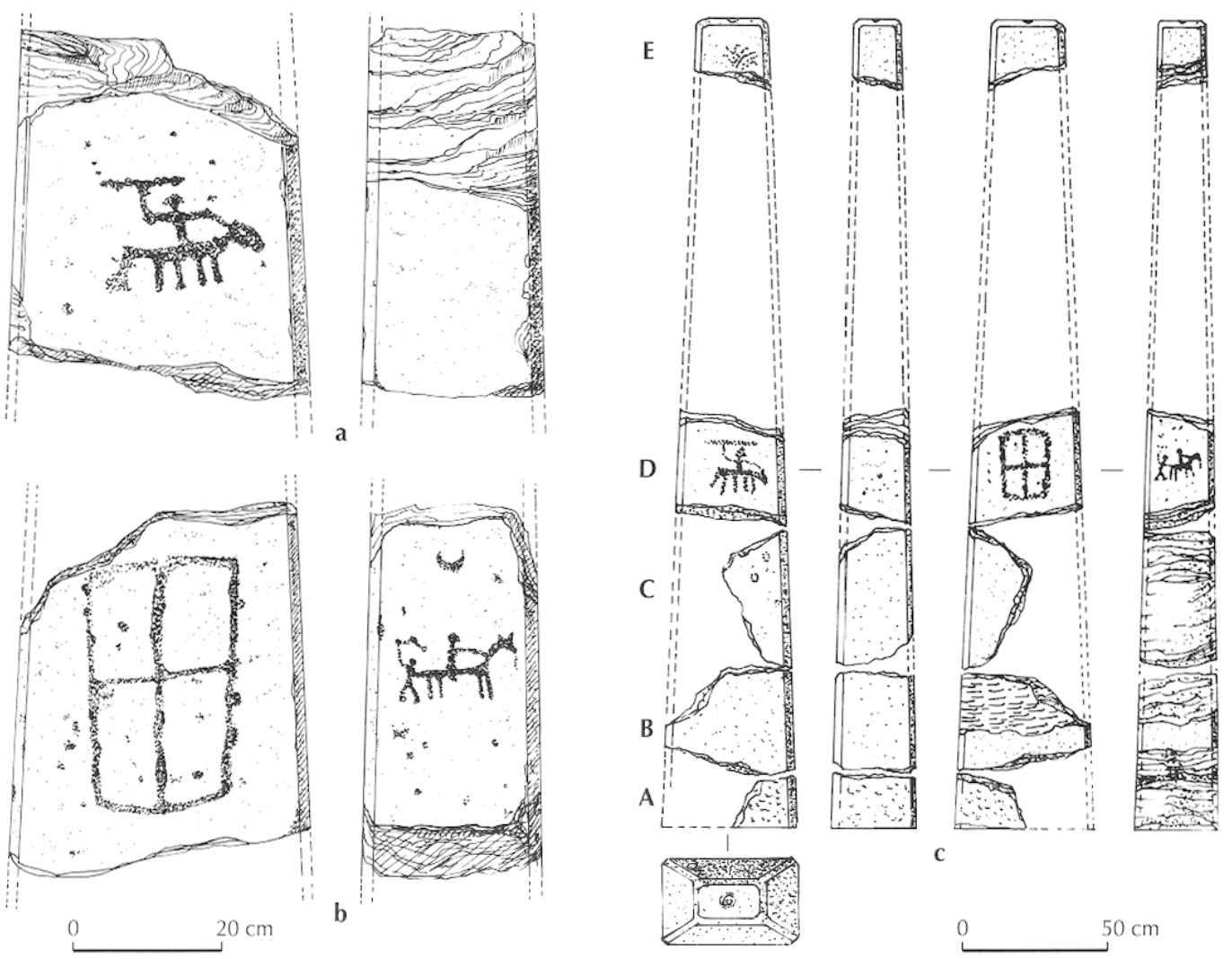

Fig. 142 - Saint-Rémy-de-Provence (Bouches-du-Rhône), Glanon :

$a, b$, deux aspects d'un élément de stèle chanfreinée pyramidale portant plusieurs motifs symboliques et réalistes obtenus par piquetage ; c, restitution de la stèle pyramidale à partir des cinq éléments retrouvés en remploi près de la porte (relevés J.-L. Paillet, CNRS).

quartier et de mettre en évidence l'existence d'aménagements à caractère public ou cultuel.

Le réexamen des données de fouilles anciennes, confronté aux résultats des travaux récents, menés tant sur l'architecture que sur le mobilier du site, permet aujourd'hui d'aller un peu plus loin dans l'interprétation de cet ensemble dont l'organisation s'avère complexe. La présence d'une sépulture à incinération dans l'habitat constitue en soi un fait marquant, d'autant que la richesse du mobilier renforce son caractère exceptionnel, d'où sa dénomination en tant que "tombe de chef " en liaison probable avec un véritable hérôon. La chronologie relative établie entre cette tombe et son environnement immédiat, en l'occurrence un podium dallé bordé de blocs taillés soigneusement ajustés courant le long des bâtiments 49D et 49B (fig. 143b), reste sujette à débat: une stricte contemporanéité entre la sépulture et le bâti n'est pas établie. L'édification de la terrasse est $a$ priori attribuée à la phase III du site. Dans le même temps, une datation voisine, soit dans la première moitié du III ${ }^{c}$ s., ressort de l'examen du mobilier de la tombe. Cependant, l'absence de dallage dans la partie septentrionale du podium, précisément là où se trouve la sépulture, laisse à penser que le revêtement initialement présent sur l'ensemble de la surface a pu être démonté au moment du dépôt funéraire, qui serait alors intervenu dans un second temps. On note par ailleurs que la tombe se situe à l'aplomb d'un dispositif en demicercle, adossé au mur de façade du bâtiment 49B. Il s'agit là manifestement de la base d'un ou plusieurs éléments exposés, parmi lesquels se trouvait peut-être une dalle (stèle ?) mentionnée par les fouilleurs, retrouvée basculée sur la terrasse. Enfin, un dépôt constitué d'une centaine de valves de Cardium a été mis au jour à proximité, à la base du podium.

Ce problème de contemporanéité n'est pas anodin, dans la mesure où il change la lecture que l'on peut faire du bâti environnant. Or, plus qu'une simple architecture liée à la sépulture, il semble bien que cette partie du site possède antérieurement au $\mathrm{III}^{\mathrm{e}} \mathrm{s}$. une vocation en tant qu'espace public, où intervient, à des moments divers, une série d'éléments à valeur cultuelle. Dans ce cas, l'installation de la « tombe de chef » dans ce secteur de l'habitat semble bien 


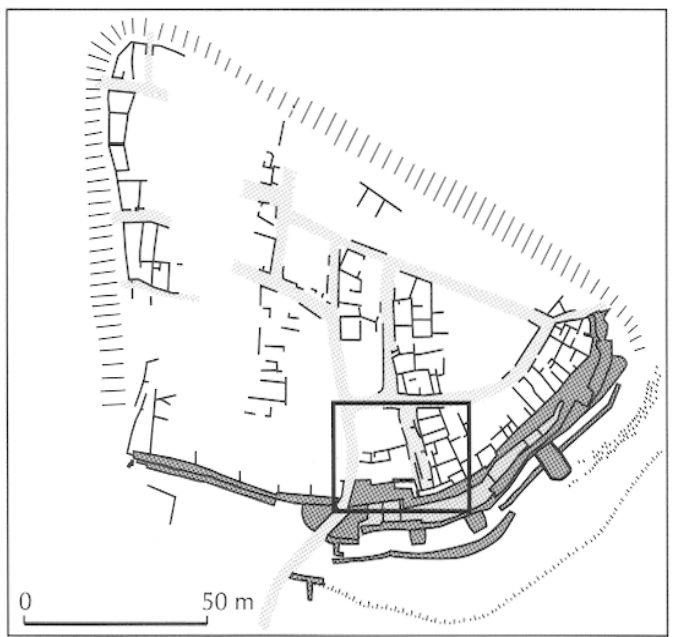

a

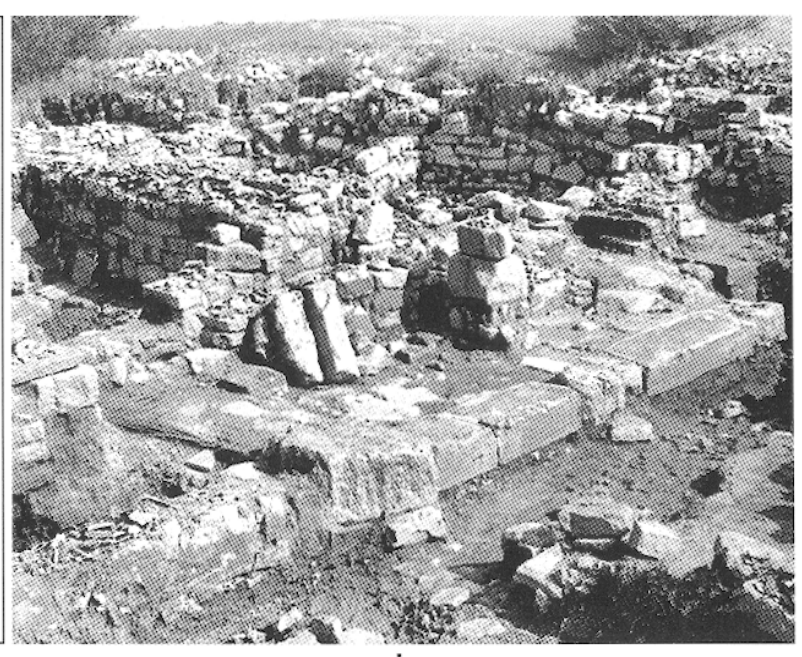

b

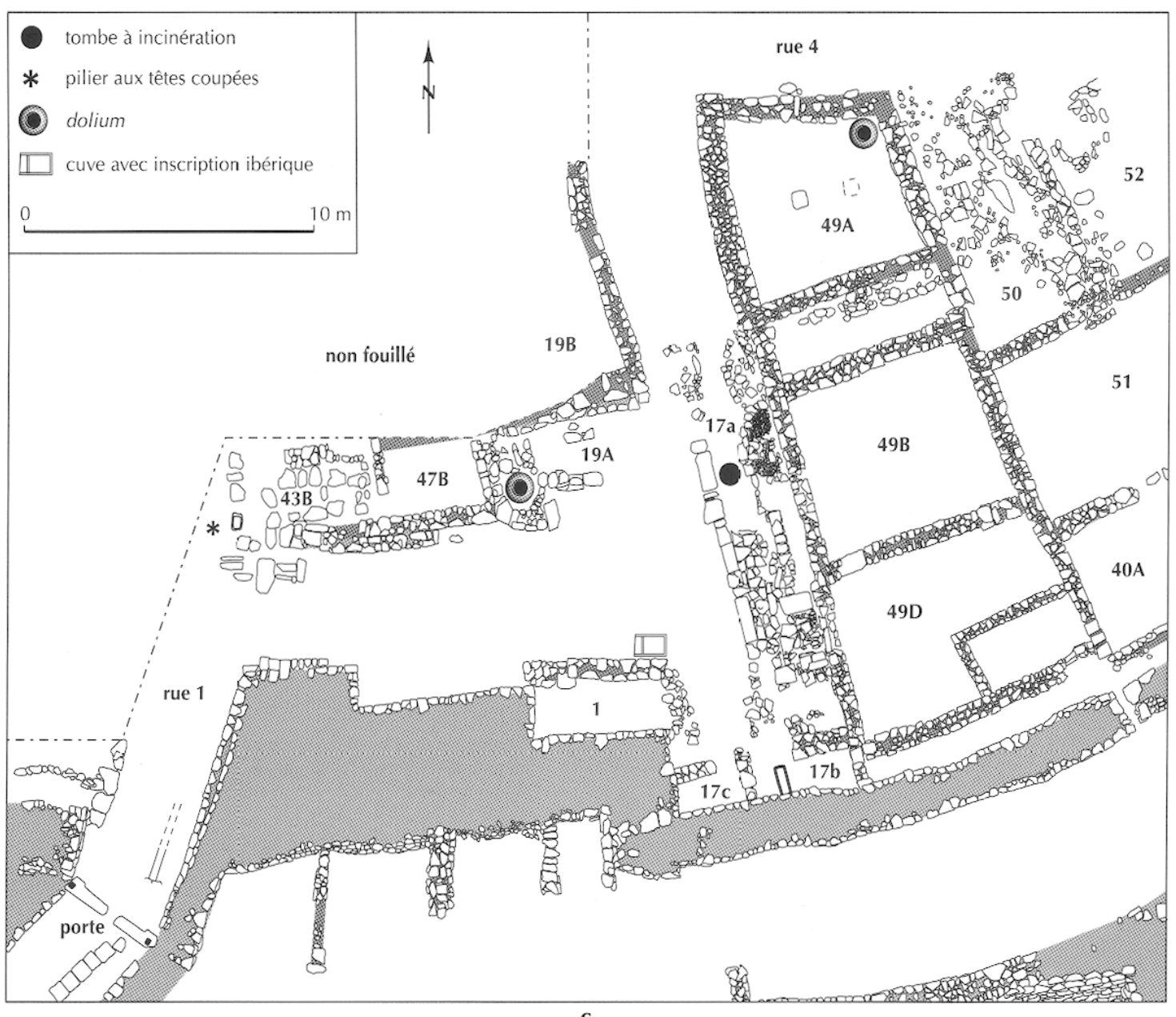

Fig. 143 - Sigean (Aude), Pech Maho. Plan général du site avec l'emplacement du secteur étudié, près de la porte (a). Relevé détaillé de ce derrier, état du III' s. av. J.C. (c) (relevé G. Marchand, E. Gailledrat, CNRS). L'espace de la tombe au moment de la fouille en 1959 (b) (photo Y. Solier, CNRS). 
avoir été motivée par la destination spécifique préexistante de ce dernier.

L'analyse architecturale révèle en tout cas que ce quartier présente, dès la phase II du site (v. 450-325/300 avant J.-C.), un certain nombre d'originalités qui évoquent bel et bien un espace à caractère public. Une fois passée la porte charretière (fig. 143c), la rue 1 donne directement à droite sur un espace ouvert, puis sur un ensemble de constructions érigées durant la phase II : le tracé des bâtiments 47B, 49A, 49B et 49D ne connaît en effet pratiquement pas de remaniements entre les phases II et III. Par ailleurs, c'est durant cette même phase II que le rempart intérieur subit des modifications notables: la nouvelle courtine suit un tracé régulier, tandis que vers la porte, le rempart initial (phase I) est renforcé afin de créer un épais bastion dont la fonction défensive paraît secondaire. Plus encore, ce bastion reçoit (du côté intérieur de l'habitat) un habillage en moyen appareil particulièrement soigné, similaire à celui présent au niveau de la porte. Ce renfort présente en plan une succession de trois décrochements à angle droit sans aucune valeur poliorcétique. Le soin apporté à la réalisation de cet ouvrage lui confère un caractère monumental indéniable, qui doit s'expliquer par une volonté de souligner à la fois le caractère ostentatoire de la fortification et l'importance du quartier dont il est question ici.

De la sorte, cet espace ouvert constitue une véritable place qui s'élargit vers l'est. Antérieurement à l'aménagement durant la phase III (?) des espaces 1 et 19A, cette place adopte alors un plan en $T$ relativement régulier dont le sommet est délimité par les édifices $49 \mathrm{D}$ et $49 \mathrm{~B}$, dans lesquels on est tenté de voir autre chose que de simples habitations, hypothèse que la documentation disponible ne permet malheureusement pas de vérifier.

En dépit du caractère incomplet de la fouille dans les secteurs 43B, 47B et 19A, l'état récent (III ${ }^{\mathrm{e}} \mathrm{s}$.) de cette partie $\mathrm{du}$ site peut en revanche être relativement bien défini. $\mathrm{Au}$ nord du croisement avec la rue 1 , une base de pilier a probablement servi à l'exposition de crânes humains (étoile). Il s'agit d'un socle en pierre taillée, mouluré du côté exposé aux regards, ayant manifestement servi de support à un pilier en bois. À proximité ont été retrouvés les restes correspondant à au moins cinq crânes, qu'il est logique d'imaginer avoir été initialement fixés sur un support aujourd'hui disparu. Plus encore, la présence de blocs et de dalles alignés selon un axe nord-sud peut laisser penser que ce pilier aux têtes coupées pouvait en réalité appartenir à un portique marquant la façade ouest d'un ou de plusieurs bâtiments auxquels doivent être rattachés les espaces 43B et 47B. Le secteur 43B, partiellement dallé, doit être interprété comme un espace semi-couvert. Bordé à l'ouest par le pilier supportant des têtes coupées, il donne accès vers l'est à une petite pièce d'un peu moins de $7 \mathrm{~m}^{2}$ (47B) dont la fonction, bien qu'énigmatique, ne peut en aucun cas relever du simple domaine domestique. À l'est de celle pièce, le secteur 19A voit la mise en place d'une base maçonnée servant de calage à un dolium. Un léger emmarchement permet d'accéder à l'ouverture de ce dernier, tandis qu'un muret et une possible base de pilier (aujourd'hui disparue) suggèrent l'existence d'une couverture en forme d'appentis.

De l'autre côté de la placette, un nouveau mur est édifié, qui vient délimiter un espace probablement couvert, d'une surface d'environ $8 \mathrm{~m}^{2}$ (pièce 1). La destination de ce nouveau réduit, qui vient lui aussi amputer l'espace en $\mathrm{T}$ aménagé durant la phase précédente, est une nouvelle fois problématique. À l'extérieur, contre le mur nord de cette pièce, une cuve taillée ayant servi de support à une inscription en caractères ibériques a été interprétée par Y. Solier comme une possible vasque destinée à des pratiques cultuelles (libations). Cette hypothèse est rendue d'autant plus plausible non seulement par le contexte architectural et l'existence de la sépulture, mais également par la présence quasi symétrique du dolium de l'espace 19A, pour lequel on peut imaginer une destination similaire.

L'espace ouvert débouche vers l'est, tout comme durant la phase précédente, sur les bâtiments 49D (dorénavant divisé en deux pièces de dimensions inégales) et 49B. Durant la phase III, ces deux espaces, d'une superficie intérieure de 37 et $29 \mathrm{~m}^{2}$ environ, sont précédés de la terrasse dallée où est implantée la sépulture.

Ce podium correspond vraisemblablement à la base d'un portique (fig. 143b) : les blocs taillés disposés en façade montrent en effet l'alternance d'éléments rectangulaires de grandes dimensions et d'éléments plus petits qu'il est possible d'interpréter comme des bases de piliers en bois, hypothèse renforcée par les nombreuses traces de rubéfaction observées sur ces pierres au moment de la fouille et liées à l'incendie qui marque la destruction du site. Ce stylobate aurait alors été surmonté d'au minimum quatre piliers, peut-être davantage. Danss la mesure où l'on accepte cette hypothèse, il est évident que les bâtiments 49D et 49B ne peuvent correspondre à de simples habitations. Concernant le mobilier mis au jour, si les informations manquent pour le premier, l'analyse du mobilier du second laisse en revanche apparaître une fréquence élevée des vases fins à vernis noir qui représentent à eux seuls plus de la moitié de la vaisselle présente. Par ailleurs, la description de la stratigraphie ne permet pas d'exclure l'existence d'un étage, au moins pour ce même bâtiment 49B. On relève avec intérêt la description faite d'un dallage recouvrant la partie méridionale de la pièce et d'une grande fosse recelant un mélange de cendres et de coquilles de moules, ainsi que 
deux coupes à vernis noir, une hache et une pointe, toutes deux en fer. L'abondance de vases fins, principalement du service de table, peut suggérer l'existence d'une salle de réunion pour des banquets collectifs. En ce qui concerne la construction 49D, les fouilleurs signalent la présence de deux grandes cuves en pierre, d'un dolium avec la marque en caractères grecs EY $\Sigma$ PATI $\Delta$, d'une amphore grécoitalique avec inscription ibérique et (ici encore) d'une grande quantité de tessons à vernis noir.

Au sud de la terrasse dallée, deux réduits sont aménagés durant la même phase III (pièces $17 \mathrm{~b}$ et $17 \mathrm{c}$ ). Dans le prolongement exact des blocs formant le stylobate du portique, un dispositif interprété comme une stèle consiste en un bloc parallélépipédique de $35 \mathrm{~cm}$ de haut, surmonté de deux blocs taillés parfaitement juxtaposés, de $60 \mathrm{~cm}$ de haut. On peut également imaginer qu'il s'agit en tait du socle d'un élément disparu depuis (statuaire ?). Quoi qu'il en soit, situé juste au niveau de l'ouverture de cette pièce, cet aménagement était clairement destiné à être vu depuis l'espace compris entre les pièces 1 et 49D.

La situation de cette terrasse monumentale, au débouché d'un espace de circulation perpendiculaire à la rue principale, traduit de manière claire son insertion raisonnée dans le tissu urbain. L'ensemble correspond à un secteur à caractère public lié à des manifestations d'ordre cultuel, dont les premiers éléments constitutifs remontent aux débuts du second âge du Fer. Bien sûr, la signification exacte des divers aménagements évoqués reste à préciser, mais il est intéressant de souligner que cet ensemble témoigne de l'émergence sur les côtes du Languedoc occidental d'une expression architecturale élaborée des croyances collectives.

Bibliographie : Solier, 1968, 1976 ; Dedet, Schwaller, 1990 ; Arcelin et al., 1992.

É. Gaillentat et G. Marchand

\section{NOTICE 7}

\section{VELAUX (BOUCHES-DU-RHÔNE)}

\section{ROQUEPERTUSE}

Ce site archéologique, célèbre par sa statuaire et l'ancienneté de ses recherches, est situé dans la basse vallée de l'Arc, au débouché des gorges de Roquefavour, à faible distance de l'étang de Berre. Il se développe sur plusieurs types de relief : plateau en partie cerné de falaises, vallon donnant sur un cirque rocheux et versants, au total sur 0,5 ha de superficie lors de la phase de plus grande expansion (fig. 144). Le lieu s'insère dans un petit massif dominant d'une vingtaine de mètres la plaine alluviale de l'Arc, et il ne commande qu'un petit réseau de chemins, a priori sans grande importance. Contrairement à ce qui a pu ctrc dit, Roqucpertuse n'occupe pas forcément une position centrale dans la basse vallée de l'Arc. La plupart des sites auxquels on a voulu le relier ne sont pas tous contemporains, notamment le plus proche, celui de Sainte-Propice, dont l'occupation est plus tardive. La contemporanéité est possible avec l'oppidum de Meynes, qui reste mal documenté par l'archéologie.

\section{Le site, sa conception et sa chronologie}

Le réexamen des collections anciennes, puis la reprise des recherches de terrain en 1994 sous l'impulsion de B. Lescure, enfin sous notre direction après cette date, apportent un renouvellement complet de l'interprétation de la nature comme de la chronologie de ce site. À l'issue d'une première tranche de recherches qui s'est achevée en 2002 pour publication, le tableau suivant peut être présenté : bien que très incomplètement fouillé, l'habitat exhumé apparaît commun dans ses composantes morphologiques et technologiques, mais plus singulier dans leur assemblage spatial et la présence d'une importante documentation iconographique à connotation cultuelle. L'aire concernée comporte deux secteurs bâtis distincts: d'une part, un secteur supérieur (plateau sommital et terrasse 1) (fig. 144b) enclos par une enceinte à tour(s) circulaire(s), porte frontale et fossé sec (creusé dans le rocher) ; d'autre part, une zone inférieure a priori ouverte, s'étendant vers la plaine (terrasse 2 et en aval) ainsi qu'une extension latérale sur le plateau contigu (plateau des Amandiers). À une exception près, toutes les unités architecturales mises en évidence relèvent des activités domestiques ou associées à la vie de la maison : petite métallurgie, bergerie, stockage, etc.

La structuration de cet habitat est dictée par la topographie et la présence du rempart isolant une partie du site. Le plateau sommital est impossible à dater car très lessivé par l'érosion, mais il comporte les traces entaillées dans le rocher de maisons accolées à la falaise et d'un îlot central. Les recherches montrent désormais des installations successives, dans la durée.

L'occupation du site débute à la fin du Néolithique, sans traces de structures bâties, avec un mobilier en position secondaire. La première occupation véritable remonte à l'extrême fin du premier âge du Fer. On relève, durant la seconde moitié du Ves. avant J.-C., les traces indubitables d'habitations sur poteaux porteurs, non agglomérées, peutêtre sans fortification. Le site est probablement en partie déserté au $\mathrm{IV}^{\mathrm{e}} \mathrm{s}$. Au total, ce sont désormais cinq phases (avec des sous-phases) d'occupation qui rythment la vie du 


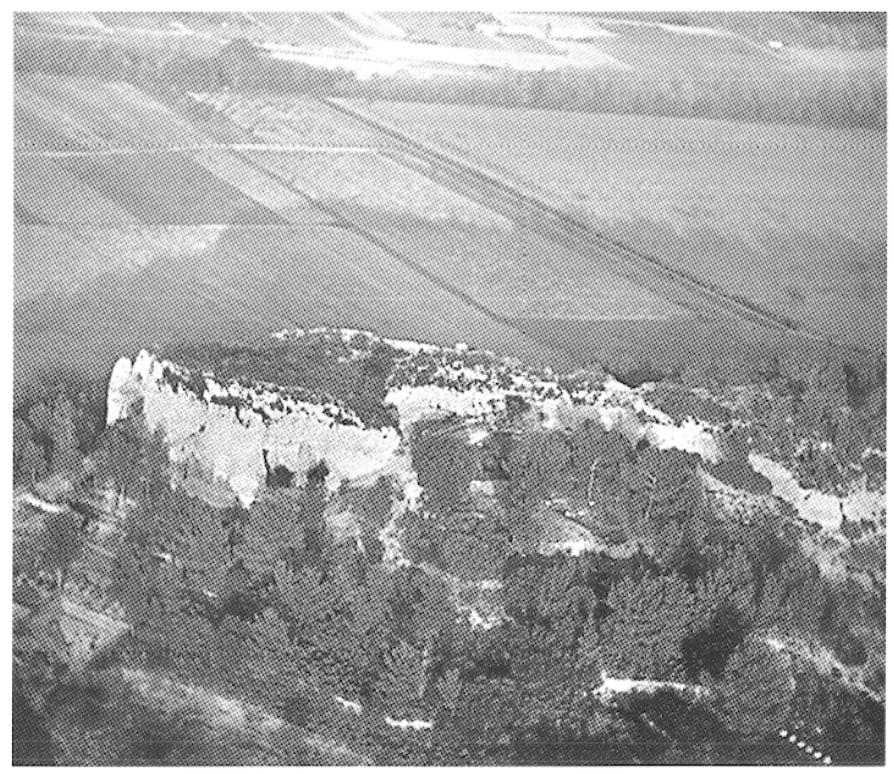

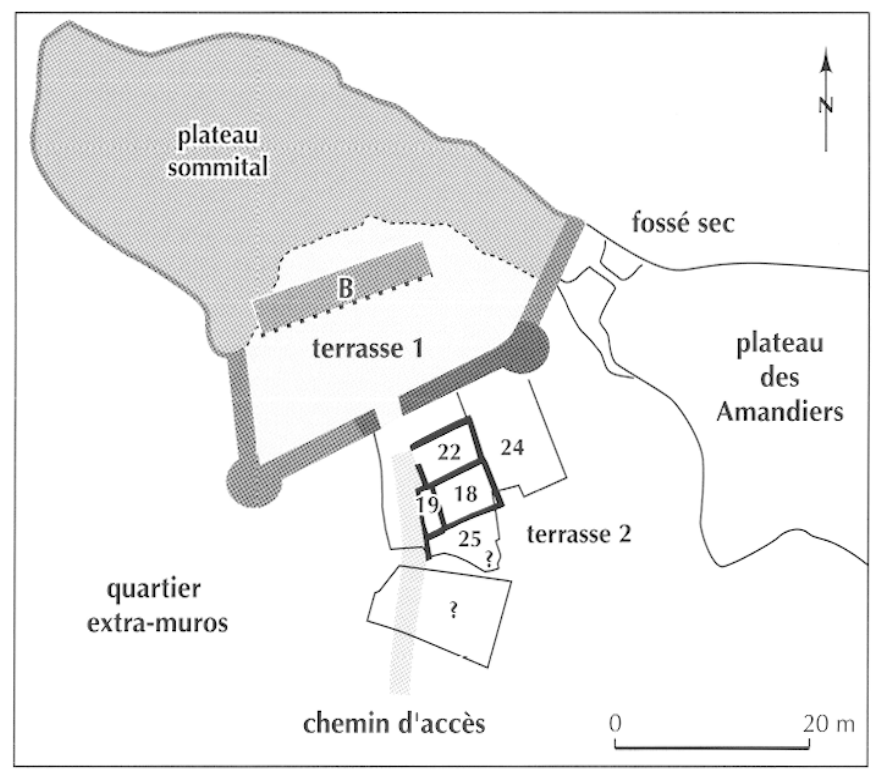

b

Fig. 144 - Velaux (Bouches-du-Rhône), Roquepertuse. Le site en extrémité d'un plateau dominant la plaine de la basse vallée de l'Arc: $a$, vue du plateau et du vallon méridional (photo L. Chabot); b, plan schématique du site, de sa fortification du III s. av. J.-C. et de son quartier extérieur partiellement décapé (relevé P. Boissinot, université Cergy-Pontoise).

lieu, de la fin du $\mathrm{IV}^{\mathrm{e}} \mathrm{s}$. au tout début du $\mathrm{II}^{\mathrm{e}} \mathrm{s}$. avant J.-C., moment de l'abandon définitif. La fortification est construite à la transition des $\mathrm{IV}^{\mathrm{e}}$ et III ${ }^{\mathrm{e}} \mathrm{s}$. Vers 200 avant J.-C., la phase ultime correspond à une rétraction de l'habitat dans les ruines d'une agglomération avec d'importantes activités liées à la production agricole (ferme ?). Le maximum de l'occupation semble avoir été atteint durant la seconde moitié du III $^{c} s$., période où le site est incendié à la suite d'un siège.

$\mathrm{Au}$ III $^{\mathrm{e}}$ s., le bâtiment central qui est inclus dans l'enceinte primitive (B, fig. 144b) occupe une position topographique particulière: il n'appartient pas au plateau, puisqu'il est inscrit dans le cirque rocheux en contrebas, mais le tracé de l'enceinte, très original pour cette période, tient compte de l'emplacement du bâtiment dans la partie la plus haute du vallon, révélant du même coup un véritable programme d'installation. Il occupe un secteur de transition entre le haut et le bas de l'agglomération et cette configuration lui confère un certain caractère ostentatoire (fig. 145a). L'aire qui le sépare du rempart compose un espace ouvert, véritable cour intérieure. Dans l'axe du bâtiment et du vallon se positionne l'entrée fortifiée basse du site, prolongée par une voie d'accès qui devient le principal axe structurant du village extérieur. Compte tenu de la topographie, cette construction doit se concevoir en développement sur deux étages dont la façade serait constituée par deux portiques superposés. Elle est mise en place à la charnière de la fin du IV ${ }^{e}$ ou début du III ${ }^{\mathrm{e}} \mathrm{s}$., à la même période que l'enceinte. Son abandon se situe dans le courant du III ${ }^{e} s$., deux phases avant la désertion définitive du site.

\section{Édifice et mobilier cultuels}

\section{Un bâtiment monumental}

Le bâtiment construit à cheval sur les terrasses 1 et 5 (fig. 145a) occupe un rectangle de 17,50 m de long environ (est-ouest) pour une largeur moyenne de 3,50 m (soit $61,25 \mathrm{~m}^{2}$ au sol), si l'on considère que le mur séparant les terrasses 5 et 6 constitue le dos de l'édifice (fig. 145b). Les sols associés à cette construction ne sont pas conservés.

Le rez-de-chaussée ne correspond pas à un espace de circulation, puisqu'un intervalle de $1,20 \mathrm{~m}$ environ seulement est libre de toute structure entre les piliers et le mur de soutènement arrière. D'après les emplacements trouvés au sol, les espacements entre les piliers ne sont pas réguliers; ils varient de $0,48 \mathrm{~m}$ à $2,30 \mathrm{~m}$ au sol. Le seul linteau reconstitué demeure incomplet. En faisant des hypothèses sur la symétrie des cavités, un intervalle de $2,65 \mathrm{~m}$ peut être proposé pour le second étage, compte tenu de la présence d'un encastrement indiquant la proximité d'un dispositif de couverture faiblement incliné (1\%). On ignore comment se faisait la communication entre les deux plans, l'escalier encore visible n'étant qu'un bricolage de la phase tardive, alors que le bâtiment est en ruine. Les piliers et les 


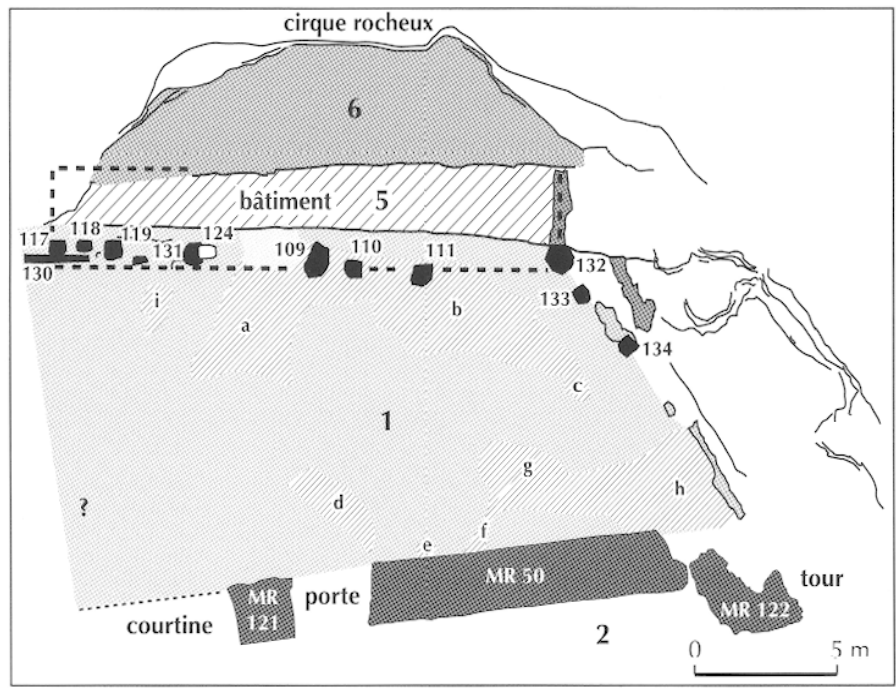

a

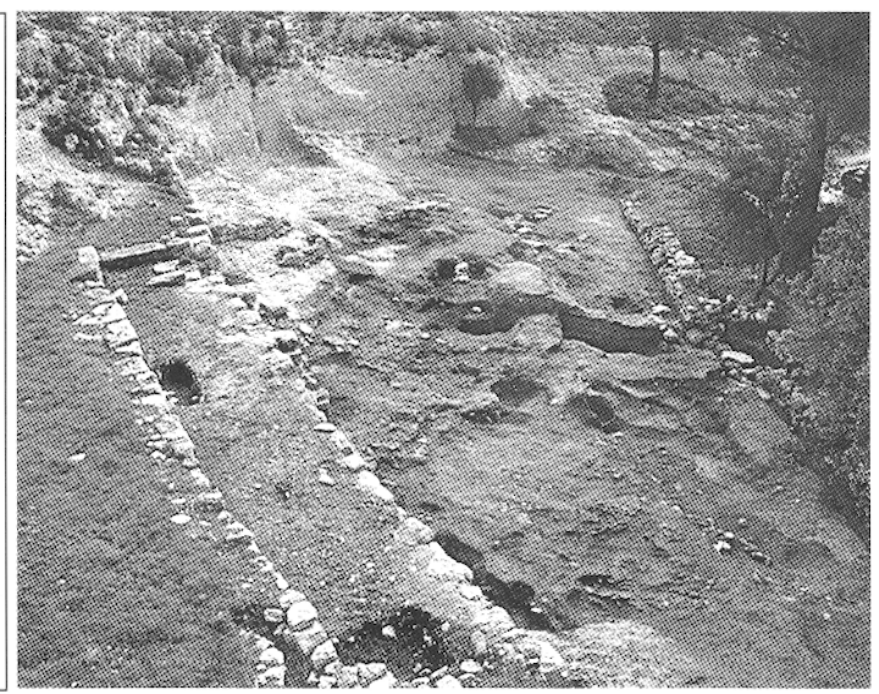

b

Fig. 145 - Velaux (Bouches-du-Rhône), Roquepertuse. Détail de la partie basse de l'aire fortifiée : a, indication du bâtiment hypostyle à cheval sur les terrasses 1 et $5 ; b$, les terrasses au moment de la reprise des fouilles en 1994 (relevé et photo P. Boissinot, université de Cergy-Pontoise).

linteaux comportaient des cavités destinées à l'exposition de crânes humains, en partie retrouvés en connexion avec les restes architecturaux. On ignore si tous les supports ont été utilisés. Certains crânes étaient manifestement exposés côté intérieur. Ces mêmes blocs comportent des graffitis (représentation humaine), des traces de peinture noires et rouges représentant des animaux (réels ou fantastiques) ou des motifs géométriques.

Il est impossible de démontrer que les statues de guerriers ont été exposées dans le bâtiment, la plupart des fragments découverts sur le site provenant de lieux très divers, parfois situés bien au-delà de cet espace. L'exposition de l'Hermès et du rapace est plus probable compte tenu des notes précises du premier fouilleur.

L'édifice peut être daté de la même phase que la construction du rempart (vers - 300); il est détruit dans le courant du $\mathrm{III}^{\mathrm{e}} \mathrm{s}$., alors que le site ne semble pas avoir perdu de sa grandeur et que la porte sc voit parćc d'un escalier monumental. En l'absence de sol conservé et de la dispersion consécutive de l'ensemble du contenu, il est difficile d'approcher la question de la fonction du bâtiment. Si l'on admet que les crânes sont ceux de guerriers vaincus, le rôle de trophée doit évidemment convenir, comme cela a déjà été proposé. En revanche, si l'on y voit des reliques d'ancêtres, le lieu peut être envisagé comme commémoratif de la vie de la communauté ou d'une élite (aristocratique); en y ajoutant les statues de guerriers assis en tailleur, on peut penser que les héros étaient ici honorés. Son rôle peut être celui d'une résidence aristocratique ou d'un lieu public à caractère politique. En l'absence de toute offrande et/ou sacrifice reconnaissable et compte tenu de l'interprétation de la statuaire (guerriers plutôt que prêtres), il est préférable d'écarter ici une fonction religieuse spécialisée (de type sanctuaire). On rappellera que les ossements d'équidés retrouvés par $\mathrm{H}$. de Gérin-Ricard appartiennent au dernier niveau, violemment détruit à une époque où le bâtiment et les statues ne sont plus utilisés. Reste alors le culte des héros ou la galerie de portraits des élites locales.

\section{Restes osseux et mobiliers retrouvés}

Les os humains (étude en cours de P. Courtaud). Des ossements humains nombreux sont signalés par l'inventeur du site (I. Gilles). H. de Gérin-Ricard a exhumé plusieurs calottes crâniennes associées aux piliers. D'autres fragments crâniens ont été retrouvés au cours de nos fouilles, à proximité du portique et près de l'entrée basse de l'enceinte (dernière période du site). En fouille, plusieurs fosses contenant des périnataux ont été découvertes sous ou à proximité des fondations de plusieurs habitations du quartier extra-muros (rite de fondation ou domestique).

Les ossements d'animaux (étude en cours de M. Leguilloux). De petites fosses contenant des squelettes partiels d'animaux jeunes ont été retrouvées sous le sol de plusieurs des phases de l'habitat extra muros. En l'absence d'indice convaincant de sacrifices, tous les autres restes peuvent être attribués à la consommation domestique.

Les stèles. Toutes ont été trouvées en remploi (à partir du III $^{c}$ s.). Elles sont taillées dans des roches variées et adoptent des formes tout aussi variées : section carrée, rectangulaire, 
bords arrondis, sommet plat ou convexe. Elles sont relativement nombreuses (plusieurs dizaines à ce jour). Un seul exemplaire de petite taille, trouvé en remploi dans le rempart, est un cippe à sommet arrondi et base brute, comportant deux traits gravés.

La statuaire. Ce mobilier, en calcaire de Coudoux, la plupart du temps peint, a déjà fait l'objet de plusieurs études. De nombreux fragments ont été découverts en stratigraphie, démontrant que l'essentiel de la statuaire a été détruit à la fin de la période 10 , probablement dans la seconde moitié du III ${ }^{e}$ s. avant J-C. Certaines pièces ont été concassées et incorporées dans des remblais avant que le village ne soit reconstruit. Les fragments les plus nombreux ont été retrouvés sur la terrasse 2, dans le quartier extramuros. On ne connaît pas leur position d'origine.

Deux techniques peuvent être distinguées: la rondebosse et le bas-relief. La plupart des fragments appartiennent à des guerriers assis en tailleur; au moins dix exemplaires différents sont pour l'instant décomptés grâce à la décoration et la morphologie des dossières, ces cuirasses souples à couvre-nuque, qui trouvent leur parallèle dans les représentations de Glauberg en Allemagne. Ce style d'armement, daté du Ves. avant J.-C. dans le monde celtique, n'est cependant pas sans poser quelques problèmes de chronologie générale. Si la destruction des rondes-bosses est bien attestée vers le milieu du $\mathrm{III}^{\mathrm{e}} \mathrm{s}$., à quel contexte archéologique faut-il attribuer leur mise en place ? Faut-il envisager leur exposition lors de la phase de la seconde moitié du $\mathrm{V}^{\mathrm{e}} \mathrm{s}$., alors que le village semble peu structuré et sans fortifications? Ou bien doit-on imaginer que les statues ont circulé d'un site à un autre au gré du déplacement des élites?

Une date similaire doit aussi être retenue pour l'Hermès si on considère que la protubérance est bien la base de feuilles de gui ; dans ce cas, la référence de la représentation puise clairement dans l'iconographie celtique. En ce qui concerne l'oiseau, il est désormais acquis qu'il s'agit bien d'un rapace grâce à la découverte récente du bec, un thème animalier également très fréquent dans le monde celte aux $\mathrm{V}^{\mathrm{e}}$ et début du $\mathrm{IV}^{\mathrm{e}} \mathrm{s}$. avant J.-C. D'autres pièces inédites semblent correspondre à un petit animal (chien ou équidé). Bibliographie : Clerc, 1916 ; Gérin-Ricard, 1927 ; Dijoud et al., 1991 ; Lescure et al., 1994 ; Lescure, 1995 ; Herrmann, 1996 ; Boissinot, Lescure, 1998 ; Rapin, 1999, 2002 ; Boissinot, 2000 ; Boissinot et al., 2000 ; Lescure, Werth, 2000.

P. BOISSINOT 